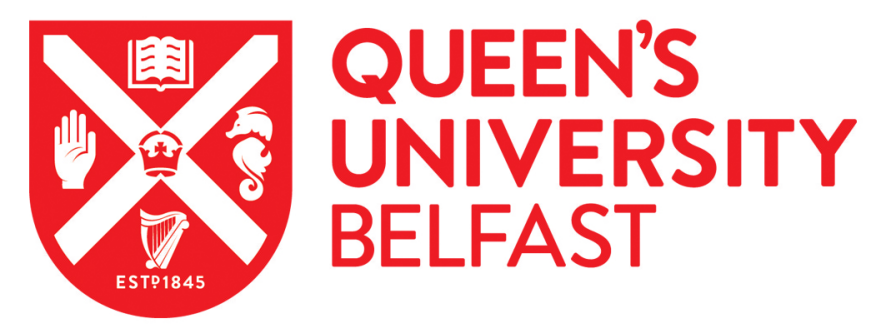

\title{
Interventions to improve the appropriate use of polypharmacy for older people
}

Rankin, A., Cadogan, C. A., Patterson, S. M., Kerse, N., Cardwell, C. R., Bradley, M. C., Ryan, C., \& Hughes, C. (2018). Interventions to improve the appropriate use of polypharmacy for older people. The Cochrane database of systematic reviews, 9, CD008165. https://doi.org/10.1002/14651858.CD008165.pub4

\section{Published in:}

The Cochrane database of systematic reviews

\section{Document Version:}

Peer reviewed version

\section{Queen's University Belfast - Research Portal:}

Link to publication record in Queen's University Belfast Research Portal

\section{Publisher rights}

Copyright $\odot 2018$ The Cochrane Collaboration. Published by John Wiley \& Sons, Ltd. This work is made available online in accordance with the publisher's policies. Please refer to any applicable terms of use of the publisher.

\section{General rights}

Copyright for the publications made accessible via the Queen's University Belfast Research Portal is retained by the author(s) and / or other copyright owners and it is a condition of accessing these publications that users recognise and abide by the legal requirements associated with these rights.

Take down policy

The Research Portal is Queen's institutional repository that provides access to Queen's research output. Every effort has been made to ensure that content in the Research Portal does not infringe any person's rights, or applicable UK laws. If you discover content in the Research Portal that you believe breaches copyright or violates any law, please contact openaccess@qub.ac.uk. 


\section{Interventions to improve the appropriate use of polypharmacy for older people}

\section{Review information}

Review type: Intervention

\section{Authors}

Audrey Rankin ${ }^{1}$, Cathal A Cadogan², Susan M Patterson ${ }^{3}$, Ngaire Kerse ${ }^{4}$, Chris R Cardwell ${ }^{5}$, Marie C Bradley ${ }^{6}$, Cristin Ryan 7 , Carmel Hughes ${ }^{1}$

${ }^{1}$ School of Pharmacy, Queen's University Belfast, Belfast, UK

2School of Pharmacy, Royal College of Surgeons in Ireland, Dublin, Ireland

${ }^{3}$ Integrated Care, No affiliation, Ballynahinch, UK

${ }^{4}$ Department of General Practice and Primary Health Care, University of Auckland, Auckland, New Zealand

${ }^{5}$ Centre for Public Health, Queen's University Belfast, Belfast, UK

${ }^{6}$ National Cancer Institute, Rockville, MD, USA

${ }^{7}$ School of Pharmacy and Pharmaceutical Sciences, Trinity College Dublin, Dublin 2, Ireland

Citation example: Rankin A, Cadogan CA, Patterson SM, Kerse N, Cardwell CR, Bradley MC, Ryan C, Hughes C. Interventions to improve the appropriate use of polypharmacy for older people. Cochrane Database of Systematic Reviews 2018 , Issue 8. Art. No.: CD008165. DOI: 10.1002/14651858.CD008165.pub4 .

\section{Contact person}

Carmel Hughes

Professor of Primary Care Pharmacy

School of Pharmacy

Queen's University Belfast

97 Lisburn Road

Belfast

Northern Ireland

BT9 7BL

UK

E-mail: c.hughes@qub.ac.uk

Dates

Assessed as Up-to-date:7 February 2018

Date of Search: 7 February 2018

NextStage Expected: 5 June 2021

ProtocolFirst Published:Issue 4,2009

Review First Published: Issue 5, 2012

Last Citation Issue: Issue 8,2018

What's new

\begin{tabular}{|l|l|l|}
\hline Date & Event & Description \\
\hline 7 February 2018 & New citation: conclusions changed & Change to conclusion. Second update of this review. \\
\hline 7 February 2018 & Updated & $\begin{array}{l}\text { Updated searches completed. Twenty new included studies } \\
\text { added to the review. } \\
\text { Changes made to pooling of outcome data in meta- } \\
\text { analysis. }\end{array}$ \\
\hline $\begin{array}{l}\text { History } \\
\text { Date }\end{array}$ & Event & Description \\
\hline
\end{tabular}

\section{Abstract}

\section{Background}

Inappropriate polypharmacy is a particular concern in older people and is associated with negative health outcomes. Choosing the best interventions to improve appropriate polypharmacy is a priority, hence interest in appropriate polypharmacy, where many medicines may be used to achieve better clinical outcomes for patients, is growing. This is the second update of this Cochrane Review. 
Interventions to improve the appropriate use of polypharmacy for older people

\section{Objectives}

To determine which interventions, alone or in combination, are effective in improving the appropriate use of polypharmacy and reducing medication-related problems in older people.

\section{Search methods}

We searched CENTRAL, MEDLINE, Embase, CINAHLand two trials registers up until 7 February 2018 , togetherwith handsearching of reference lists to identify additional studies.

\section{Selection criteria}

We included randomised trials, non-randomised trials, controlled before-after studies, and interrupted time series. Eligible studies described interventions affecting prescribing aimed at improving appropriate polypharmacy in people aged 65 years and older, prescribed polypharmacy (four or more medicines), which used a validated tool to assess prescribing appropriateness. These tools can be classified as either implicit tools (judgement-based/based on expert professional judgement) or explicit tools (criterion-based, comprising lists of drugs to be avoided in older people).

\section{Data collection and analysis}

Two review authors independently reviewed abstracts of eligible studies, extracted data and assessed risk of bias of included studies. We pooled study-specific estimates, and used a random-effects model to yield summary estimates of effect and $95 \%$ confidence intervals (Cls). We assessed the overall certainty of evidence for each outcome using the GRADE approach.

\section{Main results}

We identified 32 studies, 20 from this update. Included studies consisted of 18 randomised trials, 10 cluster randomised trials (one of which was a stepped-wedge design), two non-randomised trials and two controlled before-after studies. One intervention consisted of computerised decision support (CDS); and 31 were complex, multi-faceted pharmaceutical-care based approaches (i.e. the responsible provision of medicines to improve patient's outcomes), one of which incorporated a CDS component as part of their multi-faceted intervention. Interventions were provided in a variety of settings. Interventions were delivered by healthcare professionals such as general physicians, pharmacists and geriatricians, and all were conducted in high-income countries. Assessments using the Cochrane 'Risk of bias' tool, found that there was a high and/or unclear risk of bias across a number of domains. Based on the GRADE approach, the overall certainty of evidence for each pooled outcome ranged from low to very low.

It is uncertain whether pharmaceutical care improves medication appropriateness (as measured by an implicit tool), mean difference (MD) $-4.76,95 \% \mathrm{Cl}-9.20$ to $-0.33 ; 5$ studies, $\mathrm{N}=517$; verylow-certaintyevidence). It is uncertain whether pharmaceutical care reduces the number of potentially inappropriate medications (PIMs), (standardised mean difference (SMD) $-0.22,95 \% \mathrm{Cl}-0.38$ to $-0.05 ; 7$ studies; $\mathrm{N}=1832$; very low-certainty evidence). It is uncertain whether pharmaceutical care reduces the proportion of patients with one or more PIMs, (risk ratio (RR) $0.79,95 \% \mathrm{Cl} 0.61$ to $1.02 ; 11$ studies; $\mathrm{N}=$ 3079; very low-certainty evidence). Pharmaceutical care may slightly reduce the number of potential prescribing omissions (PPOs) (SMD - $0.81,95 \% \mathrm{Cl}-0.98$ to $-0.64 ; 2$ studies; $\mathrm{N}=569$; low-certainty evidence), however it must be noted that this effect estimate is based on only two studies, which had serious limitations in terms of risk bias. Likewise, it is uncertain whether pharmaceutical care reduces the proportion of patients with one or more PPOs (RR $0.40,95 \% \mathrm{Cl} 0.18$ to $0.85 ; 5$ studies; $\mathrm{N}=1310$; very low-certainty evidence). Pharmaceutical care may make little or no difference in hospital admissions (data not pooled; 12 studies; $\mathrm{N}=4052$; low-certainty evidence). Pharmaceutical care may make little or no difference in quality of life (data not pooled; 12 studies; $\mathrm{N}=3211$; low-certainty evidence). Medication-related problems were reported in eight studies ( $N=10,087)$ using different terms (e.g. adverse drugreactions, drug-drug interactions). Noconsistent intervention effect on medication-related problems was noted across studies.

\section{Authors' conclusions}

It is unclear whether interventions to improve appropriate polypharmacy, such as reviews of patients' prescriptions, resulted in clinically significant improvement; however, they may be slightly beneficial in terms of reducing potential prescribing omissions (PPOs); but this effect estimate is based on only two studies, which had serious limitations in terms of risk bias.

\section{Plain language summary}

\section{A review of the ways that healthcare professionals can improve the use of suitable medicines for older people What is the aim of this review?}

The aim of this Cochrane Review was to find out which types of approaches can improve the use of suitable medicines in older people. Researchers collected and analysed all relevant studies to answer this question and included 32 trials in the review.

\section{Key messages}

Taking medicine to treat symptoms of chronic illness and to prevent worsening of disease is common in older people. However, taking too many medicines can cause harm.

\section{What was studied in the review?}

This review examines studies in which healthcare professionals have taken action to make sure that older people are receiving the most effective and safest medicines for their illness. Actions taken included providing a service, known as pharmaceutical care, which involves promoting the correct use of medicines by identifying, preventing and resolving 
medication-related problems. Another strategy which we were interested in was using computerised decision support, which involves a programme on the doctor's computer that aids the selection of appropriate treatment(s).

\section{What are the main results of the review?}

Review authors found 32 relevant trials from 12 countries that involved 28,672 older people. These studies compared interventions aiming to improve the appropriate use of medicines with usual care. It is uncertain whether the interventions improved the appropriateness of medicines (based on scores assigned by expert professional judgement), reduced the number of potentially inappropriate medicines (medicines in which the harms outweigh the benefits), reduced the proportion of patients with one or more potentially inappropriate medications, or reduced the proportion of patients with one or more potential prescribing omissions (cases where a useful medicine has not prescribed) because the certainty of the evidence is verylow. The interventions maylead to little or no difference in hospital admissions or quality of life, however, the interventions may slightly decrease the number of potential prescribing omissions.

\section{How up-to-date is this review?}

Review authors searched for studies that had been published up to February 2018.

\section{Background}

Prescribing for older people is complex because of factors such as age-related changes in body composition and multiple pathologies. Finding the balance between aggressively treating diseases and avoiding medication-related harm is a critical objective for healthcare professionals, yet has proven challenging to achieve in clinical practice (Steinman 2007). This review updates the previous Cochrane Review of Interventions to improve the appropriate use of polypharmacy for older people (Patterson 2014), which concluded that despite the potential to reduce inappropriate prescribing, it was unclear whether interventions to improve appropriate polypharmacy in older people resulted in clinically significant improvements such as reduced hospital admissions or improved quality of life.

Polypharmacy refers to the use of multiple medicines. The term itself has been the subject of much discussion but no standard definition is used consistently (Cadogan 2016a; King's Fund 2013; Stewart 1990). A simple definition has been used ("the administration of more medicines than are clinically indicated, representing unnecessary drug use" Montamat 2004). For the purpose of this update of the review, we defined it as 'the concomitant ingestion of four or more medicines', however, in recognition of the fact that the number of medicines used to define polypharmacy is arbitrary, the focus of the interventions of interest to this review is the appropriateness of the medications prescribed for older people. $\neg$

Polypharmacy is common in older people, conventionally defined as those aged 65 years and older, as this age group is often subject to multimorbidity (defined as two or more chronic conditions) (Barnett 2012), such as cardiovascular disease and diabetes that require multiple medicines for treatment and prophylaxis. In the USA, the prevalence of polypharmacy in older people has increased over time, and the most recent available data indicate that approximately 39\% of older people in the USA take five or more medicines (Kantor 2015). Data from The Irish Longitudinal Study on Ageing have reported polypharmacy in $27 \%$ of the older population using the same definition (McGarrigle 2017). Although prevalence estimates in older people vary across countries, polypharmacy in older people is recognised as a widespread global issue (Stewart 2017). Consequently, older people use a disproportionate quantity of health service resources. For example, in terms of medicines, in 2016, patients aged 60 and older accounted for $23 \%$ of the population in England and were dispensed $61.0 \%$ of all prescription items ( Information Centre 2017).

Multiple factors contribute to the occurrence of polypharmacy in older people including an increase in life expectancy and the resultant growth in the prevalence of multimorbidity, the wider availability of effective drug treatments, and prescribing guidelines that recommend the use of more than one medicine in the prevention and management of various health conditions (Cadogan 2016). It is widely recognised that prescribing guidelines typically focus on single diseases and when applied to complex multimorbid patients often fail to provide information on how to prioritise treatment recommendations and can act as a driving force for polypharmacy (Hughes 2012). In light of this, the National Institute for Health and Care Excellence (NICE) has recently developed guidelines for the clinical treatment of patients with multiple morbidities, highlighting the importance of appropriate prescribing in this population (NICE 2016).

Inappropriate prescribing in the context of older people can be defined as the prescribing of "medications or medication classes that should generally be avoided in persons 65 years or older because they are either ineffective or they pose unnecessarily high risk for older persons and a safer alternative is available" (Beers 1991). The term 'potentially inappropriate prescribing (PIP)' encompasses potentially inappropriate medicines (PIMs) and potential prescribing omissions (PPOs). A PIM is a medicine that could potentially lead to a significant risk of adverse drug events (ADEs) and arises from prescribing practices such as continuing therapy for longer than necessary or recommended in prescribing guidelines. A PPO involves the omission of a medication that is clinically indicated for disease treatment or prevention (ㅁ' Connor 2012).

Although polypharmacyis often clinicallyindicated and beneficial in specific conditions (e.g. hypertension, diabetes mellitus) and patient populations (e.g. patients with multimorbidity), it also poses risks of medication-related harm and safety risks to patients. A medication-related problem is described as "an event or circumstance involving a patient's drug treatment that actually, or potentially, interferes with the achievement of an optimal outcome" and includes adverse drug reactions and drug interactions (Simonson 2005). Polypharmacy in older people has been associated with PIP and negative health outcomes including an increased risk of hospital admissions, adverse drug events and mortality (Cahir 2010). The chance of medication-related problems (such as adverse drug reactions and 
drug-drug interactions) occurring increases in olderage, in part, because the ageing process reduces the efficiency of the body's organs in eliminating drugs (Mangoni 2003). A large study of community-dispensed prescribing in Scotland (between 1995 and 2010) showed that the proportion of older adults prescribed more than five medicines and with potentially serious drug-drug interactions had more than doubled to $13 \%$ in 2010 (Guthrie 2015). It is known that the number of medicines prescribed is predictive of the number of drug interactions likely to occur (Gallagher 2001). Poor understanding of causes of certain disorders makes prescribing drug combinations more difficult and treating poorly understood diseases may increase the risk for inappropriate prescribing (Werder 2003).

Despite the recognised potential for medication safety risks in older people, recent cohort studies have challenged previous assumptions that polypharmacy is hazardous and associated with poor clinical outcomes (Appleton 2014 ; Guthrie 2015). For example, an analysis of Scottish primary care data linked to hospital discharge data highlighted the limitations of crude measures of polypharmacy (i.e. the number of medicines prescribed) as quality indicators or predictors of hospital admissions when patients' clinical context is not taken into consideration(Appleton 2014). The findings showed that patients prescribed an increased number of cardiovascular medicines were more likely to experience unplanned hospital admissions. However, when the analysis was adjusted to account for clinical factors such as non-cardiovascular morbidity and drug burden, no evidence of an increase in non-cardiovascular admissions with increasing numbers of cardiovascular medicines was found.

Consequently, greater use of the term 'appropriate polypharmacy', has been advocated which refers to 'prescribing for an individual with complex or multiple conditions where medicine use has been optimised and prescribing is in accordance with best evidence' (Cadogan 2016; King's Fund 2013). In assessing older patients' prescriptions, it is important to consider whether each drug has been prescribed appropriately or inappropriately, both individually and in the context of the whole prescription (Aronson 2006). Improving appropriate polypharmacy involves encouraging use of the correct drugs under appropriate conditions to treat the right diseases. In certain circumstances, this may include the removal of unnecessary drugs or those with no valid clinical indication and the addition of useful ones. Thus, interventions that seek solely to reduce the number of prescribed medicines fail to consider polypharmacy in its entirety. PPOs are also highly prevalent in older populations and have been shown to be associated with polypharmacy, whereby the probability of under-prescription increases with the number of medicines prescribed (Galvin 2014).

These findings may be explained by the unwillingness of general practitioners (GPs) to prescribe additional drugs for patients with polypharmacy (for reasons such as complexity of drug regimens, fear of ADEs and drug-drug interactions and poor adherence) (Kuijpers 2007). This so-called treatment/risk paradox or risk/treatment mismatch is seen when patients with the highest risk of complications are determined to have the lowest probability of receiving the recommended medications (Ko 2004; Lee 2005).

Differentiating between 'many' medicines (appropriate polypharmacy) and 'too many' medicines (inappropriate polypharmacy) is a prescriber's dilemma, and choosing the best interventions aimed at ensuring appropriate polypharmacy remains a challenge for healthcare practitioners and organisations.

\section{Description of the condition}

The causes of inappropriate polypharmacy are multifactorial (Stewart 2017), and for the purpose of this review we have focused on interventions that have targeted PIM, PPO, or both, using validated instruments or screening tools such as a validated list of medicines considered inappropriate for older people (AGS 2012; Beers 1991; Fick 2003; King's Fund 2013 ), a list of clinically significant criteria for potentially inappropriate prescribing in older people (Gallagher 2008) or the Medication Appropriateness Index (MAI) (Hanlon 1992). These screening tools can be classified as either implicit (judgement-based)orexplicit (criterion-based)tools (Kaufmann 2014; O'Connor 2012). Implicit tools, such as MAl (Appendix 1) and the Assessment of Underutilization of Medication (AOU) tool (Jeffery 1999), are judgement-based indicators of prescribing quality that are applied by clinicians to a patient's prescription. Explicit tools such as Beers' criteria (Appendix 1) and Screening Tool of Older Person's Prescriptions (STOPP)/Screening Tool to Alert doctors to the Right Treatment (START) criteria (Gallagher 2008), are usually developed from literature reviews, expert opinion and consensus exercises. The criteria typically comprise lists of drugs to be avoided or added in older people.

\section{Description of the intervention}

Improvement in appropriate polypharmacy can be achieved through a wide range of interventions (e.g. educational programmes for prescribers or consumers; medication review clinics and specific prescribing audits; prescribing incentive schemes and regulatory interventions). Interventions that reduce the risk of medication-related problems are important to consider (Fick 2008). These may be provided by healthcare professionals, educators, policy makers and healthcare service planners. Previously, interventions targeting polypharmacy in older people have often focused on reducing the number of medicines prescribed (Rollason 2003), based on the assumption that polypharmacy is harmful. However, by focusing solely on the number of prescribed medicines, these interventions have failed to consider inappropriate prescribing in its entirety. As noted above, inappropriate prescribing is not restricted to over-prescribing, but also encompasses mis-prescribing (i.e. incorrect prescribing of a necessarydrug) and under-prescribing (i.e. prescribing omissions).

Methods recommended in previous intervention studies include use of computer data entry and feedback procedures, which have been shown to decrease polypharmacy and drug-drug interactions (Werder 2003); visual identification of medicines; continuous medication review and thorough patient education to optimise polypharmacy (Fulton 2005).

This review seeks to identify evidence regarding which types of interventions can improve appropriate polypharmacy in older 
Interventions to improve the appropriate use of polypharmacy for older people

people.

\section{How the intervention might work}

Interventions to improve appropriate polypharmacy are likely to achieve the following outcomes.

- Improvement in medication appropriateness (as measured by an implicittool).

- Reduction of inappropriately prescribed medication (as measured by an explicit tool).

- Reduction of prescribing omissions (as measured byan explicit tool) by promoting prescribing of evidence-based therapy where clinically indicated.

Computerised decision support (CDS) aimed at prescribers, whereby electronic alerts are produced to guide the prescriber to the right treatment, has been successful in reducing inappropriate prescribing for older people.

Pharmaceutical care is the responsible provision of drug therapy for the purpose of achieving definitive outcomes that improve a patient's quality of life (Hepler 1990). Pharmaceutical care reflects a systematic approach that ensures patients receive the correct medicines, at an appropriate dose, for appropriate indications. It involves pharmacists moderating drug management in collaboration with physician, patient and carer (Hepler 1990). Pharmacist-led interventions such as medication review, co-ordinated transition from hospital tolong-term care facility and pharmacist consultations with patients and physicians have been shown to effectively reduce inappropriate prescribing and ADEs (Hanlon 1996; Kaur 2009). Multi-disciplinary case conferences involving GPs, geriatricians, pharmacists and residential care staff, wherein individual patient cases are discussed, have reduced the use of inappropriate medications in residential care (Crotty 2004a).

Why it is important to do this review

A systematic review may help to identify how we can improve appropriate polypharmacy in older people. Inappropriate prescribing for older people is both highly prevalent and commonlyassociated with polypharmacy (Bradley 2012; Cahir 2010). It is important that the current available evidence be identified and appraised, so that interventions that are effective in managing disease with appropriate polypharmacy may be identified and put into practice. $\neg$ This is an update of the Cochrane Review (Patterson 2014).

\section{Objectives}

To determine which interventions, alone or in combination, are effective in improving the appropriate use of polypharmacy and reducing medication-related problems in older people.

\section{Methods}

\section{Criteria for considering studies for this review Types of studies}

We included randomised trials and cluster-randomised trials, non-randomised trials, controlled before-after studies (CBAs) and interrupted time series (ITS) studies meeting the Effective Practice and Organisation of Care (EPOC) specification (EPOC 2017).

We classified trials eligible for inclusion according to the degree of certainty that random allocation was used to form comparison groups in the trial. If study author(s) stated explicitly that groups compared in the trial were established by random allocation, we classified the trial as a randomised trial. If study author(s) did not state explicitly that the trial was randomised, but randomisation could not be ruled out, we classified the report as a non-randomised trial.

\section{Types of participants}

The review included studies of people aged 65 years and older, who had more than one long-term medical condition and were receiving polypharmacy (classified as four or more medicines. This included a prescribed medication (one that is scheduled or part of a repeat prescription, and does not include over-the-counter and herbal products) and included studies targeting patient groups in which polypharmacy was common practice, such as patients with Parkinson's disease or diabetes. We considered trials for inclusion if they included a majority ( $80 \%$ or more) of participants aged 65 years and older, or if the mean age of study participants was over 65 years. If studies included both older and younger people, we included them if we were able to extract relevant data. We contacted study authors to check the availability of relevant data.

We excluded studies in which the intervention focused on people with a single long-term medical condition or who were receiving short-term polypharmacy, for example, those who were terminally ill or were receiving cancer chemotherapy.

\section{Types of interventions}

We examined all types of interventions aimed at improving appropriate polypharmacy in any setting (such as pharmaceutical care) compared with usual care (as defined by the study). We included all uni-faceted interventions, for example, those targeted solely at drug prescriptions, and multi-faceted interventions, for example, specialist clinics involving comprehensive geriatric assessment. We included studies of interventions for which the target was polypharmacy across all ages, provided results for those aged 65 years and older were available separately. We examined all types of interventions as set out by the most recent EPOC taxonomy of health systems interventions (EPOC 2015; EPOC 2016) that directly or indirectly affected prescribing and were aimed at improving appropriate polypharmacy. These included the following.

- Implementation strategies (previously categorised as professional interventions), defined as interventions designed to 
bring about changes in healthcare organisations, the behaviour of healthcare professionals or the use of health services by healthcare recipients, such as educational programmes aimed at prescribers.

- Delivery arrangements (previously categorised as organisational interventions) defined as changes in how, when and where healthcare is organised and delivered, and who delivers healthcare, such as skill-mix changes, pharmacistled $\neg$ medication review services or specialist clinics, $\neg$ information and communication technology (ICT) interventions such as clinical decision support systems or use of risk screening tools.

- Financial arrangements (previously categorised as financial interventions) defined as changes in how funds are collected, insurance schemes, how services are purchased, and the use of targeted financial incentives or disincentives, such as incentive schemes for changes in prescribing practice.

- Governance arrangements (previously categorised as regulatory interventions) defined as rules or processes that affect the way in which powers are exercised, particularly with regard to authority, accountability, openness, participation, and coherence, such as changes in government policy or legislation affecting prescribing.

\section{Types of outcome measures}

Validated measures of inappropriate prescribing (such as Beers criteria (Fick 2003), MAI (Hanlon 1992), STOPP/START criteria (Gallagher 2008) or Assessing Care of Vulnerable Elderly (ACOVE) (Wenger 2001)) were the main outcome measures considered in the review. We excluded studies in which medication appropriateness was determined solely by expert opinion (i.e. no measures/tools were used).

\section{Primary outcomes}

The primary outcomes of interest for this review were the following.

- Medication appropriateness (as measured by an implicit tool), e.g. MAl (Hanlon 1992) or a defined subset of criteria from a validated instrument.

- Potentially inappropriate medications (as defined by a validated explicit tool (e.g. STOPP criteria (Gallagher 2008)), which could consist of the number of potentially inappropriate medications and/or the proportion of patients with one or more potentially inappropriate medications.

- Potential prescribing omissions (as defined by a validated explicit tool (e.g. START criteria (Gallagher 2008)), which could consist of the number of potential prescribing omissions and/or the proportion of patients with one or more potential prescribing omissions.

- Hospital admissions (including all-cause hospital admissions and unplanned hospital readmissions).

\section{Secondary outcomes}

Secondary outcomes included the following.

- Medication-related problems, for example, adverse drug reactions and drug-drug interactions.

- Adherence to medication.

- Quality of life (as assessed by a validated method).

\section{Search methods for identification of studies}

The Information Specialist for the EPOC group updated the searches and searched the Cochrane Database of Systematic Reviews and the Database of Abstracts of Reviews of Effects (DARE) for related systematic reviews, as well as the databases listed below for primary studies. Searches were conducted in May 2016, with an updated search conducted in February 2018 ; exact search dates for each database are included with the search strategies, which are provided in Appendix 2 and Appendix 3.

\section{Databases}

- Cochrane Central Register of Controlled Trials (CENTRAL; 2018, Issue 1) in the Cochrane Library

- Health Technology Assessment Database (HTA; 2016, Issue 4) in the Cochrane Library

- NHSEconomic Evaluation Database (NHSEED;2015, Issue 2) in the Cochrane Library

- MEDLINE Ovid (including Epub Ahead of Print, In-Process \& Other Non-Indexed Citations) (1946 to 31 January 2018)

- Embase Ovid (1974 to 6 February 2018)

- CINAHL EBSCO (Cumulative Index to Nursing and Allied Health Literature; 1980 to 7 February 2018)

\section{Trial registries}

Two trials registers were searched on 7 February 2018.

- InternationalClinical Trials RegistryPlatform (ICTRP), Word Health Organization (WHO) www.who.int/ictrp/en

- ClinicalTrials.gov, US National Institutes of Health (NIH) clinicaltrials.gov

Search strategies comprised keywords and, when available, controlled vocabulary such as MeSH (medical subject headings). All databases were searched for articles indexed between Nov 2013 and February 2018. Two methodological search filters were used to limit retrieval to appropriate study designs. Nolanguage restrictions were applied.

\section{Searching other resources}

- We screened selected issues of the Journal of the American Geriatrics Society (e.g. handsearching).

- We reviewed reference lists of relevant systematic reviews (Appendix 4).

- We contacted authors of relevant studies and reviews to ask that they clarify reported published information or to seek unpublished results/data. 
Interventions to improve the appropriate use of polypharmacy for older people

- We contacted researchers with expertise relevant to the review topic or to EPOC interventions.

- We conducted cited reference searches on studies selected for inclusion in this review, related reviews and other relevant citations as listed on the Institute for Scientific Information (ISI) Web of Science/Web of Knowledge.

\section{Data collection and analysis}

\section{Selection of studies}

For this update, three reviewers (AR, CAC and JC) independently screened titles and abstracts identified in searches to assess which studies met the inclusion criteria of the review. At this stage, we excluded papers that did not meet the inclusion criteria. If uncertainty or disagreement arose at this stage, we obtained full-text articles and assessed them independently to determine whether they met previously defined inclusion criteria. Any remaining disagreement or uncertainty was resolved by consensus through discussion with another review author $(\mathrm{CH})$.

\section{Data extraction and management}

Three reviewers (AR, CAC and JC) independently extracted details of articles included in this update, including study design, study population, intervention, usual care, outcome measures used and length of follow-up data, using a specially designed data extraction form based on the EPOC template (EPOC 2017). We contacted study authors to askfor missing information or clarification. We used information from data extraction forms to guide the extraction of numerical data for meta-analysis in Review Manager 5.3 (RevMan 2014).

We presented data from randomised trials and controlled before-after studies (CBA) studies using the format suggested in the EPOC Working Paper on presentation of data (EPOC 2017). We extracted outcome at the last time point reported to assess enduring effects of the intervention.

\section{Assessment of risk of bias in included studies}

Three reviewers (AR, CAC and JC) independently assessed the internal validity of each study included in this update and resolved discrepancies by discussion.

We used the Cochrane tool for assessing risk of bias (Higgins 2011 ), based on six standard criteria: adequate sequence generation, concealment of allocation, blinding of participants and personnel, blinded or objective assessment of primary outcome(s), adequately addressed incomplete outcome data, freedom from selective reporting and freedom from other risks of bias. We used three additional criteria specified by EPOC (EPOC 2017): similarity of baseline characteristics, reliable primary outcome measures and adequate protection against contamination. We reported all included studies in the 'Risk of bias' tables.

\section{Measures of treatment effect}

We measured the effect of the intervention by referencing published tools (e.g. implicit, judgement-based tools such as the MAI (Hanlon 1992) and/or explicit, criterion-based tools such as 'Beers' (Fick 2003)) used to assess inappropriate prescribing as outlined above. We reported outcomes for each study in natural units. When baseline results were available from studies, means and standard deviation (SD) values for the change from baseline for study and control groups were reported. When baseline results were not available, we reported postintervention means and SD values and/or the proportion of patients with one or more PIMs or PPOs for study and control groups. We analysed data using RevMan 5.3.

In previous versions of this review, we pooled data according to the specific screening tool used. As a modification to the original review protocol, we pooled outcome data on the basis of whether included studies had used an implicit (judgementbased) or explicit (criterion-based) tool to measure inappropriate prescribing. The reason for this change to the protocolwas that, with an ever increasing number of screening tools being used, it would not be feasible to continue to categorise trial outcome data according to specific screening tools or generate meaningful summary effect estimates. When possible, we presented results with $95 \% \mathrm{Cls}$, and estimates when different scales were used to report the same dichotomous outcomes (e.g. the proportion of patients with one or more potentially inappropriate prescriptions) as risk ratios (RRs). We used standardised mean differences (SMDs) in meta-analyses when different scales were used to report the same continuous outcome.

\section{Unit of analysis issues}

We critically examined the methods of analysis of all study types. When studies with a unit of analysis error were identified, we re-analysed the data excluding such studies (sensitivity analysis).

\section{Dealing with missing data}

We assessed the methods used in each included study to deal with missing data. Any study with a differential loss to followup between groups greater than $20 \%$ was excluded from meta-analysis.

\section{Assessment of reporting biases}

We assessed reporting bias by scrutinising study results using the 'Risk of bias' tables provided in RevMan 5.3. We examined funnel plots corresponding to meta-analysis of the primary outcome to assess the potential for small-study effects such as publication bias.

\section{Data synthesis, subgroup analysis and investigation of heterogeneity}

Methods utilised to synthesise the studies depended on their quality, design and heterogeneity. We pooled the results of studies if at least two studies were homogeneous regarding participants, interventions and outcomes. We grouped 
studies and described them according to type of intervention, setting and studydesign, and we planned to perform an assessment of evidence on the theoretical basis underpinning the interventions. For example, if studies reported that interventions were based on the Theory of Diffusion(Rogers 2003), then we planned to pool data across these studies, where appropriate, in order to develop a cumulative evidence base for the theory in question. Where possible, instead of subgrouping outcomes according to the specific tool (i.e.STOPP versus Beers), we pooled studies under the broad descriptions of medication appropriateness (as measured by an implicit tool), potentially inappropriate medications (which consists of the number of potentially inappropriate medications and/or the proportion of patients with one or more potentially inappropriate medications), and potential prescribing omissions (which consists of the number of potential prescribing omissions and/or the proportion of patients with one or more potential prescribing omissions).

In the presence of statistical heterogeneity (greater than $50 \%$, as estimated by the $I^{2}$ statistic), we applied a random-effects model for meta-analysis. For pooling, we considered only groups of studies of the same design (randomised trials and nonrandomised trials). When it was not possible to combine outcome data because of differences in reporting or substantive heterogeneity, we provided a narrative summary.

\section{Sensitivity analysis}

We performed a sensitivity analysis for pooled results based on methodological quality to assess the overall effect. Studies with a unit of analysis error or high risk of bias were excluded from the meta-analysis.

\section{'Summary of findings' table}

We graded our confidence in the evidence by creating a 'Summary of findings' table, using the approach recommended by the GRADEWorking Group and guidance developed by EPOC (EPOC 201 7b; Guyatt 2008). We included the most important outcomes, which were: medication appropriateness (as measured by an implicit tool), the number of potentially inappropriate medications, the proportion of patients with one or more potentially inappropriate medications, the number of potential prescribing omissions, the proportion of patients with one or more potential prescribing omissions, hospital admission, and quality of life. We used methods and recommendations described in Section 8.5 and Chapter 12 of the Cochrane Handbook for Systematic Reviews of Interventions (Higgins 2011 ), along with GRADE worksheets, to assess the certainty of evidence (GRADEpro GDT 2015). Two review authors (AR, CC) independently assessed the certainty of evidence for each outcome. We have presented certainty of evidence for each outcome in GRADE tables (Summary of findings table 1, Appendix 5).

\section{Results}

\section{Description of studies}

See Characteristics of included studies; Characteristics of excluded studies; Characteristics of ongoing studies; and Characteristics of studies awaiting classification.

\section{Results of the search}

We updated the electronic searches and identified 7526 potentially relevant citations (Figure 1 ). Following review of titles and abstracts, we retrieved 432 full-text publications for more detailed assessment. We identified 11 additional potentially relevant citations through searches of other sources, such as relevant reviews (Appendix 4), including the list of ongoing studies provided in the previous review (Patterson 2014), and the Clinical Trials Registry, as well as through contact with study authors. From this updated search, 20 studies met all other inclusion criteria (including study design, study population, types of interventions examined) and were added to the review. There were 27 ongoing studies (see Characteristics of ongoing studies).

\section{Included studies}

In total, we identified 32 eligible studies, of which 20 were included for this update. The North Carolina LongTerm Care Polypharmacy Initiative was published as three separate studies (Christensen 2004; Trygstad 2005; Trygstad 2009), but only two of these studies (Trygstad 2005; Trygstad 2009) met the inclusion criteria. Where data from the studies that were added to the review could notbe included in any form of meta-analysis, narrative descriptions of results are presented. Details are provided in the Characteristics of included studies table and are briefly summarised below.

\section{Study design}

Included studies consisted of 18 randomised trials (Basger 2015; Bladh 2011; Bucci 2003; Campins 2017; Crotty 2004b; Dalleur 2014; Frankenthal 2014; Fried 2017; Gallagher 2011; Haag 2016; Hanlon 1996; Michalek 2014; Milos 2013; Olsson 2012; Schmader 2004; Spinewine 2007; Taylor 2003; Wehling 2016), 10 cluster-randomised trials (Clyne 2015; Crotty 2004a; Garcia-Collarte 2014; Franchi 2016; Koberlein-Neu 2016; Muth 2016; Muth 2018; Pitkala 2014; Tamblyn 2003; Thyrian 2017), one of which was a stepped-wedge design (Koberlein-Neu 2016), two non-randomised trials (Chiu 2018; Van der Linden 2017) and two controlled before-after studies (Trygstad 2005; Trygstad 2009).

\section{Settings}

Of the 16 studies conducted in hospital settings (3779 participants), three were conducted in hospital outpatient clinics (Hanlon 1996; Bucci 2003; Schmader 2004), one at the hospital/homecare interface (Crotty $2004 \mathrm{~b})$. and 12 in an inpatient setting (Basger 2015; Bladh 2011; Chiu 2018; Dalleur 2014; Franchi 2016; Gallagher 2011; Haag 2016; Michalek 2014; Olsson 2012; Spinewine 2007; Wehling 2016; Van der Linden 2017). Ten studies were conducted in primarycare settings (14,969 participants) (Campins 2017; Clyne 2015; Fried 2017; Koberlein-Neu2016; Milos 2013; Muth 
2016; Muth 2018; Tamblyn 2003; Taylor 2003; Thyrian 2017). Six studies took place in nursing homes (9924 participants) (Crotty 2004a; Frankenthal 2014; Garcia-Gollarte 2014; Pitkala 2014; Trygstad 2005; Trygstad 2009). All studies reported trials which were confined to a single setting.

The included studies were carried out in 12 high-income countries: Australia (three studies), Belgium (three studies), Canada (two studies), Finland (one study), Germany (six studies), Hong Kong (one study), Ireland (two studies), Israel (one study), Italy (one study), Spain (two studies) and Sweden (three studies), and the USA (seven studies).

\section{Participants}

A total of 28,672 participants were included in this review, most of whom were female (64.4\%) and had a mean age of 72.8 years. In those studies where ethnicity was reported (five studies, $\mathrm{N}=8710$ ), most participants were white. All study participants had more than one long-term medical condition, which included asthma, diabetes, dyslipidaemia, hypertension, cardiovascular disease (including congestive heart failure) and dementia. On average, participants were receiving more than four medicines at baseline. In 31 of the 32 studies for which data were available (16,112 participants), participants were prescribed on average 8.9 medicines at baseline.

\section{Interventions $\neg$}

In all cases, interventions were classified as either delivery arrangements (Basger 201 5; Bladh 201 1; Bucci 2003; Chiu 2018; Crotty 2004b; Fried 2017; Haag 2016; Koberlein-Neu 2016; Michalek 2014; Milos 2013; Muth 2016; Muth 2018; Olsson 2012; Schmader 2004; Spinewine 2007; Thyrian 2017; Van der Linden 2017), implementation strategies (Franchi 2016; Garcia-Collarte 2014), or both (Campins 201 7; Clyne 201 5; Crotty 2004a; Dalleur 2014; Frankenthal 2014; Gallagher 201 1; Hanlon 1996; Pitkala 2014; Tamblyn 2003; Taylor 2003; Trygstad 2005; Trygstad 2009; Wehling 2016)(see Types of interventions for definitions).

Thirty-one studies examined complex, multi-faceted interventions of pharmaceutical care in a variety of settings. One uni-faceted study (Tamblyn 2003) examined computerised decision support (CDS) provided to GPs in their own practices. Pharmaceutical care was commonly provided by pharmacists working closelywith other healthcare professionals in a variety of settings. In hospital settings, pharmacists worked as part of a multi-disciplinary team in outpatient clinics (Bucci 2003; Hanlon 1996; Schmader 2004), in inpatient services on hospital wards as a clinical pharmacy service (Basger 2015; Bladh 2011; Chiu 2018; Dalleur 2014; Franchi 2016; Gallagher 2011; Haag 2016; Michalek 2014; Olsson 2012; Spinewine 2007; Van der Linden 2017; Wehling 2016), or as part of the hospital discharge process (Crotty 2004b). In community settings, pharmaceutical care services, including medication reviews, patient interviews and counselling, were provided by different healthcare professionals. This included pharmacists working in community-based family medicine clinics (Taylor 2003), or within primary care centres (Campins 2017; Milos 2013), GP (Clyne 2015; Fried 2017; Koberlein-Neu 2016) and nurses/healthcare assistants (Muth 2016; Muth 2018; Thyrian 2017 ). In nursing homes, interventions involved multi-disciplinary case conferences combined with staff education provided by pharmacists (Crotty 2004a), medication reviews by the study pharmacists and discussed with the chief physician (Frankenthal 2014), training sessions for staff(Garcia-Gollarte 2014; Pitkala 2014), and a drug therapy management service (Trygstad 2005; Trygstad 2009).

Physicians delivered the intervention via a computerised support programme in one study (Tamblyn 2003), whereas in all other studies, structured processes were used to develop recommendations for improving the appropriateness of prescribing to prescribers.

Models of pharmaceutical care provided in the included studies were complex and variable. In 17 studies, the pharmacist(s)conducted an independent medication review using participant notes (Bladh 2011; Campins 2017; Crotty 2004a; Crotty 2004b; Koberlein-Neu 2016; Milos 2013; Van der Linden 2017), together with participants during a faceto-face encounter (Basger 2015; Bucci 2003; Chiu 2018; Frankenthal 2014; Hanlon 1996; Schmader 2004; Spinewine 2007; Tamblyn 2003; Taylor 2003), or during an medication therapy management (MTM) consultation over the telephone (Haag 2016). Following medication reviews, recommendations were discussed with a multi-disciplinary team during case conferences (Crotty 2004a; Crotty 2004b), sent to patient's own GPs or consultants (Basger 2015; Bladh 2011; Campins 2017; Frankenthal 2014; Milos 2013; Vander Linden 2017), or discussed with prescribers and followed up by written recommendations (Hanlon 1996) from multi-disciplinary team members at the same outpatient clinic (Bucci 2003), or during inpatient ward rounds (Spinewine 2007). In five studies, medicine reviews were undertaken by the doctor (Clyne 2015; Fried 2017; Muth 2016; Muth 2018; Wehling 2016). In three studies, nurses were asked to identify potential medication-related problems and bring these to the attention of the consulting physician (Pitkala 2014), or conduct prescription reviews (Thyrian 2017), which were sent to the study physician (Olsson 2012). In one study, the pharmacist was an integral member of the multi-disciplinary team (Schmader 2004) and contributed to the pharmaceutical care aspect of participants' care plans at the point of decision making. In two studies, consultant pharmacists performed a comprehensive profile review of the computerised drug profiles of selected participants using a range of tools such as the Beers criteria and made recommendations to prescribers in nursing homes by fax, telephone or written communication $\neg$ (Trygstad 2005; Trygstad 2009).

In four studies, participants' medication lists were screened by a geriatrician (Dalleur 2014), or by the primary research physician (Gallagher 2011; Garcia-Gollarte 2014; Michalek 2014) upon admission to hospital, and oral and written recommendations outlining appropriate prescribing changes were then provided to the attending physicians. In the Dalleur 2014 study, no pharmacist was available to collaborate with the inpatient geriatric consultation team owing to lack of resources within the hospital. 
Participant education was provided as part of the pharmaceutical care intervention in four of six studies in which the intervention was conducted face-to-face, and these participants were given 'directive guidance' and specialised medication scheduling tools (e.g. monitored dosage systems) to encourage adherence to their prescribed medication regimens (Bucci 2003; Hanlon 1996; Spinewine 2007; Taylor 2003). Directive guidance describes pharmaceutical care activities such as provision of information about medications, their administration and their adverse effects (Bucci2003 ). In one study, patients received information leaflets during the medicines reviews, describing potentially inappropriate prescribing (PIP) and alternative treatment options (pharmacological and non-pharmacological) (Clyne 2015).

Education was provided to prescribers and other healthcare professionals included in the multi-disciplinary team as part of the intervention in 10 studies (Bucci 2003; Clyne 2015; Crotty 2004a; Crotty 2004b; Franchi 2016; Garcia-Gollarte 2014; Hanlon 1996; Pitkala 2014; Spinewine 2007; Wehling 2016); this occurred at case conferences, during ward rounds, as part of workshops, or when evidence-based information and answers to specific medication-related queries were presented. In two studies in which the pharmacist was part of a multi-disciplinary team, no educational intervention was specified in the methodology (Schmader 2004; Taylor 2003).

The timing of provision of the intervention was variable. Interventions were delivered over a period of time, for example, during the hospital inpatient stay and at discharge (Bladh 2011; Chiu 2018; Franchi 2016; Haag 2016; Michalek 2014; Schmader 2004; Spinewine 2007; Van der Linden 2017), or over several clinic visits and over several months on an ongoing basis (Tamblyn 2003). Interventions were also delivered at the time of an event, for example, following hospital admission (Dalleur 2014; Gallagher 2011), at discharge from hos pital (Basger 2015), during attendance at outpatient clinics (Bucci 2003; Hanlon 1996; Schmader 2004; Taylor 2003), at nursing home visits (Crotty 2004a; Trygstad 2005; Trygstad 2009), at hospital discharge to a nursing home (Crotty 2004b), home visit by a nurse (0lsson 2012), or GP visit (Campins 2017; Clyne 2015; Fried 2017; Muth 2016; Muth 2018). In studies for which details of intervention administration were provided, interventions were most commonly administered during a single episode of care (Bucci 2003 ; Crotty 2004a; Hanlon 1996; Tamblyn 2003; Taylor 2003; Trygstad 2005; Trygstad 2009). Interventions were implemented over varying durations, ranging from five or six months (Bucci 2003; Trygstad 2005), one year (Frankenthal 2014; Koberlein-Neu 2016), to three years and three months (Schmader 2004). Further details of the interventions are detailed in the Characteristics of included studies tables.

\section{Outcomes $\neg$}

The first primary outcomes of interest in this review were medication appropriateness (as measured by an implicit tool), potentially inappropriate medications (PIMs) and potential prescribing omissions (PPOs). Validated assessments of appropriateness reported in all included studies were measured independentlyby pharmacists, geriatricians or the research team, who had access to participants' charts and medication records, except in Trygstad 2005 and Trygstad 2009 , where the Medicaid dispensed prescription claims database was used. Time between delivery of the intervention and follow-up outcome measurement varied from immediately postintervention (e.g. post hospital discharge or clinic visit) (Michalek 2014; Schmader 2004; Spinewine 2007; Tamblyn 2003; Wehling 2016) to at least one month (Bucci 2003 ), eight weeks (Crotty 2004b), three months (Basger 2015; Crotty 2004a; Garcia-Collarte 2014; Trygstad 2005; Trygstad 2009), six months (Clyne 2015; Gallagher 2011), up to one year (Dalleur 2014; Franchi 2016; Hanlon 1996; Pitkala 2014; Taylor 2003), and up to two years (Frankenthal 2014).

Eleven studies measured medication appropriateness (as measured by an implicit tool); the only implicit tool (judgement-based) used was the Medication Appropriateness Index (MAl) (Bucci 2003; Chiu 2018; Crotty 2004a; Crotty 2004b; Gallagher 2011; Hanlon 1996; Muth 2016; Muth 2018; Schmader 2004; Spinewine 2007; Taylor 2003). Six studies reported MAI as a change from baseline and nine studies reported postintervention scores. One study reported the MAI score in terms of the number of prescriptions with inappropriate medications; this was unsuitable for inclusion in the meta-analysis (Taylor2003).

Twenty-one studies measured PIMs (Bladh 2011; Campins 2017; Clyne 2015; Dalleur 2014; Franchi 2016; Frankenthal 2014; Fried 2017; Gallagher 2011; Garcia-Gollarte 2014; Haag 2016; Koberlein-Neu 2016; Milos 2013; Olsson 2012; Pitkala 2014; Schmader 2004; Spinewine 2007; Tamblyn 2003; Thyrian 2017; Trygstad 2005; Trygstad 2009; Van der Linden 2017 ). These studies used a range of explicit (criterion-based) tools, including Beers criteria (Franchi 2016; Pitkala 2014; Schmader 2004; Spinewine 2007; Trygstad 2005; Trygstad 2009), Screening Tool of Older Person's Prescriptions (STOPP) criteria (Campins 2017; Clyne 2015; Dalleur 2014; Frankenthal 2014; Gallagher 2011; Garcia-Gollarte 2014; Haag 2016), Tool to Reduce Inappropriate Medication (TRIM) recommendations (Fried 2017), the drug-specific quality indicators established by the Swedish National Board of Health and Welfare (Bladh 201 1; Milos 2013; Olsson 2012 ), the PRISCUS criteria (Koberlein-Neu 2016; Thyrian 2017) and the Rationalization of home medication by an Adjusted STOPP in older Patients (RASP) list (Van der Linden 2017), which were measured at varying time points ranging from at the point of in patient discharge to 24-months follow-up. Seven studies reported the number of PIMs, as identified using Beers criteria (Pitkala 2014; Schmader 2004; Spinewine 2007) and STOPP criteria (Clyne 2015; Garcia-Gollarte 2014), the PRISCUS criteria (Koberlein-Neu 2016), and the RASP list (Van der Linden 2017). Thirteen studies reported the proportion of patients with one or more PIMs, as identified using Beers criteria (Pitkala 2014; Spinewine 2007 ), the STOPP criteria (Clyne 2015; Dalleur 2014; Frankenthal 2014; Gallagher 2011 ; Garcia-Gollarte 2014; Haag 2016), the drug-specific quality indicators established by the Swedish National Board of Health and Welfare (Milos 2013), TRIM recommendations (Fried 2017) or the PRISCUS criteria (Thyrian 2017).

One study used the McLeod criteria and reported the rate of inappropriate medications prescribed per physician visit postintervention (Tamblyn 2003). 
Potential prescribing omissions (PPOs) or under-use of medication were reported in six studies (Frankenthal 2014; Gallagher 2011; Garcia-Gollarte 2014; Haag 2016; Schmader 2004; Spinewine 2007), and both were reported as postintervention scores. The only implicit tool used was the Assessment of Under-utilisation of Medication (AUM) instrument (Jeffery 1999; Gallagher 2011; Schmader 2004). Five studies used explicit tools including the seven process measures from the full range of Assessing Care of Vulnerable Elderly (ACOVE) criteria (Spinewine 2007 ) and the Screening Tool to Alert doctors to the Right Treatment(START) criteria (Frankenthal 2014; Gallagher 201 1; Garcia-Gollarte 2014; Haag 2016). All five studies using an explicit tool reported the proportion of patients with one or more PPOs, which were measured at varying time points ranging from at the point of in patient discharge to 24-months follow-up.

Three other studies reported results in the form of combined PIM and PPO indicators/scores (Basger 2015; Michalek 2014; Wehling 2016). One study measured appropriateness using the prescribing appropriateness criteria-set for application in older Australians (Basger 2012) and reported changes in the number of criteria met (Basger 2015). This method uses a combination of both explicit and implicit tools to measure appropriateness. Two studies used the Fit for The Aged (FORTA) criteria (Kuhn-Thiel 2014), to evaluate the appropriateness of medications in terms of unnecessary, inappropriate or harmful medications and drug omissions (Michalek 2014Wehling 2016). In the Michalek 2014 study, the number of drugs within each FORTA classification (i.e. FORTA drug labels range from A (indispensable), B (beneficial), C (questionable) to D (avoid)), while the Wehling 2016 study reported the summated FORTA score postintervention along with the change in FORTA score postintervention.

No other validated criteria (e.g. Zhan criteria) were reported.

The other primary outcome of interest in this review was hospital admissions (including unplanned hospital readmissions). Twelve studies measured hospital admissions by examining hospital records at varying time points postintervention(Campins 2017; Chiu 2018; Crotty 2004b; Franchi2016; Frankenthal 2014; Gallagher 2011; Haag 2016; Muth 2018; Spinewine 2007; Taylor 2003; Trygstad 2005; Van der Linden 2017) ranging from eight weeks (Crotty 2004b; Spinewine 2007), one to three months (Chiu 2018; Haag 2016; Trygstad 2009; Van der Linden 2017) and six months to one year (Campins 2017; Franchi 2016; Frankenthal 2014; Gallagher 2011; Muth 2018; Taylor 2003). ᄀ

The secondary outcomes of interest in this review were medication-related problems (i.e. drug interactions, adverse drug reactions (ADRs)), adherence to medication and quality of life. Medication-related problems, were measured in eight studies and were reported as medication misadventures (defined as iatrogenic incidents that occur as a result of error, immunological response or idiosyncratic response and are always unexpected or undesirable to the participant) ( Taylor 2003), potential drug therapy problems (Trygstad 2005; Trygstad 2009), potential drug-drug interaction (DDI) and potentially severe DDI (Franchi 2016) or postintervention adverse drug events (ADEs) (Crotty 2004b; Hanlon 1996; Schmader 2004; Wehling 2016). Adherence to medication was measured in five studies (Campins 2017; $\underline{\text { Haag 2016; Muth }}$ 2016; Muth 2018; Taylor 2003), three studies used Morisky-Green test (Campins 2017; Muth 2016; Muth 2018), one study used an adapted Morisky Medication Adherence Scale (MMAS) (Haag 2016), and one study assessed adherence to medication via participant self-report (Taylor 2003). Adherence to medications was assessed at varying time points postintervention ranging from 30 days (Haag 2016), six to nine months (Campins 2017; Muth 2018) and one year (Muth 2016; Taylor 2003). Quality of life (QoL) was assessed in 12 studies using the Medical Outcomes Study 36-item Short Form health survey (SF-36) in three studies (Basger 2015; Hanlon 1996; Taylor 2003), the Medical Outcomes Study 12-item Short-Form Health Survey (SF-12) in one study (Frankenthal 2014), the EuroQol-ED (EQ-5D) in six studies (Bladh 2011; Campins 2017; Muth 2016; Muth 2018; Olsson 2012; Van der Linden 2017 ) the 15 dimensional instrument of health-related quality of life (15D) in one study (Pitkala 2014), and the Quality of Life in Alzheimer Disease instrument in one study (Thyrian 2017). Quality of life was assessed at varying time points postintervention ranging from three months (Basger 2015; Van der Linden 2017), six to nine months (Bladh 2011 ; Campins 2017; Muth 2018) and one year (Frankenthal 2014; Hanlon 1996; Muth 2016; Olsson 2012; Pitkala 2014; Taylor 2003; Thyrian 2017).

\section{Excluded studies}

Excluded publications that were read in full are summarised along with the reasons for exclusion in the Characteristics of excluded studies table.

\section{Studies awaiting classification}

Studies for which sufficient information was not available to determine eligibility for inclusion in this review have been allocated to the Studies awaiting classification section.

\section{Ongoing studies}

We described ongoing studies identified during completion of the review and provided details such as primary author, research question(s) and methods and outcome measures, together with an estimate of the reporting date in the Characteristics of ongoing studies table appended to this review.

\section{Risk of bias in included studies}

Details of the risk of bias are presented in Figure 2 and Figure 3 and in the Characteristics of included studies tables.

\section{Allocation (selection bias)}

Fourteen trials reported adequate sequence generation (Bucci 2003; Campins 2017; Clyne 201 5; Crotty 2004a; Crotty

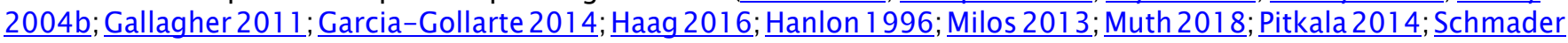


Interventions to improve the appropriate use of polypharmacy for older people

2004; Thyrian 2017), and 13 reported concealment of allocation (Bladh 2011; Campins 2017; Clyne 2015; Crotty 2004a: Crotty 2004b; Frankenthal2014; Gallagher 2011; Haag 2016; Koberlein-Neu 2016; Michalek 2014; Milos 2013; Pitkala 2014; Wehling 2016).

\section{Blinding (performance bias and detection bias)}

In 14 studies, blinded measurement of outcomes had taken place to ensure that primary outcome assessors had no knowledge of the intervention received by participants (Bucci 2003; Clyne 2015; Crotty 2004b; Dalleur 2014; Franchi 2016; Frankenthal 2014; Gallagher 201 1; Haag 2016; Hanlon 1996; Muth 2016; Pitkala 2014; Schmader 2004; Tamblyn 2003; Wehling 2016). Blinding of participants and personnel had taken place to ensure there was no performance bias in five studies (Garcia-Gollarte 2014; Michalek 2014; Muth 2016; Olsson 2012; Pitkala 2014).

\section{Incomplete outcome data (attrition bias)}

Incomplete outcome data were adequately addressed in 21 studies. In one study (Schmader 2004), 864 participants were randomlyassigned but only 834 were included in the analysis, and no intention-to-treat analysis was reported. Therefore, it was unclear whether all outcome data were included.

\section{Selective reporting (reporting bias)}

Three studies (Koberlein-Neu 2016; Spinewine 2007; Thyrian 2017) were considered at high risk of reporting bias. In the Spinewine 2007 study, the authors failed to report one of the secondary outcomes, medications taken.

\section{Similarity of baseline characteristics}

In eight studies, baseline demographic differences existed between intervention and control groups and there was no reported adjustment of results to account for baseline differences in analyses.

\section{Other potential sources of bias}

The primary outcome measures used were reliable instruments in all studies, for example, MAl kappa value $=0.84$.

Participants in six studies were protected from contamination (Clyne 201 5; Crotty 2004a; Michalek 2014; Muth 2018; Pitkala 2014, Thyrian 2017). In 14 studies it was unclear whether protection against contamination had been provided (Basger 2015; Dalleur 2014; Franchi 2016; Frankenthal 2014; Fried 2017; Gallagher 2011; Garcia-Gollarte 2014; Milos 2013; Muth 2016; Olsson 2012; Schmader 2004; Tamblyn 2003; Trygstad 2005; Trygstad 2009), and 12 studies were determined to have high risk of contamination (Bladh 2011; Bucci 2003; Campins 2017; Chiu 2018; Crotty 2004b; Haag 2016; Hanlon 1996; Koberlein-Neu 2016; Spinewine 2007; Taylor 2003; Van der Linden 2017; Wehling 2016). Contamination bias occurs when members of the control group are inadvertently exposed to the intervention, thus potentiallyminimising differences in outcomes between the two groups (Higgins 2011). This is an important limitation for this review, where, in some studies, for example, a pharmacist involved in the provision of pharmaceutical care to members of the intervention group may have inadvertently modified the treatment of those in the control group as a result of having knowledge of the intervention. The possible influence of contamination bias should be considered when the results of this review are interpreted.

Funnel plots of postintervention estimates of medication appropriateness (as measured byan implicit tool), the number of potentially inappropriate medications, the proportion of patients with one or more potentially inappropriate medications and the proportion of patients with one or more potential prescribing omissions showed little evidence of publication bias (Figure 4; Figure 5; Figure 6).

\section{Effects of interventions}

There was a lack of certainty regarding the effects of pharmaceutical care interventions included in this reviewon inappropriate prescribing (medication appropriateness (as measured by an implicit tool), the number of potentially inappropriate medications (PIMs), the proportion of patients with one or more PIMs and the proportion of patients with one or more potential prescribing omissions (PPOs)). Pharmaceutical care may reduce the number of PPOs, however it must be noted that this effect estimate is based on only two studies, which had serious limitations in terms of risk bias. Hospital admissions, as reported in 12 studies, were reduced in four studies (Chiu 2018; Crotty 2004b; Taylor 2003; Trygstad 2009) (in one cohort, but not in the remaining nine cohorts), and eight studies (Campins 2017; Franchi 2016; Frankenthal 2014; Gallagher 2011; Haag 2016; Muth 2018; Spinewine 2007; Van der Linden 2017) found little or no difference.

No consistent intervention effect on medication-related problems was observed across studies (eight studies); these problems were reported in terms of adverse drug events (ADEs) (Crotty 2004b; Hanlon 1996; Schmader 2004; Wehling 2016), medication misadventures (Taylor 2003), potential drug therapy problems (Trygstad 2005; Trygstad 2009), and potential drug-drug interactions (DDIs) or potentially severe DDIs (Franchi 2016). Improvement in adherence to medication was demonstrated in one study (Taylor 2003), while the other four studies (Campins 201 7; Haag 2016; Muth 2016; Muth 2018) found little or no difference. In the Van der Linden 2017 study, analysis showed that participants in the intervention group experienced an increased quality of life (QoL), in the Pitkala 2014 study, there was a decline in QoL in both the intervention and control groups, although the decline was significantly lower in the intervention group $(-0.038$ in the intervention group versus -0.072 in the control group), and no changes in QoL were detected in 10 studies (Bladh 2011; Basger 2015; Campins 2017; Frankenthal 2014; Hanlon 1996; Muth 2016; Muth 2018; Olsson 2012; Taylor 2003; Thyrian 2017). 
Based on the GRADE approach (Guyatt 2008), the overall certainty of the body of evidence for each primary outcome for which data were included in a meta-analysis was deemed to be low or very low, which means that the confidence in the effect estimates is very limited. Although each study included in the meta-analyses was of a randomised design, and, where as sessed, no evidence of publication bias was found (Figure 4; Figure 5; Figure 6), the certainty of the body of evidence was downgraded for each outcome based on other GRADE considerations (i.e. study limitations, consistency of effect, imprecision, indirectness) (Appendix 5).

\section{Primary outcome results}

\section{Medication appropriateness (as measured by an implicit tool)}

It is uncertain whether pharmaceutical care improves medication appropriateness (as measured by an implicit tool) because the certainty of this evidence is very low ( 5 studies, $\mathrm{N}=517$ ). Three studies reported medication appropriateness using an implicit (judgement-based) assessment tool (Bucci 2003; Crotty 2004a; Muth 2016), and further unpublished data were received from the authors of two studies (Crotty 2004b; Spinewine 2007). All of these studies used the Medication Appropriateness Index (MAI) as the implicit tool. Comparison of medication appropriateness (as measured by an implicit tool) from baseline to follow-up between the intervention group and the control group is shown in Analysis 1.1. $\neg$ Overall, a greater improvement in medication appropriateness (as measured by an implicit tool) postintervention was seen in the intervention group compared with the control group (mean difference (MD) -4.76, 95\% confidence interval $(\mathrm{Cl})-9.20$ to $-0.33 ; \mathrm{I}^{2}=95 \% ; 5$ studies; $\mathrm{N}=517$, Analysis 1.1$)$. $\neg$ Marked heterogeneity between studies was noted (95\%). Crotty 2004a reported a unit of analysis error; nursing homeswere the unit of randomisation, but the analysis was conducted at the participant level. A sensitivity analysis excluding Crotty 2004a showed a similar improvement in medication appropriateness (as measured by an implicit tool) (MD -5.16,95\% Cl-1 1.04 to $0.72 ; I^{2}=96 \% ; \mathrm{N}=446$, Analysis 1.2) in favour of the intervention group. A further sensitivity analysis removing both Crotty $2004 \mathrm{a}$ and $\underline{\mathrm{Spinewine}}$ 2007, an outlying study with a large effect size that had a high risk of bias with respect to selection bias (allocation concealment), performance bias, detection bias, contamination bias and selective reporting, also showed a greater improvement in medication appropriateness (as measured by an implicit tool) in the intervention group, but the magnitude of the difference was smaller compared with previous analyses $\left(\mathrm{MD}-0.50,95 \% \mathrm{Cl}-2.27\right.$ to $1.28 ; \mathrm{I}^{2}=57 \% ; \mathrm{N}=260$, Analysis 1.3). The level of heterogeneity between studies was also found to have reduced.

We downgraded the certainty of the body of evidence for medication appropriateness (as measured by an implicit tool) to verylow. Very serious design limitations with implications in terms of selection bias, performance bias, reporting bias and risk of contamination bias were identified in several studies. Spinewine 2007 was deemed to have high risk of bias in terms of selection bias (allocation concealment), performance bias, detection bias, contamination bias and selective reporting, which resulted in the downgrading of the certainty of evidence. The certainty of evidence was downgraded due to indirectness, some studies answered a restricted version of the research question, as a validated assessment of under-prescribing was not included as part of the overall assessment of inappropriate prescribing. Therefore, interventions did not directly target appropriate polypharmacy. Additionally, evidence of inconsistency $\left(I^{2}=95 \%\right)$ was identified, as well as imprecision in the effect estimate, whereby the $95 \%$ Clwas wide and/orcrossed the line of no effect. These observations resulted in the downgrading of the certainty of evidence.

Potentially inappropriate medications (PIMs) (including the number of potentially inappropriate medications and the proportion of patients with one or more PIMs)

Pooled data from seven studies (Bladh 2011; Clyne 2015; Garcia-Gollarte 2014; Koberlein-Neu 2016; Pitkala 2014; Schmader 2004; Spinewine 2007) showed that the number of potentially inappropriate medications was lower in the intervention group participants compared with control group participants postintervention (standardised mean difference (SMD) $-0.22,95 \% \mathrm{Cl}-0.38$ to $-0.05 ; 1^{2}=67 \% ; 7$ studies; $\mathrm{N}=1832$, Analysis 1.4 ). The numbers of PIMs were determined using explicit (criterion-based) assessment tools, including Screening Tool of Older Person's Prescriptions (STOPP) (version 1 : Gallagher 2008), and Beers (1997 version: Beers 1997 and 2003 version: Fick 2003), PRISCUS criteria (Holt 2010 ), and the drug-specific quality indicators established by the Swedish National Board of Health and Welfare (Fastbom 2015 ). However, it is uncertain whether pharmaceutical care reduces the number of potentially inappropriate medications because the certainty of this evidence is verylow. The Trygstad 2009 study, which also reported the number of Beers list drugs, comprised 10 cohorts. It was notincluded in the meta-analysis, as the studydesign, analysis and reporting (e.g. using propensity matching, reporting results as difference-in-difference) differed from the others, resulting in estimates that were not sufficiently similar to support inclusion. The Trygstad 2009 study, also reported no statistically significant reductions in Beers list alerts, which is not inline with the meta-analysis results. The Olsson 2012 study reported number of drug-risk indicators per patient according to the drug-specific quality indicators established by the Swedish National Board of Health and Welfare and the Campins 2017 study reported the proportion of patients with at least one drug discontinuation based on STOPP criteria. These studies were not included in the meta-analyses as the analysis and reporting differed from the other. We were also unable to ascertain the standard deviation of the results for two studies (Trygstad 2005; Van der Linden 2017), which were also not included in the meta-analysis.

We downgraded the certainty of the body of evidence for the number of potentially inappropriate medications to very low due to very serious design limitations in both studies that were included in the meta-analysis, with implications in terms of risk of selection bias, performance bias and contamination bias. Evidence of inconsistency $\left(I^{2}=67 \%\right)$ was identified possibly due to some of the studies answering a restricted version of the research question, as a validatedassessment of underprescribing was not included as part of the overall assessment of inappropriate prescribing. Therefore, all of the interventions did not directly target appropriate polypharmacy. 
Eleven studies reported the proportions of patients with one or more potentially inappropriate medications (Clyne 2015; Dalleur 2014; Franchi 2016; Frankenthal 2014; Fried 2017; Gallagher 2011; Garcia-Gollarte 2014; Haag 2016; Milos 2013; Spinewine 2007; Thyrian 2017) before and after intervention. The proportions of patients with one or more PIMs were determined using explicit (criterion-based) assessment tools, including STOPP (version 1 : Gallagher 2008), and Beers (1997 version: Beers 1997 and 2012 version: AGS 2012) (Appendix 1), the Tool to Reduce Inappropriate Medication (TRIM) recommendations based on Beers (2012 version: AGS 2012) and STOPP criteria (version 1 : Gallagher 2008), PRISCUS (Holt 2010) and the drug-specific quality indicators established by the Swedish National Board of Health and Welfare (Fastbom 2015). Pooled data from 11 studies showed that improvements were reported in the proportion of intervention patients with one or more PIMs, compared to the control group participants, between baseline and discharge (risk ratio (RR) $0.79,95 \% \mathrm{Cl} 0.61$ to $1.02 ; I^{2}=85 \% ; 11$ studies; $\mathrm{N}=3079$, Analys is 1.5 ). There was considerable heterogeneity among the 11 trials (heterogeneity: $\left.\mathrm{Tau}^{2}=0.14 ; \mathrm{Chi}^{2}=64.90, \mathrm{df}=10(\mathrm{P}<0.00001) ; \mathrm{I}^{2}=85 \%\right)$. A sensitivity analysis excluding Spinewine 2007, a study with a large effect size that had a high risk of bias with respect to selection bias (allocation concealment), performance bias, detection bias, contamination bias and selective reporting, showed similar improvements in the proportion of intervention patients with one or more PIMs, compared to the control group participants, between baseline and discharge (RR $0.79,95 \% \mathrm{Cl} 0.61$ to $1.02 ; I^{2}=86 \% ; 10$ studies; $\mathrm{N}=2893$, Analysis 1.6). A further sensitivity analysis removing both Spinewine 2007 and Gallagher 2011 , which had a smaller treatment effect compared to the other studies, also showed similar improvements in the proportion of intervention patients with one or more PIMs, compared to the control group participants, between baseline and discharge (RR $0.88,95 \% \mathrm{Cl} 0.72$ to $1.09 ; I^{2}=75 \% ; 9$ studies; $\mathrm{N}=2535$, Analys is 1.7). It is uncertain whether pharmaceutical care reduces the proportion of patients with one or more potentially inappropriate medications because the certainty of this evidence is very low.

We downgraded the certainty of the body of evidence for the proportion of patients with one or more potentially inappropriate medications to very low. Very serious design limitations with implications in terms of selection bias, performance bias and risk of contamination bias were identified in several studies. Spinewine 2007 was deemed to have high risk of bias in terms of selection bias (allocation concealment), performance bias, detection bias, contamination bias and selective reporting which resulted in the downgrading the certainty of evidence. The certainty of evidence was downgraded due to indirectness, as some studies answered a restricted version of the research question, as a validated assessment of under-prescribing was not included as part of the overall assessment of inappropriate prescribing. Therefore, interventions did not directly target appropriate polypharmacy. Additionally, evidence of inconsistency $\left(1^{2}=85 \%\right)$ as well as imprecision in the effect estimate, whereby the $95 \% \mathrm{Cl}$ was wide and/or crossed the line of no effect was identified which resulted in the downgrading of the certainty of evidence.

\section{Potential prescribing omissions (PPOs) (including the number of potential prescribing omissions and the proportion of patients with one or more PPOs)}

Pooled data from two studies (Garcia-Gollarte 2014; Spinewine 2007) showed that the number of PPOs waslowerin the intervention group participants compared with control group participants postintervention (SMD $-0.81,95 \% \mathrm{Cl}-0.98$ to -0.64 2 studies; $N=569$, Analysis 1.8). The number of PPOs was determined using explicit (criterion-based) assessment tools, including Assessing Care of the Vulnerable Elderly (ACOVE) (version 1 : Wenger 2001) and START (version 1 : Gallagher 2008). Pharmaceutical care may slightly reduce the number of potential prescribing omissions (low-certainty evidence).

We downgraded the certainty of the body of evidence for the number of potential prescribing omissions to low. Very serious design limitations with implications in terms of selection bias, performance bias and risk of contamination bias were high or unclear in both studies. Spinewine 2007 was deemed to have high risk of bias in terms of selection bias (allocation concealment), performance bias, detection bias, contamination bias and selective reporting which resulted in the downgrading of the certainty of evidence.

Five studies (Frankenthal 2014; Gallagher 2011; Garcia-Gollarte 2014; Haag 2016; Spinewine 2007), also reported the proportion of patients with one or more potential prescribing omissions. The proportions of patients with one or more PPOs were determined using explicit (criterion-based) assessment tools, including START (version 1: Gallagher 2008), and ACOVE (version 1 : Wenger 2001). The proportion of patients in the intervention group with one or more potential prescribing omissions was lower than for those in the control group (RR $0.40,95 \% \mathrm{Cl} 0.18$ to $0.85 ; \mathrm{I}^{2}=90 \% ; 5$ studies; $\mathrm{N}=$ 1310, Analysis 1.9). There was considerable heterogeneity among the four trials (heterogeneity: $\mathrm{Tau}^{2}=0.67 ; \mathrm{Chi}^{2}=41.82, \mathrm{df}^{2}$ $\left.=4(\mathrm{P}<0.00001) ; I^{2}=90 \%\right)$. It is uncertain whether pharmaceutical care reduces the proportion of patients with one or more potential prescribing omissions because the certainty of this evidence is very low.

We downgraded the quality of the body of evidence for the proportion of patients with one or more PPOs due to very serious design limitations with implications in terms of selection bias, performance bias and risk of contamination bias in several studies. Spinewine 2007 was deemed to have high risk of bias in terms of selection bias (allocation concealment), performance bias, detection bias, contamination bias and selective reporting which resulted in downgrading the certainty of evidence. Evidence of inconsistency $\left(I^{2}=90 \%\right)$ was identified which resulted in the downgrading of the certainty of evidence.

As only one uni-faceted study was included (Tamblyn 2003), a subgroup analysis was not possible.

\section{Hospital admissions}

Twelve studies measured hospital admissions postintervention (Campins 201 7; Chiu 201 8; Crotty 2004b; Franchi 2016; Frankenthal 2014; Gallagher 2011; Haag 2016; Muth 2018; Spinewine 2007; Taylor 2003, Trygstad 2009; Van der Linden 2017). Eight studies (Campins 201 7; Franchi 2016; Frankenthal 2014; Gallagher 2011; Haag 2016; Muth 2018; Spinewine 2007; Van der Linden 2017) $(\mathrm{N}=3041)$ reported similar hospital admissions between intervention and control group participants postintervention, and the remaining studies reported some overall reductions in hospital admissions using a 
variety of measurements, as detailed below.

$\underline{T a y l o r} 2003$ reported a reduction in both the number of hospital admissions (Pvalue $=0.003)$ and the number of emergency department visits ( $P$ value $=0.044$ ) during the intervention year compared with preintervention. Crotty $2004 \mathrm{~b}$ reported less hospital usage among participants who received the intervention and were still alive at eight weeks postintervention compared with control group participants (risk ratio (RR) $0.38,95 \% \mathrm{Cl} 0.15$ to 0.99 ). However, analysis of all participants including deaths and losses to follow-up showed similar hospital usage in the intervention and control groups (-9 (16.7\%) with intervention versus -15 (26.8\%) with control; RR $0.58,95 \% \mathrm{Cl} 0.28$ to 1.21 ). Trygstad 2009 showed a reduction in the RR of hos pital admissions in one cohort of nursing home residents receiving retrospective-only-type medication reviews (RR $0.84,95 \% \mathrm{Cl} 0.71$ to $1.00 ;$ Pvalue $=0.04$ ). The remaining eight cohorts al so had an RR below 1.0 ; however, confidence intervals for the individual point estimates crossed the line of no effect. Inappropriate prescribing was also reported by these studies. In the study by Trygstad 2009, the Beers list was used to measure inappropriate medication, but no reductions were observed in the cohorts receiving retrospective medication review. In the remaining four studies, inappropriate prescribing was reduced, as shown by reductions in PIMs, but the association with hospital admissions was inconsistent. Chiu 2018 reported that the unplanned hospital readmission rate one month after discharge was significantly lower in the intervention group than that in the control group (13.2\% versus $29.1 \% ; \mathrm{P}=0.005$ ).

Because of differences in methods used to measure hospital admissions and the expression of results, a meta-analysis was not possible for studies reporting hospital admissions. Overall, pharmaceutical care may make little or no difference in hospital admissions (low-certainty evidence). We downgraded the certainty of the body of evidence for hospital admissions to verylow due to very serious design limitations with implications in terms of selection bias, performance bias and risk of contamination bias in severalstudies.

\section{Secondary outcome results $\neg$}

Medication-related problems (e.g. adverse drug reactions (ADRs), drug-drug interactions (DDIs)) Medication-related problems were reported in eight studies (Crotty 2004b; Franchi 2016; Hanlon 1996; Schmader 2004; Taylor 2003; Trygstad 2005; Trygstad 2009; Wehling 2016, N = 10,087) using different terms. In the studies which gave details, medication-related problems were measured viahospital records (Wehling 2016), patient self-report during closeout telephone interviews (Hanlon 1996), reviewing the adverse event narrative using Naranjo's algorithm (Schmader 2004), and using the INTERcheck ${ }^{\circledR}$ software to detect DDIs (Franchi 2016 ).

No consistent intervention effect on medication-related problems was noted across studies. Four studies reported medication-related problems as adverse drug events (ADEs) (Crotty 2004b; Hanlon 1996; Schmader 2004; Wehling 2016). Schmader 2004 showed that the risk of a serious ADE was reduced (RR $0.65,95 \% \mathrm{Cl} 0.45$ to $0.93 ; \mathrm{Pvalue}=0.02)$ in a geriatric outpatient clinic compared with usual outpatient care; however, little or no difference in the risk of an ADE was noted when all types of ADEs were considered (RR 1.03, 95\% CI 0.86 to 1.23; P value $=0.75$ ). Wehling 2016 showed that the total number of adverse drug reactions (ADRs) of specific geriatric relevance (incidence of falls, confusion, nausea, dizziness, obstipation, diarrhoea, dyspnoea, cardiac decompensation, angina pectoris and renal failure) were significantly reduced by implementation of the FORTA-based intervention (Pvalue $<0.05$ ). The other two studies (Crotty 2004b; Hanlon 1996), showed little or no difference between proportions of intervention and control group participants with ADEs at follow-up. Franchi 2016 also reported no decrease in the prevalence of at least one potential DDI (odds ratio (OR) $0.67,95 \% \mathrm{Cl} 0.34$ to 1.28 ) and potentially severe DDI(OR $0.86,95 \% \mathrm{Cl} 0.63$ to 1.15$)$ at discharge. Taylor 2003 reported medication-related problems as medication misadventures. Proportions of intervention group (2.8\%) and control group (3.0\%) participants with at least one medication misadventure at 12 months were similar $(P$ value $=0.73)$.

Potential medication problems categorised as 'consider duration' (of therapy), 'clinical initiatives' and 'therapeutic duplication'

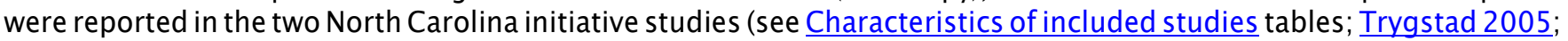
Trygstad 2009). At three months, duration alert rates were reduced by $6.3 \%$ in the intervention group $(\mathrm{N}=5160)$ and by $16.7 \%$ in the control group $(\mathrm{N}=2202)$; $\neg$ clinical initiatives were reduced by $10.8 \%$ in the intervention group and $0.7 \%$ in the control group, and therapeutic duplication was reduced in the interventiongroup by $9.4 \%$ and in the control group by $8.8 \%$ (Trygstad 2005). Control group results were not reported separately in Trygstad 2009. At three months, duration of therapy alerts were reduced by $27.8 \%$ (mean difference in the difference $(\mathrm{mDID})=-0.023$; Pvalue $>0.05)$; clinical initiative alerts were reduced by $13.9 \%(\operatorname{mDID}=-0.24 ; \mathrm{P}<0.05)$; and therapeutic duplication alerts were reduced by $5.6 \%(\mathrm{mDID}=-0.087 ; \mathrm{P}$ value $>0.05)($ Trygstad 2009$)$.

\section{Adherence to medication}

Five studies reported adherence to medication. Four studies reported little or no differences in adherence scores between intervention and control groups at follow-up (Campins 2017; Haag 2016; Muth 2016; Muth 2018) based on the Morisky-Green test and adapted Morisky Medication Adherence Scale. One study (Taylor 2003) (N=69) reported adherence to medication in terms of compliance scores, calculated through assessment of participants' reports of missed doses. Those with medication compliance scores of $80 \%$ to $100 \%$ increased by $15 \%$ at 12 months from a mean ( \pm standard deviation (SD)) of $84.9 \pm 6.7 \%$ to $100 \%$ in the intervention group $(\mathrm{N}=33)$, but the control group $(\mathrm{N}=36)$ did not change from $88.9 \% \pm 5.8 \%$ at baseline to $88.9 \% \pm 6.3 \%$ at 12 months (Pvalue $=0.115$ ). Because of differences in methodology in the measurement of adherence and the expression of results, a meta-analysis was not possible for studies reporting adherence to medication.

Quality of life (QoL) (as assessed by a validated method)

Twelve studies (Basger 2015; Bladh 2011; Campins 2017; Frankenthal 2014; Hanlon 1996; Muth 2016; Muth 2018; $\underline{\text { Olsson }}$ 
2012; Pitkala 2014; Taylor 2003; Thyrian 2017; Van der Linden 2017, $\mathrm{N}=3211$ ) assessed QoL using four different scales (EQ-5D, SF-36, SF-12 and 15D). In the Van der Linden 2017 study, analysis showed that participants in the intervention group experienced an increased QoL when compared to the control group. In the Pitkala 2014 study, there was a decline in QoL (using the 15D) in both the intervention and control groups, although the decline was significantly lower in the intervention group (-0.038 in the intervention group versus -0.072 in the control group). Little or no differences in QoL scores (SF-36, EQ-5D and SF-12) were observed between groups at baseline or at endpoint in ten studies (Basger 2015; Bladh 2011; Campins 2017; Frankenthal 2014; Hanlon 1996; Muth 2016; Muth 2018; Olsson 2012; Taylor 2003; Thyrian 2017). Pharmaceutical care may makelittle or no difference in QoL (low-certainty evidence). The certainty of the body of evidence for QoL was downgraded to low. Very serious design limitations with implications in terms of selection bias, performance bias and risk of contamination bias were identified in several studies. Because of differences in methodology in the measurement of quality of life and the expression of results, a meta-analysis was not possible for studies reporting quality of life.

\section{Discussion}

\section{Summary of main results}

The addition of 20 studies to this updated review, which now includes 32 studies, highlights a notable increase in intervention studies that have been conducted to date aimed at improving appropriate polypharmacy in older people. However, these additional 20 studies had little impact on the overall findings of the review. The included studies were limited by their small sample sizes and poor certainty of evidence (as assessed using GRADE).

The presentation of primaryoutcome data in this update differed to previous versions of the review. The reviewauthors considered that with the ever-increasing number of tools/indicators being developed and used in studies to assess inappropriate prescribing, it may not be helpful to continue subgrouping outcomes according to the specific tool (i.e.STOPP versus Beers). Instead, the outcomes were classified under the broad categorisation of medication appropriateness (as measured by an implicit tool), potentially inappropriate medications (PIMs) (which consists of the number of PIMs and/or the proportion of patients with one or more PIMs) and potential prescribing omissions (PPOs) (which consists of the number of PPOs and/or the proportion of patients with one or more PPOs). For example, rather than looking at explicit tools like STOPP and Beers individually, the current review has focused on the number of PIMs and pooled relevant data (using appropriate statistical methods), assessed by different tools. The standardised mean difference (SMD) is used as a summary statistic in meta-analyses when the studies all assess the same continuous outcome but measure it in a variety of ways (for example, the studies measuring the numbers of PIMs using different explicit tools). In this circumstance, it is necessary to standardise the results of the studies to a uniform scale before they can be combined. The SMD expresses the size of the intervention effect in each study relative to the variability observed in that study. This would also therefore ameliorate any differences between revised versions of the same scale (i.e. Beers criteria: 1997, 2003 and 2012 versions).

Medication appropriateness (as measured by an implicit tool) were normally distributed and were more suitable for metaanalysis, but greater heterogeneity was noted among the included studies $\left(I^{2}=95 \%\right)$, largely because of the influence of the results of one study (Spinewine 2007). Overall, medication appropriateness (as measured by an implicit tool) in the intervention group postintervention was greater than that in the control group and indicated an improvement in the appropriateness of the medications prescribed. A sensitivity analysis in which Crotty 2004 a was removed because of a unit of analysis error showed further improvement in the effect estimate when compared with the metaanalysis. Furthermore, removal of an outlying study with a large effect size (Spinewine 2007), reduced heterogeneity but also reduced the effectestimate. This may have been related to the small sample size for this meta-analysis ( 82 intervention participants and 85 control participants). However, it is uncertain whether pharmaceutical care improves medication appropriateness (as measured by an implicit tool) because the certainty of this evidence is very low.

When the studies measuring PIMs (i.e. based on the number of PIMs and/or the proportion of patients with one or more PIMs), as determined using explicit tools (criterion-based), were combined the number of PIMs: Bladh 2011; Clyne 2015; Garcia-Gollarte 2014; Koberlein-Neu 2016; Pitkala 2014; Schmader 2004; Spinewine 2007; the proportion of patients with one or more PIMs: Clyne 2015; Dalleur 2014; Franchi 2016; Frankenthal 2014; Fried 2017; Gallagher 2011; Garcia-Gollarte 2014; Haag 2016; Milos 2013; Spinewine 2007; Thyrian 2017), differences between intervention and control groups in the number of PIMs favoured the intervention group. A sensitivity analysis excluding Spinewine 2007, a study with a large effect size that had a high risk of bias showed similar improvements in the proportion of intervention patients with one or more PIMs, compared to the control group participants, between baseline and discharge. A further sensitivity analysis removing both Spinewine 2007 and Gallagher 2011 , which had a smaller treatment effect compared to the other studies, also showed similar improvements in the proportion of intervention patients with one or more PIMs, compared to the controlgroup participants, between baseline and discharge. It is uncertain whether pharmaceutical care reduces the number of PIMs or the proportion of patients with one or more PIMs because the certainty of this evidence is very low.

When the studies measuring PPOs (i.e. based on the number of PPOs and / or the proportion of patients with one or more potential prescribing omissions), as determined using explicit tools (criterion-based), were combined (The number of PPOs: Garcia-Gollarte 2014; Spinewine 2007; the proportion of patients with one or more PPOs: Frankenthal 2014; Gallagher 201 1; Garcia-Gollarte 2014; Haag 2016; Spinewine 2007), there was a reduction in the proportion of patients with one or more PPOs in the interventions group compared to the control groups. The heterogeneity present in the metaanalysis may have been due to the fact that the studies employed a number of different measurement instruments (Analysis 1.8; Analysis 1.9). Furthermore, differences between intervention and control groups in the number of PPOs also favoured the intervention group. It is uncertain whether pharmaceutical care reduces the proportion of patients with one or more PPOs 
because the certainty of this evidence is very low. Yet, pharmaceutical care may slightly reduce the number of PPOs (lowcertainty evidence). However, the clinical significance of these changes is unclear due to the fact that this effect estimate is based on only two studies, which had serious limitations in terms of high risk of bias.

The various tools used to assess inappropriate prescribing in the included studies are surrogate markers of appropriate polypharmacy. As was observed in previous versions of this review, few studies examined clinical outcomes, and this should be addressed in future studies. For example, only 12 studies reported on hospital admissions and quality of life. However, we were unable to combine these results, as the reporting styles were different across studies. Based on available evidence, pharmaceutical care may make little or no difference in hospital admissions or quality of life (low-certainty evidence).

\section{Overall completeness and applicability of evidence}

The types of interventions included in the review were limited. Few trials aimed to improve the skills of the prescriber. Most interventions were pharmaceutical care interventions, which included outreach by pharmacists, screening of automated drug alerts by consultant pharmacists visiting nursing homes and clinical pharmacist interventions in various settings. Only two trials involving computerised decision support (CDS) (one of which had incorporated CDS as a component of a multi-faceted intervention) were identified. $\neg$ The interventions were complex and most were multi-faceted. The observed heterogeneity observed in the pooled estimates means that the results of the meta-analyses should be treated cautiously as the interventions did not seem to work consistently across all studies. There was also a lack of studies which have explored implementation at the population level. In addition, study-specific factors, such as variation in the quality of studies, may have played a role. The methods sections of studies provided little detail on how complex interventions were developed, how trials were designed and how staff were trained in delivery of the intervention. Other information pertinent to the success of pharmaceutical care interventions including background practice and culture, documentation, communication and sharing of information and extent of access to clinical records given to intervention pharmacists was not stated clearly in the papers.

Although the effect of interventions on potentially inappropriate prescribing (PIP) was potentially promising and suggested that some of the interventions described in this review may have helped to improve the appropriateness of polypharmacy, despite observed limitations in the available evidence, the clinical impact of these reductions in inappropriate prescribing is not known. For example, the clinical impact of a mean difference of 0.22 PIMs between intervention and control group patients is unclear. This is partly due to the fact that the predictive validity of many assessment tools has not been established (Cahir 2014). In addition, we were unable to pool data from included studies for clinical outcomes such as hospital admissions due to heterogeneity in terms of outcome assessment and reporting across studies

Furthermore, few rigorously conducted studies have tested interventions and examined clinically relevant outcomes such as hospital admissions or ADEs. Twelve studies in this review reported hospital admissions postintervention (Campins 2017; Chiu 2018; Crotty 2004b; Franchi 2016; Frankenthal 2014; Gallagher 201 1; Haag 2016; Muth 2018; Spinewine 2007; Taylor 2003; Trygstad 2009; Van der Linden 2017), and four studies (Crotty 2004b; Gallagher 201 1; Spinewine 2007; Taylor 2003) reported that the appropriateness of prescribing improved, as was shown by reductions in PIMs, although the association with hospital admissions was inconsistent. In Trygstad 2009, little or no difference was found in the number of Beers list alerts postintervention, but the relative risk of hospital admissions was reduced. Use of different appropriateness scales in the included studies made it difficult to assess the impact of any change of medication appropriateness on hospital admissions. Similarly, some associations between measures of medication appropriateness and medication-related problems appeared to exist butwere difficult to assess because of variation in scales used to measure outcomes and in reporting methods.

Evidence of potential bias was found in numerous studies. For example, only 13 studies reported adequate concealment of allocation, and only six reported appropriate protection from contamination, both of which may have influenced the effect estimate in these studies and therefore the overall pooled estimate.

The aim of many of the intervention studies included in this review was to reduce harm resulting from inappropriate prescribing and to ensure that older people were prescribed appropriate medications that enhance their quality of life. In previous iterations of this review, several studies focused on reducing the number of medications, rather than improving overall appropriateness of prescribing, including under-prescribing, that is, recommending medications that are clinically indicated yet are currently missing. An increasing number of studies meeting the inclusion criteria included a validated assessment of under-prescribing; three studies in the updated reviewassessed under-prescribing adding to the three studies reported in the previous version. Furthermore, an increasing number of studies meeting the inclusion criteria also included a measure of quality of life, however only one of the 12 studies reported a benefit; this may be due to the fact that the follow-up period ranged from three months to 12-months follow-up.

\section{Certainty of the evidence}

Although we identified 32 studies, pooled analyses remain limited. For example, the meta-analysis based on the number of PPOs per participant comprised just two studies. This limits the value of any pooled effect estimate. Furthermore, as shown in the Summary of findings table 1, the certainty of evidence presented in this review, as described by the GRADE approach, remains low orverylow. Despite inclusion of datafrom randomised trial designs in the meta-analyses, the certainty of the body of evidence was subsequently downgraded when each of the GRADE considerations (i.e. study limitations, consistency of effect, imprecision, indirectness, publication bias) was taken into account. This limits our confidence in the pooled effect estimates.

Based on observed heterogeneity in the pooled effect estimates, the findings of meta-analyses [medication appropriateness (as measured by an implicit tool), the number of PIMs and proportion of patients with one or more PIMs or PPOs) should be 
treated cautiously, as the interventions did not seem to work consistently across all studies. Factors contributing to this heterogeneity could have included variation in type, intensity and duration of interventions, as well as differences in the timing of follow-up assessments. In addition, study-specific factors such as variation in study quality may have played a role. However, no systematic approach was used to ensure a consistent level of detail in published reports of the interventions. For example, the methods sections of the studies provided little detail on the development of complex interventions, trial design or staff training in delivery of interventions. Other information pertinent to intervention success, such as documentation, communication and intervention pharmacists' level of access to clinical records, was not clearly reported in the papers. The specific processes that constituted successful interventions were often unclear, which may have contributed to heterogeneity in effect estimates.

\section{Potential biases in the review process}

No language restrictions were placed on the search strategy, but all of the included trials were published in English and were conducted in high-income countries. Despite the limited number of studies included in the meta-analyses, funnel plots of studies reporting medication appropriateness (as measured by an implicit tool), the number of PIMs, the proportion of patients with one or more PIMs, the number of PPOs and the proportion of patients with one or more PPOs, outcomes revealed no apparent publication bias.

\section{Agreements and disagreements with other studies or reviews}

Other systematic reviews have reported that the most influential factor affecting the results of pharmaceutical care interventions is the way that interventions were conducted, for example, face-to-face consultations with physicians achieved a greater reduction in the number of medications taken than was achieved by written recommendations (Rollason 2003). Another narrative review reported that timely provision of the intervention, that is, prospective advice at the time of prescription rather than at the time of dispensing of medication, is more effective (Spinewine 2007a). Arecent and related Cochrane Review of interventions to optimise prescribing for older people in care homes (Alldred 2016), found no evidence of an intervention effect on any of the primary outcomes, which included ADEs and hospital admissions. Other studies of interventions conducted across a variety of settings have also been unable to detect the effects of pharmaceutical care on these outcome measures (Holland 2007; Spinewine 2007a; Johansson 2016). One systematic review (Kaur 2009), revealed that the most successful types of interventions used to reduce inappropriate prescribing in older peoplewere those that had multi-disciplinary involvement including a geriatrician, utilised CDS or had mandatory pharmaceutical services or drug restriction policies in place. Results of this current review largely support the findings described above, as most of the pharmaceutical care interventions involved a multi-disciplinary component, and the CDS intervention study (Tamblyn 2003) reported a positive result. ACochrane Review of interventions to improve outcomes in patients with multimorbidity in primary care and community settings (Smith 2016), found that there may have been smallimprovements in provider behaviour (in terms of prescribing behaviour) and patient-reported outcomes (i.e. quality of life). Additionally, a systematic review and meta-analysis (Meid 2015) found that pharmaceutical care interventions, including medication reviews, can significantly reduce medication underuse in older people.

\section{Authors' conclusions}

\section{Implications for practice}

The evidence obtained when results of these studies were combined is rather weak, and it is uncertain whether interventions provided to improve appropriate polypharmacy, such as pharmaceutical care, resulted in clinically significant improvement. Uncertainty surrounds the effects of such interventions on hospital admissions and medication-related problems, and it could be argued that these are the critical outcomes for patients. However, the pooled effect estimates suggest some improvements in outcomes such as the number of potential prescribing omissions (PPOs) and potentially inappropriate prescriptions but due to limitations with the quality of evidence, uncertainty exists. There was a lack of certainty regarding the effects of pharmaceutical care interventions included in this review on inappropriate prescribing (medication appropriateness (as measured by an implicit tool), the number of potentially inappropriate medications (PIMs), the proportion of patients with one or more PIMs and the proportion of patients with one or more PPOs. Pharmaceutical care may slightly reduce the number of PPOs (however it must be noted that this effect estimate is based on only two studies, which had serious limitations in terms of high risk of bias), especially when a multi-disciplinaryelement is included in the provision of care (Bucci 2003; Crotty 2004a; Crotty 2004b; Gallagher 2011; Garcia-Gollarte 2014; Hanlon 1996; Schmader 2004; Spinewine 2007; Taylor 2003). In addition, although only two studies that involved CDS were included in this review, it would appear that computerised decision support (CDS) is a helpful component of interventions for improving appropriate polypharmacy (lyne 201 5; Tamblyn 2003).

Given the difficulties involved in applying the results of clinical studies to older people, physicians should carefully consider their sources of evidence and recommendations to find the right balance between avoiding the 'risk/treatment paradox' (high-risk olderpatients denied safe medications capable of materiallyimproving survival or quality of life) and avoiding inappropriate use of medications for which risks are likely to outweigh benefits (Scott 2010). It must also be noted that the intervention studies included in this review focused on reducing inappropriate prescribing of prescription medications and over-the-counter (OTC) medication use was often not assessed, nor was it specifically examined as part of this review. OTC medication use is common among older patients receiving prescription medications with the potential for drug interactions to occur (Agbabiaka 201 7). This should not be overlooked by healthcare professionals when reviewing older patients' medication use.

Based on the findings of our updated review, we are still uncertain about which elements of the intervention processes 
constitute success in improving appropriate polypharmacy, and a number of questions remain unanswered. For example, is it sufficient to provide the intervention during a single episode of care, or should patients be exposed to the intervention on a daily/weekly or monthly basis? What is the optimal duration of an intervention, and should interventions ideally be multifaceted or uni-faceted? It is clear that control of processes to supportfidelity and control of the chosen interventions is critical. Staff training is important to ensure consistency; the receptiveness of prescribers, patients and staffinvarious settings will have an impact on the uptake and effectiveness of interventions in older people. $\neg$

\section{Implications for research}

Overall, the quality of the studies in this reviewwas poor, and further research should attend to rigour in study design. More research is needed to test whetherexisting tools for comprehensive medication review(e.g. the hyperpharmacotherapy assessment tool (HAT tool) (Bushardt 2008) and other similar interventions) can improve appropriate polypharmacy. Since the last update of this review, a Scottish working group has published a guidance document on polypharmacy, which included a seven-step process for standardised and structured medicines reviews that are holistic, patient-centred and consider non-pharmacological treatments (Scottish Government Model of Care 2018), as well as a review of the quality of development of available guidelines to promote appropriate polypharmacy (Stewart 2017). Further population-based research is required to evaluate the implementation and effect of these resources on prescribing for olderpeople.

Uncertainty about which elements of the intervention are critical to successful outcomes needs to be addressed. On the basis of the studies included in this review, this poses challenges, as details of intervention development and deliverywere lacking. Methods of specifying and reporting complex interventions, as well as their implementation strategies, are necessary to strengthen the evidence base required for interventions to be more effective, implementable and replicable across different settings (Michie 2011; Proctor 2013). Future intervention studies targeting appropriate polypharmacy could benefit from guidance provided by the framework of the Medical Research Council (MRC) on the design of complex interventions (MRC 2008). This framework recognises the importance of the initial stage of intervention development, in which evidence and theory are used to inform the selection of relevant components before the intervention is piloted, and the feasibility of delivering it in practice is assessed. These initial stages precede formal evaluations seeking to establish the effectiveness of the intervention. Despite the potential availability of the MRC guidelines before the start of the new studies highlighted in this update, only one included study (Clyne 2015) and two ongoing studies (Anrys 2016; Sinnott 2017) referred to using the MRC guidelines when developing and evaluating their interventions.

Adequate documentation of intervention development and intervention content as well as the training and background of providers that may be critical to intervention effectiveness is essential for facilitating replication of successful interventions in practice. However, no studies included in this review referred to using available intervention tools reporting, such as TIDieR (Template for Intervention Description and Replication)checklist (Hoffmann 2014).

The framework of the MRC 2008 also outlines the potential application of qualitative methodologies, such as semistructured interviews, to involve users and to gain insights into the processes of change that underlie the intervention. For example, establishing the reasons why not all interventions are accepted maybe enlightening and may support research into the development of more successful interventions. There appears to be a ceiling effect (approximately 75\%), whereby inappropriate prescribing continues despite the evidence base of interventions (Furniss 2000; Zermansky 2006). Qualitative interviews of prescribers may uncover reasons as to why they did not accept interventions (e.g. timing or appropriateness of provision of the intervention, the expertise of providers). Additionally, poor prescribing practice must be explored and understood with the goal of learning how to improve it and how to enhance patient safety by reducing the need for intervention. The importance of these investigations extends beyond the research context alone. Given the high financial expenditure that has been attributed to potentially inappropriate prescribing (PIP) in older people (Bradley 2012; Cahir 2010), it is likely that policy makers will continue to be interested in the costs of these types of interventions.

In the previous version of this review (Patterson 2014), we recommended that future studies should utilise clearer definitions of appropriate polypharmacy because the term 'polypharmacy' can be both negative and positive, and this duality of meaning makes objective research difficult (Bushardt 2008). Reports by the King's Fund in the UK (King's Fund 2013) and Scottish Guidance on polypharmacy (Scottish Government Model of Care 2018), discussed the need to reconsider current definitions of polypharmacy on account of the increasing numbers of medications being prescribed to patients and recommended that polypharmacy should be defined as appropriate (i.e. medicine use has been optimised and medicines prescribed according to best evidence) or problematic (i.e. medicines have been prescribed inappropriately or intended benefits have not been realised). Although the potential benefit of having a simple means of identifying patients at particular risk for inappropriate prescribing and adverse effects was acknowledged, the authors of the King's Fund report noted that existing thresholds used to define polypharmacy, such as four or five or more medicines, maybe too low. A pragmatic approach was proposed to identify patients warranting medication review, which focused on particular patient groups (e.g. patients receiving $\geq 10$ regular medicines, patients receiving four to nine medicines with other risk factors).

For the purpose of this update, the definition of polypharmacy was not changed from that used in the original review. Although a threshold of fouror more medicines may now be considered to be low in the context of older people with multimorbidity, it is important to recognise that the number of medicines used to define polypharmacyis arbitrary. Furthermore, conceptualising polypharmacy solely on the basis of the number of medicines prescribed is often unhelpful as this approach fails to recognise that the appropriate number of medicines varies according to 
individual patients' clinical needs and, moreover, may overlook the omission of potentially beneficial medications, which can equally have a negative impact on clinical outcomes (Cadogan 2016). Hence, for the purpose of the current update, our focus was on interventions targeting the appropriateness of the medications prescribed for older people. However, future updates of this review may reconsider the criteria used to define polypharmacy were validated tools to assess potentially inappropriate prescribing in older people, such as Beers criteria, are not specifically designed to measure appropriate polypharmacy, it is important that future interventions should include assessments of potentially inappropriate omissions/under-prescribing with the goal of improving appropriate polypharmacy.

The judgement as to whether many (appropriate polypharmacy) or too many (inappropriate polypharmacy) medications are use is difficult. The complexity of the clinical situation, patient attributes and wishes and the individuality of prescribing for older complex patients will remain a challenge in this regard. Development of a new, universal, easily applied, valid and reliable outcome measure of appropriate polypharmacy in primary care is currently underway (Burt 2016). Ideally, this measure should be globally applicable across various healthcare and cultural settings.

It is important that sufficient detail about the context in which complex interventions are conducted, such as those included in this review, is reported and understood, so the transferability of complex interventions can be assessed (Wells 2012). For example, heterogeneity among older people in relation to differing levels of frailty (Spinewine 2007a) means that translational research and retesting of successful interventions may be necessary in dissemination to new populations, as a population of quite healthy 70-year-old people may respond differently to an intervention compared with a group of very frail 92-year-old individuals.

It is worth noting that only one of the included studies followed participants for longer than 12 months (Frankenthal 2014 ). The lack of evidence of effectiveness of pharmaceutical care interventions may be due in part to inadequate length of followup. Future studies should be longer in duration to address this issue and to evaluate the longer-term sustainability of pharmaceutical care interventions in improving the appropriate use of polypharmacy for older people.

Perhaps most critically, the selection of clinical and humanistic outcomes appropriate for older people (e.g. hospital admissions, adverse drug events (ADEs)) will be important to consider in future studies. Strategies for improving the evidence base for older patient care have been reviewed by Scott 2010 . Indeed, a key challenge for interventions aimed at improving appropriate polypharmacy for older people is the selection and reporting of consistent outcomes (i.e. patient-related or medication-related outcomes). The Core Outcome Measures for Effectiveness Trials (COMET) initiative was launched to develop and apply core outcome sets (COS), which have been proposed as one method of addressing this problem (Williamson 2017). A COS is an agreed and standardised set of outcomes or outcome domains which should be measured and reported, as a minimum, in all trials in a specific clinical area. Alongside the Core Outcome Set-STAndards for Reporting (COS-STAR) guidelines (Kirkham 2016), the development of COSs in a specific health area should facilitate more robust synthesis of evidence in the future. A COS for use in interventions to improve the appropriate use of polypharmacy for older people in primary care is now available (Rankin 2018). The adoption of this COS will streamline the outcomes routinely measured in trials investigating appropriate polypharmacy in older people in primary care. This will ultimately facilitate the comparison and synthesis of outcome data across studies, thereby helping to determine which interventions work and inform both clinical decision making and health policy.

\section{Acknowledgements}

We would like to acknowledge the valuable input of Alexandra Mcllroy(Queen's University Belfast)and PaulMiller(EPOC Group Information specialist) in development of the search strategy. We would like to thank all members of the EPOC Group at Newcastle University, UK, led by Professor Martin Eccles, for their kind assistance with preparation of the protocol. We would like to thank Dr. Janine Cooper (JC) for their assistance in the second review update including screening articles and data extraction. We would also like to thank Julia Worswick and Daniela Gonçalves Bradley (EPOC Group) for their assistance and the referees (Dr. Holly Holmes and Professor Derek Stewart) and editors (Dr. Pierre Durieux) for their contribution to the review.

National Institute for Health Research, via Cochrane Infrastructure funding to the Effective Practice and Organisation of Care Group. The views and opinions expressed therein are those of the authors and do not necessarily reflect those of the Systematic Reviews Programme, NIHR, NHS or the Department of Health.

\section{Contributions of authors}

S Patterson (SP) prepared the protocol under the direction of $C$ Hughes (CH), N Kerse (NK) and CR Cardwell (CRC). A Rankin (AR), CA Cadogan (CAC) and C Ryan (CR) were involved in updating the review. SP, M Bradley (MB), CH, CC and CR are pharmacists, NK is a GP and an experienced researcher with an interest in geriatric medicine, CRC is a biomedical statistician and $A R$ is a researcher with an interest in public health. $M B, C H, N K, C R, A R$ and $C R C$ have been involved in systematic reviews in other areas. SP undertook the database searches and reviewed the literature identified in the original review. AR and CAC undertook the second review update including data extraction, risk of bias assessment and writing of the reviewupdate. MB, NK, CRC and CR acted as independent Co-reviewauthors. CH is an author of the OPTI-SCRIPT study (Clyne 2015) and was not involved in the screening or data extraction of this study to avoid potential biases.

\section{Declarations of interest}

AR: none known. CAC: none known. SP: none known. NK: none known. CRC: none known. MCB: none known. CR: none 
known. $\mathrm{CH}$ : none known.

\section{Differences between protocol and review}

As only two studies (Bucci 2003; Crotty 2004a) reported the primary outcome measure of change in medication appropriateness used in the previous iteration of this review, we used postintervention results of potentially inappropriate medications (PIMs) and potential prescribing omissions (PPOs) in the meta-analyses to compare the effect sizes of the interventions.

Furthermore, we modified our approach to pooling outcome data for potentially inappropriate prescribing (PIP), to instead classify the outcomes under the broad categorisation of PIMs or PPOs. For example, rather than looking at explicit tools or implicit tools individually (i.e. the Screening Tool of Older Person's Prescriptions (STOPP) versus the Medication Appropriateness Index (MAI)), the current reviewhas focused on PIMs (i.e. the number of PIMs), while the meta-analysis previous entitled "change in MAI score" has been refocused to include studies including data on "medication appropriateness (as measured by an implicit tool)" to align with the original primary outcomes of interest.

The search strategy was modified slightly from that used in the original review to avoid limiting the search unnecessarily. Based on a recommendation made following the search development process for the previous review, the term 'polypharmacy' was searched alone (e.g. not combined with the concept of "age" using the Boolean operator "AND") because most of the literature on polypharmacy focuses on olderpopulations. The search strategywas also modified to include relevant new index terms in MEDLINE since the last search, (such as: potentially inappropriate medication list/) and additional search terms included (such as deprescribing and drug discontinuation).

EBM Reviews, ACP Journal Club, The Joanna Briggs Institute EBP Database and PsycINFO were not searched for this update because they ceased updates, are currently indexed in other databases (MEDLINE, Embase and CINAHL) and it was deemed unlikely to yield anything unique for the topic respectively.

To comply with Cochrane and EPOC requirements, we have now included the most important outcomes in the 'Summary of findings' table which were: medication appropriateness (as measured by an implicit tool), the number of PIMs, the proportion of patients with one or more PIMs, the number of PPOs, the proportion of patients with one or more PPOs, quality of life, and hospital admissions.

\section{Published notes}

\section{Characteristics of studies}

\section{Characteristics of included studies}

Basger 2015 
Interventions to improve the appropriate use of polypharmacy for older people

\begin{tabular}{|c|c|}
\hline Methods & $\begin{array}{l}\text { Study design: randomised trial } \\
\text { Unit of allocation/analysis: participant } \\
\text { Follow-up: } 3 \text { months post discharge } \\
\text { Duration: unclear } \\
\text { Providers: clinical pharmacist, GPs and registered nurses }\end{array}$ \\
\hline Participants & $\begin{array}{l}\text { Setting/participants: Quote: " } 216 \text { older patients (over } 65 \text { years old) were randomised } \\
\text { into control orintervention groups at discharge from a } 50 \text { bed private hospital in } \\
\text { Sydney, Australia. Patients were admitted for treatment of chronic medical conditions } \\
\text { such as diabetes and heart failure, in addition to rehabilitation after joint replacement } \\
\text { surgery performed at other hospitals. Their medical conditions and medications were } \\
\text { representative of older Australian community patients. Eligibility criteria consisted of } \\
\text { age over } 65 \text { years, English speaking, taking five or more medications and living within } \\
\text { a } 15 \mathrm{~km} \text { radius of the hospital. Patients with cognitive impairment were excluded" } \\
\text { Focus on polypharmacy: included participants taking five or more medications } \\
\text { (number of regular medications reported as control patients: } 10.6 \pm 3.2 \text {, range } 4 \text { to } 20 \text {; } \\
\text { intervention patients } 11.3 \pm 3.3 \text {, range } 4 \text { to } 20 \text {. P value }=0.11 \text { ) } \\
\text { Age (mean): } 82.7 \pm 7.3 \text { years, range } 65 \text { to } 97 \text { years intervention, } 80.2 \pm 6.7 \text { years, } \\
\text { range } 65 \text { to } 93 \text { years control } \\
\text { Male: } 22.5 \% \text { intervention, } 22.8 \% \text { control } \\
\text { Ethnicity: no information given }\end{array}$ \\
\hline Interventions & $\begin{array}{l}\text { Model of pharmaceutical care: pharmacists worked on hospital wards as a clinical } \\
\text { pharmacy service, the pharmacist(s) conducted an independent medication review } \\
\text { togetherwith participants during a face-to-face encounter which was sent to the } \\
\text { patient's own GP } \\
\text { Training: unclear if training was provided as part of theintervention } \\
\text { Timing of intervention: at hospital discharge } \\
\text { Quote: "Intervention patients then received medication counselling and an in-depth } \\
\text { interview from the clinical pharmacist to facilitate completion of a medication review, } \\
\text { sent to their GP within } 3 \text { days of discharge. Medication review consisted of medication } \\
\text { reconciliation, identification of (potential) causes of DRPs and recommendations for } \\
\text { their resolution and prevention. Opportunities for self-management were discussed } \\
\text { with the patient. Reviews explained medication changes made in hospital. } \\
\text { They were completed by a clinical pharmacist (BJB) with postgraduate qualifications in } \\
\text { clinical pharmacy, } 15 \text { years' experience in medication reviewand accreditation through } \\
\text { proof of continuing education and by examination. Recommendations represented an } \\
\text { evidence-based risk-benefit evaluation of the consequences of discontinuing or } \\
\text { initiating medication. Intervention patients received a copy of the review. Separately } \\
\text { and as perhospital protocol, a registered nurse explained each patients discharge } \\
\text { medications to them-both control and intervention-with a copy sent to the patients } \\
\text { GP, together with a medical summary written for those patients attended by a } \\
\text { specialist } \\
\text { Control participants received usual care" }\end{array}$ \\
\hline Outcomes & $\begin{array}{l}\text { Change in the number of prescribing appropriateness criteria met (prescribing } \\
\text { appropriateness criteria-set for application in older Australians) } \\
\text { Change in HRQoL (SF-36) }\end{array}$ \\
\hline Notes & \\
\hline
\end{tabular}

Risk of bias table 
Interventions to improve the appropriate use of polypharmacy for older people

\begin{tabular}{|c|c|c|}
\hline Bias & \begin{tabular}{|l|} 
Authors' \\
judgement
\end{tabular} & Support for judgement \\
\hline $\begin{array}{l}\text { Random sequence generation } \\
\text { (selection bias) }\end{array}$ & Unclear risk & Insufficient information to permit judgement \\
\hline $\begin{array}{l}\text { Allocation concealment (selection } \\
\text { bias) }\end{array}$ & Unclear risk & Insufficient information to permit judgement \\
\hline $\begin{array}{l}\text { Blinding of participants and } \\
\text { personnel (performance bias) }\end{array}$ & High risk & $\begin{array}{l}\text { Quote: "The clinical pharmacist (one of the authors) collected all relevant } \\
\text { demographic, medical and medication data and intervention patients then } \\
\text { received medication counselling and an in-depth interview from the clinica } \\
\text { pharmacist to facilitate completion of a medication review; lack of blinding } \\
\text { also acknowledged as a limitation of the study" }\end{array}$ \\
\hline $\begin{array}{l}\text { Blinding ofoutcome assessment } \\
\text { (detection bias) }\end{array}$ & Unclear risk & Insufficient information to permit judgement \\
\hline $\begin{array}{l}\text { Incomplete outcome data (attrition } \\
\text { bias) }\end{array}$ & High risk & $\begin{array}{l}22 \text { intervention patients and } 11 \text { control group patients were lost to follow- } \\
\text { up: analysis was based on patients available at follow-up }\end{array}$ \\
\hline Selective reporting (reporting bias) & Low risk & All outcomes described were reported \\
\hline Baseline characteristics similar? & High risk & $\begin{array}{l}\text { Baseline demographic differences existed between intervention and } \\
\text { controlgroups. No reported adjustment of results to account for baseline } \\
\text { differences in analysis }\end{array}$ \\
\hline Reliable Primary outcome measure & Low risk & $\begin{array}{l}\text { Validated assessment tools were used to assess appropriateness of } \\
\text { prescribing (Australian prescribing indicators) }\end{array}$ \\
\hline Protection against contamination & Unclear risk & Insufficient information to permit judgement \\
\hline
\end{tabular}

Bladh 2011 
Interventions to improve the appropriate use of polypharmacy for older people

\begin{tabular}{|c|c|}
\hline Methods & $\begin{array}{l}\text { Study design: randomised trial } \\
\text { Unit of allocation/analysis: participant } \\
\text { Follow-up: } 6 \text {-months follow-up } \\
\text { Duration: unclear } \\
\text { Providers: pharmacist }\end{array}$ \\
\hline Participants & $\begin{array}{l}\text { Setting/participants: } 400 \text { older patients (199 intervention and } 201 \text { control) patients } \\
\text { admitted in two internal wards at Sahlgrenska University Hospital/Mölndal in Sweden } \\
\text { Focus on polypharmacy: median (IQR) number of drugs at baseline was } 7 \text { (4 to 9) } \\
\text { intervention, } 7 \text { (4 to 10) control } \\
\text { Age (median (IQR)): } 81 \text { ( } 72 \text { to } 87 \text { ) years intervention, } 82 \text { ( } 75 \text { to } 86 \text { ) years control } \\
\text { Male: } 39 \% \text { intervention, } 40 \% \text { control } \\
\text { Ethnicity: no information given }\end{array}$ \\
\hline Interventions & $\begin{array}{l}\text { Model of pharmaceutical care: medication reviews by pharmacists with feedback to the } \\
\text { physicians, drug treatment discussion with patients at discharge and medication } \\
\text { reports } \\
\text { Training: no educational intervention was specified } \\
\text { Timing of intervention: during inpatient stay } \\
\text { Quote: "In the intervention group, patients were treated by the same physicians / nurses } \\
\text { and the following additional interventions were performed by one of three pharmacists } \\
\text { (LB, EO or JK): } \\
\text { - Continuous medication reviews including oral feedback on prescribing to physicians; } \\
\text { - Drug treatment discussion with the patient at discharge; } \\
\text { - A medication report, given to the patient at discharge and sent to the patient's GP } \\
\text { (the regular discharge summary was sent to the patient's GP independent of the } \\
\text { study). Data on prescribing were obtained from the medical records. } \\
\text { No medication history was taken by the pharmacists. } \\
\text { Medication reviews were performed with a computer support system (MiniQ), which } \\
\text { identified potentially inappropriate prescribings according to the three drug-specific } \\
\text { quality indicators (PIPs) analysed in } \\
\text { the present study, established by the Swedish National Board of Health and Welfare } \\
\text { for evaluation of drug therapy in the elderly: } \\
\text { - Drugs that should beavoided inthe elderly: for example long-acting benzodiazepines } \\
\text { and drugs with anticholinergic action. } \\
\text { - Three or more psychotropic drugs: that is antipsychotics, anxiolytics, hypnotic- } \\
\text { sedatives and antidepressants. } \\
\text { - Potentially serious drug-drug interactions: category D according to the } \\
\text { pharmaceutical specialities in Sweden (FASS), that is, drug combinations that should } \\
\text { be avoided" } \\
\text { Patients in the control group received normal care }\end{array}$ \\
\hline Outcomes & $\begin{array}{l}\text { Drug-specific quality indicators (PIPs) - the Swedish National Board of Health and } \\
\text { Welfare for evaluation of drug therapy in the elderly } \\
\text { Quality of life (EQ-5D) }\end{array}$ \\
\hline Notes & NCT0106301 \\
\hline
\end{tabular}


Interventions to improve the appropriate use of polypharmacy for older people

\begin{tabular}{|c|c|c|}
\hline Bias & \begin{tabular}{|l} 
Authors' \\
judgement
\end{tabular} & Support for judgement \\
\hline $\begin{array}{l}\text { Random sequence generation } \\
\text { (selection bias) }\end{array}$ & Unclear risk & Insufficient information to permit judgement \\
\hline $\begin{array}{l}\text { Allocation concealment (selection } \\
\text { bias) }\end{array}$ & Low risk & $\begin{array}{l}\text { Quote: "Sequentially numbered, sealed envelopes were opened after } \\
\text { participant details were written and transferred to the assignment card } \\
\text { via a carbon paper inside the envelope" }\end{array}$ \\
\hline $\begin{array}{l}\text { Blinding of participants and } \\
\text { personnel (performance bias) }\end{array}$ & Unclear risk & Insufficient information to permit judgement \\
\hline $\begin{array}{l}\text { Blinding of outcome assessment } \\
\text { (detection bias) }\end{array}$ & Unclear risk & Insufficient information to permit judgement \\
\hline $\begin{array}{l}\text { Incomplete outcome data (attrition } \\
\text { bias) }\end{array}$ & Low risk & $\begin{array}{l}\text { Missing outcome databalanced in numbers across intervention groups, } \\
\text { with similar reasons for missing data across groups }\end{array}$ \\
\hline Selective reporting (reporting bias) & Low risk & $\begin{array}{l}\text { The studyprotocol is not available but it is clear that the published } \\
\text { reports include all expected outcomes, including those that were pre- } \\
\text { specified }\end{array}$ \\
\hline Baseline characteristics similar? & Unclear risk & $\begin{array}{l}\text { Authors state that "No differences in baseline characteristics could be } \\
\text { detected between the randomisation groups." However, results of formal } \\
\text { statistical comparison not reported }\end{array}$ \\
\hline Reliable Primary outcome measure & Low risk & $\begin{array}{l}\text { Three drug-specificquality indicators (PIPs) analysed in the present } \\
\text { study, established by the Swedish National Board of Health and Welfare } \\
\text { for evaluation of drug therapy in the elderly }\end{array}$ \\
\hline Protection against contamination & High risk & $\begin{array}{l}\text { Patients in the intervention and control groups were treated in the same } \\
\text { wards by the samephysicians }\end{array}$ \\
\hline
\end{tabular}

Bucci 2003 
Interventions to improve the appropriate use of polypharmacy for older people

\begin{tabular}{|c|c|}
\hline Methods & $\begin{array}{l}\text { Studydesign: randomised trial (block design, using a computerised randomisation } \\
\text { scheme) } \\
\text { Unit of allocation/analysis: participant } \\
\text { Follow-up: } 1 \text { month after intervention } \\
\text { Duration: unclear } \\
\text { Providers: pharmacists }\end{array}$ \\
\hline Participants & $\begin{array}{l}\text { Setting/participants: } 80 \text { participants ( } 39 \text { intervention and } 41 \text { control) enrolled at a } \\
\text { hospital clinic at the University Health Network Toronto General Hospital, Canada } \\
\text { Focus on polypharmacy: mean number of medications at baseline } 7.6 \text { intervention, } 6.0 \\
\text { control } \\
\text { Age (mean): } 56.4 \text { years intervention, } 60.2 \text { years control } \\
\text { Male: } 78.9 \% \text { intervention, } 78 \% \text { control } \\
\text { Ethnicity: no information given }\end{array}$ \\
\hline Interventions & $\begin{array}{l}\text { Model of pharmaceutical care pharmacists: worked as part of a multi-disciplinaryteam } \\
\text { in outpatient clinics, the pharmacist(s) conducted an independent medication review } \\
\text { togetherwith participants during a face-to-face encounterwhich were discussed with } \\
\text { the multi-disciplinary team members } \\
\text { Training: educationwas provided to prescribers and other healthcare professionals } \\
\text { included in the multi-disciplinary team } \\
\text { Timing of intervention: at hospital discharge } \\
\text { Quote: "The intervention involved receipt of pharmacist services, that is, functioning as } \\
\text { part of a healthcare team, meeting participants' drug-related needs and ensuring } \\
\text { continuity of care. Specifically, this involved the pharmacist reviewing the } \\
\text { appropriateness of drug therapy, making recommendations for change and providing } \\
\text { information about medications, their administration and their adverse effects } \\
\text { Those randomlyassigned to the non-intervention group received usual care from other } \\
\text { clinic staff" }\end{array}$ \\
\hline Outcomes & $\begin{array}{l}\text { Quote: "Participant outcomes were assessed by the research assistant pharmacist at } \\
\text { baseline and at follow-up using the MAI and the directive guidance scale } \\
\text { Appropriateness of prescribing was determined by preintervention and } \\
\text { postintervention mean MAl scores } \\
\text { The Purdue Pharmacist Directive Guidance score rated the guidance provided by the } \\
\text { pharmacist. Directive guidance is described as pharmaceutical care activities such as } \\
\text { providing information about medicines, their administration and their potential to cause } \\
\text { adverse effects" }\end{array}$ \\
\hline Notes & $\begin{array}{l}\text { Quote: "The participant chart was reviewed by a research assistant pharmacist who } \\
\text { was blinded to the intervention, and information required to assess the } \\
\text { appropriateness of medications was abstracted. A summated MAI score was } \\
\text { determined for each participant at least } 1 \text { month after the intervention. Follow-up took } \\
\text { place at a scheduled clinic visit or by telephone" }\end{array}$ \\
\hline
\end{tabular}

Risk of bias table 
Interventions to improve the appropriate use of polypharmacy for older people

\begin{tabular}{|c|c|c|}
\hline Bias & \begin{tabular}{|l|} 
Authors' \\
judgement
\end{tabular} & Support for judgement \\
\hline $\begin{array}{l}\text { Random sequence generation } \\
\text { (selection bias) }\end{array}$ & Low risk & Quote: "Using a computerised randomisation scheme" \\
\hline $\begin{array}{l}\text { Allocation concealment (selection } \\
\text { bias) }\end{array}$ & Unclear risk & Insufficient information to permit judgement \\
\hline \multirow[t]{2}{*}{$\begin{array}{l}\text { Blinding of participants and } \\
\text { personnel (performance bias) }\end{array}$} & Unclear risk & $\begin{array}{l}\text { Quote: "The research assistant was blinded to the intervention. Patient } \\
\text { charts were reviewed by the research assistant, blinded to the } \\
\text { intervention, and information to assess the appropriateness of } \\
\text { medications was abstracted" }\end{array}$ \\
\hline & & Unclear if staff or patients were blinded \\
\hline $\begin{array}{l}\text { Blinding ofoutcome assessment } \\
\text { (detection bias) }\end{array}$ & Low risk & $\begin{array}{l}\text { Quote: "Patient outcomes were assessed by the research assistant } \\
\text { (blinded to the intervention) at baseline and at follow-up" }\end{array}$ \\
\hline $\begin{array}{l}\text { Incomplete outcome data (attrition } \\
\text { bias) }\end{array}$ & Low risk & One participant in the intervention group had died at follow-up \\
\hline Selective reporting (reporting bias) & Low risk & All outcomes were reported \\
\hline Baseline characteristics similar? & Low risk & $\begin{array}{l}\text { Baseline participant characteristics were reported. Results adjusted to } \\
\text { account for baseline demographic differences between intervention and } \\
\text { control groups }\end{array}$ \\
\hline Reliable Primary outcome measure & Low risk & $\begin{array}{l}\text { The MAl has good }(\text { kappa value }=0.59) \text { to excellent }(\text { kappa value }=0.83) \\
\text { reproducibility }\end{array}$ \\
\hline Protection against contamination & High risk & $\begin{array}{l}\text { Quote: "The presence of the pharmacist in the clinic may have } \\
\text { contaminated medication appropriateness results of the non-intervention } \\
\text { group" }\end{array}$ \\
\hline
\end{tabular}

Campins 2017 
Interventions to improve the appropriate use of polypharmacy for older people

\begin{tabular}{|c|c|}
\hline Methods & $\begin{array}{l}\text { Study design: randomised trial } \\
\text { Unit of allocation/analysis: participant } \\
\text { Follow-up: } 1 \text { year } \\
\text { Duration: unclear } \\
\text { Providers: clinical pharmacist }\end{array}$ \\
\hline Participants & $\begin{array}{l}\text { Setting/participants: } 503 \text { older patients ( } 252 \text { intervention and } 251 \text { control) recruited } \\
\text { from Primary Health Care Centres in Spain } \\
\text { Focus on polypharmacy: included participants taking eight or more medications } \\
\text { Age (mean } \pm \text { SD): } 79.16 \pm 5.5 \text { years intervention, } 78.78 \pm 5.5 \text { years control } \\
\text { Male: } 39.7 \% \text { intervention, } 42.6 \% \text { control } \\
\text { Ethnicity: no information given }\end{array}$ \\
\hline Interventions & $\begin{array}{l}\text { Model of pharmaceutical care: clinical pharmacist evaluated all drugs prescribed to } \\
\text { each patient using the GP-GP algorithm, which were discussed with the patient's } \\
\text { physician } \\
\text { Training: no educational intervention was specified } \\
\text { Timing of intervention: during a single GP visit } \\
\text { Quote: "The intervention consisted of } 3 \text { consecutive phases. First, a trained and } \\
\text { experienced clinical pharmacist evaluated all drugs prescribed to each patient using } \\
\text { the GP-GP algorithm and basing their decision about appropriateness on the } \\
\text { STOPP/START criteria. Second, the pharmacist discussed recommendations for each } \\
\text { drug with the patient's physician in order to come up with a final set of } \\
\text { recommendations. } \\
\text { Drug assessment was conducted in all cases by the sameclinical pharmacist (IG). } \\
\text { Finally, these recommendations were discussed with the patient, and a final decision } \\
\text { was agreed by physicians and their patients in a face-to-facevisit. All changes in } \\
\text { prescribed medication were registered in the electronic clinical notes and in the study's } \\
\text { record form. The goal of the study intervention was to improve current prescription } \\
\text { medication in community-dwelling elderly persons in oursetting and so improve } \\
\text { routine clinical practice. } \\
\text { Control group patients followed the usual treatments and control procedures of their } \\
\text { physicians" }\end{array}$ \\
\hline Outcomes & $\begin{array}{l}\text { Drug appropriateness (STOPP/START criteria) } \\
\text { Hospitalisations } \\
\text { Quality of life (EQ-5D) } \\
\text { Adherence (Morisky-Green) }\end{array}$ \\
\hline Notes & \\
\hline
\end{tabular}

Risk of bias table 
Interventions to improve the appropriate use of polypharmacy for older people

\begin{tabular}{|c|c|c|}
\hline Bias & \begin{tabular}{|l|} 
Authors' \\
judgement
\end{tabular} & Support for judgement \\
\hline $\begin{array}{l}\text { Random sequence generation } \\
\text { (selection bias) }\end{array}$ & Low risk & $\begin{array}{l}\text { Quote: "One-to-one assignment was based on a list of random numbers } \\
\text { generated by a statistical program" }\end{array}$ \\
\hline $\begin{array}{l}\text { Allocation concealment (selection } \\
\text { bias) }\end{array}$ & Low risk & $\begin{array}{l}\text { Quote: "Each family physician received } 10 \text { sealed, opaque envelopes with } \\
\text { identification numbers (assigned consecutively in strict chronological order } \\
\text { of recruitment) on the back. Each envelope contained a card with the } \\
\text { same identification number and the intervention group to which the subject } \\
\text { was assigned" }\end{array}$ \\
\hline $\begin{array}{l}\text { Blinding of participants and } \\
\text { personnel (performance bias) }\end{array}$ & High risk & $\begin{array}{l}\text { Quote: "Open-label trial; physicians aware of patients' allocation to } \\
\text { intervention and control groups" }\end{array}$ \\
\hline $\begin{array}{l}\text { Blinding of outcome assessment } \\
\text { (detection bias) }\end{array}$ & High risk & The results were not evaluated blind \\
\hline $\begin{array}{l}\text { Incomplete outcome data (attrition } \\
\text { bias) }\end{array}$ & High risk & Differences in losses to follow-up between intervention and control group \\
\hline Selective reporting (reporting bias) & Low risk & $\begin{array}{l}\text { The study protocol is not available but all outcomes outlined in the } \\
\text { methods section are analysed and reported }\end{array}$ \\
\hline Baseline characteristics similar? & Low risk & $\begin{array}{l}\text { Baseline participant characteristics were reported. No significant baseline } \\
\text { differences between intervention and control groups }\end{array}$ \\
\hline Reliable Primary outcome measure & Low risk & $\begin{array}{l}\text { Quote: "Decisions regarding medication appropriateness guided by } \\
\text { STOPP/START" }\end{array}$ \\
\hline Protection against contamination & High risk & $\begin{array}{l}\text { Quote: "A second limitation is possible intervention-to-control contagion, } \\
\text { given that the prescribing physicians who received recommendations from } \\
\text { the pharmacist regarding intervention group patients also had patients in } \\
\text { the control group. The control group could thus have indirectly benefited } \\
\text { from the intervention, thereby diluting-but not increasing-the effect of } \\
\text { the intervention study" }\end{array}$ \\
\hline
\end{tabular}

Chiu 2018 
Interventions to improve the appropriate use of polypharmacy for older people

\begin{tabular}{|c|c|}
\hline Methods & $\begin{array}{l}\text { Study design: non-randomised trial } \\
\text { Unit of allocation/analysis: participant } \\
\text { Follow-up: 3-months post discharge } \\
\text { Duration: unclear } \\
\text { Providers: clinical pharmacist }\end{array}$ \\
\hline Participants & $\begin{array}{l}\text { Setting/participants: } 212 \text { older patients ( } 108 \text { intervention and } 104 \text { control) recruited } \\
\text { from Primary Health Care Centres in Spain } \\
\text { Focus on polypharmacy: number of drugs on admission (mean } \pm \text { SD), } 9.4 \pm 3.4 \text {, } \\
\text { intervention, } 9.4 \pm 3.7 \text {, control } \\
\text { Age (mean } \pm \text { SD): } 83.3 \pm 5.7 \text { years intervention, } 83.3 \pm 5.6 \text { years control } \\
\text { Male: } 50.0 \% \text { intervention, } 46.2 \% \text { control } \\
\text { Ethnicity: no information given }\end{array}$ \\
\hline Interventions & $\begin{array}{l}\text { Model of pharmaceutical care: the pharmacist performed medication reconciliation an } \\
\text { medication reviews } \\
\text { Training: no educational intervention was specified } \\
\text { Timing of intervention: during inpatient stay } \\
\text { Quote: "Intervention was conducted by a pharmacist who was present in the unit from } \\
\text { Monday to Saturday. The pharmacist provided pharmaceutical care from admission to } \\
\text { discharge. Interventions performed by the pharmacist consisted of the following: } \\
\text { (1) Medication reconciliation on admission to identify unintended discrepancies } \\
\text { between medications prescribed on admission and the usual medications priorto } \\
\text { admission } \\
\text { (2) Medication review to check for medication appropriateness on admission and also } \\
\text { at discharge-medication appropriateness was assessed by the Medication } \\
\text { Appropriateness Index (MAl). } \\
\text { (3) Pharmacist counselling on admission and also at discharge was provided to } \\
\text { improve patients'drug knowledge to ensure properuse of drugs and compliance after } \\
\text { discharge. Adischarge counselling service was provided for all patients who returned } \\
\text { home. } \\
\text { The control group received routine clinical services" }\end{array}$ \\
\hline Outcomes & $\begin{array}{l}\text { MAI score per patient } \\
\text { The proportion of subjects with inappropriate medications } \\
\text { Unplanned hospitalisations }\end{array}$ \\
\hline Notes & \\
\hline
\end{tabular}

Risk of bias table 
Interventions to improve the appropriate use of polypharmacy for older people

\begin{tabular}{|c|c|c|}
\hline Bias & \begin{tabular}{|l} 
Authors' \\
judgement
\end{tabular} & Support for judgement \\
\hline $\begin{array}{l}\text { Random sequence generation } \\
\text { (selection bias) }\end{array}$ & High risk & $\begin{array}{l}\text { Quote: "Eligible subjects were assigned to an intervention or control group } \\
\text { according to the admission day of the week. Those who were admitted on } \\
\text { Monday through Thursday were assigned to the intervention group, and } \\
\text { those admitted on Friday through Sunday to the control group" }\end{array}$ \\
\hline $\begin{array}{l}\text { Allocation concealment (selection } \\
\text { bias) }\end{array}$ & High risk & $\begin{array}{l}\text { Quote: "Eligible subjects were assigned to an intervention or control group } \\
\text { according to the admission day of the week. Those who were admitted on } \\
\text { Monday through Thursday were assigned to the intervention group, and } \\
\text { those admitted on Friday through Sunday to the control group" }\end{array}$ \\
\hline $\begin{array}{l}\text { Blinding of participants and } \\
\text { personnel (performance bias) }\end{array}$ & High risk & $\begin{array}{l}\text { Quote: "The pharmacist who carried out the review and data extraction } \\
\text { was not blinded to the study hypothesis and the group status of the } \\
\text { subjects" }\end{array}$ \\
\hline $\begin{array}{l}\text { Blinding of outcome assessment } \\
\text { (detection bias) }\end{array}$ & High risk & $\begin{array}{l}\text { Quote: "The pharmacist who carried out the review and data extraction } \\
\text { was not blinded to the study hypothesis and the group status of the } \\
\text { subjects" }\end{array}$ \\
\hline $\begin{array}{l}\text { Incomplete outcome data (attrition } \\
\text { bias) }\end{array}$ & $\begin{array}{l}\text { Unclear } \\
\text { risk }\end{array}$ & $\begin{array}{l}\text { Loss between admission and discharge reported, but no information } \\
\text { given regarding loss to follow-up }\end{array}$ \\
\hline Selective reporting (reporting bias) & Low risk & All outcomes highlighted in the methods section were reported \\
\hline Baseline characteristics similar? & Low risk & $\begin{array}{l}\text { Baseline participant characteristics were reported. Quote: "There were no } \\
\text { statistical differences in the baseline characteristics of patients" }\end{array}$ \\
\hline Reliable Primary outcome measure & Low risk & MAl is a validated tool \\
\hline Protection against contamination & High risk & Study conducted within a single hospital unit \\
\hline
\end{tabular}

Clyne 2015 
Interventions to improve the appropriate use of polypharmacy for older people

\begin{tabular}{|c|c|}
\hline Methods & $\begin{array}{l}\text { Study design: randomised trial (cluster) } \\
\text { Unit of allocation: GP practices } \\
\text { Unit of analysis: participant } \\
\text { Follow-up: unclear } \\
\text { Duration: unclear } \\
\text { Providers: GPs and pharmacist }\end{array}$ \\
\hline Participants & $\begin{array}{l}\text { Setting/participants: } 196 \text { patients from } 12 \mathrm{GPpractices} \text { within the greater Dublin area } \\
\text { were invited to participate by e-mail with a follow-up telephone call. Practices were } \\
\text { eligible if they had at least } 80 \text { patients aged } 70 \text { years or older and were based in } \\
\text { greater Dublin. Consenting practices were instructed to randomly select } 50 \text { patients } \\
\text { from this age-group with capacity to provide informed consent. } \\
\text { Focus on polypharmacy: number of repeat medications, mean (SD), } 10.2 \text { (4.5) } \\
\text { intervention, } 9.5(4.1) \text { control } \\
\text { Age (mean): } 77.1 \text { (4.9) years intervention, } 76.4(4.8) \text { years control } \\
\text { Male: } 55.6 \% \text { intervention, } 51.5 \text { control } \\
\text { Ethnicity: no information given }\end{array}$ \\
\hline Interventions & $\begin{array}{l}\text { Model of pharmaceutical care: medication review provided by the GP } \\
\text { Training: education in the form of academic detailing with the pharmacistwas provided } \\
\text { to GPs, patients also received information leaflets during the medicines' reviews } \\
\text { Timing of intervention: during a single GP visit } \\
\text { Quote: "Intervention participants received a complex, multifaceted intervention } \\
\text { incorporating academic detailing; review of medicines with web-based pharmaceutical } \\
\text { treatment algorithms that provide recommended alternative-treatmentoptions; and } \\
\text { tailored patient information leaflets } \\
\text { The multifaceted intervention involved academic detailing with a pharmacist on how } \\
\text { GPs can review medicines with participating patients; the medicine reviews were } \\
\text { supported by web-based pharmaceutical treatment algorithms for GPs that provided } \\
\text { evidence basedalternative treatment options to PIPdrugs, and tailored patient } \\
\text { information leaflets } \\
\text { Control practices delivered usual care and received simple, patient-level PIP } \\
\text { feedback" }\end{array}$ \\
\hline Outcomes & $\begin{array}{l}\text { The proportion of patients with potentially inappropriate prescriptions } \\
\text { The mean number of potentially inappropriate prescriptions based on STOPP criteria }\end{array}$ \\
\hline Notes & \\
\hline
\end{tabular}

Risk of bias table 
Interventions to improve the appropriate use of polypharmacy for older people

\begin{tabular}{|c|c|c|}
\hline Bias & \begin{tabular}{|l|} 
Authors' \\
judgement
\end{tabular} & Support for judgement \\
\hline $\begin{array}{l}\text { Random sequence generation } \\
\text { (selection bias) }\end{array}$ & Low risk & $\begin{array}{l}\text { Quote: "Practices were allocated to intervention and control groups by an } \\
\text { independent researcher using minimisation" }\end{array}$ \\
\hline $\begin{array}{l}\text { Allocation concealment (selection } \\
\text { bias) }\end{array}$ & Low risk & $\begin{array}{l}\text { Quote: "Selection bias was minimized by collecting baseline data before } \\
\text { minimization, which was carried out byan independent third party" }\end{array}$ \\
\hline $\begin{array}{l}\text { Blinding of participants and } \\
\text { personnel (performance bias) }\end{array}$ & High risk & Quote: "Patients and GPs were not blinded to allocations" \\
\hline $\begin{array}{l}\text { Blinding of outcome assessment } \\
\text { (detection bias) }\end{array}$ & Low risk & Quote: "Outcome assessor was blinded to allocations" \\
\hline $\begin{array}{l}\text { Incomplete outcome data (attrition } \\
\text { bias) }\end{array}$ & Low risk & $\begin{array}{l}\text { No practices lostto follow-up and losses of patients within intervention anc } \\
\text { control arms were equal (six patients in each arm). Analyses were } \\
\text { performed according to ITT }\end{array}$ \\
\hline Selective reporting (reporting bias) & Low risk & All outcomes described were reported \\
\hline Baseline characteristics similar? & Low risk & $\begin{array}{l}\text { Baseline participant characteristics were reported. Results adjusted to } \\
\text { account for baseline demographic differences between intervention and } \\
\text { control groups }\end{array}$ \\
\hline Reliable Primary outcome measure & Low risk & $\begin{array}{l}\text { Quote: "The preliminary list of individual PIP criteria for inclusion in the } \\
\text { study was compiled from the most commonly cited existing published } \\
\text { criteria. These included the Beers criteria, the STOPP criteria, The } \\
\text { McLeod criteria, the Improving Prescribing in the Elderly Tool (IPET), the } \\
\text { Assessing Care of the Vulnerable Elder (ACOVE) and the Prescription } \\
\text { Peer Academic Detailing (Rx-PAD) study" }\end{array}$ \\
\hline Protection against contamination & Low risk & $\begin{array}{l}\text { Quote: "A cluster design was chosen to avoid the possibility of } \\
\text { contamination across arms" }\end{array}$ \\
\hline
\end{tabular}

Crotty 2004a 
Interventions to improve the appropriate use of polypharmacy for older people

\begin{tabular}{|c|c|}
\hline Methods & $\begin{array}{l}\text { Study design: randomised trial (cluster) } \\
\text { Unit of allocation: } 10 \text { residential facilities } \\
\text { Unit of analysis: participant } \\
\text { Follow-up: } 3 \text { months } \\
\text { Duration: } 2 \text { case conferences } 6 \text { to } 12 \text { weeks apart } \\
\text { Providers: resident's GP, geriatrician, pharmacist, home care staff and Alzheimer's } \\
\text { Society representative }\end{array}$ \\
\hline Participants & $\begin{array}{l}\text { Setting/participants: } 154 \text { residents ( } 100 \text { intervention and internal control and } 54 \\
\text { external control) from } 10 \text { high-level residential aged care facilities (nursing homes) in } \\
\text { Southern Adelaide } \\
\text { Focus on polypharmacy: residents were prescribed more than } 5 \text { medications } \\
\text { Age (mean): } 85.3 \text { years ( } 95 \% \mathrm{Cl} 84.0 \text { to } 86.6 \text { ) intervention, } 83.6 \text { years }(95 \% \mathrm{Cl} 81.3 \text { to } \\
85.9 \text { ) external control } \\
\text { Male: } 44 \% \text { intervention, } 43 \% \text { external control } \\
\text { Ethnicity: no information given }\end{array}$ \\
\hline Interventions & $\begin{array}{l}\text { Model of pharmaceutical care:the pharmacist conducted an independent medication } \\
\text { review using participant notes which were then were discussed with a multi- } \\
\text { disciplinary team during case conferences } \\
\text { Training: education (provided by the Alzheimer's Association of South Australiain)the } \\
\text { form of a training workshop was provided to all members of the multi-disciplinary team } \\
\text { Timing of intervention: during a single nursing home visit } \\
\text { Quote: "A medication review was conducted before a multi-disciplinary case } \\
\text { conference. The resident's GP, a geriatrician, a pharmacist, carers and a } \\
\text { representative from the Alzheimer's Association of South Australia attended the case } \\
\text { conferences, which were held at the nursing home. At the case conference, care staff } \\
\text { expanded on any issues in the case notes that required discussion, and the } \\
\text { Alzheimer's representative discussed non-pharmacological management of dementia- } \\
\text { related behaviour. A problem list was developed by the GP in collaboration with the } \\
\text { care staff } \\
\text { A half-day training workshopexamining use of a toolkit in the management of } \\
\text { challenging behaviourswas provided toall facilities in the study, including control } \\
\text { facilities" }\end{array}$ \\
\hline Outcomes & $\begin{array}{l}\text { Medication appropriateness was assessed using the MAI. Change in MAI was } \\
\text { reported. All residents had their medication charts reviewed before and after the } \\
\text { intervention by an independent pharmacist } \\
\text { The Nursing Home Behaviour Problem Scale (NHBPS) was used to assess the effect } \\
\text { of the intervention on residents' behaviour } \\
\text { Monthly drug costs for all regular medications on the government's pharmaceutical } \\
\text { benefits schemewere calculated for all residents in the intervention and control groups }\end{array}$ \\
\hline Notes & $\begin{array}{l}\text { Mean MAI score at baseline and at follow-up (3 months) } \\
\text { Unit of analysis error }\end{array}$ \\
\hline
\end{tabular}

Risk of bias table 
Interventions to improve the appropriate use of polypharmacy for older people

\begin{tabular}{|c|c|c|}
\hline Bias & \begin{tabular}{|l} 
Authors' \\
judgement
\end{tabular} & Support for judgement \\
\hline $\begin{array}{l}\text { Random sequence generation } \\
\text { (selection bias) }\end{array}$ & Low risk & $\begin{array}{l}\text { Quote: "Computer-generated random numbers were used bya } \\
\text { researcher independent of investigators" }\end{array}$ \\
\hline $\begin{array}{l}\text { Allocation concealment (selection } \\
\text { bias) }\end{array}$ & Low risk & $\begin{array}{l}\text { Quote: "Randomly allocated by the pharmacy department using } \\
\text { sequential sealed opaque envelopes to receive the case conferences" }\end{array}$ \\
\hline $\begin{array}{l}\text { Blinding of participants and } \\
\text { personnel (performance bias) }\end{array}$ & Unclear risk & Insufficient information to permit judgement \\
\hline $\begin{array}{l}\text { Blinding of outcome assessment } \\
\text { (detection bias) }\end{array}$ & Unclear risk & Insufficient information to permit judgement \\
\hline $\begin{array}{l}\text { Incomplete outcome data (attrition } \\
\text { bias) }\end{array}$ & Low risk & Those lost to follow-up were stated, and an ITT analysis was used \\
\hline Selective reporting (reporting bias) & Low risk & $\begin{array}{l}\text { The impact of case conferences on appropriateness of medication and } \\
\text { participant behaviours were stated as the objectives }\end{array}$ \\
\hline Baseline characteristics similar? & Unclear risk & $\begin{array}{l}\text { Baseline participant characteristics were reported. Results of statistical } \\
\text { comparisons between intervention and control groups not reported }\end{array}$ \\
\hline Reliable Primary outcome measure & Low risk & $\begin{array}{l}\text { The MAI has good to excellent reproducibility (kappa value }=0.59 \text { to } \\
0.83 \text { ) }\end{array}$ \\
\hline Protection against contamination & Low risk & $\begin{array}{l}\text { No evidence was found of a carry-over effect to other residents within } \\
\text { the facilities }\end{array}$ \\
\hline
\end{tabular}

Crotty 2004b 
Interventions to improve the appropriate use of polypharmacy for older people

\begin{tabular}{|c|c|}
\hline Methods & $\begin{array}{l}\text { Study design: single-blind randomised trial } \\
\text { Unit of allocation/analysis: participants } \\
\text { Follow-up: at } 8 \text { weeks } \\
\text { Duration: unclear } \\
\text { Providers: transition co-ordinator pharmacist, nurses }\end{array}$ \\
\hline Participants & $\begin{array}{l}\text { Setting/participants: } 110 \text { ( } 56 \text { intervention and } 54 \text { control) eligible patients making first- } \\
\text { timetransition froma hospital to } 1 \text { of } 85 \text { long-term residential care facilities in Southern } \\
\text { Adelaide, South Australia. Patients were eligible if they or their carer gave consent and } \\
\text { they had a life expectancy }>1 \text { month } \\
\text { Focus on polypharmacy: the number of preadmission medicines was } 6.6 \text { intervention } \\
\text { group and } 7.7 \text { control group } \\
\text { Age (mean): } 82 \text { years ( } 95 \% \mathrm{Cl} 80.2 \text { to } 83.7 \text { ) intervention, } 83.4 \text { years }(95 \% \mathrm{Cl} 81.7 \text { to } \\
85.1 \text { ) control } \\
\text { Female: } 58.9 \% \text { intervention, } 63 \% \text { control } \\
\text { Ethnicity: non-English speaking background: } 8.9 \% \text { intervention, } 5.6 \% \text { control }\end{array}$ \\
\hline Interventions & $\begin{array}{l}\text { Model of pharmaceutical care: the pharmacist conducted an independent medication } \\
\text { reviewusing participant notes which was then discussed with a multi-disciplinaryteam } \\
\text { during case conferences } \\
\text { Training: education was provided to all members of the multi-disciplinary team } \\
\text { Timing of intervention: during hospital discharge to a nursing home } \\
\text { Quote: "The intervention focused on transferring information on medications to care } \\
\text { providers in long-term care facilities (first-time transition). When discharged from } \\
\text { hospital to long-term care facilities, participants' family physicians and community } \\
\text { pharmacists were faxed a medication transfer summary compiled by the transition } \\
\text { pharmacist. After transfer, the transition pharmacist co-ordinated an evidence-based } \\
\text { medication review that was conducted by community pharmacists within } 10 \text { to } 14 \text { days } \\
\text { of transfer } \\
\text { Acase conference that involved thetransition co-coordinator, the family physician, the } \\
\text { community pharmacist and the nurse was held within } 14 \text { to } 28 \text { days of transfer } \\
\text { Usual hospital discharge process was received by controls and included a standard } \\
\text { hospital discharge summary" }\end{array}$ \\
\hline Outcomes & $\begin{array}{l}\text { Quote: "The appropriateness of prescribing was measured using the MAI. A single } \\
\text { score was determined for each medication received. A total MAI score for each } \\
\text { resident was calculated as a sum of MAI scores } \\
\text { Secondary outcome measures included unplanned visits to the emergency department } \\
\text { or hospital readmissions (grouped together as hospital usage), ADEs, falls, worsening } \\
\text { of mobility, behaviours, pain and increasing confusion" }\end{array}$ \\
\hline Notes & \\
\hline
\end{tabular}

Risk of bias table 
Interventions to improve the appropriate use of polypharmacy for older people

\begin{tabular}{|c|c|c|}
\hline Bias & \begin{tabular}{|l|} 
Authors' \\
judgement
\end{tabular} & Support for judgement \\
\hline $\begin{array}{l}\text { Random sequence generation } \\
\text { (selection bias) }\end{array}$ & Low risk & $\begin{array}{l}\text { Quote: "A computer-generated allocation sequence that used block } \\
\text { randomisation" }\end{array}$ \\
\hline $\begin{array}{l}\text { Allocation concealment (selection } \\
\text { bias) }\end{array}$ & Low risk & Quote: "Centralised hospital pharmacy service used for randomisation" \\
\hline $\begin{array}{l}\text { Blinding of participants and } \\
\text { personnel (performance bias) }\end{array}$ & Unclear risk & Insufficient information to permit judgement \\
\hline $\begin{array}{l}\text { Blinding ofoutcome assessment } \\
\text { (detection bias) }\end{array}$ & Low risk & $\begin{array}{l}\text { Quote: "Independent pharmacists who were blinded to studygroup } \\
\text { allocation assessed patients' medication charts and case notes" }\end{array}$ \\
\hline $\begin{array}{l}\text { Incomplete outcome data (attrition } \\
\text { bias) }\end{array}$ & Low risk & $\begin{array}{l}12 \text { participants inthe intervention group and } 10 \text { in the control group died } \\
\text { or did not complete the study for other reasons }\end{array}$ \\
\hline Selective reporting (reporting bias) & Unclear risk & Insufficient information to permit judgement \\
\hline Baseline characteristics similar? & High risk & $\begin{array}{l}\text { Baseline demographic differences existed between intervention and } \\
\text { control groups. No reported adjustment of results to account for baseline } \\
\text { differences in analysis }\end{array}$ \\
\hline Reliable Primary outcome measure & Low risk & The validity of the MAI has been reported previously \\
\hline Protection against contamination & High risk & $\begin{array}{l}\text { Quote: "The transition pharmacist also co-ordinated a case conference } \\
\text { involving himself or herself, the family physician, the community } \\
\text { pharmacist and a registered nurse at the facility within } 14 \text { to } 28 \text { days of the } \\
\text { transfer. At this case conference, the transition pharmacist provided } \\
\text { information concerning medication usage and appropriateness" }\end{array}$ \\
\hline
\end{tabular}

Dalleur 2014 
Interventions to improve the appropriate use of polypharmacy for older people

\begin{tabular}{|c|c|}
\hline Methods & $\begin{array}{l}\text { Study design: randomised trial } \\
\text { Unit of allocation/analysis: participant } \\
\text { Follow-up: at discharge and } 1 \text { year after discharge } \\
\text { Duration: unclear } \\
\text { Provider: inpatient geriatric consultation team (IGCT) }\end{array}$ \\
\hline Participants & $\begin{array}{l}\text { Setting/participants: Quote: "1 } 46 \text { (74 intervention and } 72 \text { control) frail patients } \geq 75 \\
\text { years of age admitted to Cliniques Universitaires Saint-Luc, a } 975 \text {-bed teaching } \\
\text { hospital in Brussels, Belgium" } \\
\text { Focus on polypharmacy: mean number of medications at baseline: } 7.2 \text { intervention, } \\
7.3 \text { control } \\
\text { Age (median (IQR)): } 84 \text { years (IQR } 81 \text { to } 87 \text { ) intervention, } 86 \text { years (IQR } 81 \text { to } 89 \text { ) } \\
\text { control } \\
\text { Female: } 58.1 \% \text { intervention, } 68.1 \% \text { control } \\
\text { Ethnicity: no information given }\end{array}$ \\
\hline Interventions & $\begin{array}{l}\text { Model of pharmaceutical care: participants' medication lists were screened by a } \\
\text { geriatrician } \\
\text { Training: unclear iftraining was provided as part of the intervention } \\
\text { Timing of intervention: during inpatient stay } \\
\text { Quote: "Inthe intervention group, geriatricians used 64STOPPcriteria ('Duplicate } \\
\text { drug classes'was not considered) to systematically screen the list of medications } \\
\text { being taken by participants on admission for potentially inappropriate medications and } \\
\text { provided oral and written recommendations to the ward physician during } \\
\text { hospitalisation for discontinuation of potentially inappropriate medications. Participants } \\
\text { also received standard IGCT care } \\
\text { Participants in the control group received standard care from the IGCT. Control } \\
\text { participants' medications were routinely reviewed by the ICCT geriatrician, using an } \\
\text { implicit approach (i.e. no explicit tool was used)" }\end{array}$ \\
\hline Outcomes & $\begin{array}{l}\text { Discontinuation of potentially inappropriate medications identified using STOPP criteria } \\
\text { Clinical significance of STOPP-related recommendations }\end{array}$ \\
\hline Notes & \\
\hline
\end{tabular}

Risk of bias table 
Interventions to improve the appropriate use of polypharmacy for older people

\begin{tabular}{|c|c|c|}
\hline Bias & $\begin{array}{l}\text { Authors' } \\
\text { judgement }\end{array}$ & Support for judgement \\
\hline $\begin{array}{l}\text { Random sequence generation } \\
\text { (selection bias) }\end{array}$ & $\begin{array}{l}\text { Unclear } \\
\text { risk }\end{array}$ & $\begin{array}{l}\text { Quote: "Eligible participants were allocated by the ICCT nurse to control or } \\
\text { intervention group bydrawing of lots-Insufficient information to permit } \\
\text { judgement" }\end{array}$ \\
\hline $\begin{array}{l}\text { Allocation concealment (selection } \\
\text { bias) }\end{array}$ & $\begin{array}{l}\text { Unclear } \\
\text { risk }\end{array}$ & $\begin{array}{l}\text { Quote: "IGCT nurse assigned each participant to the geriatrician who had } \\
\text { been allocated to the intended group after randomisation-insufficient } \\
\text { information on nurse's involvement in IGCT to permit judgement of yes/no" }\end{array}$ \\
\hline $\begin{array}{l}\text { Blinding of participants and } \\
\text { personnel (performance bias) }\end{array}$ & $\begin{array}{l}\text { Unclear } \\
\text { risk }\end{array}$ & $\begin{array}{l}\text { Quote: "The attending ward physician (who was responsible for } \\
\text { prescriptions during hospitalisation and at discharge), the evaluator and } \\
\text { participants were blinded to group assignment. However, the IGCT nurse } \\
\text { was not blinded, and insufficient information was provided on nurses" } \\
\text { involvement in the IGCT to permit judgement" }\end{array}$ \\
\hline $\begin{array}{l}\text { Blinding ofoutcome assessment } \\
\text { (detection bias) }\end{array}$ & Low risk & $\begin{array}{l}\text { Quote: "The IGCT nurse provided the evaluator with alist of the patients } \\
\text { included in the study, which did not specify allocation group. The evaluator } \\
\text { gathered data on the primary outcome" }\end{array}$ \\
\hline \multirow[t]{2}{*}{$\begin{array}{l}\text { Incomplete outcome data (attrition } \\
\text { bias) }\end{array}$} & \multirow[t]{2}{*}{$\begin{array}{l}\text { Unclear } \\
\text { risk }\end{array}$} & $\begin{array}{l}3 \text { participants in the intervention group and } 9 \text { in the control group were not } \\
\text { included in the primary outcome assessment because they did not receive } \\
\text { the allocated intervention, or because data were missing from their } \\
\text { discharge letters }\end{array}$ \\
\hline & & Subset of participants in each groupwas assessed at 1-yearfollow-up \\
\hline Selective reporting (reporting bias) & $\begin{array}{l}\text { Unclear } \\
\text { risk }\end{array}$ & $\begin{array}{l}\text { Characteristics associated with discontinuation of potentially inappropriate } \\
\text { medications at dischargewere listed as a secondaryoutcome measure } \\
\text { but were not clearly reported in the results }\end{array}$ \\
\hline Baseline characteristics similar? & Low risk & $\begin{array}{l}\text { Baseline participant characteristics were reported. No significant baseline } \\
\text { differences between intervention and control groups }\end{array}$ \\
\hline Reliable Primary outcome measure & Low risk & STOPP criteria \\
\hline Protection against contamination & $\begin{array}{l}\text { Unclear } \\
\text { risk }\end{array}$ & $\begin{array}{l}\text { Quote: "Toavoid contamination bias, } 2 \text { of the } 4 \text { geriatricians involvedin } \\
\text { the ICCT during the study period were allocated to the intervention group } \\
\text { because they used the STOPP criteria in their current practice; the other } 2 \text {, } \\
\text { who had never worked with the STOPP criteria, were allocated to the } \\
\text { control group. However, this was a single-site study; therefore the } \\
\text { possibility of contamination bias cannot be ruled out" }\end{array}$ \\
\hline
\end{tabular}

Franchi 2016 
Interventions to improve the appropriate use of polypharmacy for older people

\begin{tabular}{|c|c|}
\hline Methods & $\begin{array}{l}\text { Study design: randomised trial (cluster) } \\
\text { Unit of allocation: hospital wards } \\
\text { Unit of analysis: participant } \\
\text { Follow-up: } 12 \text { months post-discharge } \\
\text { Duration: unclear } \\
\text { Providers: physicians }\end{array}$ \\
\hline Participants & $\begin{array}{l}\text { Setting/participants: Quote: "Patients consecutively admitted to ten internal medicine } \\
\text { and ten geriatric wards of Italian hospital. All patients aged } 75 \text { years or over } \\
\text { consecutively admitted to the participating wards were eligible" } \\
\text { Focus on polypharmacy: mean number of drugs, } 6.3(3.3) \text { intervention, } 5.7(3.1) \\
\text { control, subpopulation of patients on polypharmacy } \\
\text { Age (mean): } 83.7( \pm 5.9) \text { years intervention, } 83.8( \pm 5.6) \text { years control } \\
\text { Male: } 40.9 \% \text { intervention, } 43.7 \% \text { control } \\
\text { Ethnicity: no information given }\end{array}$ \\
\hline Interventions & $\begin{array}{l}\text { Model of pharmaceutical care: pharmacists worked as part of inpatient services on } \\
\text { hospital wards as a clinical pharmacy service } \\
\text { Training: education in the form of e-learning was provided to all clinicians } \\
\text { Timing of intervention: during inpatient stay } \\
\text { Quote: "E-learning platform. E-learning was delivered through an interactive web- } \\
\text { based platform } \\
\text { Contents of e-learning for the intervention arm. The program delivered to clinicians on } \\
\text { the wards randomly assigned to the intervention arm included notions of CGAand } \\
\text { geriatric pharmacology, together with training for the use of a third generation } \\
\text { assessment instrument (InterRAI Acute Care). The course on geriatric pharmacology } \\
\text { was structured in three main areas and five modules as follows: Area 1: main concepts } \\
\text { of CGA (Module A); Area 2: general geriatric pharmacology notions (Module B); Area } \\
\text { 3: prescription appropriateness and related issues in older adults: (a) assessment and } \\
\text { management of patients exposed to polypharmacy (Module C); (b) criteria and tools } \\
\text { for the revision and evaluation of prescription appropriateness in older people, such as } \\
\text { Beers Criteria, Screening Tool of OlderPerson's Prescriptions (STOPP), Assessing } \\
\text { Care of the Vulnerable Elderly (ACOVE), Inappropriate Prescribing in the Elderly Tool } \\
\text { (IPET) and the Medication Appropriateness Index (MAl) (Module D); (c) criteria and } \\
\text { tools to evaluate potential drug-drug interactions (Module E) } \\
\text { The access to and utilization of each teaching module was linked to a self-evaluation } \\
\text { test and to specific centralized controls. Each modulewas divided in four sub-modules } \\
\text { that each participant completed with specific case reports and questions. The } \\
\text { INTERcheck }{ }^{\circledR} \text { software, a computerized prescription support system, was made } \\
\text { available toclinicians in the intervention arm through the interactive web-based } \\
\text { platform, separately from the electronic clinical report form } \\
\text { Contents of e-learning for the control arm. The e-learning program for clinicians of the } \\
\text { control arm consisted only of a refresher on the basic notions of geriatric } \\
\text { pharmacology using Module B as a weapon. The e-learning program for clinicians of } \\
\text { the control arm consisted only of a refresher on the basic notions of geriatric } \\
\text { pharmacology" }\end{array}$ \\
\hline Outcomes & $\begin{array}{l}\text { Reduction in the prescriptions at hospital discharge of PIMs (Beers criteria) } \\
\text { Reduction of prescription of potential DDIs (PDDIs) or potentially severe DDIs } \\
\text { Length of hospital stay, mortality and incidence of any re-hospitalisation during the 12- } \\
\text { month follow-up period }\end{array}$ \\
\hline Notes & \\
\hline
\end{tabular}


Interventions to improve the appropriate use of polypharmacy for older people

\begin{tabular}{|c|c|c|}
\hline Bias & \begin{tabular}{|l} 
Authors' \\
judgement
\end{tabular} & Support for judgement \\
\hline $\begin{array}{l}\text { Random sequence generation } \\
\text { (selection bias) }\end{array}$ & Unclear risk & Insufficient information was provided to permit judgement \\
\hline $\begin{array}{l}\text { Allocation concealment (selection } \\
\text { bias) }\end{array}$ & Unclear risk & Insufficient information was provided to permit judgement \\
\hline $\begin{array}{l}\text { Blinding of participants and } \\
\text { personnel (performance bias) }\end{array}$ & High risk & $\begin{array}{l}\text { Quote: "Single-blind controlled study: participating clinicians were not } \\
\text { blind to study aims and treatment allocation" }\end{array}$ \\
\hline $\begin{array}{l}\text { Blinding ofoutcome assessment } \\
\text { (detection bias) }\end{array}$ & Low risk & $\begin{array}{l}\text { Quote: "All investigators involved in data collection were blinded to arm } \\
\text { allocation" }\end{array}$ \\
\hline $\begin{array}{l}\text { Incomplete outcome data (attrition } \\
\text { bias) }\end{array}$ & Low risk & $\begin{array}{l}\text { Participants lost to follow-up in intervention and control group were } \\
\text { stated, and both ITT analysis and per protocol analysis were used }\end{array}$ \\
\hline Selective reporting (reporting bias) & Low risk & $\begin{array}{l}\text { The study protocol is available and all of the study's pre-specified } \\
\text { (primary and secondary) outcomes that are of interest in the review } \\
\text { have been reported }\end{array}$ \\
\hline Baseline characteristics similar? & High risk & $\begin{array}{l}\text { Baseline demographic differences existed between intervention and } \\
\text { control groups. No reported adjustment of results to account for baseline } \\
\text { differences in analysis }\end{array}$ \\
\hline Reliable Primary outcome measure & Low risk & $\begin{array}{l}\text { Validated assessment tool used to assess appropriateness of } \\
\text { prescribing (Beers Criteria 2012) }\end{array}$ \\
\hline Protection against contamination & Unclear risk & Insufficient information was provided to permit judgement \\
\hline
\end{tabular}

Frankenthal 2014 
Interventions to improve the appropriate use of polypharmacy for older people

\begin{tabular}{|c|c|}
\hline Methods & $\begin{array}{l}\text { Study design: randomised trial (parallel group) } \\
\text { Unit of allocation/analysis: participant } \\
\text { Follow-up: } 12 \text { months } \\
\text { Duration: } 12 \text { months } \\
\text { Providers: chief physician and study pharmacist }\end{array}$ \\
\hline Participants & $\begin{array}{l}\text { Setting/participants: Quote: "A chronic care geriatric facility in central Israel. The facility } \\
\text { has } 384 \text { beds. } 12 \text { wards: five nursing departments for residents dependentintheir } \\
\text { activities of daily living (ADLs) with and without cognitive impairment (ADL-dependent } \\
\text { group), fourdepartments for elderly adults independent in theirADLs but dependent in } \\
\text { instrumental ADLs (e.g., use of telephone, shopping, food preparation, travel, } \\
\text { housekeeping, handling finances } 17 \text { (ADL-independent group), and three departments } \\
\text { for residents who are primarily cognitively impaired but are able to walk independently } \\
\text { and therefore need special care to prevent them from getting lost (primarily cognitively } \\
\text { impaired group)." } \\
\text { Focus on polypharmacy: baseline number of medications, mean (SD): Intervention } n= \\
183,8.8 \text { (SD } 3.4) \text {; Control } n=176,8.2 \text { (SD } 3) \\
\text { Age (mean): Age, } n \text { (\%): } 65 \text { to } 74 \text { years } n=29(15.8) ; 75 \text { to } 84 \text { years } n=63(34.4) ; \geq \\
85 n=91 \text { ( } 49.7) \text { intervention, } 65 \text { to } 74 \text { years } n=36(20.5) ; 75 \text { to } 84 \text { years } n=63 \\
\text { (35.8); } \geq 85 n=77 \text { (43.8) control } \\
\text { Male: } 29.5 \% \text { intervention, } 37.5 \text { control } \\
\text { Ethnicity: no information given }\end{array}$ \\
\hline Interventions & $\begin{array}{l}\text { Model of pharmaceutical care: medication reviews conducted by the study } \\
\text { pharmacists which where discussed with the chief physician } \\
\text { Training: unclearif training was provided as part of the intervention } \\
\text { Timing of intervention: during inpatient stay } \\
\text { Quote: "The intervention consisted of a medication review by the study pharmacist for } \\
\text { all residents at studyopening and } 6 \text { and } 12 \text { months later. TheSTOPP/START criteria } \\
\text { were applied to identify PIMs and PPOs. Interventional recommendations that the } \\
\text { study pharmacist made for residents in the intervention group but not in the control } \\
\text { group were discussed with the chief physician at study opening and after } 6 \text { months. } \\
\text { The chief physician decided whether to accept these recommendations and implement } \\
\text { prescribing changes. } \\
\text { The control group received usual pharmaceutical care" }\end{array}$ \\
\hline Outcomes & $\begin{array}{l}\text { Proportion of potentially inappropriate prescriptions identified by STOPP } \\
\text { Proportion of PPOs identified by START } \\
\text { Quality of life (SF-12), falls, hospitalisations }\end{array}$ \\
\hline Notes & \\
\hline
\end{tabular}

Risk of bias table 
Interventions to improve the appropriate use of polypharmacy for older people

\begin{tabular}{|c|c|c|}
\hline Bias & \begin{tabular}{|l|} 
Authors' \\
judgement
\end{tabular} & Support for judgement \\
\hline $\begin{array}{l}\text { Random sequence generation } \\
\text { (selection bias) }\end{array}$ & Unclear risk & Insufficient information to permit judgement \\
\hline $\begin{array}{l}\text { Allocation concealment (selection } \\
\text { bias) }\end{array}$ & Low risk & $\begin{array}{l}\text { Quote: "A physician who was not part of the study randomized } \\
\text { participants. Fixed stratified randomization was used to allocate residents } \\
\text { to groups according to the three types of residents. Group allocation was } \\
\text { concealed from the study pharmacist, and participants were assigned to } \\
\text { one of the two groups using sealed envelopes" }\end{array}$ \\
\hline $\begin{array}{l}\text { Blinding of participants and } \\
\text { personnel (performance bias) }\end{array}$ & High risk & $\begin{array}{l}\text { Quote: "The intervention consisted of a medication review by the study } \\
\text { pharmacist for all residents at study opening and } 6 \text { and } 12 \text { months later. } \\
\text { The study pharmacists and the chief physician were not blinded to group } \\
\text { assignment" }\end{array}$ \\
\hline $\begin{array}{l}\text { Blinding ofoutcome assessment } \\
\text { (detection bias) }\end{array}$ & Low risk & $\begin{array}{l}\text { Quote: "Nurses whowere unaware of participants' group assignments } \\
\text { assessed the outcome measures in the study population" }\end{array}$ \\
\hline $\begin{array}{l}\text { Incomplete outcome data (attrition } \\
\text { bias) }\end{array}$ & Low risk & $\begin{array}{l}\text { Participants lost to follow-up in intervention and control group were stated } \\
\text { and similar across both groups }\end{array}$ \\
\hline Selective reporting (reporting bias) & Low risk & $\begin{array}{l}\text { The study protocol is available and all of the study's pre-specified (primary } \\
\text { and secondary) outcomes that are of interest in the review have been } \\
\text { reported }\end{array}$ \\
\hline Baseline characteristics similar? & Low risk & $\begin{array}{l}\text { Baseline participant characteristics were reported. No significant baseline } \\
\text { differences between intervention and control groups }\end{array}$ \\
\hline Reliable Primary outcome measure & Low risk & $\begin{array}{l}\text { Validated assessment tool used to assess appropriateness of prescribing } \\
\text { (STOPP/START criteria) }\end{array}$ \\
\hline Protection against contamination & Unclear risk & Insufficient information to permit judgement \\
\hline
\end{tabular}

Fried 2017 
Interventions to improve the appropriate use of polypharmacy for older people

\begin{tabular}{|c|c|}
\hline Methods & $\begin{array}{l}\text { Study design: randomised trial } \\
\text { Unit of allocation/analysis: participant } \\
\text { Follow-up: 3-months post discharge } \\
\text { Duration: } 3 \text {-months } \\
\text { Providers: clinical pharmacist }\end{array}$ \\
\hline Participants & $\begin{array}{l}\text { Setting/participants: } 128 \text { older patients ( } 64 \text { intervention and } 64 \text { control) recruited from } \\
\text { primary care clinics at a Veterans Affairs Medical Centre in Connecticut } \\
\text { Focus on polypharmacy: Number of drugs on admission }( \pm \text { SD), } 13.4( \pm 5.2) \\
\text { intervention, } 13.8( \pm 4.8) \text { control } \\
\text { Age: mean age not reported. Participants categorised according to age bands } \\
\text { Male: } 98.4 \% \text { intervention, } 98.4 \% \text { control } \\
\text { Ethnicity: no information given }\end{array}$ \\
\hline Interventions & $\begin{array}{l}\text { Model of pharmaceutical care: clinician receives recommendations based on the } \\
\text { information provided from the TRIM web tool } \\
\text { Training: no educational intervention was specified } \\
\text { Timing of intervention: during a single GP visit } \\
\text { Quote: "The TRIM consists of two web applications. The first extracts information on } \\
\text { medications and chronic conditions from the EHR. The second consists of three } \\
\text { components. The first is an interface for data chart reviewand telephonic patient } \\
\text { assessment. These data, along with the extracted EHR data, serve as inputs for the } \\
\text { second component, a set of automated algorithms evaluating medication } \\
\text { appropriateness. TRIM evaluates medication appropriateness based on a range of } \\
\text { criteria, including feasibility in the context of the patient's cognition and social support, } \\
\text { potential overtreatment of DM or hypertension, "traditional" PIMs according to Beers } \\
\text { and Screening Tool of Older Persons' potentially inappropriate Prescriptions (STOPP) } \\
\text { criteria, inappropriate renal dosing, and patient report of adverse medication effects. } \\
\text { The algorithms generate the third component, a patient-specific medication } \\
\text { management feedback report for the clinician. This report includes a complete } \\
\text { medication reconciliation, recommendations for discontinuation or dosage changes for } \\
\text { inappropriate medications, and a recommendation regarding the need to simplify the } \\
\text { regimen of patients with problems with adherence and poor social support. The report } \\
\text { was e-mailed to the clinician } 24 \text { hours before the primary care appointment and } \\
\text { handed to the clinician just before the appointment. The algorithms also generate a } \\
\text { simple, short report for the patient consisting of a listing of medication reconciliation } \\
\text { discrepancies and reported problems with medications that is given to the patient just } \\
\text { before the appointment with brief coaching on using it to discuss medication concerns } \\
\text { withthe clinician. The telephone assessments occurred within } 3 \text { days beforetheir } \\
\text { primary care appointment. } \\
\text { The control group received usual care" }\end{array}$ \\
\hline Outcomes & $\begin{array}{l}\text { Potentially inappropriate medications (PIMs) } \\
\text { Number of Tool to Reduce Inappropriate Medication (TRIM) recommendations } \\
\text { implemented (TRIM evaluates medication appropriateness based on a range of } \\
\text { criteria, including Beers and Screening Tool ofOlder Persons' potentially inappropriate } \\
\text { Prescriptions (STOPP) criteria) }\end{array}$ \\
\hline Notes & NCT02501967 \\
\hline
\end{tabular}

Risk of bias table 
Interventions to improve the appropriate use of polypharmacy for older people

\begin{tabular}{|c|c|c|}
\hline Bias & $\begin{array}{l}\text { Authors' } \\
\text { judgement }\end{array}$ & Support for judgement \\
\hline $\begin{array}{l}\text { Random sequence generation } \\
\text { (selection bias) }\end{array}$ & Unclear risk & Insufficient information to permit judgement \\
\hline $\begin{array}{l}\text { Allocation concealment (selection } \\
\text { bias) }\end{array}$ & Unclear risk & Insufficient information to permit judgement \\
\hline $\begin{array}{l}\text { Blinding of participants and } \\
\text { personnel (performance bias) }\end{array}$ & Unclear risk & Insufficient information to permit judgement \\
\hline $\begin{array}{l}\text { Blinding ofoutcome assessment } \\
\text { (detection bias) }\end{array}$ & Unclear risk & $\begin{array}{l}\text { Insufficient information to permit judgement: unclear who assessed } \\
\text { patients medications and whether they were blinded }\end{array}$ \\
\hline $\begin{array}{l}\text { Incomplete outcome data (attrition } \\
\text { bias) }\end{array}$ & Unclear risk & Insufficient information to permit judgement \\
\hline Selective reporting (reporting bias) & Low risk & $\begin{array}{l}\text { The study trial registry page is available and all of the study's pre- } \\
\text { specified (primary and secondary) outcomes that are of interest in the } \\
\text { review have been reported in the pre-specified way }\end{array}$ \\
\hline Baseline characteristics similar? & Low risk & $\begin{array}{l}\text { Baseline participant characteristics were reported and analyses adjusted } \\
\text { for imbalances in the intervention and control groups }\end{array}$ \\
\hline Reliable Primary outcome measure & Unclear risk & $\begin{array}{l}\text { Quote: "Traditional" PIMs according to Beers and Screening Tool of } \\
\text { Older Persons' potentially inappropriate Prescriptions (STOPP) criteria" }\end{array}$ \\
\hline Protection against contamination & Unclear risk & Insufficient information to permit judgement \\
\hline
\end{tabular}

Gallagher 2011 
Interventions to improve the appropriate use of polypharmacy for older people

\begin{tabular}{|c|c|}
\hline Methods & $\begin{array}{l}\text { Study design: randomised trial } \\
\text { Unit of allocation/analysis: participant } \\
\text { Follow-up: } 2 \text { months, } 4 \text { months and } 6 \text { months post discharge } \\
\text { Duration: unclear } \\
\text { Provider: attending medical team }\end{array}$ \\
\hline Participants & $\begin{array}{l}\text { Setting/participants: } 382 \text { hospital inpatients ( } 190 \text { intervention, } 192 \text { control) aged } 65 \\
\text { years and older admitted to Cork University Hospital via the emergency department } \\
\text { under the care of a general medical physician } \\
\text { Focus on polypharmacy: mean number of medications at baseline: } 7.4 \text { intervention, } \\
8.0 \text { control } \\
\text { Age (median (IQR)): } 74.5 \text { years ( } 71.0 \text { to } 80.0 \text { ) intervention, } 77.0 \text { years ( } 71.0 \text { to } 81.75 \text { ) } \\
\text { control } \\
\text { Female: } 53.2 \% \text { intervention, } 53.1 \% \text { control } \\
\text { Ethnicity: no information given }\end{array}$ \\
\hline Interventions & $\begin{array}{l}\text { Model of pharmaceutical care: participants' medication lists were screened by the } \\
\text { primary research physician, oral and written recommendations outlining appropriate } \\
\text { prescribing changes were then provided to the attending physicians } \\
\text { Training: unclear if any training was provided a part of the intervention } \\
\text { Timing of intervention: during hospital admission } \\
\text { Quote: "The primary research physician applied STOPP/START criteriato baseline } \\
\text { data of participants in the intervention group on admission to identify potentially } \\
\text { inappropriate prescriptions and prescribing omissions. These were immediately } \\
\text { discussed with the attending medical team, and discussion was followed up by written } \\
\text { communication within } 24 \text { hours. Intervention recommendations comprised simple } \\
\text { statements highlighting potentially inappropriate prescriptions according to relevant } \\
\text { STOPP/START criteria. The attending physician judged whether these } \\
\text { recommendations should be accepted and prescribing changes implemented. } \\
\text { Medication changes were included in the discharge summary to the intervention } \\
\text { participants' general practitioners" }\end{array}$ \\
\hline Outcomes & $\begin{array}{l}\text { Prescribing appropriateness measured using the MAI, STOPP/START criteria and the } \\
\text { AUM index } \\
\text { Mortality, hospital readmissions, falls, frequency of general practitioner visits }\end{array}$ \\
\hline Notes & \\
\hline
\end{tabular}

Risk of bias table 
Interventions to improve the appropriate use of polypharmacy for older people

\begin{tabular}{|c|c|c|}
\hline Bias & $\begin{array}{l}\text { Authors' } \\
\text { judgement }\end{array}$ & Support for judgement \\
\hline $\begin{array}{l}\text { Random sequence generation } \\
\text { (selection bias) }\end{array}$ & Low risk & $\begin{array}{l}\text { Quote: "Participants were randomly assigned to the intervention group or } \\
\text { the control group using a randomisation sequence that was determined by } \\
\text { an independently generated random-numbers table using StatsDirect } \\
\text { software, version } 4.5 \text { " }\end{array}$ \\
\hline $\begin{array}{l}\text { Allocation concealment (selection } \\
\text { bias) }\end{array}$ & Low risk & $\begin{array}{l}\text { Quote: "The random-numbers table was retained, independent of } \\
\text { researchers, by a physician external to the study, who assigned } \\
\text { participants to groupsusing a sealed-envelopesystem. Groupallocation } \\
\text { was concealed from the research physician and from participants until } \\
\text { baseline data had been collected and inclusion criteria verified" }\end{array}$ \\
\hline $\begin{array}{l}\text { Blinding of participants and } \\
\text { personnel (performance bias) }\end{array}$ & High risk & $\begin{array}{l}\text { Quote: "The research physician, attending physician, and participating } \\
\text { patients could not be blinded to group assignment after randomization } \\
\text { because of the nature of the intervention" }\end{array}$ \\
\hline $\begin{array}{l}\text { Blinding of outcome assessment } \\
\text { (detection bias) }\end{array}$ & Low risk & $\begin{array}{l}\text { Quote: "An interrater reliability analysis of outcome measurements was } \\
\text { conducted to ensure that there was no bias toward more favourable } \\
\text { ratings in the intervention group as compared to the control group. There } \\
\text { was good interrater agreement between the primary researcher and the } \\
\text { physician carrying out the blinded evaluation" }\end{array}$ \\
\hline $\begin{array}{l}\text { Incomplete outcome data (attrition } \\
\text { bias) }\end{array}$ & Low risk & $\begin{array}{l}18 \text { participants ( } 10 \text { intervention, } 8 \text { control) died before the first outcome } \\
\text { measure was assessed and were excluded fromanalysis; a further } 24 \\
\text { participants ( } 10 \text { intervention, } 14 \text { control) died during the follow-up period }\end{array}$ \\
\hline Selective reporting (reporting bias) & Low risk & All outcomes were reported \\
\hline Baseline characteristics similar? & Low risk & $\begin{array}{l}\text { Baseline participant characteristics were reported. No significant baseline } \\
\text { differences between intervention and control groups }\end{array}$ \\
\hline \multirow[t]{2}{*}{ Reliable Primary outcome measure } & \multirow[t]{2}{*}{ Low risk } & $\begin{array}{l}\text { MAl reported to have good content validity and good interrater and } \\
\text { intrarater reliability when used in hospital settings }\end{array}$ \\
\hline & & $\begin{array}{l}\text { AUM reported to have good interrater reliability and identified under- } \\
\text { treatment in } 25 \% \text { to } 64 \% \text { of participants }\end{array}$ \\
\hline Protection against contamination & Unclear risk & $\begin{array}{l}\text { Insufficient information to permit judgement; study conducted at a single } \\
\text { hospital }\end{array}$ \\
\hline
\end{tabular}

Garcia-Gollarte 2014 
Interventions to improve the appropriate use of polypharmacy for older people

\begin{tabular}{|c|c|}
\hline Methods & $\begin{array}{l}\text { Study design: prospective, randomised, multicentre trial/study } \\
\text { Unit of allocation: nursing home } \\
\text { Unit of analysis: participant } \\
\text { Follow-up: 3-months postintervention } \\
\text { Duration: } 6 \text {-months } \\
\text { Providers: nursing home physician }\end{array}$ \\
\hline Participants & $\begin{array}{l}\text { Setting/participants: Quote: "1 } 1018 \text { residents in } 37 \text { nursing homes owned by a private } \\
\text { company in Spain. Persons older than } 65 \text { years, who had been living in the nursing } \\
\text { home for at least } 3 \text { months and expected to stay in it for the length of the study, were } \\
\text { clinicallystable (nochanges in prescription in thelast } 2 \text { months) and accepted that } \\
\text { their clinical data were used for the study were included. Residents receiving palliative } \\
\text { care or those usually cared by other primary care providers outside the nursing home } \\
\text { were excluded" } \\
\text { Focus on polypharmacy: number of drugs, } 8.25(3.39) \text { intervention, } 7.89(3.27) \text { control } \\
\text { Age (mean): } 84.5 \text { (10.4) years intervention, } 84.24 \text { (14.6) control } \\
\text { Male: } 27 \% \text { total population, } 27.9 \% \text { intervention, } 26.0 \% \text { control } \\
\text { Ethnicity: no information given }\end{array}$ \\
\hline Interventions & $\begin{array}{l}\text { Model of pharmaceutical care: participants' medication lists were screened by the } \\
\text { primary research physician } \\
\text { Training: a structured educational intervention delivered by nursing home physician, } \\
\text { expert in drug use in older people was provided to the physicians } \\
\text { Timing of intervention: during inpatient stay } \\
\text { Quote: "A nursing home physician, expert in drug use in older people, delivereda } \\
\text { structured educational intervention. The program included general aspects of } \\
\text { prescription and drug use in geriatric patients, how to reduce the number of drugs, to } \\
\text { perform a regular review of medications, to avoid inappropriate drug use, to } \\
\text { discontinue drugs that do not show benefits, and to avoid undertreatment with drugs } \\
\text { that have shown benefits. It also discussed in detail some drugs frequently related to } \\
\text { adverse drug reactions in olderpeople. Educational materialand referenceswere } \\
\text { given to participants. Finally, two 1-hour workshops reviewed practical real life cases } \\
\text { and promoted practice changes in participants. The educator offered further on- } \\
\text { demand advice on prescription for the next } 6 \text { months. This intervention was reinforced } \\
\text { by a single review by the researchers, using standard appropriateness criteria } \\
\text { [Screening Tool of Older Persons Prescriptions (STOPP) Screening Tool to Alert } \\
\text { Doctors to Right Treatment (START)], of a random sample of } 10 \text { residents cared by } \\
\text { each physician in the intervention group, withwritten feedback on the problems found. } \\
\text { Physicians in the control group did not receive any intervention or information aboutan } \\
\text { educational intervention been delivered in other centers" }\end{array}$ \\
\hline Outcomes & $\begin{array}{l}\text { Appropriateness and quality of drug use (STOPP-START criteria). } \\
\text { Hospital admissions (total number of days spent in hospital), falls, physician and nurse } \\
\text { visits }\end{array}$ \\
\hline Notes & \\
\hline
\end{tabular}

Risk of bias table 
Interventions to improve the appropriate use of polypharmacy for older people

\begin{tabular}{|c|c|c|}
\hline Bias & \begin{tabular}{|l|} 
Authors' \\
judgement
\end{tabular} & Support for judgement \\
\hline $\begin{array}{l}\text { Random sequence generation } \\
\text { (selection bias) }\end{array}$ & Low risk & Quote: "Randomisation was done using random number tables" \\
\hline $\begin{array}{l}\text { Allocation concealment (selection } \\
\text { bias) }\end{array}$ & Unclear risk & Insufficient information to permit judgement \\
\hline $\begin{array}{l}\text { Blinding of participants and } \\
\text { personnel (performance bias) }\end{array}$ & Low risk & $\begin{array}{l}\text { Quote: "Physicians in both groups were informed that there was a } \\
\text { company program aimed to improve drug prescription (to explain why } \\
\text { data on prescription were collected in their centers) but were blinded to } \\
\text { the fact that the educational intervention was being assessed" }\end{array}$ \\
\hline $\begin{array}{l}\text { Blinding of outcome assessment } \\
\text { (detection bias) }\end{array}$ & Unclear risk & Insufficient information to permit judgement \\
\hline $\begin{array}{l}\text { Incomplete outcome data (attrition } \\
\text { bias) }\end{array}$ & Unclear risk & Insufficient information to permit judgement \\
\hline Selective reporting (reporting bias) & Low risk & All outcomes described were reported \\
\hline Baseline characteristics similar? & High risk & $\begin{array}{l}\text { Baseline demographic differences existed between intervention and } \\
\text { controlgroups. No reported adjustment of results to account for baseline } \\
\text { differences in analysis }\end{array}$ \\
\hline Reliable Primary outcome measure & Low risk & $\begin{array}{l}\text { Validated assessment tool used to assess appropriateness of prescribing } \\
\text { (STOPP/START criteria) }\end{array}$ \\
\hline Protection against contamination & Unclear risk & $\begin{array}{l}\text { Quote: "Cluster RCT design used whereby nursing homes in the } \\
\text { intervention and control group were separate. However, authors note that } \\
\text { some cross contamination may have occurred because of informal } \\
\text { contacts between physicians" }\end{array}$ \\
\hline
\end{tabular}

Haag 2016 
Interventions to improve the appropriate use of polypharmacy for older people

\begin{tabular}{|c|c|}
\hline Methods & $\begin{array}{l}\text { Study design: randomised trial } \\
\text { Unit of allocation/analysis: patient } \\
\text { Follow-up: } 30 \text {-day follow-up } \\
\text { Duration: unclear } \\
\text { Providers: pharmacist }\end{array}$ \\
\hline Participants & $\begin{array}{l}\text { Setting/participants: } 25 \text { older patients ( } 13 \text { intervention and } 12 \text { control) recruited from a } \\
\text { primary care work group at a tertiary care academic medical centre in the Midwestern } \\
\text { USA } \\
\text { Focus on polypharmacy: number of drugs on admission, median (IQR), } 17 \text { ( } 12 \text { to } 20 \text { ) } \\
\text { intervention, } 15.5 \text { ( } 13 \text { to } 18.5 \text { ) control } \\
\text { Age (median (IQR]): } 81 \text { ( } 79 \text { to } 85 \text { ) intervention, } 86 \text { ( } 79.5 \text { to } 87 \text { ) control } \\
\text { Male: } 69 \% \text { intervention, } 83 \% \text { control } \\
\text { Ethnicity: } 96 \% \text { white }\end{array}$ \\
\hline Interventions & $\begin{array}{l}\text { Model of pharmaceutical care: MTM consultation with a pharmacist, which included a } \\
\text { comprehensive review of all prescription, nonprescription, and herbal medications } \\
\text { taken } \\
\text { Training: no educational intervention was specified } \\
\text { Timing of intervention: during a single consultation } \\
\text { Quote: "The intervention group received an MTM consultation with a pharmacist by } \\
\text { telephone, preferably within } 3 \text { (and up to 7) business days after hospital discharge. } \\
\text { This intervention was developed using successful methods of pharmacist integration } \\
\text { during care transitions, while complementing the services of an existing CTP, to } \\
\text { assess the impact on the quality of medication use. The pharmacist obtained the } \\
\text { necessary information and clinical assessments from each patient's electronic medical } \\
\text { record to complete a comprehensive review of all prescription, nonprescription, and } \\
\text { herbal medications taken. This systematic review of medications included the } \\
\text { identification, resolution, and prevention of drug-related problems, including adverse } \\
\text { events or the use of potentially inappropriate medications. In addition, the electronic } \\
\text { medical record was investigated for potential prescribing omissions. This review was } \\
\text { the foundation for the phone consultation with the patient to ensure medication } \\
\text { optimization. Decisions were based on the pharmacist's clinicaljudgment after } \\
\text { considering practice guidelines, } 2 \text { clinical support databases (Truven Health Analytics' } \\
\text { Micromedex and Wolters Kluwer Lexi-Drugs), or the highest-quality evidence } \\
\text { available, as well as patient preferences. Recommendations were communicated by } \\
\text { the pharmacist via a secure messaging function within the electronic medical record to } \\
\text { the CTP provider for review on completion of the phone consultation. } \\
\text { The usual care group was defined as the pre-existing CTP without pharmacist } \\
\text { intervention." }\end{array}$ \\
\hline Outcomes & $\begin{array}{l}\text { Potentially inappropriate medications (STOPP/START) } \\
\text { Medication utilisation quality (modified MAI) } \\
\text { Hospital readmissions } \\
\text { Adherence (Morisky-Green) }\end{array}$ \\
\hline Notes & \\
\hline
\end{tabular}

Risk of bias table 
Interventions to improve the appropriate use of polypharmacy for older people

\begin{tabular}{|c|c|c|}
\hline Bias & $\begin{array}{l}\text { Authors' } \\
\text { judgement }\end{array}$ & Support for judgement \\
\hline $\begin{array}{l}\text { Random sequence generation } \\
\text { (selection bias) }\end{array}$ & Low risk & $\begin{array}{l}\text { Quote: "Patients were randomly assigned to either the intervention group } \\
\text { orto the usual care group by a study coordinator. Randomization was } \\
\text { completed during the phone call by the study coordinator, who opened a } \\
\text { sealed envelope that contained an indication of which group the patient } \\
\text { was assigned to" }\end{array}$ \\
\hline $\begin{array}{l}\text { Allocation concealment (selection } \\
\text { bias) }\end{array}$ & Low risk & $\begin{array}{l}\text { Quote: "The study statistician used a random number generator to } \\
\text { determine the allocation sequence" }\end{array}$ \\
\hline $\begin{array}{l}\text { Blinding of participants and } \\
\text { personnel (performance bias) }\end{array}$ & High risk & $\begin{array}{l}\text { Quote: "The trial was unblinded (i.e., the participants and the investigators } \\
\text { were aware of the intervention), and the patients received a telephone cal } \\
\text { from the pharmacist if they were randomized to the intervention group" }\end{array}$ \\
\hline $\begin{array}{l}\text { Blinding ofoutcome assessment } \\
\text { (detection bias) }\end{array}$ & Low risk & $\begin{array}{l}\text { Quote: "All outcomes were assessed while blinded to the intervention or } \\
\text { the usual care group allocations" }\end{array}$ \\
\hline $\begin{array}{l}\text { Incomplete outcome data (attrition } \\
\text { bias) }\end{array}$ & Low risk & $\begin{array}{l}\text { Missing outcomedatabalanced in numbers across intervention groups, } \\
\text { with similar reasons for missing data across groups }\end{array}$ \\
\hline Selective reporting (reporting bias) & Low risk & $\begin{array}{l}\text { The study protocol is not available but all expected outcomes are reported } \\
\text { in the results }\end{array}$ \\
\hline Baseline characteristics similar? & Low risk & $\begin{array}{l}\text { Baseline participant characteristics were reported. No statistically } \\
\text { significant baseline differences between the groups }\end{array}$ \\
\hline Reliable Primary outcome measure & Low risk & STOPP/START is a validated tool \\
\hline Protection against contamination & High risk & Single-centre trial with potential for contamination \\
\hline
\end{tabular}

Hanlon 1996 
Interventions to improve the appropriate use of polypharmacy for older people

\begin{tabular}{|c|c|}
\hline Methods & $\begin{array}{l}\text { Study design: randomised trial } \\
\text { Unit of allocation/analysis: participant } \\
\text { Follow-up: } 3 \text { months and } 12 \text { months after randomisation } \\
\text { Duration: unclear } \\
\text { Providers: geriatrician, clinical pharmacist, nurse }\end{array}$ \\
\hline Participants & $\begin{array}{l}\text { Setting/participants: } 208 \text { patients who were } 65 \text { years or older and were enrolled at the } \\
\text { Veteran Affairs Medical Center, Durham, North Carolina, USA } \\
\text { Focus on polypharmacy: included participants were prescribed } 5 \text { or more regularly } \\
\text { scheduled medications bya Veteran Affairs physician and were enrolled at the } \\
\text { Veteran Affairs Medical Center, Durham, North Carolina } \\
\text { Age (mean } \pm \text { SD): } 69.7 \pm 3.5 \text { years intervention, } 69.9 \pm 4.1 \text { years control } \\
\text { Male: } 98.1 \% \text { intervention, } 100 \% \text { control } \\
\text { Ethnicity, white: } 79 \% \text { intervention, } 74.8 \% \text { control }\end{array}$ \\
\hline Interventions & $\begin{array}{l}\text { Model of pharmaceutical care: pharmacists worked as part of a multi-disciplinaryteam } \\
\text { in outpatient clinics, the pharmacist(s) conducted an independent medication review } \\
\text { together with participants during a face-to-face encounter, written recommendations } \\
\text { were then presented to the primary physician } \\
\text { Training: educationwas provided to prescribers and other healthcare professionals, } \\
\text { participant education was also provided regarding drug-related problems and } \\
\text { compliance } \\
\text { Timing of intervention: during a single attendance at outpatient clinics } \\
\text { Quote: "The clinical pharmacist monitored drug therapy outcomes by reviewing each } \\
\text { participant's medical record and medication list, ascertained current medication use, } \\
\text { identified drug-related problems by meeting with participants and carers and evaluated } \\
\text { participants'medications byapplying the MAl. The pharmacist then formulated } \\
\text { prioritised written recommendations presented orally and in writing to the primary } \\
\text { physician. After the physician visit, the clinical pharmacist educated the participant } \\
\text { regarding drug-related problems and encouraged compliance } \\
\text { In the controlgroup, the clinicnurse reviewed participants'current medications before } \\
\text { the visit" }\end{array}$ \\
\hline Outcomes & $\begin{array}{l}\text { Participant MAI scores were determined by summing MAI medication scores across } \\
\text { evaluated medications } \\
\text { HRQoL (SF-36) } \\
\text { Participant medication compliance and knowledge were assessed by participant self- } \\
\text { report } \\
\text { Potential ADEs } \\
\text { Participant satisfaction }\end{array}$ \\
\hline Notes & \\
\hline
\end{tabular}

Risk of bias table 
Interventions to improve the appropriate use of polypharmacy for older people

\begin{tabular}{|c|c|c|}
\hline Bias & \begin{tabular}{|l|} 
Authors' \\
judgement
\end{tabular} & Support for judgement \\
\hline $\begin{array}{l}\text { Random sequence generation } \\
\text { (selection bias) }\end{array}$ & Low risk & $\begin{array}{l}\text { Quote: "Participants were randomly assigned to the control group or the } \\
\text { intervention group using a computer-generated scheme" }\end{array}$ \\
\hline $\begin{array}{l}\text { Allocation concealment (selection } \\
\text { bias) }\end{array}$ & Unclear risk & Insufficient information to permit judgement \\
\hline $\begin{array}{l}\text { Blinding of participants and } \\
\text { personnel (performance bias) }\end{array}$ & Unclear risk & Insufficient information to permit judgement \\
\hline $\begin{array}{l}\text { Blinding ofoutcome assessment } \\
\text { (detection bias) }\end{array}$ & Low risk & $\begin{array}{l}\text { Quote: "Assessments of outcome measures were blinded } \\
\text { (appropriateness, prescribing appropriateness, HRQOL, adverse drug } \\
\text { events, medication compliance)" }\end{array}$ \\
\hline $\begin{array}{l}\text { Incomplete outcome data (attrition } \\
\text { bias) }\end{array}$ & Low risk & $\begin{array}{l}36 \text { participants were not interviewed. } 5 \text { in control and intervention groups } \\
\text { were institutionalised. } 5 \text { from the intervention group and } 1 \text { from the } \\
\text { control group were lost to follow-up. } 7 \text { from the intervention group and } 10 \\
\text { from the control group died } \neg\end{array}$ \\
\hline Selective reporting (reporting bias) & Unclear risk & Insufficient information to permit judgement \\
\hline Baseline characteristics similar? & Low risk & $\begin{array}{l}\text { Baseline participant characteristics were reported. Results adjusted to } \\
\text { account for baseline demographic differences between intervention and } \\
\text { control groups }\end{array}$ \\
\hline Reliable Primary outcome measure & Low risk & $\begin{array}{l}\text { Quote: "Previous MAl assessments made by a clinical pharmacist and a } \\
\text { physician demonstrated excellent interrater (kappa value }=0.83) \text { and } \\
\text { intrarater reliability (kappa value }=0.92) \text { " }\end{array}$ \\
\hline Protection against contamination & High risk & $\begin{array}{l}\text { Potential for contamination because physicians had patients in both } \\
\text { intervention and control groups }\end{array}$ \\
\hline
\end{tabular}

Koberlein-Neu 2016 
Interventions to improve the appropriate use of polypharmacy for older people

\begin{tabular}{|c|c|}
\hline Methods & $\begin{array}{l}\text { Study design: stepped-wedge (cluster) randomised trial } \\
\text { Unit of allocation: GP practices } \\
\text { Unit of analysis: patients } \\
\text { Follow-up: 3-months follow-up } \\
\text { Duration: unclear } \\
\text { Providers: home-care specialists, pharmacist, physician }\end{array}$ \\
\hline Participants & $\begin{array}{l}\text { Setting/participants: } 142 \text { older patients from general practices in Northwest Germany } \\
\text { Focus on polypharmacy: five or more long-term drug treatments } \\
\text { Age (mean } \pm \text { SD): } 76.8 \pm 6.3 \text { years } \\
\text { Male: } 46.5 \% \\
\text { Ethnicity: not reported }\end{array}$ \\
\hline Interventions & 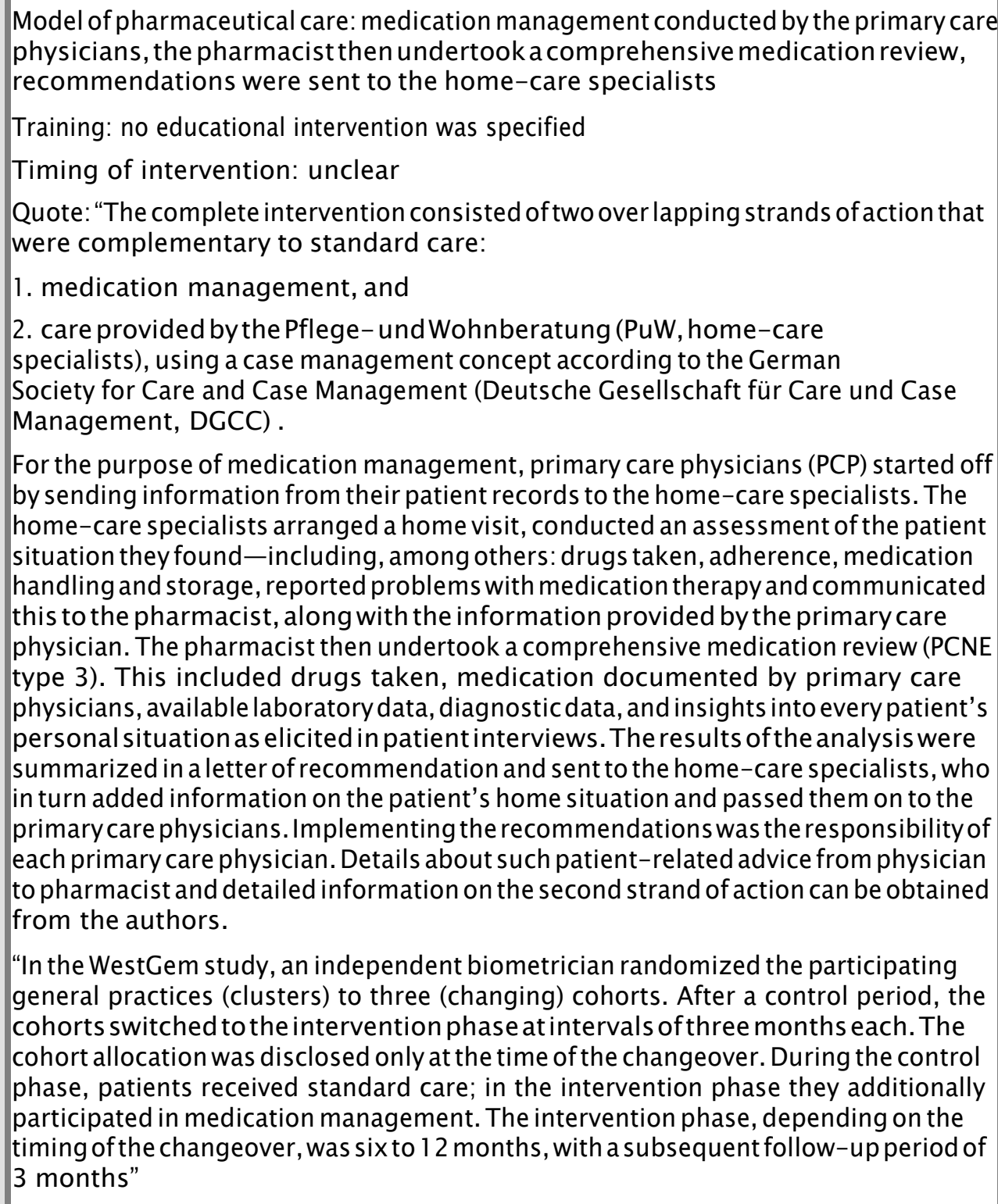 \\
\hline Outcomes & $\begin{array}{l}\text { Number of PIM prescribed (based on PRISCUS list) } \\
\text { Medication appropriateness index }\end{array}$ \\
\hline Notes & \\
\hline
\end{tabular}


Interventions to improve the appropriate use of polypharmacy for older people

\begin{tabular}{|c|c|c|}
\hline Bias & \begin{tabular}{|l|} 
Authors' \\
judgement
\end{tabular} & Support for judgement \\
\hline $\begin{array}{l}\text { Random sequence generation } \\
\text { (selection bias) }\end{array}$ & Unclear risk & Insufficient information to permit judgement \\
\hline $\begin{array}{l}\text { Allocation concealment (selection } \\
\text { bias) }\end{array}$ & Low risk & $\begin{array}{l}\text { Quote: "An independent biometrician randomized the participating } \\
\text { general practices (clusters) to three (changing) cohorts The cohort } \\
\text { allocation was disclosed only at the time of the changeover" }\end{array}$ \\
\hline $\begin{array}{l}\text { Blinding of participants and } \\
\text { personnel (performance bias) }\end{array}$ & Unclear risk & $\begin{array}{l}\text { Protocol states that Quote: "in this trial the patient is blinded to the } \\
\text { pharmacist" }\end{array}$ \\
\hline $\begin{array}{l}\text { Blinding ofoutcome assessment } \\
\text { (detection bias) }\end{array}$ & High risk & $\begin{array}{l}\text { The pharmacists had been blinded when calculating scores as to which } \\
\text { cohort a patient was allocated to, but they were involved in some cases in } \\
\text { conducting the medication reviews. They can therefore not be regarded } \\
\text { as completely independent }\end{array}$ \\
\hline $\begin{array}{l}\text { Incomplete outcome data (attrition } \\
\text { bias) }\end{array}$ & Unclear risk & Insufficient information to permit judgement \\
\hline Selective reporting (reporting bias) & High risk & Not all of the study's pre-specified primary outcomes have been reported \\
\hline Baseline characteristics similar? & High risk & No statistical comparison of baseline characteristics reported \\
\hline Reliable Primary outcome measure & Low risk & MAl used \\
\hline Protection against contamination & High risk & $\begin{array}{l}\text { Cluster-randomised trial; unclear if/how contamination protected against } \\
\text { with stepped wedge design }\end{array}$ \\
\hline
\end{tabular}

Michalek 2014 
Interventions to improve the appropriate use of polypharmacy for older people

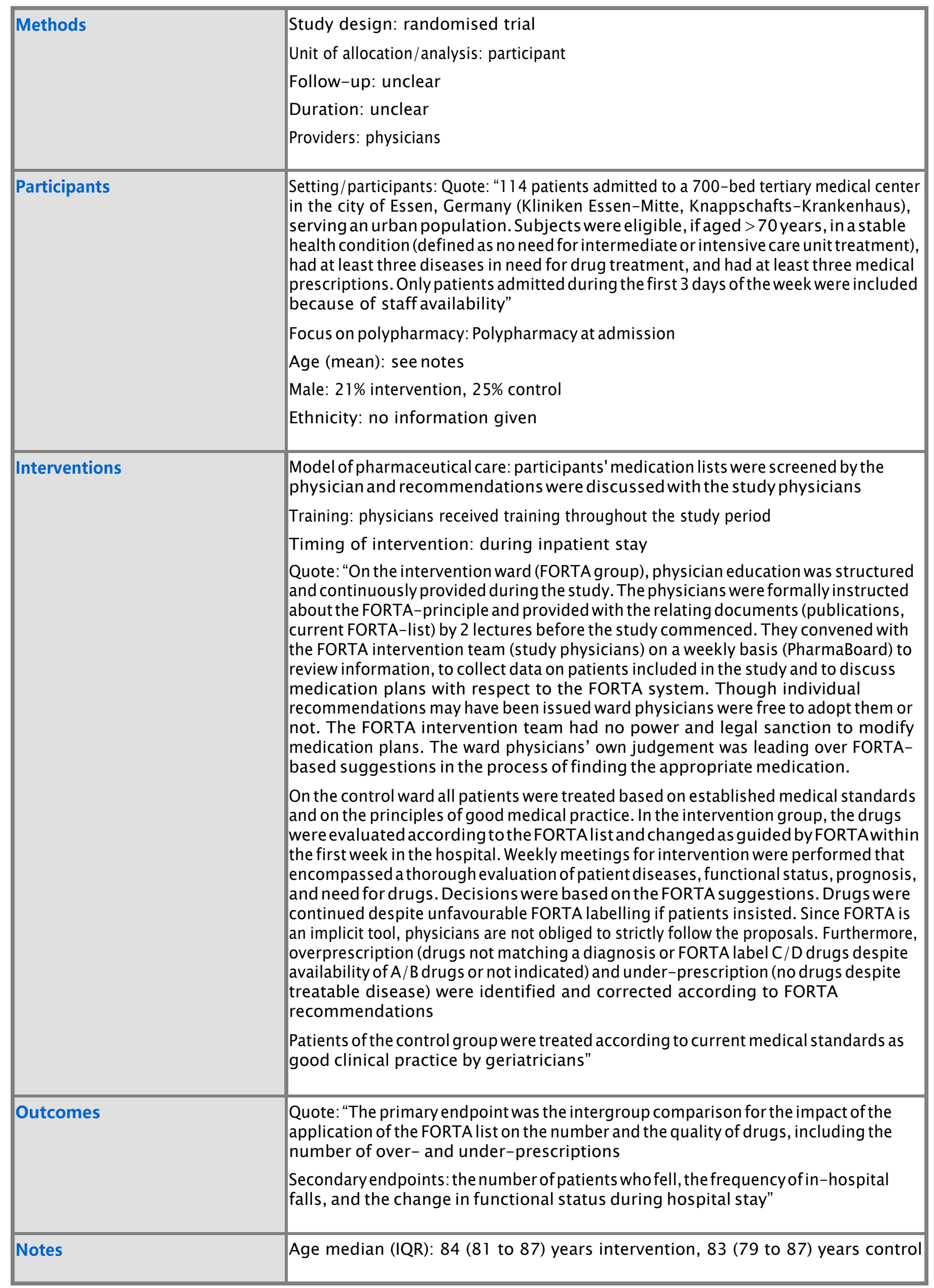


Interventions to improve the appropriate use of polypharmacy for older people

\begin{tabular}{|c|c|c|}
\hline Bias & \begin{tabular}{|l|} 
Authors' \\
judgement
\end{tabular} & Support for judgement \\
\hline $\begin{array}{l}\text { Random sequence generation } \\
\text { (selection bias) }\end{array}$ & High risk & $\begin{array}{l}\text { Quote: "Patients were assigned randomly by number of entrance to one } \\
\text { of two wards. In addition, patients could only be included in the study } \\
\text { during the first } 3 \text { days of the week due to staff availability" }\end{array}$ \\
\hline $\begin{array}{l}\text { Allocation concealment (selection } \\
\text { bias) }\end{array}$ & Low risk & $\begin{array}{l}\text { Quote: "Patients were assigned randomly by number of entrance to one } \\
\text { of two wards. The assignment was performed by a manager not involved } \\
\text { in patient care and blinded to the aim of the study" }\end{array}$ \\
\hline $\begin{array}{l}\text { Blinding of participants and } \\
\text { personnel (performance bias) }\end{array}$ & Low risk & $\begin{array}{l}\text { Quote: "Two physicians familiar with the FORTA classification were } \\
\text { responsible for the intervention process. They were not involved in the } \\
\text { treatment of the patients of the control area. All other staff of both wards } \\
\text { were blinded to the aim of the study" }\end{array}$ \\
\hline $\begin{array}{l}\text { Blinding of outcome assessment } \\
\text { (detection bias) }\end{array}$ & Unclear risk & Insufficient information to permit judgement \\
\hline $\begin{array}{l}\text { Incomplete outcome data (attrition } \\
\text { bias) }\end{array}$ & Low risk & All patients completed the study protocol \\
\hline Selective reporting (reporting bias) & Low risk & $\begin{array}{l}\text { The study protocol is available and all of the study's pre-specified } \\
\text { (primary and secondary) outcomes that are of interest in the review have } \\
\text { been reported }\end{array}$ \\
\hline Baseline characteristics similar? & Low risk & $\begin{array}{l}\text { Baseline participant characteristics were reported. No significant baseline } \\
\text { differences between intervention and control groups }\end{array}$ \\
\hline Reliable Primary outcome measure & Low risk & $\begin{array}{l}\text { Validated assessment tool used to assess appropriateness of prescribing } \\
\text { (FORTA list) }\end{array}$ \\
\hline Protection against contamination & Low risk & $\begin{array}{l}\text { Quote: "One ward served as the intervention area and the other ward as } \\
\text { the control area. The wards rather than individual subjects were chosen } \\
\text { to minimize contamination of results caused by staff" }\end{array}$ \\
\hline
\end{tabular}

\section{Milos 2013}

\begin{tabular}{|l|l|}
\hline Methods & $\begin{array}{l}\text { Study design: randomised trial } \\
\text { Unit of allocation/analysis: participant } \\
\text { Follow-up: } 2 \text {-months follow-up } \\
\text { Duration: unclear } \\
\text { Providers: pharmacist }\end{array}$ \\
\hline Participants & $\begin{array}{l}\text { Setting/participants: patients } 369 \text { (182 intervention, } 187 \text { control) } \\
\text { Focus on polypharmacy: mean (SD) number of drugs at baseline was } 11.4(4.2), \\
\text { intervention, } 12.1(4.7), \text { control } \\
\text { Age (mean } \pm \text { SD): } 87.0 \pm 5.8 \text { intervention, } 87.7 \pm 5.5 \text { years control } \\
\text { Male: } 24.2 \% \text { intervention, } 24.1 \% \text { control } \\
\text { Ethnicity: no information given }\end{array}$ \\
\hline
\end{tabular}


Interventions to improve the appropriate use of polypharmacy for older people

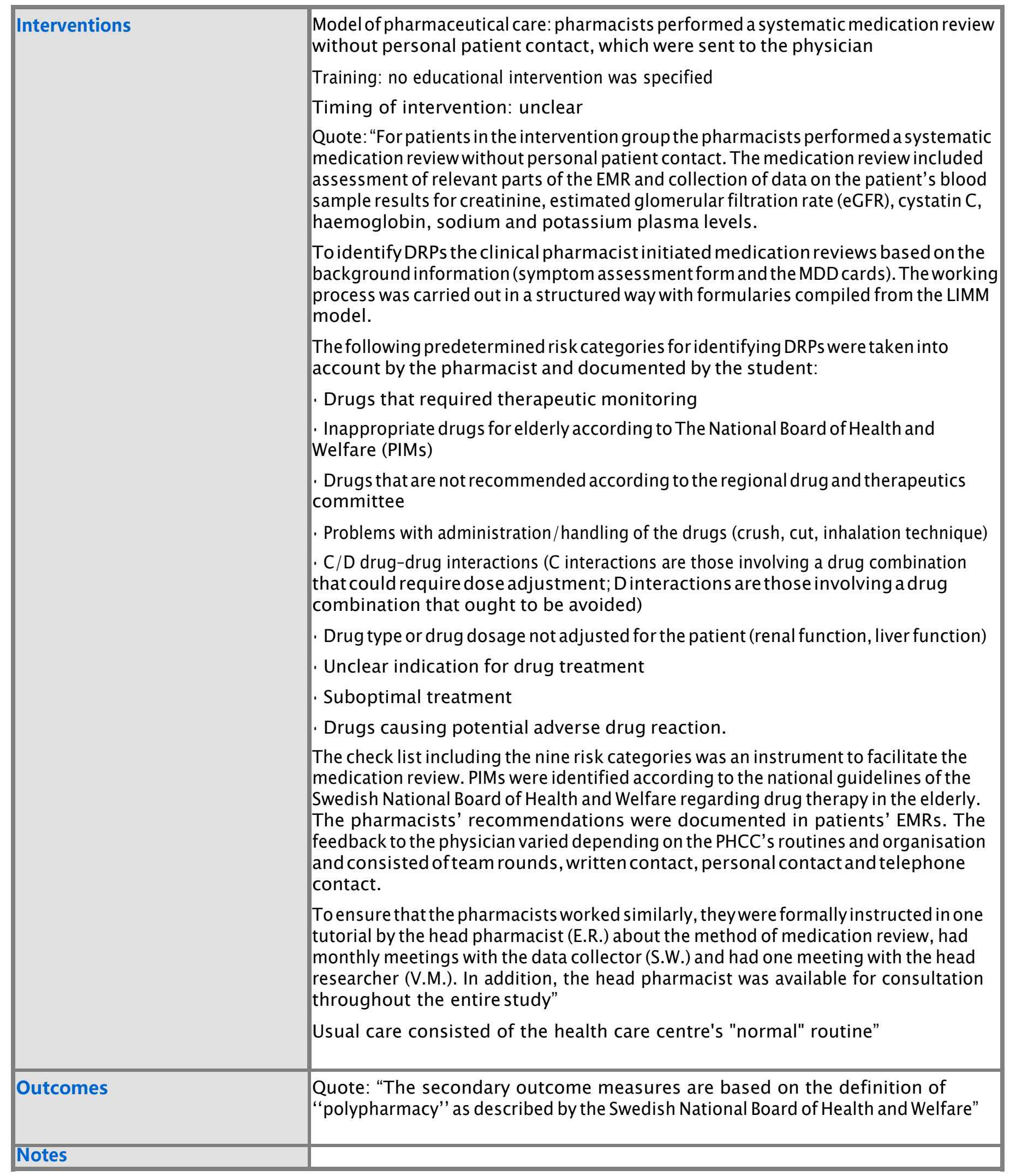

Risk of bias table 
Interventions to improve the appropriate use of polypharmacy for older people

\begin{tabular}{|c|c|c|}
\hline Bias & $\begin{array}{l}\text { Authors' } \\
\text { judgement }\end{array}$ & Support for judgement \\
\hline $\begin{array}{l}\text { Random sequence generation } \\
\text { (selection bias) }\end{array}$ & Low risk & $\begin{array}{l}\text { Quote: "The randomisation was performed using a random number } \\
\text { generator" }\end{array}$ \\
\hline $\begin{array}{l}\text { Allocation concealment (selection } \\
\text { bias) }\end{array}$ & Low risk & $\begin{array}{l}\text { Quote: "The pharmacist used closed, nontransparent envelopes to } \\
\text { randomise the patient to one of two groups: control orintervention" }\end{array}$ \\
\hline $\begin{array}{l}\text { Blinding of participants and } \\
\text { personnel (performance bias) }\end{array}$ & Unclear risk & Insufficient information to permit judgement \\
\hline $\begin{array}{l}\text { Blinding of outcome assessment } \\
\text { (detection bias) }\end{array}$ & Unclear risk & Insufficient information to permit judgement \\
\hline $\begin{array}{l}\text { Incomplete outcome data (attrition } \\
\text { bias) }\end{array}$ & Low risk & $\begin{array}{l}\text { Missing outcome data balanced in numbers across intervention groups, } \\
\text { with similar reasons for missing data across groups }\end{array}$ \\
\hline Selective reporting (reporting bias) & Low risk & $\begin{array}{l}\text { The study protocolis not availablebutitis clearthat the published } \\
\text { reports include all expected outcomes, including those that were pre- } \\
\text { specified }\end{array}$ \\
\hline Baseline characteristics similar? & Low risk & $\begin{array}{l}\text { Baseline characteristics reported Quote: "the control and intervention } \\
\text { groups were similar" }\end{array}$ \\
\hline Reliable Primary outcome measure & Low risk & $\begin{array}{l}\text { PIMs were identified according to the national guidelines of the Swedish } \\
\text { National Board of Health and Welfare regarding drug therapy in the } \\
\text { elderly }\end{array}$ \\
\hline Protection against contamination & Unclear risk & Insufficient information to permit judgement \\
\hline
\end{tabular}

Muth 2016 
Interventions to improve the appropriate use of polypharmacy for older people

\begin{tabular}{|c|c|}
\hline Methods & $\begin{array}{l}\text { Study design: randomised trial (cluster) } \\
\text { Unit of allocation: GP practices } \\
\text { Unit of analysis: patients } \\
\text { Follow-up: } 12 \text {-weeks follow-up } \\
\text { Duration: unclear } \\
\text { Providers: GPs }\end{array}$ \\
\hline Participants & $\begin{array}{l}\text { Setting/participants: } 100 \text { older patients ( } 50 \text { intervention and } 50 \text { control) recruited from } \\
20 \mathrm{GP} \text { practices in Germany } \\
\text { Focus on polypharmacy: included participants taking five or more long-term } \\
\text { prescriptions } \\
\text { Age (mean } \pm \text { SD): } 75.8 \pm 6.70 \text { years intervention, } 72.5 \pm 5.88 \text { years control } \\
\text { Male: } 44 \% \text { intervention, } 52 \% \text { control } \\
\text { Ethnicity: not reported }\end{array}$ \\
\hline Interventions & $\begin{array}{l}\text { Model of pharmaceutical care: a brown bag review and a checklist-based } \\
\text { preconsultation interview with the patient conducted by the HCA, a computer-assisted } \\
\text { medication review carried out by the GP and a GP-patient consultation } \\
\text { Training: no educational intervention was specified } \\
\text { Timing of intervention: on a single occasion } \\
\text { Quote: "The elements of the complex intervention consist of a brown bag review and a } \\
\text { checklist-based preconsultation interview with the patient that is conducted by the } \\
\text { HCA, a computer-assisted medication review carried out by the GP and a GP-patient } \\
\text { consultation. } \\
\text { GPs in the intervention group received practice guidelines for older patients and the } \\
\text { complex intervention was implemented at their practice on a single occasion. } \\
\text { Control group: GPs in the control group also received the practice guidelines for older } \\
\text { patients, } 35 \text { but continued with usual care" }\end{array}$ \\
\hline Outcomes & $\begin{array}{l}\text { Medication appropriateness index (MAl) } \\
\text { Health-related quality of life (EQ-5D index) } \\
\text { Self-reportedadherence (Moriskythe Medication Adherence Rating Scale-MARS) }\end{array}$ \\
\hline Notes & ISRCTN99691973 \\
\hline
\end{tabular}

Risk of bias table 
Interventions to improve the appropriate use of polypharmacy for older people

\begin{tabular}{|c|c|c|}
\hline Bias & $\begin{array}{l}\text { Authors' } \\
\text { judgement }\end{array}$ & Support for judgement \\
\hline $\begin{array}{l}\text { Random sequence generation } \\
\text { (selection bias) }\end{array}$ & Unclear risk & Insufficient information to permit judgement \\
\hline $\begin{array}{l}\text { Allocation concealment (selection } \\
\text { bias) }\end{array}$ & Unclear risk & Insufficient information to permit judgement \\
\hline $\begin{array}{l}\text { Blinding of participants and } \\
\text { personnel (performance bias) }\end{array}$ & Unclear risk & Insufficient information to permit judgement \\
\hline $\begin{array}{l}\text { Blinding of outcome assessment } \\
\text { (detection bias) }\end{array}$ & Low risk & $\begin{array}{l}\text { Quote: "An experienced clinical pharmacologist (SH) coded the MAI } \\
\text { following a blinded chart review" }\end{array}$ \\
\hline $\begin{array}{l}\text { Incomplete outcome data (attrition } \\
\text { bias) }\end{array}$ & Low risk & Losses to follow-up were small and similar across both groups. \\
\hline Selective reporting (reporting bias) & Low risk & $\begin{array}{l}\text { The study protocolis not available butitis clearthat the published } \\
\text { reports include all expected outcomes, including those that were pre- } \\
\text { specified. }\end{array}$ \\
\hline Baseline characteristics similar? & Unclear risk & $\begin{array}{l}\text { Baseline characteristics reported but no statement given on differences } \\
\text { between intervention groups }\end{array}$ \\
\hline Reliable Primary outcome measure & Low risk & MAI is a validated tool \\
\hline Protection against contamination & Unclear risk & $\begin{array}{l}\text { Quote: "Reduction in inappropriate prescriptions was observed in both } \\
\text { groups, indicating a likely contamination effect in the control group" }\end{array}$ \\
\hline
\end{tabular}

Muth 2018 
Interventions to improve the appropriate use of polypharmacy for older people

\begin{tabular}{|c|c|}
\hline Methods & $\begin{array}{l}\text { Study design: randomised trial (cluster) } \\
\text { Unit of allocation: GP practices } \\
\text { Unit of analysis: patients } \\
\text { Follow-up: 9-months follow-up } \\
\text { Duration: unclear } \\
\text { Providers: GPs }\end{array}$ \\
\hline Participants & $\begin{array}{l}\text { Setting/participants: } 505 \text { older patients ( } 252 \text { intervention and } 253 \text { control) recruited } \\
\text { from } 72 \text { GP practices in Germany } \\
\text { Focus on polypharmacy: included participants taking five or more long-term } \\
\text { prescriptions } \\
\text { Age (mean } \pm \text { SD): } 72.5 \pm 6.5 \text { years intervention, } 71.7 \pm 7.4 \text { years control } \\
\text { Male: } 47 \% \text { intervention, } 48 \% \text { control } \\
\text { Ethnicity: not reported }\end{array}$ \\
\hline Interventions & $\begin{array}{l}\text { Model of pharmaceutical care: a brown bag review and a checklist-based } \\
\text { preconsultation interview with the patient conducted by the HCA, a computer-assisted } \\
\text { medication review carried out by the GP and a GP-patient consultation } \\
\text { Training: no educational intervention was specified } \\
\text { Timing of intervention: on a single occasion } \\
\text { Quote: "There are four elements of the complex intervention. It consists of (1) a brown } \\
\text { bag review and (2) a checklist-based preconsultation interview with the patient that is } \\
\text { conducted } \\
\text { bythe healthcare assistant (HCA), (3) a computerised decision support system } \\
\text { (CDSS)-assisted medication review carried out by the GP, and (4) a GP-patient } \\
\text { consultation to optimise and prioritise medication. GPs had the option to use the } \\
\text { CDSS to help prepare the medication review with the patient, and during the } \\
\text { consultation itself. Trained HCAs and GPs implemented the intervention on a single } \\
\text { occasion, which tookthe GPand the HCA a per-patient average of } 35 \text { and } 45 \text { min, } \\
\text { respectively.35 The practice team for the intervention group received the GP } \\
\text { guidelines for ambulatory geriatric care prepared by the Hesse Guideline Group. } \\
\text { Recommendations in the guideline focus on primary and secondary prevention (e.g. } \\
\text { physical exercise, fall assessment and prevention). } \\
\text { The control group continued to receive usual care but the practice team also received } \\
\text { the GP guidelines for ambulatory geriatric care to harmonise usual care in both } \\
\text { groups" }\end{array}$ \\
\hline Outcomes & $\begin{array}{l}\text { MAI score } \\
\text { Health-related quality of life (EQ-5D) } \\
\text { All-cause hospitalisation } \\
\text { Adherence (Morisky-Green) }\end{array}$ \\
\hline Notes & ISRCTN99691973; NCT011 171339 \\
\hline
\end{tabular}

Risk of bias table 
Interventions to improve the appropriate use of polypharmacy for older people

\begin{tabular}{|c|c|c|}
\hline Bias & \begin{tabular}{|l|} 
Authors' \\
judgement
\end{tabular} & Support for judgement \\
\hline $\begin{array}{l}\text { Random sequence generation } \\
\text { (selection bias) }\end{array}$ & Low risk & $\begin{array}{l}\text { Quote: "Practice allocation to treatment groups will be performed bycentral } \\
\text { randomisation by a study-independent researcher at the IGP after } \\
\text { registration of the first patient per practice. Once a practice has been } \\
\text { randomised, all the patients recruited for the practice will be deemed } \\
\text { intervention or control depending on which arm of the study each practice } \\
\text { was allocated. After completion of the baseline documentation of all study } \\
\text { patients per practice, the study-independent researcheratthe IGPwill } \\
\text { inform the study team at the IGP about the practice status as either } \\
\text { intervention or control. The study team will send a fax with the } \\
\text { randomisation result to the practice" }\end{array}$ \\
\hline $\begin{array}{l}\text { Allocation concealment (selection } \\
\text { bias) }\end{array}$ & High risk & $\begin{array}{l}\text { Quote: "Practice allocation to treatment groups will be performed bycentral } \\
\text { randomisation by a study-independent researcher at the IGP after } \\
\text { registration of the first patient per practice. Once a practice has been } \\
\text { randomised, all the patients recruited for the practice will be deemed } \\
\text { intervention or control depending on which arm of the study each practice } \\
\text { was allocated. After completion of the baseline documentation of all study } \\
\text { patients per practice, the study-independent researcheratthe IGPwill } \\
\text { inform the study team at the IGP about the practice status as either } \\
\text { intervention or control. The study team will send a fax with the } \\
\text { randomisation result to the practice" }\end{array}$ \\
\hline $\begin{array}{l}\text { Blinding of participants and } \\
\text { personnel (performance bias) }\end{array}$ & Low risk & $\begin{array}{l}\text { Quote: "Owing to the nature of the intervention, it was not possible to blind } \\
\text { GPs, HCAs, patients and the study team" }\end{array}$ \\
\hline $\begin{array}{l}\text { Blinding of outcome assessment } \\
\text { (detection bias) }\end{array}$ & $\begin{array}{l}\text { Unclear } \\
\text { risk }\end{array}$ & $\begin{array}{l}\text { Quote: "Treatment allocation was blinded to the clinical pharmacologist } \\
\text { conducting medication reviews for the primary outcome (MAl) and to the } \\
\text { statistician" }\end{array}$ \\
\hline $\begin{array}{l}\text { Incomplete outcome data (attrition } \\
\text { bias) }\end{array}$ & $\begin{array}{l}\text { Unclear } \\
\text { risk }\end{array}$ & $\begin{array}{l}\text { Insufficient reporting of attrition/exclusions to permit judgement of 'Low risk' } \\
\text { or 'High risk' }\end{array}$ \\
\hline Selective reporting (reporting bias) & Low risk & $\begin{array}{l}\text { The study protocol is available and all of the study's pre-specified (primary } \\
\text { and secondary) outcomes that are of interest in the review have been } \\
\text { reported in the pre-specified way }\end{array}$ \\
\hline Baseline characteristics similar? & Low risk & $\begin{array}{l}\text { Baseline participant characteristics were reported and analyses adjusted } \\
\text { for imbalances in the intervention and control groups }\end{array}$ \\
\hline Reliable Primary outcome measure & Low risk & MAI is a validated tool \\
\hline Protection against contamination & Low risk & CRCT - allocation was by practice \\
\hline
\end{tabular}

Olsson 2012 
Interventions to improve the appropriate use of polypharmacy for older people

\begin{tabular}{|c|c|}
\hline Methods & $\begin{array}{l}\text { Study design: randomised trial } \\
\text { Unit of analysis: patients } \\
\text { Follow-up: 12-months follow-up } \\
\text { Duration: unclear } \\
\text { Providers: GPs }\end{array}$ \\
\hline Participants & $\begin{array}{l}\text { Setting/participants: } 150 \text { older patients ( } 50 \text { intervention group B, } 50 \text { intervention group } \\
\text { C and } 50 \text { control) ready for discharge from the University Hospital in Örebro } \\
\text { Focus on polypharmacy: included participants taking five or more drugs } \\
\text { Age (mean } \pm \text { SD): } 83.9 \pm 5.1 \text { years intervention, } 82.5 \pm 4.9 \text { years control } \\
\text { Male: } 36 \% \text { intervention, } 44 \% \text { control } \\
\text { Ethnicity: not reported }\end{array}$ \\
\hline Interventions & $\begin{array}{l}\text { Model of pharmaceutical care: home visit by a nurse and a prescription review } \\
\text { conducted by nurses the sent study physician to the physician/primary health care } \\
\text { centre } \\
\text { Training: no educational intervention was specified } \\
\text { Timing of intervention: unclear } \\
\text { Quote: "Group A (control): home visit by study nurse within one month after discharge, } \\
\text { QoL survey by post at six months, and second home visit by study nurse at } 12 \\
\text { months. } \\
\text { Group B (intervention): as group A and a letter with a prescription review (according to } \\
\text { points } 1 \text { - } 4 \text { below) sent to the physician / primary health care centre. } \\
\text { Group C (intervention): as group B combined with a current and comprehensive } \\
\text { medication record consisting of the patient's written drug regimen and indications sent } \\
\text { to the patient to enable participation in his / her drug treatment. } \\
\text { This was accompanied by an instruction to utilize the record throughout the health } \\
\text { care system, make notes, and discuss their drug treatment with their physicians. } \\
\text { During the home visit patients in all three groups were asked about their drug regimen } \\
\text { and compliance to capture their "true" medication record. The study physician } \\
\text { completed a prescription review assessing the following as indicators of prescription } \\
\text { quality: } \\
\text { 1. number of drugs; total, on regular basis and on demand; } \\
\text { 2. number of drug-risk indicators (long- and short-acting benzodiazepines, sleeping } \\
\text { pills, NSAIDs, digitalis, diuretics, SSRI, PPI, neuroleptics, and drugs with } \\
\text { anticholinergic effects); } \\
\text { 3. drug interactions by usinga computer program thatwarns for interactions ofC-type } \\
\text { (adjustment of dose recommended) and D-type (avoidance of drug recommended); } \\
\text { 4. number of medication errors and/or discrepancies between medication list } \\
\text { (prescriptions) and the patient's own regime (drugs noted but not taken, drugs taken } \\
\text { but not noted, and wrong dosages)" }\end{array}$ \\
\hline Outcomes & $\begin{array}{l}\text { Quality of prescriptions (The National Board of Health and Welfare. Indicators for } \\
\text { evaluation of quality of drug treatment for elderly) } \\
\text { Quality of life (EQ-5D index, EQ VAS) }\end{array}$ \\
\hline Notes & For the purpose of this review we focused on intervention group C versus control \\
\hline
\end{tabular}


Interventions to improve the appropriate use of polypharmacy for older people

\begin{tabular}{|c|c|c|}
\hline Bias & $\begin{array}{l}\text { Authors' } \\
\text { judgement }\end{array}$ & Support for judgement \\
\hline $\begin{array}{l}\text { Random sequence generation } \\
\text { (selection bias) }\end{array}$ & Unclear risk & Insufficient information to permit judgment \\
\hline $\begin{array}{l}\text { Allocation concealment (selection } \\
\text { bias) }\end{array}$ & Unclear risk & Insufficient information to permit judgment \\
\hline $\begin{array}{l}\text { Blinding of participants and } \\
\text { personnel (performance bias) }\end{array}$ & Low risk & $\begin{array}{l}\text { Quote: "All home visits throughout the study were done by the same } \\
\text { study nurse who was blinded to the groups" }\end{array}$ \\
\hline $\begin{array}{l}\text { Blinding ofoutcome assessment } \\
\text { (detection bias) }\end{array}$ & Unclear risk & Insufficient information to permit judgment \\
\hline $\begin{array}{l}\text { Incomplete outcome data (attrition } \\
\text { bias) }\end{array}$ & Low risk & $\begin{array}{l}\text { Quote: "No significant differences between the groups were observed in } \\
\text { respect of mortality or dropouts" }\end{array}$ \\
\hline Selective reporting (reporting bias) & Low risk & $\begin{array}{l}\text { The study protocolis not available butitis clearthat the published } \\
\text { reports include all expected outcomes, including those that were pre- } \\
\text { specified }\end{array}$ \\
\hline Baseline characteristics similar? & Low risk & $\begin{array}{l}\text { Baseline characteristics are reported. Quote:"No significant differences } \\
\text { between the groups were observed in respect of mortality or dropouts" }\end{array}$ \\
\hline Reliable Primary outcome measure & Low risk & $\begin{array}{l}\text { Based on The National Board of Health and Welfare. Indicators for } \\
\text { evaluation of quality of drug treatment for elderly }\end{array}$ \\
\hline Protection against contamination & Unclear risk & Insufficient information to permit judgment \\
\hline
\end{tabular}

Pitkala 2014 
Interventions to improve the appropriate use of polypharmacy for older people

\begin{tabular}{|c|c|}
\hline \multirow[t]{6}{*}{ Methods } & Study design: randomised trial (cluster) \\
\hline & Unit of allocation/analysis: wards \\
\hline & Unit of analysis: participant \\
\hline & $\begin{array}{l}\text { Follow-up: unclear, states that repeated assessments were performed at } 6 \text { and } 12 \text { - } \\
\text { months }\end{array}$ \\
\hline & $\begin{array}{l}\text { Duration: unclear, states that repeated assessments were performed at } 6 \text { and } 12 \text { - } \\
\text { months }\end{array}$ \\
\hline & Providers: nurses and consulting physician \\
\hline \multirow[t]{5}{*}{ Participants } & $\begin{array}{l}\text { Setting/participants: } 227 \text { residents ( } 118 \text { intervention, } 109 \text { control) in } 20 \text { wards in an } \\
\text { assisted living facility in Helsinki. Eligible residents of assisted living facilities in } \\
\text { Helsinki. Inclusion criteria: age } 65 \text { years or older; living permanently in an assisted } \\
\text { living facility; Finnish speaking; using at least } 1 \text { medication; having an estimated life } \\
\text { expectancy }>6 \text { months; and being able to provide written informed consent (or have a } \\
\text { proxy who is able to provide written informed consent in the case of cognitive } \\
\text { impairment). }\end{array}$ \\
\hline & $\begin{array}{l}\text { Focus on polypharmacy: mean number of regular medications (SD), } 7.5 \text { (2.8) } \\
\text { intervention, } 7.8 \text { (3.1) control }\end{array}$ \\
\hline & Age (mean): 82.9 (7.5) intervention, 83.5 (6.9) control \\
\hline & Male: $34.7 \%$ intervention, $22.9 \%$ control \\
\hline & Ethnicity: no information given \\
\hline \multirow[t]{5}{*}{ Interventions } & $\begin{array}{l}\text { Model of pharmaceutical care: nurses identified potential medication-related problems } \\
\text { and discussed these with the consulting physician }\end{array}$ \\
\hline & $\begin{array}{l}\text { Training: two 4-hour training sessions for nursing staff based on the principles of } \\
\text { constructive learning theory }\end{array}$ \\
\hline & Timing of intervention: unclear \\
\hline & $\begin{array}{l}\text { Quote: "The intervention comprised two 4-hour training sessions for nursing staff } \\
\text { based on the principles of constructive learning theory. The training sessions were } \\
\text { developed to be activating and interactive. The sessions were designed to enable } \\
\text { nurses to better recognize harmful medications and corresponding ADEs. The first } 4- \\
\text { hour afternoon sessionwas primarilylecture-based, but participants were encouraged } \\
\text { to present and openly discuss medication-related problems experienced by their own } \\
\text { residents. The session involved introducing thelist of harmful medications and suitable } \\
\text { alternatives. This session also involved discussion about medication use for residents } \\
\text { with renal impairment and drug-drug interactions. The second } 4 \text {-hour afternoon } \\
\text { session was case study based. Using the principles of problem-based learning, the } \\
\text { nurses participated in facilitated discussions about medication-related problems. To } \\
\text { demonstrate the relevance and importance of the topic, nurses were encouraged to } \\
\text { present and discuss actual resident cases from their own wards. Throughout the } \\
\text { training sessions, the nurses responsible for medication management were invited to } \\
\text { reflect on their own procedures and opportunities for improvement. We also invited } \\
\text { physicians to participate in the } 2 \text { education sessions. Two out of } 3 \text { physicians working } \\
\text { in the intervention wards attended } 1 \text { of the training sessions. The list of harmful } \\
\text { medications was provided to all nurses working in the intervention wards. Following } \\
\text { the training, the nurses were asked to identify potential medication-related problems } \\
\text { and bring these to the attention of the consulting physician. When this occurred, it was } \\
\text { the physician's responsibility to change or continue a specific medication }\end{array}$ \\
\hline & Control staff received no additional training and continued to provide routine care" \\
\hline Outcomes & $\begin{array}{l}\text { Use of potentially harmful medications (Beera criteria), HRQoL assessed using the } 15 \\
\text { dimensional instrument (15D) of health-related quality of life, health service utilisation, } \\
\text { and mortality }\end{array}$ \\
\hline Notes & \\
\hline
\end{tabular}


Interventions to improve the appropriate use of polypharmacy for older people

\begin{tabular}{|c|c|c|}
\hline Bias & $\begin{array}{l}\text { Authors' } \\
\text { judgement }\end{array}$ & Support for judgement \\
\hline $\begin{array}{l}\text { Random sequence generation } \\
\text { (selection bias) }\end{array}$ & Low risk & $\begin{array}{l}\text { Quote: "The } 36 \text { wards were assessed for possible participation, and } 20 \\
\text { wards were paired into } 10 \text { dyads. The wards in each dyad shared similar } \\
\text { resident characteristics. Acomputerized random number generatorwas } \\
\text { then used to randomize } 1 \text { ward in each dyad to the intervention arm and } \\
\text { the other to the control arm" }\end{array}$ \\
\hline $\begin{array}{l}\text { Allocation concealment (selection } \\
\text { bias) }\end{array}$ & Low risk & $\begin{array}{l}\text { Quote: "A person independent of assessment procedure telephoned } \\
\text { another person not familiar with the wards or residents to receive the } \\
\text { randomization number (intervention or control) for each ward" }\end{array}$ \\
\hline $\begin{array}{l}\text { Blinding of participants and } \\
\text { personnel (performance bias) }\end{array}$ & Low risk & $\begin{array}{l}\text { Quote: "The study nurses who recruited the residents were not aware } \\
\text { which wards had been randomized to the intervention or control groups" }\end{array}$ \\
\hline $\begin{array}{l}\text { Blinding of outcome assessment } \\
\text { (detection bias) }\end{array}$ & Low risk & $\begin{array}{l}\text { Quote: "The research nurses performed their assessments at } 0,6 \text { and } 12 \\
\text { months. These nurses were independent of the study intervention and } \\
\text { unaware of the randomization procedures" }\end{array}$ \\
\hline $\begin{array}{l}\text { Incomplete outcome data (attrition } \\
\text { bias) }\end{array}$ & High risk & $\begin{array}{l}\text { Quote: "High attrition rate: } 41 \text { residents ( } 18.1 \% \text { ) lost to follow-up at } 6 \\
\text { months and } 63 \text { residents }(27.8 \% \text { ) lost to follow-up at } 12 \text { months. All } \\
\text { residents assessed at baseline and at least } 1 \text { of the } 2 \text { follow-ups were } \\
\text { included when analyzing changes in the use of medications and HRQoL } \\
\text { (modified intention-to-treat analyses). All randomized residents were } \\
\text { included when analyzing health service utilization and mortality (intention- } \\
\text { to-treat analyses)" }\end{array}$ \\
\hline Selective reporting (reporting bias) & Low risk & $\begin{array}{l}\text { The study protocol is available; however there are some discrepancies } \\
\text { between the outcome reported in the trial registry document and the } \\
\text { paper. } 6 \text { month outcome data for all outcomes not clearly reported. Cost } \\
\text { data not reported }\end{array}$ \\
\hline Baseline characteristics similar? & High risk & $\begin{array}{l}\text { Baseline demographic differences existed between intervention and } \\
\text { control groups. Adjustment of results did not account for all identified } \\
\text { baseline differences }\end{array}$ \\
\hline Reliable Primary outcome measure & Low risk & $\begin{array}{l}\text { Validated assessment tool used to assess appropriateness of prescribing } \\
\text { (Beers criteria) }\end{array}$ \\
\hline Protection against contamination & Low risk & $\begin{array}{l}\text { Quote: "A cluster randomised design was used that involved randomizing } \\
\text { wards rather than individual residents. This was necessary to avoid } \\
\text { potential contamination of the intervention that may have arisen if nurses } \\
\text { had provided care to both residents in the intervention and control arms" }\end{array}$ \\
\hline
\end{tabular}

Schmader 2004 
Interventions to improve the appropriate use of polypharmacy for older people

\begin{tabular}{|c|c|}
\hline Methods & $\begin{array}{l}\text { Study design: randomised trial }(2 \times 2 \text { factorial design }) \\
\text { Unit of allocation/analysis: participant } \\
\text { Follow-up: telephone interviews } 12 \text { months after randomisation } \\
\text { Duration: participants were followed for } 12 \text { months } \\
\text { Provider: pharmacist/nurse/geriatrician/social worker }\end{array}$ \\
\hline Participants & $\begin{array}{l}\text { Setting / participants: } 834 \text { ( } 430 \text { intervention (inpatient), } 404 \text { control (inpatient)) } \\
\text { participants who were } 65 \text { years of age or older, were hospitalised on a medical ward or } \\
\text { surgical ward, had an expected stay of } 3 \text { or more days and met criteria for frailty, in } 11 \\
\text { Veterans Affairs hospitals, in the USA } \\
\text { Focus on polypharmacy: at baseline, the mean number of prescription drugs per } \\
\text { participant in the geriatric inpatient unit was } 7.7 ; \text { numberwas } 7.6 \text { in the usual inpatient } \\
\text { care group } \\
\text { Age (ranges): } 65 \text { to } 73 \text { years ( } 196 \text { people in intervention group, } 191 \text { people in control } \\
\text { group), } 74 \text { years or older ( } 234 \text { people in intervention group, } 213 \text { people in control } \\
\text { group) } \\
\text { Male: } 97 \% \text { intervention, } 98 \% \text { control } \\
\text { Ethnicity, white: } 71 \% \text { intervention, } 75 \% \text { control }\end{array}$ \\
\hline Interventions & $\begin{array}{l}\text { Model of pharmaceutical care: pharmacists worked as part of a multi-disciplinaryteam } \\
\text { in outpatient clinics, the pharmacist(s) conducted an independent medication review } \\
\text { together with participants during a face-to-face encounter } \\
\text { Training: no education intervention was specified } \\
\text { Duration: during inpatient period } \\
\text { Quote: "All } 11 \text { inpatient and outpatient geriatric evaluation management programmes } \\
\text { had a core team that included a geriatrician, a social worker and a nurse. Pharmacists } \\
\text { performed regular assessments and recommendations regarding medications in } 7 \\
\text { inpatient and 6 outpatient teams. For participants assigned to the GEM unit or clinic, } \\
\text { team members implemented evaluation and management protocols } \\
\text { Usual inpatient care was the customary medical or surgical treatment provided by } \\
\text { attending physicians } \\
\text { Usual outpatient care was the customary care delivered by ambulatory care attending } \\
\text { physicians or house staff under their direction" }\end{array}$ \\
\hline Outcomes & $\begin{array}{l}\text { Adverse drug reactions and serious adverse drug reactions } \\
\text { Inappropriate prescribing was assessed using the MAI and the Beers list at baseline } \\
\text { and at discharge } \\
\text { Polypharmacy and under-use were also measured using AUM }\end{array}$ \\
\hline Notes & \\
\hline
\end{tabular}

Risk of bias table 
Interventions to improve the appropriate use of polypharmacy for older people

\begin{tabular}{|c|c|c|}
\hline Bias & \begin{tabular}{|l} 
Authors' \\
judgement
\end{tabular} & Support for judgement \\
\hline $\begin{array}{l}\text { Random sequence generation } \\
\text { (selection bias) }\end{array}$ & Low risk & Quote: "Computer-generated random allocation" \\
\hline $\begin{array}{l}\text { Allocation concealment (selection } \\
\text { bias) }\end{array}$ & High risk & $\begin{array}{l}\text { Quote: "The centre notified site research assistants of each participant's } \\
\text { inpatient assignment by telephone. Outpatient assignment was revealed } \\
\text { at hospital discharge" }\end{array}$ \\
\hline $\begin{array}{l}\text { Blinding of participants and } \\
\text { personnel (performance bias) }\end{array}$ & Unclear risk & Insufficient information to permit judgement \\
\hline $\begin{array}{l}\text { Blinding of outcome assessment } \\
\text { (detection bias) }\end{array}$ & Low risk & Quote: "All assessments were performed blind to treatment status" \\
\hline $\begin{array}{l}\text { Incomplete outcome data (attrition } \\
\text { bias) }\end{array}$ & Unclear risk & Insufficient information to permit judgement \\
\hline Selective reporting (reporting bias) & Low risk & All outcomes were reported \\
\hline Baseline characteristics similar? & Low risk & $\begin{array}{l}\text { Baseline participant characteristics were reported. No significant baseline } \\
\text { differences between intervention and control groups }\end{array}$ \\
\hline Reliable Primary outcome measure & Unclear risk & $\begin{array}{l}\text { Primary outcomes were related to adverse drug reactions, which were } \\
\text { assumed when an event and a drug were determined to be causally } \\
\text { related. Disagreements on the item level were resolved byclinical } \\
\text { consensus conference }\end{array}$ \\
\hline Protection against contamination & Unclear risk & Insufficient information to permit judgement \\
\hline
\end{tabular}

Spinewine 2007 
Interventions to improve the appropriate use of polypharmacy for older people

\begin{tabular}{|c|c|}
\hline Methods & $\begin{array}{l}\text { Study design: randomised trial } \\
\text { Unit of allocation/analysis: participant } \\
\text { Follow-up: } 1 \text { month, } 3 \text { months and } 1 \text { year } \\
\text { Duration: from admission to discharge } \\
\text { Provider: pharmacists }\end{array}$ \\
\hline Participants & $\begin{array}{l}\text { Setting/participants: } 186 \text { hospital inpatients ( } 96 \text { intervention, } 90 \text { controls) aged } 70 \\
\text { years and older with acute geriatric problems in a GEM unit of a university teaching } \\
\text { hospital, Mount-Godinne, Yvoir, Belgium } \\
\text { Focus on polypharmacy: at baseline, mean }( \pm \text { SD) number of prescribed drugs was } \\
7.9( \pm 3.5) \text { for participants in the intervention group and } 7.3( \pm 3.3) \text { for those in the } \\
\text { control group } \\
\text { Age (mean } \pm \text { SD): } 82.4 \pm 6.9 \text { years intervention, } 81.9 \pm 6.2 \text { years control } \\
\text { Female: } 71.9 \% \text { intervention, } 66.7 \% \text { control } \\
\text { Ethnicity: no information given }\end{array}$ \\
\hline Interventions & $\begin{array}{l}\text { Model of pharmaceutical care: pharmacists worked as part inpatient services on } \\
\text { hospital wards as a clinical pharmacy service, the pharmacist(s) conducted an } \\
\text { independent medication reviews together with participants during a face-to-face } \\
\text { encounter, which were discussed with the prescriber } \\
\text { Training: education was provided to prescribers } \\
\text { Timing of intervention: during the hospital inpatient stay } \\
\text { Quote: "The intervention consisted of the provision of pharmaceutical care from } \\
\text { admission to discharge by a clinical pharmacist. A pharmacist was present } 4 \text { days per } \\
\text { week and participated in medical and multi-disciplinary rounds, had direct contact with } \\
\text { participants and carers and had access to participant medical records. For every } \\
\text { participant, the pharmacist performed a medication history on admission and prepared } \\
\text { a participant record with clinical and pharmaceutical data. Appropriateness of } \\
\text { treatment was analysed, and a pharmaceutical care plan was prepared. Whenever an } \\
\text { opportunity to optimise prescribing arose, the pharmacist discussed this with the } \\
\text { prescriber, who could accept or reject the advice. The pharmacist answered all } \\
\text { questions received from healthcare professionals aboutmedications. At dischargethe } \\
\text { pharmacist provided written and oral information on treatment changes to the } \\
\text { participant or carer, as well as written information to the GP" }\end{array}$ \\
\hline Outcomes & $\begin{array}{l}\text { Prescribing appropriateness measured using MAI, Beers list, ACOVE } \\
\text { Mortality, readmission (hospital admissions) or visit to an emergency department, } \\
\text { medicationstaken, unnecessarydrug use and satisfaction with information provided at } \\
\text { admission and at discharge }\end{array}$ \\
\hline Notes & \\
\hline
\end{tabular}

Risk of bias table 
Interventions to improve the appropriate use of polypharmacy for older people

\begin{tabular}{|c|c|c|}
\hline Bias & \begin{tabular}{|l} 
Authors' \\
judgement
\end{tabular} & Support for judgement \\
\hline $\begin{array}{l}\text { Random sequence generation } \\
\text { (selection bias) }\end{array}$ & $\begin{array}{l}\text { Unclear } \\
\text { risk }\end{array}$ & $\begin{array}{l}\text { Quote: "Randomisation was alternate and was stratified for age, number } \\
\text { of prescribed medicines and identity of the resident in charge of the } \\
\text { participant. A pharmacist external to the main study checked the inclusion } \\
\text { criteria and assigned participants to their groups" }\end{array}$ \\
\hline $\begin{array}{l}\text { Allocation concealment (selection } \\
\text { bias) }\end{array}$ & High risk & $\begin{array}{l}\text { Quote: "A pharmacist external to the main study checked inclusion criteria } \\
\text { and assigned participants to their groups" }\end{array}$ \\
\hline $\begin{array}{l}\text { Blinding of participants and } \\
\text { personnel (performance bias) }\end{array}$ & High risk & $\begin{array}{l}\text { Quote: "The physicians were not blinded to group assignment because of } \\
\text { the nature of the project" }\end{array}$ \\
\hline $\begin{array}{l}\text { Blinding ofoutcome assessment } \\
\text { (detection bias) }\end{array}$ & High risk & $\begin{array}{l}\text { The study was not double-blinded, and MAl evaluations at discharge } \\
\text { were unblinded }\end{array}$ \\
\hline \multirow[t]{2}{*}{$\begin{array}{l}\text { Incomplete outcome data (attrition } \\
\text { bias) }\end{array}$} & \multirow[t]{2}{*}{ Low risk } & $\begin{array}{l}7 \text { participants in both control and intervention groups were transferred to } \\
\text { another unit }\end{array}$ \\
\hline & & 5 participants in each of the groups (10 people in total) died \\
\hline Selective reporting (reporting bias) & High risk & A secondary outcome-'medications taken' was not reported \\
\hline Baseline characteristics similar? & Low risk & $\begin{array}{l}\text { Baseline participant characteristics were reported. No significant baseline } \\
\text { differences between intervention and control groups }\end{array}$ \\
\hline Reliable Primary outcome measure & Low risk & MAI, Beers criteria and ACOVE are validated measures \\
\hline Protection against contamination & High risk & Some physicians cared for control and intervention participants \\
\hline
\end{tabular}

Tamblyn 2003 
Interventions to improve the appropriate use of polypharmacy for older people

\begin{tabular}{|c|c|}
\hline Methods & $\begin{array}{l}\text { Study design: randomised trial } \\
\text { Unit of allocation: physicians } \\
\text { Unit of analysis: participant } \\
\text { Follow-up: terminated after an inappropriate prescription had been initiated or } \\
\text { discontinued } \\
\text { Duration: } 13 \text { months } \\
\text { Provider: physician }\end{array}$ \\
\hline Participants & $\begin{array}{l}\text { Setting/participants: } 107 \text { primary care physicians with at least } 100 \text { participants, who } \\
\text { were } 30 \text { years of age or older, had practices in Montreal and spentat least } 70 \% \text { of the } \\
\text { week in fee-for-service practice were randomly assigned. Participants were } 66 \text { years } \\
\text { of age or older, had been seen on } 2 \text { or more occasions by the study physician in the } \\
\text { past year and were living in the community at the start of the study } \\
\text { Focus on polypharmacy: implied } 35.6 \text { intervention } / 33.8 \text { control prescriptions per } \\
\text { elderly patient in the } 18 \text { months before the study date } \\
\text { Age (mean } \pm \text { SD): } 75.4 \pm 6.3 \text { years intervention, } 75.3 \pm 6.2 \text { years control } \\
\text { Female: } 61.2 \% \text { intervention, } 64.2 \% \text { control } \\
\text { Ethnicity: no information given }\end{array}$ \\
\hline Interventions & $\begin{array}{l}\text { Model of pharmaceutical care: physicians delivered the intervention via a } \\
\text { computerised support programme, participants' medication lists were screened by the } \\
\text { physicians } \\
\text { Training: no educational intervention specified } \\
\text { Timing of intervention: unclear } \\
\text { Quote: "Each physician was given a computer, a printer, health record software and } \\
\text { dial-upaccess to the Internet. The software documented health problems and } \\
\text { medications supplied. For each participant, trained personnel developed a health } \\
\text { problem list and documented } 26 \text { health problems related to targeted drug-disease } \\
\text { contraindications and other health problems. } \\
\text { CDS group physicians downloaded updates of dispensed prescriptions from } \\
\text { the Quebec beneficiary, medical-service and prescription claims database } \\
\text { (Regie de l'assurance maladie du Quebec (RAMQ)). Data were integrated into } \\
\text { the participant's health record and were categorised as having been } \\
\text { prescribed by the study physician or by another physician. Alerts were } \\
\text { instituted to identify } 159 \text { clinically relevant prescribing problems among the } \\
\text { elderly (McLeod 1997). Alerts appeared when the physician accessed the record, } \\
\text { when prescription record updates were downloaded from RAMQ and when current } \\
\text { health problems and prescriptions were recorded in the chart by the physician. They } \\
\text { identified the nature of the problem, possible consequences and suggested alternative } \\
\text { therapy in accordance with expert consensus" }\end{array}$ \\
\hline Outcomes & $\begin{array}{l}\text { Initiation and discontinuation rates of } 159 \text { prescription-related problems (McLeod } \\
\text { criteria) }\end{array}$ \\
\hline Notes & \\
\hline
\end{tabular}

Risk of bias table 
Interventions to improve the appropriate use of polypharmacy for older people

\begin{tabular}{|c|c|c|}
\hline Bias & \begin{tabular}{|l|} 
Authors' \\
judgement
\end{tabular} & Support for judgement \\
\hline $\begin{array}{l}\text { Random sequence generation } \\
\text { (selection bias) }\end{array}$ & Unclear risk & $\begin{array}{l}\text { Quote: "Physicians were stratified by age, sex, language, location of } \\
\text { medical school and number of elderly patients. Half of the physicians } \\
\text { within each stratum were randomly assigned to the CDS group" }\end{array}$ \\
\hline $\begin{array}{l}\text { Allocation concealment (selection } \\
\text { bias) }\end{array}$ & Unclear risk & Insufficient information to permit judgement \\
\hline $\begin{array}{l}\text { Blinding of participants and } \\
\text { personnel (performance bias) }\end{array}$ & Unclear risk & $\begin{array}{l}\text { Quote: "Physicians and patients were not told the specific outcomes of } \\
\text { the study but were aware of which group they had been assigned to" }\end{array}$ \\
\hline $\begin{array}{l}\text { Blinding of outcome assessment } \\
\text { (detection bias) }\end{array}$ & Low risk & Insufficient information to permit judgement \\
\hline $\begin{array}{l}\text { Incomplete outcome data (attrition } \\
\text { bias) }\end{array}$ & Low risk & $\begin{array}{l}\text { Number of inappropriate scripts started per } 1000 \text { visits and number of } \\
\text { inappropriate scripts discontinued per } 1000 \text { visits were reported }\end{array}$ \\
\hline Selective reporting (reporting bias) & Low risk & All results of outcomes specified in the methodology were reported \\
\hline Baseline characteristics similar? & Unclear risk & $\begin{array}{l}\text { Baseline participant characteristics were reported. Results of statistical } \\
\text { comparisons between intervention and control groups not reported }\end{array}$ \\
\hline Reliable Primary outcome measure & Unclear risk & McLeod criteria were used \\
\hline Protection against contamination & Unclear risk & $\begin{array}{l}\text { To minimise the possibility of contamination, only } 1 \text { physician pergroup } \\
\text { practice was included }\end{array}$ \\
\hline
\end{tabular}

Taylor 2003 
Interventions to improve the appropriate use of polypharmacy for older people

\begin{tabular}{|c|c|}
\hline Methods & $\begin{array}{l}\text { Study design: randomised trial } \\
\text { Unit of allocation/analysis: participant } \\
\text { Follow-up: } 12 \text { months } \\
\text { Duration: baseline until } 12 \text { months } \\
\text { Provider: pharmacists }\end{array}$ \\
\hline Participants & $\begin{array}{l}\text { Setting/participants: adult patients ( } 33 \text { intervention, } 36 \text { control) who received care at } 3 \\
\text { community-based family medicine clinics affiliated with the University of Alabama } \\
\text { School of Medicine in Tuscaloosa and other towns in Pickens County, Alabama } \\
\text { Focus on polypharmacy: patients eligible for inclusion were taking } 5 \text { or more } \\
\text { medications, } 12 \text { or more doses per day, or both } \\
\text { Age (mean } \pm \text { SD): } 64.4 \pm 13.37 \text { years intervention, } 66.7 \pm 12.3 \text { years control } \\
\text { Male: } 36.4 \% \text { intervention, } 27.8 \% \text { control } \\
\text { Ethnicity, white: } 60.6 \% \text { intervention, } 61.1 \% \text { control }\end{array}$ \\
\hline Interventions & $\begin{array}{l}\text { Model of pharmaceutical care: medication reviews were provided by pharmacists in } \\
\text { community-based family medicine clinics during a face-to-face encounter with } \\
\text { participants } \\
\text { Training: no educational intervention was specified } \\
\text { Timing of intervention: during a single attendance at outpatient clinics } \\
\text { Quote: "Participants received usual medical care along with pharmacotherapeutic } \\
\text { interventions provided by a pharmacist during regularly scheduled clinic visits, based } \\
\text { on the principles of pharmaceutical care. A participant typically met with a pharmacist } \\
\text { for } 20 \text { minutes before seeing a physician. Published therapeutic algorithms and } \\
\text { guidelines were used as the basis of the pharmacists' recommendations. Pharmacists } \\
\text { were specifically trained to evaluate a therapy's indication, effectiveness and dosage, } \\
\text { as well as the correctness and practicality ofdirections, drug-drug interactions, drug- } \\
\text { disease interactions, therapeutic duplication and duration of treatment, untreated } \\
\text { indications and expense } \\
\text { The pharmacist reviewed the medical record for medication-related problems, } \\
\text { conducted a chart review to ensure that information on drug therapy and allergies was } \\
\text { accurately documented, examined the medication history to determine compliance } \\
\text { with and complications of medications and provided comprehensive individualised } \\
\text { participanteducation, which included a brief review ofthe disease, important lifestyle } \\
\text { modifications and basicdrug information. Pharmacists monitored participants' } \\
\text { responses to drugs and attempted to improve compliance by consolidating medication } \\
\text { regimens, reducing dosage frequency, devising medication reminders and teaching } \\
\text { participants techniques for using devices such as inhalers. In addition to this, a system } \\
\text { was developed in which the participant, the physician or the nurse reported suspected } \\
\text { problems associated with drug therapy. Participants, nurses and physicians were } \\
\text { educated about the signs and symptoms of medication misadventures. } \\
\text { The control group received standard medical care" }\end{array}$ \\
\hline Outcomes & $\begin{array}{l}\text { Number of inappropriate prescriptions at baseline and at } 12 \text { months using the MAI } \\
\text { Change in number of hospital } \neg \text { admissions and emergency department visits at } 12 \\
\text { months. Medication misadventures, medication compliance (participant self-report) } \\
\text { and quality of life (SF-36) were also assessed }\end{array}$ \\
\hline Notes & \\
\hline
\end{tabular}

Risk of bias table 
Interventions to improve the appropriate use of polypharmacy for older people

\begin{tabular}{|c|c|c|}
\hline Bias & $\begin{array}{l}\text { Authors' } \\
\text { judgement }\end{array}$ & Support for judgement \\
\hline $\begin{array}{l}\text { Random sequence generation } \\
\text { (selection bias) }\end{array}$ & Unclear risk & $\begin{array}{l}\text { Quote: "Patients were randomly assigned to a control group or an } \\
\text { intervention group"; Insufficient information to permit judgement }\end{array}$ \\
\hline $\begin{array}{l}\text { Allocation concealment (selection } \\
\text { bias) }\end{array}$ & Unclear risk & Insufficient information to permit judgement \\
\hline $\begin{array}{l}\text { Blinding of participants and } \\
\text { personnel (performance bias) }\end{array}$ & Unclear risk & Insufficient information to permit judgement \\
\hline $\begin{array}{l}\text { Blinding ofoutcome assessment } \\
\text { (detection bias) }\end{array}$ & Unclear risk & Insufficient information to permit judgement \\
\hline $\begin{array}{l}\text { Incomplete outcome data (attrition } \\
\text { bias) }\end{array}$ & Low risk & 12 participants were not included because they were lost to follow-up \\
\hline Selective reporting (reporting bias) & Low risk & All outcomes described were reported \\
\hline Baseline characteristics similar? & Low risk & $\begin{array}{l}\text { Baseline participant characteristics were reported. No significant } \\
\text { baseline differences between intervention and control groups }\end{array}$ \\
\hline Reliable Primary outcome measure & Unclear risk & Insufficient information to permit judgement \\
\hline Protection against contamination & High risk & $\begin{array}{l}\text { Although participants were randomly assigned, physicians were not } \\
\text { because of the small number of physicians practising in the rural } \\
\text { community }\end{array}$ \\
\hline
\end{tabular}

Thyrian 2017 
Interventions to improve the appropriate use of polypharmacy for older people

\begin{tabular}{|c|c|}
\hline Methods & $\begin{array}{l}\text { Study design: randomised trial (cluster) } \\
\text { Unit of allocation: GP practices } \\
\text { Unit of analysis: patients } \\
\text { Follow-up: } 12 \text {-month follow-up } \\
\text { Duration: } 12 \text {-months } \\
\text { Providers: nurses }\end{array}$ \\
\hline Participants & $\begin{array}{l}\text { Setting/participants: } 516 \text { older patients ( } 348 \text { intervention and } 168 \text { control) recruited } \\
\text { from } 95 \text { GP practices in Germany } \\
\text { Focus on polypharmacy: number of drugs on admission, } 6.4 \pm 3.2 \\
\text { Age (mean } \pm \text { SD): } 80.6 \pm 5.7 \text { years intervention, } 79.8 \pm 5.0 \text { years control } \\
\text { Male: } 38.8 \% \text { intervention, } 39.7 \% \text { control } \\
\text { Ethnicity: not reported }\end{array}$ \\
\hline Interventions & $\begin{array}{l}\text { Model of pharmaceutical care: the nurses conducted an in-depth assessment, } \\
\text { computer-assisted assessment determining a personalised array of intervention } \\
\text { modules and subsequent success monitoring } \\
\text { Training: no educational intervention was specified } \\
\text { Timing of intervention: unclear } \\
\text { Quote: "Dementia care management aims to provide optimal care by integrating multi } \\
\text { professional and multimodal strategies for improving patient-and caregiver-related } \\
\text { outcomes within the framework of the established health care and social service } \\
\text { system. It was developed according to current guidelines, targeted at the individual } \\
\text { participant level, and delivered at patients' homes by } 6 \text { nurses with dementia-specific } \\
\text { qualifications supported by a computer-based intervention-management system(IMS) } \\
\text { to improve systematic identification of patients' and caregivers' unmet needs. The } \\
\text { nurses conducted an in-depth assessment. Based on these data, the IMS generated } \\
\text { an individual preliminaryintervention task list, and the nurses discussed and finalized } \\
\text { the task listinaweekly interdisciplinary case conferencewith a nursing scientist, a } \\
\text { neurologist/ psychiatrist, a psychologist, and a pharmacist. Afterwards, the list of } \\
\text { intervention tasks was summarized in a semi standardized GP information letter. This } \\
\text { letter was then discussed between the GP and nurse to establish an individual } \\
\text { treatment plan. During the first } 6 \text { months of the intervention period, the nurse } \\
\text { conducted } 6 \text { homevisits with an average duration of } 1 \text { hour, carrying out his orher } \\
\text { standard intervention tasks in close cooperation with the caregiver, the GP, and health } \\
\text { care and social service professionals. During the subsequent } 6 \text { months, the study } \\
\text { nurse monitored the completion of all intervention tasks. In line with the Pacala scale } \\
\text { forintensive case managements, each study nurse delivered intervention to, on } \\
\text { average, } 60 \text { patients with dementia } \\
\text { Participants cluster-randomised to the control group received care as usual in a } \\
\text { primary care setting" }\end{array}$ \\
\hline Outcomes & $\begin{array}{l}\text { Use of potentially inappropriate medication (PRISCUS criteria) } \\
\text { Quality of life (QoL-AD) }\end{array}$ \\
\hline Notes & \\
\hline
\end{tabular}

Risk of bias table 
Interventions to improve the appropriate use of polypharmacy for older people

\begin{tabular}{|c|c|c|}
\hline Bias & $\begin{array}{l}\text { Authors' } \\
\text { judgement }\end{array}$ & Support for judgement \\
\hline $\begin{array}{l}\text { Random sequence generation } \\
\text { (selection bias) }\end{array}$ & Low risk & $\begin{array}{l}\text { Quote: "The GPwas randomized by fair coin tossing to care as usual or } \\
\text { intervention group" }\end{array}$ \\
\hline $\begin{array}{l}\text { Allocation concealment (selection } \\
\text { bias) }\end{array}$ & Unclearrisk & Insufficient information to permit judgement \\
\hline $\begin{array}{l}\text { Blinding of participants and } \\
\text { personnel (performance bias) }\end{array}$ & High risk & $\begin{array}{l}\text { Quote: "The randomization was done before baseline assessment of the } \\
\text { individuals and the intervention cannot be classified as blinded, neither } \\
\text { on the level of the GP, nor on the level of the study participant" }\end{array}$ \\
\hline $\begin{array}{l}\text { Blinding of outcome assessment } \\
\text { (detection bias) }\end{array}$ & High risk & $\begin{array}{l}\text { Quote: "Because baseline assessment, primary outcome assessment, } \\
\text { and delivery of intervention needed to be performed by the same nurses, } \\
\text { blinding was not possible" }\end{array}$ \\
\hline $\begin{array}{l}\text { Incomplete outcome data (attrition } \\
\text { bias) }\end{array}$ & Low risk & $\begin{array}{l}\text { Missing outcome databalanced in numbers across intervention groups, } \\
\text { with similar reasons for missing data across groups }\end{array}$ \\
\hline Selective reporting (reporting bias) & High risk & $\begin{array}{l}\text { Not all of the study's pre-specified secondary outcomes have been } \\
\text { reported }\end{array}$ \\
\hline Baseline characteristics similar? & Low risk & $\begin{array}{l}\text { Baseline participant characteristics were reported.Quote: "The groups did } \\
\text { not differ significantly according to primary outcomes and } \\
\text { sociodemographic variables" }\end{array}$ \\
\hline Reliable Primary outcome measure & Low risk & PRISCUS is a validated tool \\
\hline Protection against contamination & Low risk & Randomised at practice level \\
\hline
\end{tabular}

Trygstad 2005 
Interventions to improve the appropriate use of polypharmacy for older people

\begin{tabular}{|c|c|}
\hline Methods & $\begin{array}{l}\text { Study design: controlled before-after study } \\
\text { Unit of allocation/analysis: participant } \\
\text { Follow-up: } 3 \text { months, March to June } 2003 \\
\text { Duration: } 6 \text { months } \\
\text { Providers: pharmacists }\end{array}$ \\
\hline Participants & $\begin{array}{l}\text { Setting/participants: medicaid-dependent nursing home residents from } 253 \text { nursing } \\
\text { homes in North Carolina } \\
\text { Focus on polypharmacy: participants had } 18 \text { or more prescription fills in the } 90 \text {-day } \\
\text { period before the start of the study } \\
\text { Age (mean } \pm \text { SD): } 77.57 \pm 12.72 \text { years } \\
\text { Male: } 24.98 \%\end{array}$ \\
\hline Interventions & $\begin{array}{l}\text { Model of pharmaceutical care: consultant pharmacists performed a comprehensive } \\
\text { profile review of the computerised drug profiles of selected participants using a range } \\
\text { of tools such as the Beers criteria and made recommendations to prescribers } \\
\text { Training: no educational intervention was specified } \\
\text { Timing of intervention: over a } 6 \text { months period } \\
\text { Quote: "An on-site drug profile review was completed by pharmacists. A toolkit with } \\
\text { instructions for documenting and screening criteria, used to flag drugs, was given to } \\
\text { pharmacists. Pharmacists were also provided with computer-generated drug profiles } \\
\text { from Medicaid pharmacy claims that displayed flags for patients and suggestions for } \\
\text { modification of drugs and classes of drugs. Drug profiles were a compilation of all } \\
\text { drugs forwhich a claimwas paid in the } 90 \text { days beforegeneration regardless of the } \\
\text { presence of } \neg \text { an alert. The first alert criterion was receipt of a drug widely considered to } \\
\text { be inappropriate for use in the elderly (Beers list drug). The second criterion was } \\
\text { receipt of a drug on the community care of North Carolina prescription advantage list } \\
\text { (PAL), which encourages substitution of a less expensivedrug within atherapeutic } \\
\text { class. The third criterion was appearance of a drug on the clinical initiatives list, which } \\
\text { includes } 16 \text { drugs that had potential for quality improvement and cost savings. } \\
\text { Pharmacists were asked to record the result of the review and the result of the } \\
\text { consultation with the prescribing physician. If an intervention resulted ina drugtherapy } \\
\text { change of any type, the new drug, dose and quantity were noted. Drug dose and } \\
\text { quantity were also reported for each new drug added for previously untreated } \\
\text { indications" }\end{array}$ \\
\hline Outcomes & $\begin{array}{l}\text { Number of Beers list drugs per participant, number of PAL list alerts, potential } \\
\text { medication problems categorised as 'consider duration' (of therapy), 'clinical initiatives' } \\
\text { and 'therapeutic duplication' }\end{array}$ \\
\hline Notes & \\
\hline
\end{tabular}

Risk of bias table 
Interventions to improve the appropriate use of polypharmacy for older people

\begin{tabular}{|c|c|c|}
\hline Bias & $\begin{array}{l}\text { Authors' } \\
\text { judgement }\end{array}$ & Support for judgement \\
\hline $\begin{array}{l}\text { Random sequence generation } \\
\text { (selection bias) }\end{array}$ & High risk & $\begin{array}{l}\text { Quote: "The comparison group consisted of patients in nursing homes } \\
\text { not responding to the invitation for inclusion in phase } 1 \text { of the } \\
\text { intervention" }\end{array}$ \\
\hline $\begin{array}{l}\text { Allocation concealment (selection } \\
\text { bias) }\end{array}$ & Unclear risk & Quote: "Pharmacist and physician prescriber knew the allocation" \\
\hline $\begin{array}{l}\text { Blinding of participants and } \\
\text { personnel (performance bias) }\end{array}$ & Unclear risk & Insufficient information to permit judgement \\
\hline $\begin{array}{l}\text { Blinding of outcome assessment } \\
\text { (detection bias) }\end{array}$ & Unclear risk & Insufficient information to permit judgement \\
\hline $\begin{array}{l}\text { Incomplete outcome data (attrition } \\
\text { bias) }\end{array}$ & Low risk & Dropout rates were similar between groups \\
\hline Selective reporting (reporting bias) & Unclear risk & Not stated, not registered, Insufficient information to permit judgement \\
\hline Baseline characteristics similar? & High risk & $\begin{array}{l}\text { Baseline demographic differences existed between intervention and } \\
\text { control groups. No reported adjustment of results to accountfor baseline } \\
\text { differences in analysis }\end{array}$ \\
\hline Reliable Primary outcome measure & Low risk & The Beers drug list, which is a validated instrument, was used \\
\hline Protection against contamination & Unclear risk & $\begin{array}{l}\text { Unclear as study authors stated that comparison group homes } \\
\text { participated after } 6 \text { months }\end{array}$ \\
\hline
\end{tabular}

Trygstad 2009 
Interventions to improve the appropriate use of polypharmacy for older people

\begin{tabular}{|c|c|}
\hline Methods & $\begin{array}{l}\text { Study design: controlled before-after study } \\
\text { Unit of allocation/analysis: participant } \\
\text { Follow-up: } 3 \text { months } \\
\text { Duration: } 3 \text { months } \\
\text { Providers: pharmacists }\end{array}$ \\
\hline Participants & $\begin{array}{l}\text { Setting/ participants: medicaid-dependent nursing home residents in North Carolina } \\
\text { Focus on polypharmacy: patients were included if they had } 18 \text { or more drug fills in the } \\
90 \text { days immediately preceding the intervention } \\
\text { Age (mean): } 77.6 \text { years } \\
\text { Male: } 24.9 \%\end{array}$ \\
\hline Interventions & $\begin{array}{l}\text { Model of pharmaceutical care: consultant pharmacists performed a comprehensive } \\
\text { profile review of the computerised drug profiles of selected participants using a range } \\
\text { of tools such as the Beers criteria and made recommendations to prescribers } \\
\text { Training: no educational intervention was specified } \\
\text { Timing of intervention: administered during a single nursing home visit } \\
\text { Quote: "Prescription drug records of all North Carolina nursing facilities were retrieved } \\
\text { from Medicaid claims databases for the period August } 2002 \text { to April } 2003 \text {. This period } \\
\text { encompassed the } 90 \text {-day baseline, the } 90 \text {-day intervention and the } 90 \text {-day } \\
\text { postintervention periods to allow for a difference in difference (DID) with a comparison } \\
\text { group study method. Targeted ('value added') drug regimen reviews (DRRs) were } \\
\text { performed during the routine monthly DRRs required by Omnibus Budget } \\
\text { Reconciliation Act (OBRA) nursing facility guidelines. Drug claims data were used to } \\
\text { create drug profiles that contained cost-and quality-focussed alerts for patients with } \\
18 \text { or more drug fills in the } 90 \text { days immediately preceding the intervention. Computer } \\
\text { algorithms were used to screen profiles for } 5 \text { types of drug alerts: Beers drug alerts, } \\
\text { prescription advantage list (PAL) alerts, Clinical Initiatives alerts, duration alerts for } \\
\text { specific drugs and therapeutic duplication alerts. Alerts were generated retrospectively } \\
\text { from claims data and were provided to consultant pharmacists for their retrospective } \\
\text { reviews, together with residents' most recent drug claims profiles. These profiles were } \\
\text { comprehensive in nature and considered all drugs on a resident's profile regardless of } \\
\text { the presence or absence of an alert. The prospective component of the study allowed } \\
\text { a pharmacist to intervene and request a drug change for new medication orders that } \\
\text { cameinto the dispensing facility, using the same alerting-targeting criteriadeveloped } \\
\text { for the retrospective, computer-generated drug profiles. Some residents received only } \\
\text { retrospective reviews and interventions, some received onlyprospective interventions } \\
\text { and some received both" }\end{array}$ \\
\hline Outcomes & $\begin{array}{l}\text { Number of Beers list drugs per participant, number of PAL list alerts, potential } \\
\text { medication problems categorised as 'consider duration' (of therapy), 'clinical initiatives' } \\
\text { and 'therapeutic duplication' }\end{array}$ \\
\hline Notes & \\
\hline
\end{tabular}

Risk of bias table 
Interventions to improve the appropriate use of polypharmacy for older people

\begin{tabular}{|c|c|c|}
\hline Bias & \begin{tabular}{|l} 
Authors' \\
judgement
\end{tabular} & Support for judgement \\
\hline $\begin{array}{l}\text { Random sequence generation } \\
\text { (selection bias) }\end{array}$ & High risk & $\begin{array}{l}\text { Quote: "Comparison group residents were drawn from non-participating } \\
\text { long-term care facilities" }\end{array}$ \\
\hline $\begin{array}{l}\text { Allocation concealment (selection } \\
\text { bias) }\end{array}$ & Unclearrisk & $\begin{array}{l}\text { Quote: "Consultant pharmacists performed targeted, value-added drug } \\
\text { regimen reviews for selected Medicaid-dependent residents. It is not } \\
\text { clearwhetherconsultant pharmacists worked in both intervention and } \\
\text { control homes" }\end{array}$ \\
\hline $\begin{array}{l}\text { Blinding of participants and } \\
\text { personnel (performance bias) }\end{array}$ & Unclearrisk & Insufficient information to permit judgement \\
\hline $\begin{array}{l}\text { Blinding ofoutcome assessment } \\
\text { (detection bias) }\end{array}$ & Unclearrisk & Insufficient information to permit judgement \\
\hline $\begin{array}{l}\text { Incomplete outcome data (attrition } \\
\text { bias) }\end{array}$ & Unclearrisk & 63 residents had a prospective review \\
\hline Selective reporting (reporting bias) & Unclearrisk & Insufficient information to permit judgement \\
\hline Baseline characteristics similar? & Low risk & $\begin{array}{l}\text { Quote: "After propensity scoring was complete, both study and potential } \\
\text { comparison subjects were matched using Mahalanobis metric matching } \\
\text { to achieve balance among baseline characteristics" }\end{array}$ \\
\hline Reliable Primary outcome measure & Low risk & Beers criteria \\
\hline Protection against contamination & Unclearrisk & $\begin{array}{l}\text { Not clear whether consultant pharmacists worked in both intervention } \\
\text { and control homes }\end{array}$ \\
\hline
\end{tabular}

Van der Linden 2017 
Interventions to improve the appropriate use of polypharmacy for older people

\begin{tabular}{|c|c|}
\hline Methods & $\begin{array}{l}\text { Study design: non-randomised trial } \\
\text { Unit of allocation/analysis: patient } \\
\text { Follow-up: 3-months post-discharge } \\
\text { Duration: unclear } \\
\text { Providers: clinical pharmacists }\end{array}$ \\
\hline Participants & $\begin{array}{l}\text { Setting/participants: } 214 \text { older patients ( } 117 \text { intervention and } 97 \text { control) recruited from } \\
\text { three acute geriatric wards of a } 2000 \text {-bed university hospital in Flanders, Belgium } \\
\text { Focus on polypharmacy: number of drugs at baseline [median (IQR)], } 9 \text { (7 to 12) } \\
\text { intervention, } 10 \text { ( } 7 \text { to } 13 \text { ) control } \\
\text { Age (mean } \pm \text { SD): } 84.5 \pm 4.69 \text { years intervention, } 84.5 \pm 4.97 \text { years control } \\
\text { Male: } 52 \% \text { intervention, } 44 \% \text { control } \\
\text { Ethnicity: not reported }\end{array}$ \\
\hline Interventions & $\begin{array}{l}\text { Model of pharmaceutical care: clinical pharmacists performing medication } \\
\text { reconciliation and a comprehensive medication reviewwhich were discussed with the } \\
\text { treating physician } \\
\text { Training: no educational intervention was specified } \\
\text { Timing of intervention: during inpatient stay } \\
\text { Quote: "Intervention consisted of trained clinical pharmacists (EB, SD, KW, LD, LVDL) } \\
\text { performing medication reconciliation with a subsequent two-stage medication review. } \\
\text { The reconciled drug information was registered in the electronic patient file. In a first } \\
\text { step of the medication review, the RASP list was applied. All pharmacists were trained } \\
\text { in the use of the RASP list after having received the necessary introductory courses by } \\
\text { the senior pharmacists (LVDL, LD). A second step comprised an additional } \\
\text { comprehensive medication review by the clinical pharmacist, covering mistreatment } \\
\text { (e.g. use of antipsychotic drugs in the treatment of agitation in patients with dementia), } \\
\text { overtreatment(e.g. prolongeduse of proton pumpinhibitors), as well as potential } \\
\text { undertreatment (e.g. no use of anticoagulation in atrial fibrillation). Training of the } \\
\text { clinical pharmacists was overseen by senior pharmacists (LVDL, LD) and geriatricians } \\
\text { JT, JF). In addition, senior pharmacists (LVDL, LD) attended ward rounds } \\
\text { systematically to ensure correct study conduct. In the intervention group, } \\
\text { recommendations were actively reported to the treating physician on a daily basis. It } \\
\text { was left to the discretion of the treating physician as to whether to follow the } \\
\text { pharmaceutical recommendations. Accepted recommendations were included in the } \\
\text { discharge letter to the general practitioner" } \\
\text { Subjects enrolled in the control arm underwent usual medical and pharmaceutical care } \\
\text { with registration of drug use at admission and discharge without interference of RASP } \\
\text { or clinical pharmacist }\end{array}$ \\
\hline Outcomes & $\begin{array}{l}\text { The number of RASP PIMs } \\
\text { Quality of life }\end{array}$ \\
\hline Notes & \\
\hline
\end{tabular}

Risk of bias table 
Interventions to improve the appropriate use of polypharmacy for older people

\begin{tabular}{|c|c|c|}
\hline Bias & \begin{tabular}{|l} 
Authors' \\
judgement
\end{tabular} & Support for judgement \\
\hline $\begin{array}{l}\text { Random sequence generation } \\
\text { (selection bias) }\end{array}$ & High risk & Quote: "No active randomization was performed" \\
\hline $\begin{array}{l}\text { Allocation concealment (selection } \\
\text { bias) }\end{array}$ & High risk & $\begin{array}{l}\text { Quote: "Allocation to the intervention versus the control arm was based } \\
\text { on consecutive admissions to one control and two intervention wards" }\end{array}$ \\
\hline $\begin{array}{l}\text { Blinding of participants and } \\
\text { personnel (performance bias) }\end{array}$ & Unclear risk & Insufficient information to permit judgement \\
\hline $\begin{array}{l}\text { Blinding ofoutcome assessment } \\
\text { (detection bias) }\end{array}$ & Unclear risk & Insufficient information to permit judgement \\
\hline $\begin{array}{l}\text { Incomplete outcome data (attrition } \\
\text { bias) }\end{array}$ & Low risk & $\begin{array}{l}\text { Missing outcome data balanced in numbers across intervention groups, } \\
\text { with similar reasons for missing data across groups }\end{array}$ \\
\hline Selective reporting (reporting bias) & Low risk & $\begin{array}{l}\text { The study trial registry is available and all of the study's pre-specified } \\
\text { (primary and secondary) outcomes that are of interest in the review } \\
\text { have been reported }\end{array}$ \\
\hline Baseline characteristics similar? & Low risk & $\begin{array}{l}\text { Baseline participant characteristics were reported. No statistically } \\
\text { significant differences in baseline demographics between the two study } \\
\text { groups }\end{array}$ \\
\hline Reliable Primary outcome measure & Low risk & RASP is a validated tool \\
\hline Protection against contamination & High risk & Monocentric study with potential for contamination \\
\hline
\end{tabular}

Wehling 2016 
Interventions to improve the appropriate use of polypharmacy for older people

\begin{tabular}{|c|c|}
\hline Methods & $\begin{array}{l}\text { Study design: randomised trial } \\
\text { Unit of allocation/analysis: participant } \\
\text { Follow-up: unclear, admission to discharge i.e. duration of stay } \\
\text { Duration: unclear, admission to discharge i.e. duration of stay } \\
\text { Providers: ward physicians' }\end{array}$ \\
\hline Participants & $\begin{array}{l}\text { Setting/participants: } 409 \text { patients ( } 202 \text { intervention, } 207 \text { control) aged }>65 \text { years who } \\
\text { were consecutively admitted to the geriatric departments in Germany } \\
\text { Focus on polypharmacy: number of patients with } 6-10 \text { medications (\%), } 55.0 \% \\
\text { intervention, } 56.5 \% \text { control } \\
\text { Age (mean): } 84 \text { intervention, } 82 \text { control (see notes) } \\
\text { Male: } 36.6 \% \text { intervention, } 34.3 \% \text { control } \\
\text { Ethnicity: no information given }\end{array}$ \\
\hline Interventions & $\begin{array}{l}\text { Model of pharmaceutical care: medicine reviews were undertaken by the doctor } \\
\text { Training: physician education provided during the study } \\
\text { Timing of intervention: during inpatient stay } \\
\text { Quote: "On the intervention ward (FORTA group), physician education was structured } \\
\text { and continuously provided during the study. The physicians were formally instructed } \\
\text { about the FORTA-principleand provided with the relating documents (publications, } \\
\text { current FORTA-list) by } 2 \text { lectures before the study commenced. They convened with } \\
\text { the FORTA intervention team (study physicians) on a weekly basis (PharmaBoard) to } \\
\text { review information, to collect data on patients included in the study and to discuss } \\
\text { medication plans with respect to the FORTA system. Though individual } \\
\text { recommendations may have been issued ward physicians were free to adopt them or } \\
\text { not. The FORTA intervention team had no power and legal sanction to modify } \\
\text { medication plans. The ward physicians' own judgement was leading over FORTA- } \\
\text { based suggestions in the process of finding the appropriate medication } \\
\text { On the control ward all patients were treated based on established medical standards } \\
\text { and on the principles of good medical practice" }\end{array}$ \\
\hline Outcomes & $\begin{array}{l}\text { The quality of medications was assessed by the FORTA-score. Secondary endpoints } \\
\text { were the impact of FORTA on ADR and clinical outcomes }\end{array}$ \\
\hline Notes & \\
\hline
\end{tabular}

Risk of bias table 


\begin{tabular}{|c|c|c|}
\hline Bias & $\begin{array}{l}\text { Authors' } \\
\text { judgement }\end{array}$ & Support for judgement \\
\hline $\begin{array}{l}\text { Random sequence generation } \\
\text { (selection bias) }\end{array}$ & High risk & $\begin{array}{l}\text { Quote: "Randomization had to be guided by random availability of beds on } \\
\text { one ward only with the other ward being inaccessible at admission and this } \\
\text { may have resulted in observed heterogeneities between the control and } \\
\text { intervention groups at baseline" }\end{array}$ \\
\hline $\begin{array}{l}\text { Allocation concealment (selection } \\
\text { bias) }\end{array}$ & Low risk & $\begin{array}{l}\text { Quote: "The assignment was performed by a manager blinded to the } \\
\text { purpose of the study" }\end{array}$ \\
\hline $\begin{array}{l}\text { Blinding of participants and } \\
\text { personnel (performance bias) }\end{array}$ & High risk & $\begin{array}{l}\text { Quote: "Study described as an "open randomized controlled trial". No } \\
\text { apparent blinding of physicians based on intervention ward: on the } \\
\text { intervention ward (FORTA group), physician education was structured and } \\
\text { continuously provided during the study. The physicians were formally } \\
\text { instructed about the FORTA-principle and provided with the relating } \\
\text { documents (publications, currentFORTA-list) by } 2 \text { lectures before the } \\
\text { study commenced. They convened with the FORTA intervention team } \\
\text { (study physicians) on a weekly basis (PharmaBoard) to review information, } \\
\text { to collect data on patients included in the study and to discuss medication } \\
\text { plans with respect to the FORTA system" }\end{array}$ \\
\hline \multirow[t]{2}{*}{$\begin{array}{l}\text { Blinding of outcome assessment } \\
\text { (detection bias) }\end{array}$} & \multirow[t]{2}{*}{ Low risk } & $\begin{array}{l}\text { Quote: "The assessment of medication quality and the adjudication of } \\
\text { adversedrug reactions / clinicalendpoints were performed by FORTA- } \\
\text { trained physicians whowere not involved in patient recruitment, ward } \\
\text { instruction on the study conduct and patient interviewing; thus, this could } \\
\text { be done in a blinded manner after discharge of the patient on the base of a } \\
\text { note and data review to avoid bias }\end{array}$ \\
\hline & & $\begin{array}{l}\text { In addition, patients were asked for ADR and clinical records searched for } \\
\text { related entries by the study team that was not blinded but did not } \\
\text { participate in the endpoint adjudication as described above" }\end{array}$ \\
\hline $\begin{array}{l}\text { Incomplete outcome data (attrition } \\
\text { bias) }\end{array}$ & Low risk & No missing data reported \\
\hline Selective reporting (reporting bias) & Low risk & $\begin{array}{l}\text { The study protocol is available and all of the study's pre-specified (primary } \\
\text { and secondary) outcomes that are of interest in the review have been } \\
\text { reported }\end{array}$ \\
\hline Baseline characteristics similar? & High risk & $\begin{array}{l}\text { Baseline demographic differences existed between intervention and } \\
\text { controlgroups. No reported adjustment of results to account for baseline } \\
\text { differences in analysis }\end{array}$ \\
\hline Reliable Primary outcome measure & Low risk & $\begin{array}{l}\text { Validated assessment tool used to assess appropriateness of prescribing } \\
\text { (FORTA-list) }\end{array}$ \\
\hline Protection against contamination & High risk & $\begin{array}{l}\text { Increasing contamination of the control ward by the intervention prevented } \\
\text { the study authors from extending the recruitment period Authors report that } \\
\text { during the study, teams on the control ward seemed to have increasingly } \\
\text { acquired skills and knowledge from the other ward by migration and / or } \\
\text { communication }\end{array}$ \\
\hline
\end{tabular}

Footnotes

ACOVE: Assessing Care of the Vulnerable Elderly; ADEs: adverse drug events; AUM: Under-utilisation of Medication; CDS: computerised decision support;CDSS: computerised decision support; Cl: confidence interval; cRCT: cluster-randomised controlled trial; DID: difference in difference.; DDIs: drug-drug interaction; DRPs: drug-related problems; eGFR: estimated glomerular filtration rate; EHR: electronic health record; EMR: electronic medical record; FORTA: Fit forThe Aged; GP: general practitioner; HCA: healthcare assistant; HRQoL: health-related quality of life; IGCT: in patient geriatric consultation team; IPET: Inappropriate Prescribing in the Elderly Tool; IQR: interquartile range; ITT: intention-to-treat; MAI: Medication Appropriateness Index; MARS: Morisky the Medication Adherence Rating Scale; MTM: medication therapy management; NHBPS: Nursing Home Behavior Problem Scale; OBRA: Omnibus Budget Reconciliation Act; PAL: Prescription Advantage List; PIMs: Potentially inappropriate medications; PIP: potentially inappropriate prescribing; PPOs: potential prescribing 
omissions; RAMQ: Régie de l'assurance maladie du Québec; RASP: Rationalization of home medication by an Adjusted STOPP in older Patients; SD: standard deviation; SF-36: Short form 36; STOPP: Screening Tool of Older Person's

Prescriptions; TRIM: Tool to Reduce Inappropriate Medication

Characteristics of excluded studies

Aitichou 2015

\begin{tabular}{|l|l|}
\hline Reason for exclusion & No appropriate data \\
\hline
\end{tabular}

\section{Alassaad 2014}

\begin{tabular}{|l|l} 
Reason for exclusion & Outcome measure. No prospective assessment of appropriateness
\end{tabular}

\section{Alexopoulos 2008}

\begin{tabular}{|l|l} 
Reason for exclusion $\quad$ Not polypharmacy focus. No measure of appropriateness
\end{tabular}

\section{Alkema 2006}

\begin{tabular}{|l|l}
\hline Reason for exclusion & Unsuitable study design. No measure of appropriateness
\end{tabular}

\section{Allard 2001}

Reason for exclusion

Allen 1986

Reason for exclusion

Outcome measure. No measure of appropriateness

\section{Allen 2011}

\begin{tabular}{|l|l|}
\hline Reason for exclusion & $\begin{array}{l}\text { No data. Outcome measure: appropriateness criteria notvalidated(structured around } \\
\text { ACOVEguidelines but also included evidence-based protocols developed bythe } \\
\text { research team based on literature review) }\end{array}$
\end{tabular}

\section{Allen 2012}

Reason for exclusion No data. Outcome measure. No measure of appropriateness

\section{Altiner 2012}

\begin{tabular}{|l|l}
\hline Reason for exclusion $\quad$ No data. Outcome measure. No measure of appropriateness \\
\hline
\end{tabular}

\section{Anonymous 2005}

\begin{tabular}{|l|l|}
\hline Reason for exclusion $\quad$ No appropriate data \\
\hline
\end{tabular}

\section{Anonymous 2011}

\begin{tabular}{|l|l}
\hline Reason for exclusion & $\begin{array}{l}\text { No data. Erratum referred tolist of multiple choice questions published in Journal of } \\
\text { the American Academy of Physician Assistants }\end{array}$
\end{tabular}

\section{Anonymous 2012}

Reason for exclusion


Interventions to improve the appropriate use of polypharmacy for older people

\begin{tabular}{l|l}
\hline Reason for exclusion $\quad$ No appropriate data \\
\hline
\end{tabular}

Anrys 2015

\begin{tabular}{|l|l}
\hline Reason for exclusion $\quad$ No appropriate data \\
\hline
\end{tabular}

Arvisais 2015

\begin{tabular}{|l|l|}
\hline Reason for exclusion & Outcome measure. No measure of appropriateness \\
\hline
\end{tabular}

\section{Atkin 1996}

\begin{tabular}{|l|l}
\hline Reason for exclusion & Outcome measure. No measure of appropriateness
\end{tabular}

\section{Avorn 1992}

\begin{tabular}{|l|l}
\hline Reason for exclusion & Outcome measure. Appropriateness criteria not validated (expert opinion)
\end{tabular}

\section{Bartlett 2008}

\begin{tabular}{|l|l}
\hline Reason for exclusion & Unsuitable study design. No measure of appropriateness
\end{tabular}

\section{Beckett 2012}

Reason for exclusion

Outcome measure. Appropriateness criteria not validated (expert opinion)

\section{Beer 2011}

Reason for exclusion Outcome measure. No measure of appropriateness

\section{Bell 2011}

\begin{tabular}{|l|l}
\hline Reason for exclusion & No appropriate data. No measure of appropriateness
\end{tabular}

\section{Bergert 2014}

\begin{tabular}{|l|l}
\hline Reason for exclusion $\quad$ No appropriate data &
\end{tabular}

\section{Blais 2008}

\begin{tabular}{|l|l}
\hline Reason for exclusion & $\begin{array}{l}\text { Participants tooyoung. Not polypharmacy focus. Appropriateness of asthma } \\
\text { medication only }\end{array}$
\end{tabular}

\section{Bloomfield 2005}

Reason for exclusion

\section{Bosma 2008}

Reason for exclusion

\section{Buckmaster 2006}

Reason for exclusion
Not polypharmacy focus. No measure of appropriateness

Unsuitable study design. Appropriateness criteria not validated (WinAPHigh Risk Medicines; list of 14 high-risk medicines based on a list compiled by the Dutch Scientific Institute for Pharmacy)

Not polypharmacy focus. Participants tooyoung. No measure of appropriateness 
Interventions to improve the appropriate use of polypharmacy for older people

\begin{tabular}{|l|l}
\hline Reason for exclusion & Participants too young
\end{tabular}

Burns 1995

Reason for exclusion

Outcome measure. No measure of appropriateness

Carey 2008

\begin{tabular}{|l|l}
\hline Reason for exclusion & Unsuitable study design. No measure of appropriateness
\end{tabular}

Claesson 1998

\begin{tabular}{|l|l}
\hline Reason for exclusion & Outcome measure. Appropriateness criteria not validated (expert opinion)
\end{tabular}

Clyne 2013

\begin{tabular}{|l|l}
\hline Reason for exclusion & No data. Not polypharmacy focus
\end{tabular}

Clyne 2013a

\begin{tabular}{|l|l}
\hline Reason for exclusion & No appropriate data
\end{tabular}

Coleman 1999

Reason for exclusion

Outcome measure. Appropriateness criteria not validated (expert opinion)

Colpaert 2006

Reason for exclusion

Unsuitable study design. No measure of appropriateness

Corbi 2015

\begin{tabular}{|l|l}
\hline Reason for exclusion & Unsuitable study design
\end{tabular}

Courtenay 2007

\begin{tabular}{|l|l}
\hline Reason for exclusion $\quad$ Not polypharmacy focus. No measure of appropriateness
\end{tabular}

Darcy 2014

\begin{tabular}{|l|l}
\hline Reason for exclusion & No appropriate data
\end{tabular}

Davis 2007

\begin{tabular}{|l|l}
\hline Reason for exclusion & Unsuitable study design
\end{tabular}

Delate 2008

Reason for exclusion

Unsuitable study design. No measure of appropriateness

Denneboom 2007

Reason for exclusion

Outcome measure. No measure of appropriateness

Der 1997

Reason for exclusion

Outcome measure. Appropriateness criteria not validated (unnecessary drugs) 
Desborough 2014

\begin{tabular}{|l|l|}
\hline Reason for exclusion & No appropriate data \\
\hline
\end{tabular}

\section{Di Marzio 2012}

\begin{tabular}{l|l}
\hline Reason for exclusion $\quad$ No appropriate data &
\end{tabular}

Diaz 2003

\begin{tabular}{|l|l}
\hline Reason for exclusion $\quad$ Unsuitable study design. No measure of appropriateness \\
\hline
\end{tabular}

Dresden 2013

\begin{tabular}{|l|l}
\hline Reason for exclusion & Unsuitable design. No appropriate data
\end{tabular}

\section{Easthall 2014}

Reason for exclusion

Eckert 1991

\begin{tabular}{|l|l}
\hline Reason for exclusion $\quad$ No appropriate data &
\end{tabular}

Edmans 2013

\begin{tabular}{|l|l}
\hline Reason for exclusion & Outcome measure. No measure of appropriateness
\end{tabular}

\section{Elliott 2012}

\begin{tabular}{|l|l}
\hline Reason for exclusion & Outcome measure. No measure of appropriateness
\end{tabular}

\section{Eriksson 2012}

\begin{tabular}{|l|l}
\hline Reason for exclusion & No appropriate data
\end{tabular}

\section{Essock 2011}

Reason for exclusion Outcome measure. No measure of appropriateness. Antipsychotic polypharmacy

\section{Farris 2014}

Reason for exclusion Unsuitable study design

\section{Feder 1999}

Reason for exclusion Not polypharmacy focus. Outcome measure. No measure of appropriateness

Feldstein 2006

\begin{tabular}{|l|l}
\hline Reason for exclusion & Unsuitable study design. No measure of appropriateness
\end{tabular}

\section{Fick 2004}

\begin{tabular}{|l|l}
\hline Reason for exclusion $\quad$ Unsuitable study design \\
\hline
\end{tabular}


Interventions to improve the appropriate use of polypharmacy for older people

Reason for exclusion Unsuitable study design. No measure of appropriateness

Flores Dorado 2013

\begin{tabular}{|l|l}
\hline Reason for exclusion & Unsuitable study design
\end{tabular}

Fontaine 2006

\begin{tabular}{|l|l|}
\hline Reason for exclusion & Not polypharmacy focus. No measure of appropriateness
\end{tabular}

Frankenthal 2014a

\begin{tabular}{|l|l|}
\hline Reason for exclusion $\quad$ No appropriate data \\
\hline
\end{tabular}

Freeman 2012

\begin{tabular}{|l|l}
\hline Reason for exclusion $\quad$ No appropriate data \\
\hline
\end{tabular}

Frohnhofen 2013

\begin{tabular}{l|l}
\hline Reason for exclusion $\quad$ No appropriate data \\
\hline
\end{tabular}

Gaede 2008

Reason for exclusion

Not polypharmacy focus. No measure of appropriateness

Galindo-Ocana 2010

\begin{tabular}{|l|l}
\hline Reason for exclusion $\quad$ Unsuitable study design \\
\hline
\end{tabular}

Ganz 2010

\begin{tabular}{|l|l}
\hline Reason for exclusion & Unsuitable design. Not polypharmacy focus
\end{tabular}

Garcia 2013

\begin{tabular}{l|l}
\hline Reason for exclusion $\quad$ No appropriate data
\end{tabular}

Garcia 2014

\begin{tabular}{|l|l}
\hline Reason for exclusion $\quad$ No appropriate data
\end{tabular}

Garcia 2015

\begin{tabular}{|l|l}
\hline Reason for exclusion & Outcome measure. No measure of appropriateness
\end{tabular}

Garfinkel 2007

Reason for exclusion

Unsuitable study design. No measure of appropriateness

Gerber 2008

Reason for exclusion

Unsuitable study design. No measure of appropriateness

Geurts 2015

Reason for exclusion

Outcome measure. No measure of appropriateness 
Geurts 2016

\begin{tabular}{|l|l|}
\hline Reason for exclusion & Outcome measure. No measure of appropriateness \\
\hline
\end{tabular}

Gill 2001

\begin{tabular}{|l|l}
\hline Reason for exclusion & $\begin{array}{l}\text { Unsuitable study design. Appropriateness criteria not validated (Improved Prescribing } \\
\text { in the Elderly Tool (IPET)-improved prescriptions in the elderly tool) }\end{array}$
\end{tabular}

Gillespie 2009

Reason for exclusion

Outcome measure. No prospective assessment of appropriateness

Gillespie 2017

\begin{tabular}{|l|l|}
\hline Reason for exclusion & No appropriate data \\
\hline
\end{tabular}

Ginzburg 2012

\begin{tabular}{|l|l|}
\hline Reason for exclusion & No appropriate data \\
\hline
\end{tabular}

Gislason 2007

\begin{tabular}{|l|l}
\hline Reason for exclusion $\quad$ Unsuitable study design. No measure of appropriateness \\
\hline
\end{tabular}

\section{Giunta 2015}

\begin{tabular}{|l|l}
\hline Reason for exclusion & Outcome measure. No measure of appropriateness
\end{tabular}

\section{Gorup 2012}

\begin{tabular}{|l|l|}
\hline Reason for exclusion & No data. Protocol changed
\end{tabular}

\section{Gradman 2002}

Reason for exclusion

Graffen 2004

\begin{tabular}{|l|l}
\hline Reason for exclusion & Outcome measure. No measure of appropriateness
\end{tabular}

Gramage 2014

\begin{tabular}{|l|l|}
\hline Reason for exclusion & Outcome measure. No measure of appropriateness. Unsuitable study design
\end{tabular}

Guptha 2003

\begin{tabular}{|l|l|}
\hline Reason for exclusion & $\begin{array}{l}\text { Unsuitablestudy design. Appropriateness criterianot validated (algorithms to assess } \\
\text { appropriateness) }\end{array}$ \\
\hline
\end{tabular}

Gwadry-Sridhar 2005

Reason for exclusion

Outcome measure. No measure of appropriateness

Hamilton 2007

Reason for exclusion

Notpolypharmacy focus. Participants tooyoung. No measure of appropriateness 


\begin{tabular}{|l|l|}
\hline Reason for exclusion & No appropriate data \\
\hline
\end{tabular}

\section{Hawes 2014}

\begin{tabular}{|l|l}
\hline Reason for exclusion & Outcome measure. No measure of appropriateness
\end{tabular}

\section{Hellstrom 2011}

\begin{tabular}{|l|l}
\hline Reason for exclusion & Unsuitable design
\end{tabular}

\section{Hobbs 2006}

Reason for exclusion Unsuitable study design. No measure of appropriateness

Hogg 2009

\begin{tabular}{|l|l|}
\hline Reason for exclusion & Outcome measure. Validated appropriateness criteria not applied to control group
\end{tabular}

Houghton 2014

\begin{tabular}{|l|l|}
\hline Reason for exclusion & No appropriate data \\
\hline
\end{tabular}

\section{Howard 2014}

\begin{tabular}{|l|l}
\hline Reason for exclusion & Unsuitable study design
\end{tabular}

\section{Hugtenburg 2017}

Reason for exclusion

\section{Humphries 2007}

Reason for exclusion

\section{Hung 2012}

Reason for exclusion

\section{Ilic 2015}

\begin{tabular}{|l|l|}
\hline Reason for exclusion & Unsuitable study design \\
\hline
\end{tabular}

\section{Izquierdo 2007}

\begin{tabular}{|l|l}
\hline Reason for exclusion & Not polypharmacy focus. No measure of appropriateness
\end{tabular}

\section{Jabalquinto 2007}

\begin{tabular}{|l|l}
\hline Reason for exclusion & Unsuitable study design. No measure of appropriateness
\end{tabular}

\section{Jean-Bart 2014}

\begin{tabular}{l|l} 
Reason for exclusion $\quad$ No appropriate data &
\end{tabular}


Interventions to improve the appropriate use of polypharmacy for older people

\begin{tabular}{|l|l|}
\hline Reason for exclusion & Unsuitable study design. No measure of appropriateness \\
\hline
\end{tabular}

\section{Juola 2015}

\begin{tabular}{|l|l}
\hline Reason for exclusion & No appropriate data
\end{tabular}

\section{Jódar-Sánchez 2015}

\begin{tabular}{|l|l}
\hline Reason for exclusion & Outcome measure. No measure of appropriateness
\end{tabular}

\section{Kaboli 2004}

\begin{tabular}{|l|l}
\hline Reason for exclusion & Outcome measure. No measure of appropriateness
\end{tabular}

\section{Kairuz 2008}

\begin{tabular}{|l|l}
\hline Reason for exclusion $\quad$ Unsuitable study design. No measure of appropriateness \\
\hline
\end{tabular}

\section{Kashyap 2015}

\begin{tabular}{|l|l}
\hline Reason for exclusion $\quad$ No appropriate data \\
\hline
\end{tabular}

\section{Kassam 2001}

Reason for exclusion Unsuitable study design. No measure of appropriateness

\section{Kassam 2003}

\begin{tabular}{|l|l|}
\hline Reason for exclusion & Unsuitable study design \\
\hline
\end{tabular}

\section{Kastrissios 1998}

\begin{tabular}{|l|l}
\hline Reason for exclusion & Outcome measure. No measure of appropriateness
\end{tabular}

\section{Katzourakis 2010}

\begin{tabular}{|l|l}
\hline Reason for exclusion $\quad$ No appropriate data &
\end{tabular}

Kavanagh 2014

\begin{tabular}{l|l}
\hline Reason for exclusion $\quad$ No appropriate data &
\end{tabular}

\section{Keith 2013}

\begin{tabular}{|l|l}
\hline Reason for exclusion & Unsuitable design \\
\hline
\end{tabular}

\section{Keller 2012}

Reason for exclusion Outcome measure. Appropriateness criteria not validated (baseline risk strategy). Participants too young

\section{Key 2010}

\begin{tabular}{|l|l}
\hline Reason for exclusion & Unsuitable design
\end{tabular}


Interventions to improve the appropriate use of polypharmacy for older people

\begin{tabular}{|l|l|}
\hline Reason for exclusion & Unsuitable study design. No measure of appropriateness \\
\hline
\end{tabular}

\section{Klopotowska 2011}

\begin{tabular}{|l|l} 
Reason for exclusion $\quad$ No data. Outcome measure. Appropriatenes criteria not validated (expert opinion) \\
\hline
\end{tabular}

Kojima 2012

\begin{tabular}{|l|l|}
\hline Reason for exclusion & Unsuitable design. Outcome measure. No measure of appropriateness \\
\hline
\end{tabular}

Kojima 2014

\begin{tabular}{|l|l}
\hline Reason for exclusion & Unsuitable study design
\end{tabular}

\section{Kolhatkar 2016}

\begin{tabular}{|l|l|}
\hline Reason for exclusion $\quad$ Wrong study population \\
\hline
\end{tabular}

\section{Kouladjian 2015}

\begin{tabular}{|l|l}
\hline Reason for exclusion & No appropriate data
\end{tabular}

\section{Kroenke 1990}

Reason for exclusion

Outcome measure. No measure of appropriateness

\section{Kwan 2007}

Reason for exclusion Outcome measure. No measure of appropriateness

Kwint 2015

\begin{tabular}{|l|l}
\hline Reason for exclusion $\quad$ No appropriate data \\
\hline
\end{tabular}

\section{Ladouceur 2014}

\begin{tabular}{|l|l}
\hline Reason for exclusion $\quad$ No appropriate data
\end{tabular}

\section{Lalonde 2008}

\begin{tabular}{|l|l}
\hline Reason for exclusion & Outcome measure. No measure of appropriateness
\end{tabular}

\section{Lapane 2007}

Reason for exclusion Unsuitable study design. No measure of appropriateness

Lapane 2011

Reason for exclusion Not polypharmacy focus. No measure of appropriateness

\section{Laroche 2006}

Reason for exclusion Unsuitable study design

\section{Larson 2015}

Reason for exclusion No appropriate data 
Leach 2013

\begin{tabular}{|l|l|}
\hline Reason for exclusion & No data \\
\hline
\end{tabular}

\section{Ledwidge 2004}

\begin{tabular}{|l|l|}
\hline Reason for exclusion & Unsuitable studydesign. Appropriateness criterianotvalidated(expert opinion)
\end{tabular}

\section{Lee 2006}

\begin{tabular}{|l|l}
\hline Reason for exclusion & Outcome measure. No measure of appropriateness
\end{tabular}

\section{Lee 2013}

\begin{tabular}{|l|l}
\hline Reason for exclusion $\quad$ No appropriate data \\
\hline
\end{tabular}

\section{Leendertse 2013}

Reason for exclusion

\section{Legrain 2011}

\begin{tabular}{|l|l}
\hline Reason for exclusion & Outcome measure. Appropriateness criteria not validated (expert opinion)
\end{tabular}

Leguelinel 2013

\begin{tabular}{|l|l}
\hline Reason for exclusion $\quad$ No appropriate data
\end{tabular}

\section{Lemmens 2015}

\begin{tabular}{|l|l}
\hline Reason for exclusion & Unsuitable study design
\end{tabular}

\section{Lemmer 2014}

\begin{tabular}{|l|l}
\hline Reason for exclusion $\quad$ No appropriate data \\
\hline
\end{tabular}

\section{Lenaghan 2007}

Reason for exclusion Outcome measure. No measure of appropriateness

\section{Lichtman 2015}

Reason for exclusion No appropriate data

\section{Lidsky 2014}

\begin{tabular}{|l|l}
\hline Reason for exclusion & No appropriate data
\end{tabular}

\section{Lim 2004}

\begin{tabular}{|l|l}
\hline Reason for exclusion & Outcome measure. No measure of appropriateness
\end{tabular}

\section{Linden 2013}

\begin{tabular}{|l|l}
\hline Reason for exclusion $\quad$ No appropriate data &
\end{tabular}

\section{Linton 2010}


Interventions to improve the appropriate use of polypharmacy for older people

\begin{tabular}{|l|l|}
\hline Reason for exclusion $\quad$ Unsuitable design \\
\hline
\end{tabular}

Lipscomb 2013

\begin{tabular}{|l|l}
\hline Reason for exclusion $\quad$ No appropriate data \\
\hline
\end{tabular}

Lipton 1992

\begin{tabular}{|l|l|}
\hline Reason for exclusion & Outcome measure. Appropriateness criteria not validated (expert opinion) \\
\hline
\end{tabular}

\section{Lipton 1994}

\begin{tabular}{|l|l}
\hline Reason for exclusion & Outcome measure. No measure of appropriateness
\end{tabular}

\section{Logue 2002}

\begin{tabular}{|l|l}
\hline Reason for exclusion $\quad$ No data. Not polypharmacy focus \\
\hline
\end{tabular}

\section{Lopatto 2014}

Reason for exclusion

Appropriateness criteria not validated (Maio Criteria (an Italian adaptation of the 2002 Beers Criteria))

\section{Lourens 1994}

\begin{tabular}{|l|l}
\hline Reason for exclusion & Outcome measure. No measure of appropriateness
\end{tabular}

\section{Mador 2004}

\begin{tabular}{|l|l|}
\hline Reason for exclusion $\quad$ Not polypharmacy focus. Onlyappropriateness of psychoactive drugs measured \\
\hline
\end{tabular}

Majumdar 2007

\begin{tabular}{|l|l|}
\hline Reason for exclusion & Outcome measure. Appropriateness criterianot validated(efficacious medicine)
\end{tabular}

\section{Mannheimer 2006}

Reason for exclusion

Not polypharmacy focus. Appropriateness criteria not validated (Drug Related Problems-PharmCareNetwork Europe)

\section{Mansur 2008}

Reason for exclusion

Unsuitable study design. No measure of appropriateness

Martin 2013

\begin{tabular}{|l|l}
\hline Reason for exclusion $\quad$ No data. Outcome measure. Rate of change in benzodiazepine use \\
\hline
\end{tabular}

Masoudi 2005

\begin{tabular}{|l|l}
\hline Reason for exclusion & Unsuitable study design. No measure of appropriateness
\end{tabular}

\section{Mattison 2010}

Reason for exclusion Unsuitable design. Outcome measure. Appropriateness criteria not validated (subset of Beers medications) 
Interventions to improve the appropriate use of polypharmacy for older people

\begin{tabular}{|l|l|}
\hline Reason for exclusion & No appropriate data \\
\hline
\end{tabular}

Meredith 2002

\begin{tabular}{|l|l}
\hline Reason for exclusion & Outcome measure. Appropriateness criteria not validated (expert opinion)
\end{tabular}

Messerli 2016

\begin{tabular}{|l|l|}
\hline Reason for exclusion & Outcome measure. No measure of appropriateness \\
\hline
\end{tabular}

Mestres 2015

\begin{tabular}{|l|l}
\hline Reason for exclusion & Outcome measure. No prospective assessment of appropriateness
\end{tabular}

Meulendijk 2013

\begin{tabular}{|l|l}
\hline Reason for exclusion & Unsuitable study design
\end{tabular}

Meulendijk 2015

\begin{tabular}{|l|l|}
\hline Reason for exclusion & Unsuitable study design. Outcome measure. No measure of appropriateness \\
\hline
\end{tabular}

Meyer 1991

\begin{tabular}{|l|l}
\hline Reason for exclusion & Outcome measure. No measure of appropriateness
\end{tabular}

Midlov 2002

\begin{tabular}{|l|l}
\hline Reason for exclusion & Unsuitable study design. No measure of appropriateness
\end{tabular}

Miller 2008

\begin{tabular}{|l|l|}
\hline Reason for exclusion & Outcome measure. No measure of appropriateness \\
\hline
\end{tabular}

Miller 2014

\begin{tabular}{|l|l|}
\hline Reason for exclusion & No appropriate data \\
\hline
\end{tabular}

\section{Mills 2008}

\begin{tabular}{|l|l}
\hline Reason for exclusion $\quad$ Unsuitable study design. No measure of appropriateness \\
\hline
\end{tabular}

\section{Mistler 2009}

\begin{tabular}{|l|l}
\hline Reason for exclusion & $\begin{array}{l}\text { Unsuitable study design. Appropriateness criteria not validated (medication reduction } \\
\text { algorithm) }\end{array}$
\end{tabular}

\section{Mo 2014}

\begin{tabular}{|l|l}
\hline Reason for exclusion $\quad$ No appropriate data &
\end{tabular}

\section{Moczygemba 2011}

\begin{tabular}{|l|l|}
\hline Reason for exclusion & Unsuitable design. Outcome measure. No measure of appropriateness \\
\hline
\end{tabular}


Interventions to improve the appropriate use of polypharmacy for older people

Reason for exclusion Not all patients receiving polypharmacy

Monane 1998

\begin{tabular}{|l|l}
\hline Reason for exclusion $\quad$ Unsuitable study design &
\end{tabular}

Montero-Balosa 2015

\begin{tabular}{|l|l|}
\hline Reason for exclusion & No appropriate data \\
\hline
\end{tabular}

Moore 1998

\begin{tabular}{|l|l}
\hline Reason for exclusion & Outcome measure. No measure of appropriateness
\end{tabular}

Morecroft 2014

\begin{tabular}{|l|l}
\hline Reason for exclusion $\quad$ No appropriate data \\
\hline
\end{tabular}

Moss 2014

\begin{tabular}{l|l}
\hline Reason for exclusion $\quad$ No appropriate data \\
\hline
\end{tabular}

\section{Moss 2016}

Reason for exclusion Unsuitable study design

Moulis 2014

\begin{tabular}{|l|l}
\hline Reason for exclusion & No appropriate data
\end{tabular}

\section{Muir 2001}

\begin{tabular}{|l|l}
\hline Reason for exclusion & Outcome measure. No measure of appropriateness
\end{tabular}

Muller-Mundt 2011

\begin{tabular}{|l|l}
\hline Reason for exclusion & Outcome measure. No measure of appropriateness
\end{tabular}

\section{Muntinga 2012}

\begin{tabular}{|l|l}
\hline Reason for exclusion $\quad$ No data. Outcome measure. No measure of appropriateness \\
\hline
\end{tabular}

\section{Murray 2004}

\begin{tabular}{|l|l|}
\hline Reason for exclusion & Unsuitable study design. No measure of appropriateness
\end{tabular}

Murray 2007

Reason for exclusion

Murray 2009

Reason for exclusion

\section{Nassaralla 2014}

Reason for exclusion
Not polypharmacy focus. No measure of appropriateness

Not polypharmacy focus. No measure of appropriateness

No appropriate data 
Interventions to improve the appropriate use of polypharmacy for older people

Naveiro-Rilo 2014

\begin{tabular}{|l|l|}
\hline Reason for exclusion $\quad$ Unsuitable study design. Outcome measure \\
\hline
\end{tabular}

\section{Neutel 2007}

\begin{tabular}{|l|l}
\hline Reason for exclusion $\quad$ Unsuitable study design. No measure of appropriateness
\end{tabular}

\section{Nickerson 2005}

\begin{tabular}{|l|l}
\hline Reason for exclusion $\quad$ Participants too young. No measure of appropriateness \\
\hline
\end{tabular}

\section{O'Sullivan 2014}

\begin{tabular}{|l|l}
\hline Reason for exclusion $\quad$ Unsuitable study design. Outcome measure \\
\hline
\end{tabular}

Ogihara 2008

\begin{tabular}{|l|l}
\hline Reason for exclusion & Outcome measure. No measure of appropriateness
\end{tabular}

Ortega 2013

\begin{tabular}{|l|l|}
\hline Reason for exclusion & Outcome measure. No measure of appropriateness \\
\hline
\end{tabular}

Owens 1990

\begin{tabular}{|l|l|}
\hline Reason for exclusion & Outcome measure. Appropriateness criteria not validated ("problem pairs") \\
\hline
\end{tabular}

Oyarzun-Gonzalez 2015

\begin{tabular}{|l|l}
\hline Reason for exclusion & No appropriate data
\end{tabular}

\section{Ozturk 2015}

\begin{tabular}{|l|l}
\hline Reason for exclusion $\quad$ No appropriate data \\
\hline
\end{tabular}

\section{Pagaiya 2005}

Reason for exclusion Participants too young. Appropriateness criteria not validated (guideline adherence)

\section{Paluch 2007}

Reason for exclusion Unsuitable study design. No measure of appropriateness

\section{Patterson 2010}

Reason for exclusion Not polypharmacy focus. Approriateness of psychoactive drugs only. Appropriateness criteria not validated (medication algorithm)

\section{Payne 2015}

\begin{tabular}{|l|l}
\hline Reason for exclusion $\quad$ No appropriate data
\end{tabular}

\section{Pepine 1998}


Interventions to improve the appropriate use of polypharmacy for older people

\begin{tabular}{|l|l|}
\hline Reason for exclusion & Unsuitable studydesign \\
\hline
\end{tabular}

\section{Pfister 2017}

\begin{tabular}{|l|l}
\hline Reason for exclusion & No measure of appropriateness
\end{tabular}

Phelan 2008

\begin{tabular}{|l|l|}
\hline Reason for exclusion $\quad$ Unsuitable study design. No measure of appropriateness \\
\hline
\end{tabular}

Pimlott 2003

\begin{tabular}{|l|l|}
\hline Reason for exclusion $\quad$ Not polypharmacy focus. No measure of appropriateness \\
\hline
\end{tabular}

\section{Pit 2007}

\begin{tabular}{|l|l|}
\hline Reason for exclusion & Appropriateness criteria not validated
\end{tabular}

\section{Pitkala 2001}

Reason for exclusion $\quad$ Ou

Outcome measure. No measure of appropriateness

\section{Pitkala 2012}

Reason for exclusion No data. Outcome measure. Appropriateness of anticholinergic and psychotropic drugs only

Planton 2010

\begin{tabular}{|l|l}
\hline Reason for exclusion $\quad$ No appropriate data &
\end{tabular}

\section{Pool 2007}

\begin{tabular}{|l|l}
\hline Reason for exclusion & Not polypharmacy focus. No measure of appropriateness
\end{tabular}

\section{Potter 2016}

\begin{tabular}{|l|l}
\hline Reason for exclusion & Outcome measure. No measure of appropriateness
\end{tabular}

\section{Przytula 2015}

\begin{tabular}{|l|l}
\hline Reason for exclusion $\quad$ No appropriate data \\
\hline
\end{tabular}

\section{Pugh 2006}

Reason for exclusion Unsuitable study design. Appropriateness criteria not validated (Health Plan Employer Data and Information Set (HEDIS) 2006 quality measure)

\section{Puvanendran 2011}

\begin{tabular}{|l|l}
\hline Reason for exclusion & No appropriate data
\end{tabular}

\section{Qian 2016}

Reason for exclusion Unsuitable study design 
Interventions to improve the appropriate use of polypharmacy for older people

\begin{tabular}{|l|l|}
\hline Reason for exclusion & Unsuitable studydesign \\
\hline
\end{tabular}

\section{Raebel 2007}

\begin{tabular}{|l|l|}
\hline Reason for exclusion & Outcome measure. Appropriateness criteria not validated (expert opinion) \\
\hline
\end{tabular}

\section{Rantz 2015}

\begin{tabular}{|l|l}
\hline Reason for exclusion $\quad$ Unsuitable study design \\
\hline
\end{tabular}

\section{Raphael 2015}

\begin{tabular}{|l|l}
\hline Reason for exclusion $\quad$ No appropriate data \\
\hline
\end{tabular}

\section{Reboredo-Garcia 2014}

\begin{tabular}{|l|l|}
\hline Reason for exclusion & Unsuitable study design
\end{tabular}

\section{RESPECT 2010}

Reason for exclusion

\section{Reuben 2010}

Reason for exclusion

Reynders 2013

\begin{tabular}{|l|l}
\hline Reason for exclusion $\quad$ No appropriate data
\end{tabular}

\section{Rose 2015}

\begin{tabular}{|l|l|}
\hline Reason for exclusion & No appropriate data
\end{tabular}

\section{Roughead 2007a}

\begin{tabular}{|l|l}
\hline Reason for exclusion & Unsuitable study design. No measure of appropriateness
\end{tabular}

\section{Roughead 2007b}

\begin{tabular}{|l|l|}
\hline Reason for exclusion & Unsuitable study design
\end{tabular}

\section{Roughead 2013}

\begin{tabular}{|l|l|}
\hline Reason for exclusion & Unsuitable study design
\end{tabular}

\section{Sakakibara 2015}

Reason for exclusion Outcome measure. No measure of appropriateness

\section{Saltvedt 2002}

Reason for exclusion Outcome measure. No measure of appropriateness

\section{Santolaya-Perrin 2016}




\begin{tabular}{|l|l|}
\hline Reason for exclusion $\quad$ Not polypharmacy focus. No measure of appropriateness \\
\hline
\end{tabular}

\section{Schmidt-Mende 2017}

\begin{tabular}{|l|l}
\hline Reason for exclusion $\quad$ Not all patients receiving polypharmacy \\
\hline
\end{tabular}

\section{Schnipper 2006}

Reason for exclusion

\section{Schoenenberger 2013}

\begin{tabular}{|l|l}
\hline Reason for exclusion & No appropriate data
\end{tabular}

\section{Schrader 1996}

Reason for exclusion Unsuitable study design. No measure of appropriateness

\section{Schroder 2012}

\begin{tabular}{|l|l|}
\hline Reason for exclusion & Participants with single long-term condition
\end{tabular}

\section{Sellors 2001}

\begin{tabular}{|l|l}
\hline Reason for exclusion & Outcome measure. No measure of appropriateness
\end{tabular}

\section{Sellors 2003}

\begin{tabular}{|l|l}
\hline Reason for exclusion & Outcome measure. Appropriateness criteria not validated (expert opinion)
\end{tabular}

\section{Sennesael 2017}

\begin{tabular}{|l|l}
\hline Reason for exclusion $\quad$ Wrong study design \\
\hline
\end{tabular}

\section{Shrestha 2006}

Reason for exclusion Participants too young. No measure of appropriateness

\section{Sicras Mainar 2004}

Reason for exclusion

\section{Sicras Mainar 2005}

\begin{tabular}{|l|ll}
\hline Reason for exclusion & Unsuitable study design. No measure of appropriateness
\end{tabular}

Sicras Mainar 2007

\begin{tabular}{|l|l}
\hline Reason for exclusion & Outcome measure. No measure of appropriateness
\end{tabular}

Silkey 2005

\begin{tabular}{|l|ll}
\hline Reason for exclusion & Unsuitable study design. No measure of appropriateness
\end{tabular}


Interventions to improve the appropriate use of polypharmacy for older people

Reason for exclusion Not polypharmacy focus. No measure of appropriateness

Simon 2006

Reason for exclusion Outcome measure. Appropriateness criteria not validated (expert opinion)

Simonson 2015

\begin{tabular}{|l|l|}
\hline Reason for exclusion & No appropriate data
\end{tabular}

\section{Sinnott 2015}

\begin{tabular}{|l|l|}
\hline Reason for exclusion & Unsuitable study design
\end{tabular}

\section{Smeets 2013}

\begin{tabular}{|l|l}
\hline Reason for exclusion & No appropriate data
\end{tabular}

\section{Smith 1996}

Reason for exclusion

Outcome measure. No measure of appropriateness

\section{Sorensen 2004}

Reason for exclusion

Outcome measure. No measure of appropriateness

\section{Soumerai 1998}

Reason for exclusion Not polypharmacy focus. No measure of appropriateness

\section{Straand 2006}

\begin{tabular}{|l|l}
\hline Reason for exclusion & Unsuitable study design. No measure of appropriateness
\end{tabular}

\section{Stuck 1995}

\begin{tabular}{|l|l|}
\hline Reason for exclusion & Unsuitable study design. No measure of appropriateness
\end{tabular}

\section{Sturgess 2003}

\begin{tabular}{|l|l}
\hline Reason for exclusion & Outcome measure. No measure of appropriateness
\end{tabular}

\section{Tallon 2016}

\begin{tabular}{|l|l}
\hline Reason for exclusion & Unsuitable study design
\end{tabular}

\section{Teichert 2013}

\begin{tabular}{|l|l|}
\hline Reason for exclusion & Unsuitable design
\end{tabular}

\section{Terceros 2007}

Reason for exclusion Unsuitable study design. No measure of appropriateness

Terrell 2009 
Interventions to improve the appropriate use of polypharmacy for older people

Reason for exclusion

Outcome measure. Appropriateness criteria not validated (expert panel selected subset of medications from Beers criteria)

Thiem 2011

\begin{tabular}{|l|l}
\hline Reason for exclusion $\quad$ No appropriate data \\
\hline
\end{tabular}

Thomas 2014

\begin{tabular}{|l|l}
\hline Reason for exclusion & No appropriate data
\end{tabular}

Thompson 2008

Reason for exclusion

Outcome measure. No measure of appropriateness. Participants too young

Thurmann 2011

\begin{tabular}{|l|l}
\hline Reason for exclusion $\quad$ No appropriate data
\end{tabular}

Thyrian 2012

Reason for exclusion

No data. Participants with single long-term condition

Tomaes 2015

\begin{tabular}{|l|l|}
\hline Reason for exclusion & Unsuitable study design
\end{tabular}

Touchette 2012

\begin{tabular}{|l|l}
\hline Reason for exclusion & $\begin{array}{l}\text { Outcome measure. Appropriateness criteria notvalidated(Drug Related } \\
\text { Problems-Pharmaceutical Care NetworkEurope) }\end{array}$
\end{tabular}

Tse 2008

\begin{tabular}{|l|l}
\hline Reason for exclusion & Outcome measure. No measure of appropriateness
\end{tabular}

Van Balen 2014

Reason for exclusion

No appropriate data

Van Den Broucke 2014

\begin{tabular}{|l|l|}
\hline Reason for exclusion & Unsuitable study design
\end{tabular}

Van der Elst 2006

\begin{tabular}{|l|l}
\hline Reason for exclusion & $\begin{array}{l}\text { Outcome measure. Appropriateness criteria not validated (Peer Review Group } \\
\text { consensus) }\end{array}$
\end{tabular}

van Hees 2008

\begin{tabular}{|l|l}
\hline Reason for exclusion & Outcome measure. No measure of appropriateness
\end{tabular}

van Marum 2015

Reason for exclusion

Unsuitable study design 
Interventions to improve the appropriate use of polypharmacy for older people

\begin{tabular}{|l|l|}
\hline Reason for exclusion & Unsuitable study design. No measure of appropriateness \\
\hline
\end{tabular}

Verrue 2010

\begin{tabular}{|l|l|}
\hline Reason for exclusion & No appropriate data \\
\hline
\end{tabular}

Vetter 1992

\begin{tabular}{|l|l|}
\hline Reason for exclusion & Outcome measure. No measure of appropriateness \\
\hline
\end{tabular}

Viktil 2006

\begin{tabular}{|l|l}
\hline Reason for exclusion & Unsuitable study design. No measure of appropriateness
\end{tabular}

\section{Volume 2001}

\begin{tabular}{|l|l}
\hline Reason for exclusion & Outcome measure. No measure of appropriateness
\end{tabular}

\section{Wallis 2015}

\begin{tabular}{l|l}
\hline Reason for exclusion $\quad$ No appropriate data \\
\hline
\end{tabular}

\section{Watson 2014}

\begin{tabular}{|l|l|}
\hline Reason for exclusion & Unsuitable study design \\
\hline
\end{tabular}

Weber 2008

Reason for exclusion Outcome measure. No measure of appropriateness

Wehling 2015

\begin{tabular}{|l|l}
\hline Reason for exclusion $\quad$ No appropriate data \\
\hline
\end{tabular}

Weingart 2008

\begin{tabular}{|l|l}
\hline Reason for exclusion $\quad$ Participants too young. No measure of appropriateness
\end{tabular}

Wenger 2007

\begin{tabular}{|l|ll}
\hline Reason for exclusion & Unsuitable study design. (ACOVE criteria development/assessment)
\end{tabular}

\section{Wessell 2008}

\begin{tabular}{|l|l}
\hline Reason for exclusion & $\begin{array}{l}\text { Unsuitable study design. Appropriateness criteria not validated (potentially } \\
\text { inappropriate medication indicators based on Zhan criteria) }\end{array}$
\end{tabular}

\section{Westberg 2014}

Reason for exclusion Outcome measure. No measure of appropriateness

Whalen 2014

\begin{tabular}{|l|l|}
\hline Reason for exclusion & Unsuitable study design
\end{tabular}


Interventions to improve the appropriate use of polypharmacy for older people

\begin{tabular}{|l|l|}
\hline Reason for exclusion & Unsuitable study design \\
\hline
\end{tabular}

Willeboordse 2017

\begin{tabular}{l|l} 
Reason for exclusion & Not all patients receiving polypharmacy. No measure of appropriateness
\end{tabular}

Williams 2004

\begin{tabular}{|l|l|}
\hline Reason for exclusion & Outcome measure. No measure of appropriateness \\
\hline
\end{tabular}

Wouters 2017

\begin{tabular}{|l|l|}
\hline Reason for exclusion $\quad$ Not all patients receiving polypharmacy \\
\hline
\end{tabular}

Wu 2006

\begin{tabular}{|l|l}
\hline Reason for exclusion & Outcome measure. No measure of appropriateness
\end{tabular}

\section{Wu 2016}

\begin{tabular}{|l|l|}
\hline Reason for exclusion & No measure of appropriateness \\
\hline
\end{tabular}

\section{Xin 2016}

\begin{tabular}{|l|l}
\hline Reason for exclusion & Outcome measure. No measure of appropriateness
\end{tabular}

\section{Zermansky 2006}

\begin{tabular}{|l|l}
\hline Reason for exclusion & Outcome measure. No measure of appropriateness
\end{tabular}

\section{Zuckerman 2005}

\begin{tabular}{|l|l|}
\hline Reason for exclusion & Unsuitable study design
\end{tabular}

\section{Footnotes}

ACOVE: Assessing Care of the Vulnerable Elderly MAI: Medication Appropriateness Index

Characteristics of studies awaiting classification

Cossette 2016 
Interventions to improve the appropriate use of polypharmacy for older people

\begin{tabular}{|c|c|}
\hline Methods & Segmented regression analysis of an interrupted time series \\
\hline Participants & Quote: "Individuals aged 75 and older discharged from the hos pital in 2013 / 14 " \\
\hline Interventions & $\begin{array}{l}\text { Quote: “The KT strategy was based on a previously proposed knowledge-to-action } \\
\text { framework and designed to be dynamic and evolving throughout its implementation. } \\
\text { The geriatricians' presentations were modified in an iterative process based on } \\
\text { clinician feedback from the preintervention phase. This feedback influencedthe choice } \\
\text { of the CAS alerts. Scheduling presentations with multiple groups of clinicians within a } \\
\text { short time frame was difficult. Practical considerations superseded methodological } \\
\text { considerations, and interventions were scheduled based on clinician availability. The } \\
\text { preintervention period was defined as January } 2013 \text { to February } 2014 \text {, with four of the } \\
12 \text { geriatricians' presentations made in } 2013 \text { (February, May, August, October) and } \\
\text { the pharmacists' presentations to the pharmacy department made in October } 2013 \text {. } \\
\text { The main intervention period was March and April } 2014 \text {; the PIM lists (Appendices S1 } \\
\text { and S2) were distributed on April } 22,2014 \text {, and six of the } 12 \text { geriatricians' } \\
\text { presentations were between February } 19 \text { and May } 2,2014 \text {. In the postintervention } \\
\text { period, defined as May to December } 2014 \text {, one geriatrician presentation each was } \\
\text { made in June and September. The CAS pilot study was conducted from April } 28 \text { to } \\
\text { June } 20,2014 \text {. The CAS intervention was stopped at the end of the pilot study to } \\
\text { evaluate the results and restarted in } 2015 \text {. } \\
\text { Control Groups: The rate and slope of the preintervention period served as control for } \\
\text { the postintervention period. Analyses were also conducted to account for } \\
\text { environmental factors that could have been present during the intervention period and } \\
\text { influenced PIM use. A control group of individuals aged } 18 \text { to } 64 \text { admitted to the } \\
\text { Centre Hospitalier Universitaire de Sherbrooke (CHUS) was constituted to evaluate } \\
\text { the effect on PIM use of possible co-interventions such as a reduction in drug price" }\end{array}$ \\
\hline Outcomes & $\begin{array}{l}\text { Rate of potentially inappropriate medication use (number of patient days with use of at } \\
\text { least one PIM/number of patient-days of hospitalisation for individuals aged } \geq 75 \text { ) }\end{array}$ \\
\hline Notes & $\begin{array}{l}\text { We are currently waiting for confirmation from the authors for more information to } \\
\text { ascertain whether participants were receiving polypharmacy }\end{array}$ \\
\hline
\end{tabular}

\section{Cossette 2017}

\begin{tabular}{|l|l|}
\hline Methods & Pragmatic single-site randomised trial \\
\hline Participants & $\begin{array}{l}\text { Quote: “Eligible patients were all adults aged 65 or older who presented with at least } \\
\text { one of the geriatric explicit criteria for PIMs" }\end{array}$ \\
\hline Interventions & $\begin{array}{l}\text { Quote: “The KT strategy was composed of the following: (1) distribution of educational } \\
\text { materials to all physicians, medical residents, and pharmacists, (2) in-services in the } \\
\text { various medical and surgical departments by the geriatricians, (3) comprehensive } \\
\text { geriatric assessments, and (4)CAS-based pharmacist-physician interventions" }\end{array}$ \\
\hline Outcomes & PIM drug cessation or dosage decrease - based on Beers and STOPP criteria \\
\hline Notes & $\begin{array}{l}\text { We are currently waiting for confirmation from the authors for more information to } \\
\text { ascertain whether participants were receiving polypharmacy }\end{array}$ \\
\hline
\end{tabular}

Leguelinel-Blache 2018 
Interventions to improve the appropriate use of polypharmacy for older people

\begin{tabular}{|c|c|}
\hline Methods & Multicentric stepped wedge randomised study \\
\hline Participants & $\begin{array}{l}\text { Quote: "Patients aged at least } 65 \text { years, hospitalized in one of the participating care } \\
\text { units" }\end{array}$ \\
\hline \multirow[t]{2}{*}{ Interventions } & $\begin{array}{l}\text { Quote: "During the control period, there will be no clinical pharmacist in the care unit. } \\
\text { The hospital physician will write the AMO, then a pharmacy technician or a pharmacy } \\
\text { studentwill perform the best possible medication history (BPMH) according tothe } \\
\text { SOP MED'REC [35] and collect all the relevant bioclinical data to perform prescription } \\
\text { review. No information will be transmitted to the healthcare team except in life- } \\
\text { threatening emergencies. A clinical study technician from the promoter center will call } \\
\text { all the patients at } 30 \pm 10 \text { and } 90 \pm 10 \text { days after their hospital discharge to determine } \\
\text { whether they had died or been re-hospitalized. If they report that they had been re- } \\
\text { hospitalized, a pharmacy resident from the promotercenterwill call them again to } \\
\text { investigate if the cause of the hospitalization is due to medication regimen. After the } \\
\text { follow-up, the medication reconciliation and review will be retrospectively conducted by } \\
\text { the clinical pharmacists who have participated in the interventional period in each } \\
\text { investigator center. Finally, experts will retrospectively assess the potential clinical } \\
\text { harm of each medication error detected. In the interventional period, a senior clinical } \\
\text { pharmacist based in the care unit will perform medication reconciliation by comparing } \\
\text { the BPMH to the AMO and notifying the prescriber of any possible discrepancies. }\end{array}$ \\
\hline & $\begin{array}{l}\text { He/She will collect all relevant bioclinical data and perform medication review of the } \\
\text { AMO by using the STOPP and START tools [1 8], the French list of potentially } \\
\text { inappropriate medications in elderly [36], and the PAPA guide about medication } \\
\text { prescription adapted to the elderly, published by the French Society of Geriatric and } \\
\text { Gerontology [37]. The clinical pharmacist will have a collaborative meeting with both } \\
\text { the prescriberand the nurse in order to notify any possible medication errors and } \\
\text { suggest any proposals to optimize the AMOaccording to the medical history, the } \\
\text { clinical status, and the therapeutic adherence etc. (e.g. change of galenic form due to } \\
\text { swallowing problem, dose adjustment to renal function, etc.). After the collaborative } \\
\text { meeting, the clinical pharmacist will check whether the prescriber has accepted his/her } \\
\text { suggestion(s) and modified the AMO. All the pharmaceutical interventions, i.e. the } \\
\text { medication errors detected and the pharmaceutical suggestions of order modification, } \\
\text { will becollected and characterized in a standardized form according to the French } \\
\text { Society of Clinical Pharmacy [38]. The post-discharge follow-up and the retrospective } \\
\text { assessment of the potential harm of each errorwill be performed as in the control } \\
\text { period. At the end of the study, a satisfaction survey will be sent to all the care } \\
\text { providers involved in the collaborative pharmaceutical care" }\end{array}$ \\
\hline \multirow[t]{6}{*}{ Outcomes } & STOPP/START used in the intervention \\
\hline & Number of patients with at least one preventable medication \\
\hline & Preventable medication error \\
\hline & Number of patients at high risk for adverse drug events \\
\hline & Readmission rate for in-patient hospitalisation \\
\hline & Length of hospital stay \\
\hline \multirow[t]{2}{*}{ Notes } & NCT02598115 \\
\hline & $\begin{array}{l}\text { We are currently waiting for confirmation from the authors for more information to } \\
\text { ascertain ifresults of the primary outcomes of interest(STOPP/START) will be } \\
\text { reported }\end{array}$ \\
\hline
\end{tabular}


Interventions to improve the appropriate use of polypharmacy for older people

\begin{tabular}{|l|l|}
\hline Methods & Randomised trial \\
\hline Participants & Patients aged 65 years and older \\
\hline Interventions & $\begin{array}{l}\text { Quote: "The intervention consisted of several steps. The first step was a self- } \\
\text { assessment questionnaire, to be answered by the primary care centres together with } \\
\text { pharmacies, hospitals and municipally provided home care. It consisted of questions } \\
\text { regarding how patient safety is maintained during prescription of medication, } \\
\text { medication use and follow-up, and specifically frail elderly patients at the primarycare } \\
\text { centre. The focus of the questions was on how the primary care centres currently } \\
\text { handle medication reviews, co-operation with pharmacies and secondary care, and, } \\
\text { not least, how to ensure these measures are followed. In the second step of the } \\
\text { intervention, a group of selected doctors, nurses and pharmacists, with vast } \\
\text { experience in elderly care, served as reviewers. With support from the project } \\
\text { management team and written instructions and documents, the reviewers analysed } \\
\text { the self-assessment questionnaires and anyadditional material supplied bythe } \\
\text { primarycare units. They had opportunity to get clarifications regarding any questions } \\
\text { during sitevisits. Thereafter, the reviewers produced a written feedback report for the } \\
\text { primarycare unit and, togetherwith the management at the primary care unit, agreed } \\
\text { on an action plan for improvements" }\end{array}$ \\
\hline Outcomes & $\begin{array}{l}\text { Potentially inappropriate medications - six drug-specific quality indicators, in } \\
\text { accordance with the indicators described by the Swedish National Board of Health and } \\
\text { Welfare }\end{array}$ \\
\hline Notes & $\begin{array}{l}\text { We are currently waiting for confirmation from the authors for more information to } \\
\text { ascertain whether participants were receiving polypharmacy }\end{array}$ \\
\hline
\end{tabular}

\section{Footnotes}

AMO: admission medication order

BPMH: best possible medication history

CAS: computerised alert systems

CDS: Clinical Decision Support

EMR: electronic medical record

KT: knowledge translation

PAPA: medication prescription adapted to elderly PIMs: potentially inappropriate medications

PIP: potentially inappropriate prescribing START: Screening Tool to Alert doctors to the Right Treatment

STOPP: Screening Tool of Older Person's Prescriptions

Characteristics of ongoing studies

ACTRN12617000665336 
Interventions to improve the appropriate use of polypharmacy for older people

\begin{tabular}{|c|c|}
\hline Study name & $\begin{array}{l}\text { Impact of clinical pharmacist medication review on appropriate prescribing in elderly } \\
\text { patients: A randomized, trial }\end{array}$ \\
\hline Methods & Randomised trial \\
\hline Participants & $\begin{array}{l}\text { Quote: "Patients are eligible for the study if they } 1 \text { ) attend medical follow up in } \\
\text { Specialized Out-patient Clinic (SOPC) of the Department of Medicine, 2) are } 65 \text { years } \\
\text { orolder, 3) have hyper-polypharmacy (defined as } 10 \text { ormore regulardrugs and } 4 \text { ) } \\
\text { agree to provide oral informed consent" }\end{array}$ \\
\hline \multirow[t]{2}{*}{ Interventions } & $\begin{array}{l}\text { Quote: "For the intervention group, clinical pharmacist with } 5 \text { years of clinical } \\
\text { experience will perform medication chart review prior to the next SOPC follow-up, The } \\
\text { reviewincludes assessing theappropriateness of each of the regular medications } \\
\text { based on laboratory findings, medication lists, consultation and discharge notes, } \\
\text { procedures and test results. Face-to-face interview (lasts for around } 30-45 \text { mins) will } \\
\text { then be conducted with patients on the day prior to the SOPC follow-up. Clinical } \\
\text { pharmacists will assess drug use history, identify drug-related problems and provide } \\
\text { drug therapyinterventions through written pharmacist note to physicians during the } \\
\text { SOPC follow-up, based on the medication chart review and the above pharmaceutical } \\
\text { assessments. Immediately after the SOPC follow up, clinical pharmacist will provide } \\
\text { education (which lasts about } 15 \text { minutes) on drug-related problem identified before the } \\
\text { visit, reinforce physician's instruction, and encourage drug compliance using written } \\
\text { patient educational leaflets. Phone follow follow-up will be conducted } 1 \text { month after the } \\
\text { pharmacist intervention." }\end{array}$ \\
\hline & $\begin{array}{l}\text { "For patient randomized to control group, they will attend the medical follow-up as } \\
\text { usual and receive usual care, in which patients would have visit their physicians during } \\
\text { the Specialist Out-patient Clinic(SOPC) and with theirmedication dispensed in the } \\
\text { Out-patient pharmacy as usual. No pharmacist medication review will be performed, } \\
\text { and no pharmacist interview with patients for the control group" }\end{array}$ \\
\hline \multirow[t]{6}{*}{ Outcomes } & Primary outcome: Medication Appropriateness Index (MAl) \\
\hline & Secondary outcome: \\
\hline & $\begin{array}{l}\text { Change in number of drugs prescribed to each participant, Potentially Inappropriate } \\
\text { Medications (PIMs) identified by Screening Tool of Older Persons' Prescription } \\
\text { (STOPP), Potential Prescription Omission (PPOs) identified by the Screening Tool to } \\
\text { Alert Doctors to the Right Treatment (START), }\end{array}$ \\
\hline & Changes in total number of drug-related problems, \\
\hline & 30 day-unplanned hospital admission, \\
\hline & Medication adherence measured by Morisky Score (MMAS-4) \\
\hline Starting date & July 2017 \\
\hline \multirow[t]{3}{*}{ Contact information } & Miss Heidi Chan \\
\hline & $\begin{array}{l}\text { Pharmacy, Pamela Youde Nethersole Eastern Hospital 3Lok Man Road, Chai Wan, } \\
\text { HK, Hong Kong }\end{array}$ \\
\hline & cyh123@ha.org.hk \\
\hline Notes & Intervention phase complete, no results currently published \\
\hline
\end{tabular}


Interventions to improve the appropriate use of polypharmacy for older people

\begin{tabular}{|c|c|}
\hline Study name & $\begin{array}{l}\text { Collaborative approach to Optimise MEdication use for Older people in Nursing homes } \\
\text { (COME-ON) }\end{array}$ \\
\hline Methods & randomised trial (cluster) \\
\hline \multirow[t]{2}{*}{ Participants } & $\begin{array}{l}\text { Quote: "63 Belgian nursing homes ( } 30 \text { intervention; } 33 \text { control). In each of these } \\
\text { nursing homes, } 35 \text { residents ( } \geq 65 \text { years) are selected for participation }\end{array}$ \\
\hline & $\begin{array}{l}\text { Residents were considered eligible if they were aged } 65 \text { years or older and were under } \\
\text { the care of a participating GP" }\end{array}$ \\
\hline Interventions & $\begin{array}{l}\text { Quote: "The key element of this complex intervention is the structured and repeated } \\
\text { interdisciplinary resident's medication review (referred to hereafter as 'interdisciplinary } \\
\text { case conferences') supported by training and local concertation" }\end{array}$ \\
\hline \multirow[t]{2}{*}{ Outcomes } & $\begin{array}{l}\text { Quote: "Primary: The appropriateness of prescribing at the resident leveland are } \\
\text { defined as (1) among residents who had at least one PIM/PPO at baseline, the } \\
\text { proportion of them forwhom there is a decrease of at least one of these PIM/PPO at } \\
\text { the end of study and (2) among all residents, the proportion of them for whom at least } \\
\text { one new PIM/PPO is present at the end of the study as compared to baseline. }\end{array}$ \\
\hline & $\begin{array}{l}\text { PIMs/PPOs will be identified from a pre-defined list of explicit criteria that includes } \\
\text { STOPP/START (version 2) and Beers (2015) criteria" }\end{array}$ \\
\hline Starting date & April 2015 \\
\hline \multirow[t]{3}{*}{ Contact information } & Pauline Anrys \\
\hline & $\begin{array}{l}\text { Louvain Drug Research Institute, Clinical Pharmacy Research Group, Université } \\
\text { Catholique de Louvain, Brussels, Belgium }\end{array}$ \\
\hline & pauline.anrys@uclouvain.be \\
\hline \multirow[t]{4}{*}{ Notes } & ISRCTN66138978 \\
\hline & $\begin{array}{l}\text { Protocol: Anrys et al. (2016). Collaborative approach to Optimise MEdication use for } \\
\text { Older people in Nursing homes (COME-ON): study protocol of a cluster controlled trial. } \\
\text { Implementation Science, } 11(1), 35\end{array}$ \\
\hline & $\begin{array}{l}\text { Process Evaluation: Anrys et al. (2016a). The COME-ON study: Collaborative } \\
\text { approach to optimise MEdication use for Older people in Nursing homes-process } \\
\text { evaluation protocol }\end{array}$ \\
\hline & Intervention phase complete, no results currently published \\
\hline
\end{tabular}

Dauphinot 2017 
Interventions to improve the appropriate use of polypharmacy for older people

\begin{tabular}{|c|c|}
\hline Study name & $\begin{array}{l}\text { Optimization of drug prescribing in an elderly population of geriatric consultations } \\
\text { (OPTIM) }\end{array}$ \\
\hline Methods & Multicentre, open-label, randomized trial \\
\hline Participants & $\begin{array}{l}\text { Quote: "Patients aged } 65 \text { and over, patients received for the first time in a geriatric or } \\
\text { memory consultation, patients living at home, patients with the ability to express } \\
\text { themselves orally or in writing in French sufficiently to carry out clinical assessments, } \\
\text { patients who led the last drugs prescription from his referring physician, at the } \\
\text { geriatric/memory consultation (in current practice, patients should take the last } \\
\text { prescription established by the referring physician), and patients accompanied by a } \\
\text { caregiver" }\end{array}$ \\
\hline Interventions & $\begin{array}{l}\text { Quote: "The intervention group will participate to the optimization program: clinical } \\
\text { medication review performed by a pharmacist in cooperation with the clinician. This } \\
\text { aim is to identify actual and potential DRP, to decrease the potential iatrogeny of drug } \\
\text { prescription and to improve the drug adherence of the patient. This intervention will be } \\
\text { standardized across participating centers through a "Drug prescription optimization" } \\
\text { form. The pharmacist will complete this report form including the patient data (medical, } \\
\text { social, lab results and medication), their synthesis of medication review, and their PI in } \\
\text { order to achieve drug optimization and their counseling/specific strategies in order to } \\
\text { improve the drug adherence. In our study, the clinical medication review will be at the } \\
\text { inclusion, } 6 \text { months and } 18 \text { months. The review of current medication performed by the } \\
\text { pharmacist, in collaboration with the clinician (specialist physician), will also identify } \\
\text { DRP (including pharmacological redundancy, medication overdose, need for a change } \\
\text { in dosage form and PIP) taking into account the specificities of drug management in } \\
\text { elderly patients. The DRP will be identified through a structured approach for each } \\
\text { patient and the pharmacist will perform PI. The medication review will be standardized } \\
\text { through various tools, including current national professional guidelines and } \\
\text { international recommendations, medications databases, and prescription } \\
\text { appropriateness as assessed by a set of validated quality indicators including } \\
\text { Screening Tool of Older Persons' potentiallyinappropriate prescriptions and Screening } \\
\text { Tool to Alert doctors to Right Treatment (STOPP-START) and Beers criteria. The PI } \\
\text { are defined as "any action initiated by a pharmacist directly resulting in a change of the } \\
\text { patient's management or therapy' to the physician" and including addition of a new } \\
\text { drug, discontinuation, switch, dose adjustment, optimization of administration and drug } \\
\text { monitoring. In order to optimize drug adherence, the pharmacist will provide } \\
\text { comprehensive counseling and perform specific adherence strategies (information } \\
\text { about medications and administration)" }\end{array}$ \\
\hline \multirow[t]{3}{*}{ Outcomes } & $\begin{array}{l}\text { Proportion of potential inappropriate medication (from clinical trial page) } \\
\text { STOPP/START }\end{array}$ \\
\hline & $\begin{array}{l}\text { The occurrence and the number of all-cause hos pitalisations and all-cause emergency } \\
\text { department visits }\end{array}$ \\
\hline & Quality of life of the patients measured by the questionnaire EUROQOL5D(EQ-5D) \\
\hline Starting date & May 2016 \\
\hline Contact information & $\begin{array}{l}\text { Dr Dauphinot Virginie } \\
\text { virginie.dauphinot@chu-lyon.fr / d_virginie@hotmail.com }\end{array}$ \\
\hline Notes & $\begin{array}{l}\text { NCT02740764 } \\
\text { Intervention phase ongoing }\end{array}$ \\
\hline
\end{tabular}

Desborough 2011 
Interventions to improve the appropriate use of polypharmacy for older people

\begin{tabular}{|c|c|}
\hline Study name & Multi-professional clinical medication reviews in care homes for the elderly \\
\hline Methods & Randomised trial (cluster) \\
\hline Participants & $\begin{array}{l}\text { Quote: "Care homes for older people (average age }>65 \text { years), registered with the } \\
\text { Care Quality Commission (CQC) for at least } 6 \text { months and not specifically for people } \\
\text { (of all ages) with learning disability, sensory impairment, mental health problems, } \\
\text { physical disabilities and alcohol dependence. Care homes will also be excluded if they } \\
\text { have received a medication review service from the Primary Care Trust in the previous } \\
6 \text { months, if they receive the services of a community geriatrician or if they are subject } \\
\text { to investigation of the safeguarding of vulnerable adults" }\end{array}$ \\
\hline Interventions & $\begin{array}{l}\text { Quote: "Intervention homes will receive a multi-professional medication review } \\
\text { (MMRS) at baseline and at } 6 \text { months, with follow-up at } 12 \text { months. Control homes will } \\
\text { receive usual care (support they currently receive from the National Health Service) } \\
\text { with data collection at baseline and } 12 \text { months" }\end{array}$ \\
\hline \multirow[t]{2}{*}{ Outcomes } & $\begin{array}{l}\text { Quote: "Primary: number of falls (mean number per participant per month), potentially } \\
\text { inappropriate prescribing (number of drugs matching STOPPcriteriaat each data } \\
\text { collection point) }\end{array}$ \\
\hline & $\begin{array}{l}\text { Secondary: medication costs (mean drug cost per participant-net ingredient costs for } \\
28 \text { days); utilisation of primary care, secondary care and personal social services } \\
\text { health professional time (general practitioner (GP), nurse and other); emergency } \\
\text { hospital admissions and accident and emergency visits (number of admissions in } 6 \\
\text { months per participant), mortality" }\end{array}$ \\
\hline Starting date & November 2010 \\
\hline Contact information & $\begin{array}{l}\text { Julie Houghton } \\
\text { j.houghton@uea.ac.uk }\end{array}$ \\
\hline Notes & $\begin{array}{l}\text { ISRCTN90761620 } \\
\text { Intervention phase complete, no results currently published }\end{array}$ \\
\hline
\end{tabular}

DRKS00003610 
Interventions to improve the appropriate use of polypharmacy for older people

\begin{tabular}{|c|c|}
\hline Study name & Reduction of potentially inappropriate medication in the elderly \\
\hline Methods & Randomised trial (cluster) \\
\hline Participants & $\begin{array}{l}\text { Patient participants: aged } 70 \text { years and older, taking at least } 6 \text { different drugs on a } \\
\text { regularbasis, life expectancy of at least } 6 \text { months (at the discretion of the treating } \\
\text { primary care physician), legal competence, willingness to comply with study } \\
\text { arrangements (i.e. assessment in the primary care office, telephone interviews) and to } \\
\text { provide written informed consent, accessible by phone }\end{array}$ \\
\hline Interventions & $\begin{array}{l}\text { Quote: "Written information sources (pocket-sized quick reference guide and } \\
\text { comprehensive manual) containing recommendations from the PRISCUS list of } \\
\text { potentially inappropriate medications in the elderly will be provided to general } \\
\text { practitioners in the intervention arm. General practitioners will also be offered different } \\
\text { training opportunities, depending on their needs and requirements, to allowthem to } \\
\text { get familiar with recommendations and to practice their application" }\end{array}$ \\
\hline Outcomes & $\begin{array}{l}\text { Quote: "Primary: proportion of participants per office with potentially inappropriate } \\
\text { medication as defined by PRISCUS list (time frame: after } 12 \text { months of follow-up)" }\end{array}$ \\
\hline Starting date & May 2012 \\
\hline Contact information & $\begin{array}{l}\text { Prof. Hans-Joachim Trampsich } \\
\text { Department of Medical Informatics, Biometryand Epidemiology, University of Bochum, } \\
\text { Bochum, Germany } \\
\text { hans.j.trampisch@ruhr-uni-bochum.de }\end{array}$ \\
\hline Notes & Intervention phase complete, no results currently published \\
\hline
\end{tabular}

DRKS00012246 
Interventions to improve the appropriate use of polypharmacy for older people

\begin{tabular}{|c|c|}
\hline Study name & SiMbA-Optimizing nursing home residents` safety by checking prescribed medication \\
\hline Methods & Non-randomised trial \\
\hline Participants & $\begin{array}{l}\text { Quote: "Inclusion criteria for nursing home residents are, at least } 65 \text { years old, written } \\
\text { informed consent of the resident or legal representative, at least one prescription" }\end{array}$ \\
\hline \multirow[t]{4}{*}{ Interventions } & Quote: "The study intervention includes three processes: \\
\hline & $\begin{array}{l}\text { 1) Knowledge training for nurses, GPs and pharmacists including face to face and } \\
\text { online teaching about drug risk management and related topics }\end{array}$ \\
\hline & $\begin{array}{l}\text { 2) A special online tool, the SiMbA-Platform (SiM-PI) was developed and introduced to } \\
\text { enhance health care professional `s communication }\end{array}$ \\
\hline & $\begin{array}{l}\text { 3) The Intervention is completed with therapy checks by the GPs, the pharmacists use } \\
\text { the medication type I analysis to review the appropriateness of the prescribed } \\
\text { medication. The care staff in the nursing homes record abnormal symptoms of } \\
\text { residents in therapy monitoring forms and inform the GPs" }\end{array}$ \\
\hline \multirow[t]{2}{*}{ Outcomes } & $\begin{array}{l}\text { Quote: "Primary outcome: Appropriateness of medication measured by the medication } \\
\text { appropriateness index, (MAI) }\end{array}$ \\
\hline & $\begin{array}{l}\text { Secondary outcomes: Assessment of the residents' mobility and tendency of falls, } \\
\text { occurrence of delirium, the registration of potential malnutrition and the evaluation of } \\
\text { health related quality oflife" }\end{array}$ \\
\hline Starting date & November 2016 \\
\hline Contact information & $\begin{array}{l}\text { Dagmar Schaffler-Schaden } \\
\text { Institute of General Practice, Family Medicine and Preventive Medicine, Paracelsus } \\
\text { Medical University, Strubergasse 21, } 5020 \text { Salzburg, Austria. } \\
\text { dagmar.schaffler@pmu.ac.at }\end{array}$ \\
\hline \multirow[t]{2}{*}{ Notes } & $\begin{array}{l}\text { Protocol: Schaffler-Schaden D, Pitzer S, Schreier M, DellingerJ, Brandauer-Stickler B, } \\
\text { Lainer M, et al. Improving medication appropriateness in nursing home residents by } \\
\text { enhancing interprofessional co-operation: A study protocol. Journal of interprofessional } \\
\text { care } 2018 ; 1-4\end{array}$ \\
\hline & Intervention phase ongoing \\
\hline
\end{tabular}

DRKS00013588 
Interventions to improve the appropriate use of polypharmacy for older people

\begin{tabular}{|c|c|}
\hline Study name & $\begin{array}{l}\text { HIOPP-3-iTBX: Appropriate and safe medication for nursing home residents using an } \\
\text { interdisciplinary toolbox (AMTS-Toolbox) }\end{array}$ \\
\hline Methods & Randomised trial \\
\hline Participants & $\begin{array}{l}\text { Quote: "Residents eligible to participate in our study need to be at least } 65 \text { years old } \\
\text { and long-term residents in a nursing home" }\end{array}$ \\
\hline Interventions & $\begin{array}{l}\text { Quote: "Arm 1: Participating nursing home residents in the intervention group receive a } \\
\text { multimodal interprofessional intervention consisting of a medication reviewbya } \\
\text { specially trained pharmacist accompanied by change management measures, } \\
\text { trainings and a toolbox aimed to improve and support the cooperation of the } \\
\text { professions involved in the medication management in nursing homes. } \\
\text { Arm 2: Among the control group usual care will be observed, no intervention will be } \\
\text { conducted." }\end{array}$ \\
\hline Outcomes & $\begin{array}{l}\text { Quote: "Primary Outcome: The rate of nursing home residents with PIM (and/or two } \\
\text { antipsychotic drugs. PIMs will be classified according to the 'PRISCUS' list (Personal } \\
\text { communication). } \\
\text { Secondary Outcomes: Number of active pharmaceutical components, PIM, } \\
\text { neuroleptics, falls, hospitalisations and their duration, emergency medical services, } \\
\text { unplanned/unscheduled GP contacts, quality of life, health economic outcomes, health } \\
\text { care utilisation and patient care based on routine health data" }\end{array}$ \\
\hline Starting date & February 2018 \\
\hline Contact information & $\begin{array}{l}\text { Dr. med. Olaf Krause } \\
\text { Krause.Olaf@mh-hannover.de }\end{array}$ \\
\hline Notes & Intervention phase ongoing \\
\hline
\end{tabular}

Husebo 2015 
Interventions to improve the appropriate use of polypharmacy for older people

\begin{tabular}{|c|c|}
\hline Study name & $\begin{array}{l}\text { Improving quality of life in nursing home residents: a cluster randomized clinical trial of } \\
\text { efficacy (COSMOS) }\end{array}$ \\
\hline Methods & $\begin{array}{l}\text { Pilot study and multicenter, cluster randomised effectiveness-implementation clinical } \\
\text { hybrid trial with follow-up }\end{array}$ \\
\hline Participants & $\begin{array}{l}\text { Patient participants: Nursing home patients }(n=571) \text { with and without dementia, } \geq 65 \\
\text { years old, with polypharmacy }(\geq 4 \text { drugs) from } 67 \text { nursing home units }\end{array}$ \\
\hline Interventions & $\begin{array}{l}\text { Quote: "COmmunication, Systematic assessment and treatment of pain, Medication } \\
\text { review, Occupational therapy, Safety (COSMOS): The intervention group will receive a } \\
\text { 2-day education programincluding written guidelines, repeated theoretical and } \\
\text { practical training (credited education of caregivers, physicians and nursing home } \\
\text { managers), case discussions and role play. The 1-day midway evaluation, information } \\
\text { and interviews of nursing staff and a telephone hotline all support the implementation } \\
\text { process. } \\
\text { The control group will receive care as usual, during the trial and follow-up period" }\end{array}$ \\
\hline Outcomes & $\begin{array}{l}\text { Quote: "Total medication and use of psychotropic drugs in number and dose will be } \\
\text { assessed with respect to drug-related problems and drug-drug interactions using } \\
\text { STOPP and START criteria. Other measures include quality of life in late-stage } \\
\text { dementia, hospital admission and mortality" }\end{array}$ \\
\hline Starting date & Before July 2015 \\
\hline Contact information & $\begin{array}{l}\text { Elisabeth Flo } \\
\text { Department of Global Public Health and Primary Care, Centre for Elderly-and } \\
\text { Nursing Home Medicine, University of Bergen, Kalfarveien 31,N-5020 Bergen, } \\
\text { Norway. elisabeth.flo@uib.no }\end{array}$ \\
\hline Notes & $\begin{array}{l}\text { NCT02238652 } \\
\text { Intervention phase complete, no results currently published }\end{array}$ \\
\hline
\end{tabular}


Interventions to improve the appropriate use of polypharmacy for older people

\begin{tabular}{|c|c|}
\hline Study name & Hospital discharge study \\
\hline Methods & Randomised trial (cluster) \\
\hline Participants & $\begin{array}{l}\text { Quote: "Participant inclusion criteria } \\
\text { 1. In-hospital patient at the time of inclusion } \\
\text { 2. Male or female of } 60 \text { years or older with } 5 \text { or more drugs prescribed" }\end{array}$ \\
\hline Interventions & $\begin{array}{l}\text { Quote: "In the intervention group, the senior hospital physicians takes part in a } \\
\text { teaching session of two hours duration about how to integrate astructured medication } \\
\text { review and specific elements of communication into the daily discharge routine. The } \\
\text { senior physicians are responsible for instructing their assistant physicians in patient } \\
\text { recruitment and carrying out the correct discharge procedure. } \\
\text { The assistant physicians criticallyreview their patients' medication lists, discuss the } \\
\text { results of these reviews and their suggestions with the patients and compile revised } \\
\text { medication lists which they then communicate to the patients' general practitioners } \\
\text { with an invitation for discussion. } \\
\text { The senior hospital physicians in the control group undergo a two hour instruction } \\
\text { addressing multimorbidity, patient in- and exclusion and the handling of the different } \\
\text { data collection forms. Their assistant physicians will follow the "usual" discharge } \\
\text { routine of their clinics" }\end{array}$ \\
\hline Outcomes & $\begin{array}{l}\text { Primary outcome measures: time (in days) without readmission to hospital } \\
\text { Secondary outcome measures: } \\
\text { readmission rates, } \\
\text { numbers of drugs at discharge and at } 1,3 \text { and } 6 \text { months after discharge, Proportions } \\
\text { of potentially inappropriate medications (PIMs) at discharge and at } 1,3 \text { and } 6 \text { months } \\
\text { after discharge are (consecutive classification at study centre based on updated Beers } \\
\text { criteria, } 2012 \text { and PRISCUS list), } \\
\text { patients' quality of life at discharge and at } 1,3 \text { and } 6 \text { months after discharge } \\
\text { (EQ-5D-3L-scale) }\end{array}$ \\
\hline Starting date & January 2017 \\
\hline Contact information & $\begin{array}{l}\text { Dr. med. Stefan Neuner-Jehle MPH (Scientific) } \\
\text { stefan.neuner-jehle@usz.ch }\end{array}$ \\
\hline Notes & Currently in recruitment phase \\
\hline
\end{tabular}

Johansen 2018 
Interventions to improve the appropriate use of polypharmacy for older people

\begin{tabular}{|c|c|}
\hline Study name & $\begin{array}{l}\text { Interdisciplinary collaboration across secondary and primary care to improve } \\
\text { medication safety in the elderly (IMMENSE study) }\end{array}$ \\
\hline Methods & A non-blinded randomised trial \\
\hline Participants & $\begin{array}{l}\text { Quote: "Inclusion criteria: age } \geq 70 \text { years, acutely admitted and willing to provide } \\
\text { written informed consent (patient or next of kin). Exclusion criteria: admitted to the } \\
\text { study ward more than } 72 \text { hours before evaluation of eligibility, moved to and } \\
\text { discharged from otherwards during the index stay, inability to understand Norwegian } \\
\text { (patient or next of kin), considered terminallyill orwith a short life expectancy, planned } \\
\text { discharged on the inclusion day, occupying a bed in a study ward but under the care of } \\
\text { physicians from a non-study ward or ifan intervention from a study pharmacist is } \\
\text { considered necessary for ethical reasons (before randomisation or in control group)" }\end{array}$ \\
\hline \multirow[t]{2}{*}{ Interventions } & $\begin{array}{l}\text { Quote: "Patients randomised to the intervention group receive the IMM-based } \\
\text { intervention including: (1)MedRecat admission, (2) medication review and monitoring } \\
\text { during the hospital stay, (3) patient counselling designed to meet the needs of each } \\
\text { individual patient, (4) MedRec at discharge together with an updated and structured } \\
\text { medication list given to patients and submitted to primary care at discharge and (5) a } \\
\text { follow-up phone call to the patient's GPand nurses in home care service/nursing } \\
\text { home to inform about and discuss current medication therapy and recommendations. } \\
\text { Step } 5 \text { is in addition to the original IMM model. The study pharmacist is performing all } \\
\text { steps in close collaboration with the hospital physician who has the medical } \\
\text { responsibility for the patients. }\end{array}$ \\
\hline & $\begin{array}{l}\text { Patients assigned to standard care receive treatment from a team consisting of } \\
\text { physicians, nurses, nurse assistants, and sometimes occupational therapists and } \\
\text { physiotherapists. Standard care may include elements as MedRec, medication review } \\
\text { and patient counselling performed by physicians or nurses during the hospital stay" }\end{array}$ \\
\hline \multirow[t]{7}{*}{ Outcomes } & $\begin{array}{l}\text { Quote: "Primary outcome: The primary outcome is the rate of 'acute readmissions and } \\
\text { ED visits' } 12 \text { months after discharge. }\end{array}$ \\
\hline & Secondary outcomes: \\
\hline & Change in self-reported HRQoL, \\
\hline & Length of index hospital stay, \\
\hline & $\begin{array}{l}\text { Change in total score of the Medication Appropriateness Index (MAl) from admission } \\
\text { to discharge, }\end{array}$ \\
\hline & $\begin{array}{l}\text { Change in potentially inappropriate medications prescribed identified by The } \\
\text { Norwegian General Practice-Nursing Home criteria (NORGEP-NH), Screening Tool } \\
\text { ofOlderPersons'Prescriptions (STOPP) V.2 and Screening Tool to Alert doctors to } \\
\text { Right treatment (START) V.2 from admission to discharge, }\end{array}$ \\
\hline & $\begin{array}{l}\text { Change in potentially inappropriate medications prescribed using START V.2, STOPP } \\
\text { V.2 and NORGEPNH from discharge to } 3 \text { and } 12 \text { months" }\end{array}$ \\
\hline Starting date & September 2016 \\
\hline Contact information & $\begin{array}{l}\text { Jeanette Schultz Johansen } \\
\text { jeajoh@uit.no }\end{array}$ \\
\hline Notes & $\begin{array}{l}\text { NСТ02816086 } \\
\text { Intervention phase ongoing }\end{array}$ \\
\hline
\end{tabular}

Jäger 2013 
Interventions to improve the appropriate use of polypharmacy for older people

\begin{tabular}{|c|c|}
\hline Study name & $\begin{array}{l}\text { A tailored implementation intervention to implement recommendations addressing } \\
\text { polypharmacy in multimorbid patients }\end{array}$ \\
\hline Methods & Randomised trial (cluster) \\
\hline Participants & $\begin{array}{l}\text { Quote: "Patient participants: The eligibility criteria for patients are age older than } 64 \\
\text { years, enrolment in the HzV AOK Baden-Württemberg care contract, prescriptions for } \\
\text { more than four different drugs in at least one quarter of the year, diagnosis of at least } \\
\text { three chronic conditions based on a previously published diagnosis list and high risk of } \\
\text { medication problems (according to the personal assessment of the GP, such as } \\
\text { nonadherence or hospitalisation due to medication-related events)" }\end{array}$ \\
\hline \multirow[t]{2}{*}{ Interventions } & $\begin{array}{l}\text { Quote: "Practice teams ( } 1 \text { general practitioner, } 1 \text { health care assistant per practice) will } \\
\text { participate in a workshop about polypharmacotherapy. The practice teams will create } \\
\text { an individual concept which describes how they are planning to implement the } \\
\text { recommendations into their practice. Theywill puttheir concept into practiceand } \\
\text { perform medication reviews and medication counselling for the included patients. } \\
\text { Checklists, posters and flyers will be offered to them to facilitate implementation. } \\
\text { Patients of the intervention group will complete an educational tool concerning } \\
\text { medication-related topics on a tablet PC }\end{array}$ \\
\hline & $\begin{array}{l}\text { Patients and physicians of the control group will perform care as usual and will not } \\
\text { receive any special training or information material" }\end{array}$ \\
\hline Outcomes & $\begin{array}{l}\text { Quote: "Primary outcome is the degree of implementation of the three } \\
\text { recommendations, which will be measured using a prespecified set of indicators. } \\
\text { Additionally, the PIM prescription rate (based on the PRISCUS list), patient activation, } \\
\text { patients' beliefs about medicine, medication adherence and patients' social support } \\
\text { will be measured" }\end{array}$ \\
\hline Starting date & $01 / 11 / 2013$ \\
\hline \multirow[t]{3}{*}{ Contact information } & Cornelia Jäger \\
\hline & $\begin{array}{l}\text { Department of General Practice and Health Services Research, University Hos pital } \\
\text { Heidelberg, Voßstrasse 2, Heidelberg 691 15, Germany }\end{array}$ \\
\hline & cornelia.jaeger@med.uni-heidelberg.de \\
\hline \multirow[t]{3}{*}{ Notes } & ISRCTN34664024 \\
\hline & $\begin{array}{l}\text { Process Evaluation: Jäger, C., Steinhäuser, J., Freund, T., Kuse, S., Szecsenyi, J., \& } \\
\text { Wensing, M. (2017). A tailored programme to implement recommendations for } \\
\text { multimorbid patients with polypharmacy in primary care practices-process evaluation } \\
\text { of a cluster randomized trial }\end{array}$ \\
\hline & Intervention phase complete, no results currently published \\
\hline
\end{tabular}

Kua 2017 
Interventions to improve the appropriate use of polypharmacy for older people

\begin{tabular}{|c|c|}
\hline Study name & Nursing home team-care deprescribing study \\
\hline Methods & Cluster-randomised stepped-wedge intervention \\
\hline Participants & Nursing home residents at least 65 years old and on five or more medications. \\
\hline Interventions & 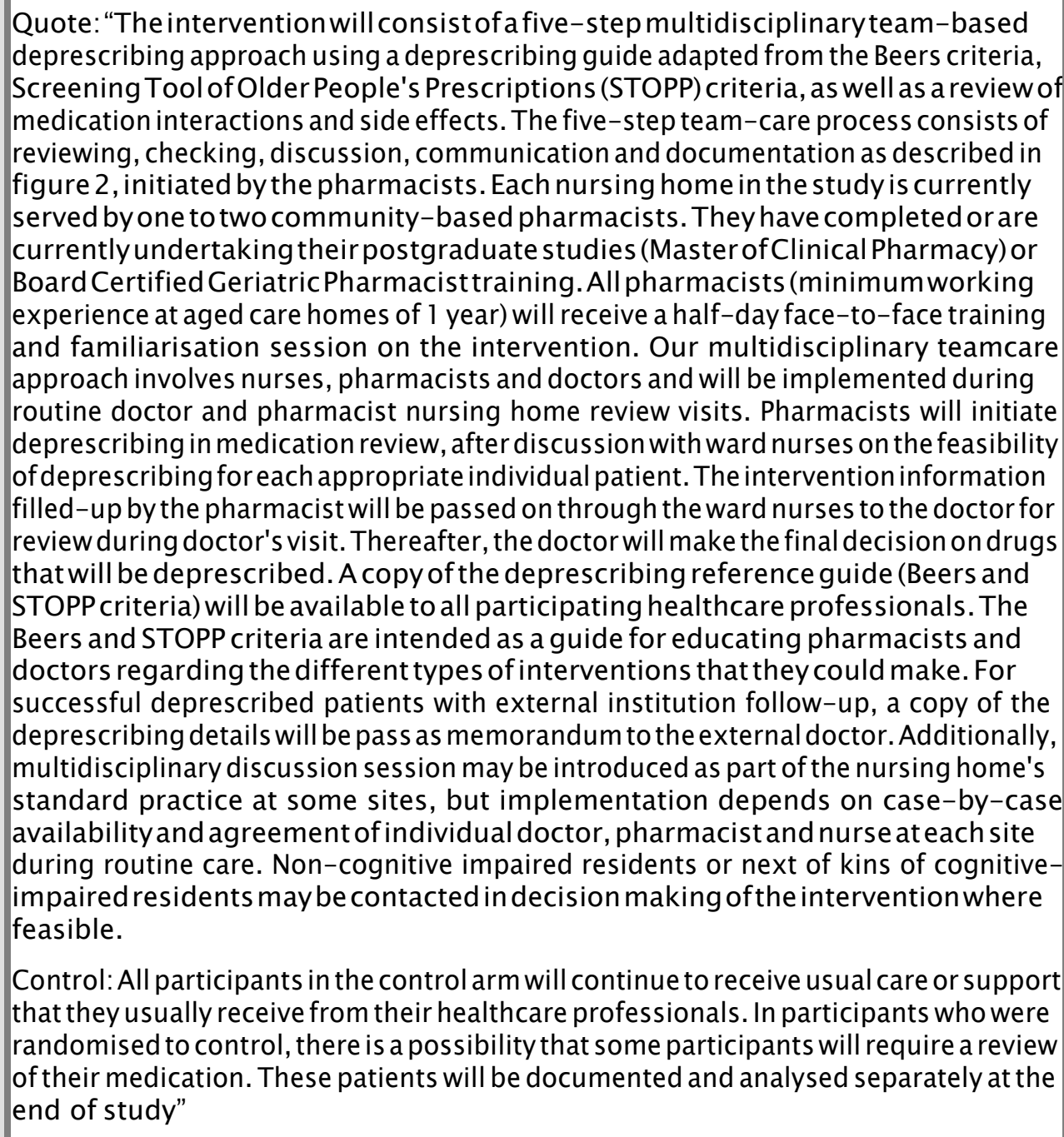 \\
\hline Outcomes & $\begin{array}{l}\text { The number of STOPP criteria and Beers criteria interventions made } \\
\text { The type and percentage of drug-related problems }\end{array}$ \\
\hline Starting date & November 2016 \\
\hline Contact information & $\begin{array}{l}\text { Mr. Chong-Han Kua; } \\
\text { chong.kua@monash.edu }\end{array}$ \\
\hline Notes & $\begin{array}{l}\text { NCT02863341 } \\
\text { Intervention phase complete, no results currently published }\end{array}$ \\
\hline
\end{tabular}


Interventions to improve the appropriate use of polypharmacy for older people

\begin{tabular}{|c|c|}
\hline Study name & Optimizing polypharmacy among elderly hospital patients with chronic diseases \\
\hline Methods & Randomised trial (cluster) \\
\hline Participants & $\begin{array}{l}\text { Quote: "Patient participants: patients aged } 65+\text { years who take five or more prescribed } \\
\text { long-term drugs and who are likely to spend at least } 5 \text { days in the participating } \\
\text { hospitals will be recruited and included consecutively" }\end{array}$ \\
\hline \multirow[t]{2}{*}{ Interventions } & $\begin{array}{l}\text { Quote: "During in-patient treatment of chronically ill patients affected by polypharmacy, } \\
\text { a pharmacist specially trained in communication skills performs a narrative-based } \\
\text { medication review. Apart from detecting potentially inadequate medication, a major } \\
\text { aim is to identify patient preferences and to include them - whenever possible - into a } \\
\text { list of evidence-based medication recommendations. Patients will be motivated to } \\
\text { narrate the drugs they currently take and describe their experiences and expectations } \\
\text { related to these drugs. Based on this information the pharmacist prepares a list of } \\
\text { possible drugs to be stopped, which will then be discussed with the hospital physician } \\
\text { in charge and will be submitted for consent to the patients' General Practitioner. The } \\
\text { active involvement of patients allows for transparency of the decision-making process } \\
\text { and will increase the chance for a sustainable medication optimization }\end{array}$ \\
\hline & Patients of the control group receive care as usual" \\
\hline Outcomes & $\begin{array}{l}\text { Quote: "The independent two main primary outcomes are }(1) \text { health-related quality of } \\
\text { life (EQ-5D) and (2) the difference in the number of prescribed long-term } \\
\text { pharmaceutical agents between intervention and control group. The secondary } \\
\text { outcomes are appropriateness of prescribed medication (PRISCUS list, Beers Criteria, } \\
\text { MAI), patient satisfaction (TSQM), patient empowerment (PEF-FB-9), patient } \\
\text { autonomy (IADL), falls, re-hospitalization, and death" }\end{array}$ \\
\hline Starting date & November 2013 \\
\hline Contact information & $\begin{array}{l}\text { Christin Löffler } \\
\text { Institute of General Practice, Rostock University Medical Center, Rostock, German } \\
\text { christin.loeffler@med.uni-rostock.de }\end{array}$ \\
\hline Notes & $\begin{array}{l}\text { ISRCTN42003273 } \\
\text { Intervention phase complete, no results currently published }\end{array}$ \\
\hline
\end{tabular}

McCarthy 2017 
Interventions to improve the appropriate use of polypharmacy for older people

\begin{tabular}{|c|c|}
\hline Study name & $\begin{array}{l}\text { Supporting prescribing in older people with multimorbidity and significant } \\
\text { polypharmacy in primary care(SPPiRE) }\end{array}$ \\
\hline Methods & Randomised trial (cluster) \\
\hline Participants & $\begin{array}{l}\text { Quote: "Patients will be considered eligible if they are aged } \geq 65 \text { years and they are } \\
\text { being prescribed } 15 \text { or more repeat medicines, which is a measure of both significant } \\
\text { polypharmacy and complex multimorbidity" }\end{array}$ \\
\hline \multirow[t]{2}{*}{ Interventions } & $\begin{array}{l}\text { Quote: "Intervention arm: GPs will receive log in details to access online academic } \\
\text { detailing and will be asked to arrange a medication review with their recruited patients. } \\
\text { This will be supported by a website which will provide a basic structure for the review } \\
\text { and a patient outcome form which will collect information about any changes made to } \\
\text { the medication regime and reasons for process evaluation. Follow up data will be } \\
\text { collected } 6 \text { months after the medication review is completed. }\end{array}$ \\
\hline & Control arm: Usual care will be delivered for the duration of the study" \\
\hline \multirow[t]{2}{*}{ Outcomes } & $\begin{array}{l}\text { Primary outcome measures pertain to the individual patient level and are the } \\
\text { proportion of patients with any PIP and the number of repeat medicines }\end{array}$ \\
\hline & $\begin{array}{l}\text { Secondary outcomes: quality of life, patient's attitudes to deprescribing and treatment } \\
\text { burden }\end{array}$ \\
\hline Starting date & August 2016 \\
\hline Contact information & $\begin{array}{l}\text { Professor Susan Smith } \\
\text { susansmith@rcsi.ie }\end{array}$ \\
\hline Notes & $\begin{array}{l}\text { ISRCTN12752680 } \\
\text { Intervention phase ongoing }\end{array}$ \\
\hline
\end{tabular}

Mestres 2017 
Interventions to improve the appropriate use of polypharmacy for older people

\begin{tabular}{|c|c|}
\hline Study name & Supporting clinical rules engine in the adjustment of medication (SCREAM) \\
\hline Methods & Multicentre, prospective, randomised study with a cluster group design \\
\hline Participants & Quote: "Residents living in a nursing home in the Netherlands" \\
\hline Interventions & $\begin{array}{l}\text { Quote: "Intervention group: The datasets will be screened through the CRR on a } \\
\text { weekly basis. The messages delivered by the CRR will be sent via mail to the specific } \\
\text { physicians. Each remark will be sent on a separate mail in a standardised way. In } \\
\text { response to the report, the physician will send a feedback message within } 36 \mathrm{~h} \\
\text { indicating, in a standardised way, whether: the advice was not followed, the advice } \\
\text { was followed or the advice was changed. After receiving this feedback, the } \\
\text { investigators will process it in the CRR, in order to create the database for the study. } \\
\text { Additionally, regular care will be also applied. That is according to the Dutch } \\
\text { Healthcare Inspectorate, a yearly medication review with a physician and a } \\
\text { pharmacist, even though there is a substantial variation [25], For the centres included } \\
\text { in this study there are no dedicated clinical pharmacist working in the nursing home" }\end{array}$ \\
\hline \multirow[t]{3}{*}{ Outcomes } & MAI \\
\hline & $\begin{array}{l}\text { The proportion of patients with at least one of the events, including hospital referrals } \\
\text { (i.e. referral to a specialist, emergency department visit and hospital admission) }\end{array}$ \\
\hline & The quality of life will be measured using the EQ-5D \\
\hline Starting date & June 2013 \\
\hline Contact information & $\begin{array}{l}\text { Carlota Mestres Gonzalvo } \\
\text { c.mestresgonzalvo@zuyderland.nl }\end{array}$ \\
\hline \multirow[t]{2}{*}{ Notes } & NTR5165 \\
\hline & Intervention phase ongoing \\
\hline
\end{tabular}


Interventions to improve the appropriate use of polypharmacy for older people

\begin{tabular}{|c|c|}
\hline Study name & $\begin{array}{l}\text { Pharmaceutical care and clinical outcomes for the elderly taking potentially } \\
\text { inappropriate medication: a randomized-controlled trial }\end{array}$ \\
\hline Methods & Randomised trial \\
\hline Participants & Elderly with chronic disease. 65 to 90 years old, hospitalised \\
\hline Interventions & $\begin{array}{l}\text { Quote: "Behavioural: } \neg \text { pharmacist intervention. Participants in the interventiongroup } \\
\text { will receive pharmaceutical care delivered by a clinical pharmacist, including } \\
\text { medication review, medication reconciliation, participant education and recommended } \\
\text { actions" }\end{array}$ \\
\hline Outcomes & $\begin{array}{l}\text { Primary outcome measures: number of unsolved drug-related problems } \\
\text { (time } \neg \text { frame: } \neg 14 \text { days after randomisation) } \\
\text { Secondary outcome measures: rate of ADE during hospitalisation (time } \neg \text { frame: } \neg 14 \\
\text { days after randomisation) } \\
\text { Number of potentially inappropriate medications (time } \neg \text { frame: } \neg 14 \text { days after } \\
\text { randomisation) }\end{array}$ \\
\hline Starting date & February 2009 \\
\hline Contact information & $\begin{array}{l}\text { Liu Jen Wei, MS, Principal Investigator, } \\
\text { Shin Kong Wo Ho-Su Memorial Hospital, Department of Pharmacy, Taipei, } 111 \text {, } \\
\text { Taiwan }\end{array}$ \\
\hline Notes & Intervention phase complete, no results currently published \\
\hline
\end{tabular}


Interventions to improve the appropriate use of polypharmacy for older people

\begin{tabular}{|c|c|}
\hline Study name & $\begin{array}{l}\text { Using clinical alerts in a computerized provider order entry system to decrease } \\
\text { inappropriate medication prescribing among hospitalized elders }\end{array}$ \\
\hline Methods & Randomised trial \\
\hline Participants & Patient participants: hospitalised patients over 65 years of age \\
\hline Interventions & $\begin{array}{l}\text { Quote: "A series of clinical alerts will be developed in the hospital's computerised } \\
\text { provider order entry system to reduce the use of potentiallyinappropriate medications } \\
\text { among hospitalised older patients. A synchronous alert (i.e. a 'pop-up') will appear } \\
\text { whenever a physician attempts to place an order for a high-risk medication on the } \\
\text { Beers list and the intended recipient is over } 65 \text { years of age. The alert will inform the } \\
\text { physician about the risks associated with the medication and will propose safer } \\
\text { alternatives" }\end{array}$ \\
\hline \multirow[t]{2}{*}{ Outcomes } & $\begin{array}{l}\text { Primary: percentage of older participants who received a specified high-risk } \\
\text { medication from the Beer's list (time frame: earlier hospital stay or end of study) }\end{array}$ \\
\hline & $\begin{array}{l}\text { Secondary: average number of specified high-risk medications prescribed per } \\
\text { participant (time frame: earlier hospital stay or end of study), restraint use (time frame: } \\
\text { earlier hospital stay or end of study), falls (time frame: earlier hospital stay or end of } \\
\text { study), length of stay (time frame: earlier hospital stay or end of study), total cost (time } \\
\text { frame: earlier hospital stay or end of study), discharge status (time frame: } 6 \text { months) }\end{array}$ \\
\hline Starting date & April 2013 \\
\hline Contact information & $\begin{array}{l}\text { Linda Canty, MD, Assistant Clinical Professor of Medicine } \\
\text { Baystate Medical Cente, Springfield, Massachusetts, USA }\end{array}$ \\
\hline Notes & Intervention phase complete, no results currently published \\
\hline
\end{tabular}


Interventions to improve the appropriate use of polypharmacy for older people

\begin{tabular}{|l|l|}
\hline Study name & $\begin{array}{l}\text { Apharmacist-led medicines management outpatient service for patients athigh risk of } \\
\text { medication related problems }\end{array}$ \\
\hline Methods & Randomised trial \\
\hline Participants & $\begin{array}{l}\text { Quote: "Patients aged } 18 \text { years and older admitted to one of the study hospitals as } \\
\text { acute/ unscheduled medical admissions and meeting at least } 1 \text { of the following criteria: } \\
\text { prescribed } 5 \text { or more regular long-term medications; have } 3 \text { or more changes to } \\
\text { medications during hospital stay; past history of medication-related problems; referred } \\
\text { to the medicines management clinic service by hospital doctor or clinical pharmacist } \\
\text { because of concerns about ability to manage medicines in primary care" }\end{array}$ \\
\hline Interventions & $\begin{array}{l}\text { Quote: "Medicines management outpatient service: Participants assigned tothe } \\
\text { intervention group will receive a new customised clinical pharmacy service (medicines } \\
\text { management clinic and follow-up phone calls)" }\end{array}$ \\
\hline Outcomes & $\begin{array}{l}\text { Primary: time to hos pital readmission (time frame: } 12 \text { months post discharge) } \\
\text { Secondary: number of hospital readmissions (time frame: } 12 \text { months post discharge); } \\
\text { number of GP consultations and GP home visits (time frame: } 12 \text { months post } \\
\text { discharge); number of accident and emergency visits (time frame: } 12 \text { months post } \\
\text { discharge); Medication Appropriateness Index score (time frame: } 4,8 \text { and } 12 \text { months } \\
\text { post discharge), health-related quality of life (EQ-5D) (time frame: every } 4 \text { months over } \\
12 \text { months post discharge); medication adherence assessments (time frame: } 12 \\
\text { months post discharge), cost utility analysis (time frame: } 12 \text { months post discharge) }\end{array}$ \\
\hline Notes & $\begin{array}{l}\text { November } 2011 \\
\text { Starting date }\end{array}$ \\
\hline $\begin{array}{l}\text { Intervention phase complete, no results currently published } \\
\text { Queen's University, Belfast, Northern Ireland }\end{array}$ \\
\hline anformation
\end{tabular}

NCT01578525 
Interventions to improve the appropriate use of polypharmacy for older people

\begin{tabular}{|c|c|}
\hline Study name & $\begin{array}{l}\text { Medication safety of elderly patients in hospital and ambulatory setting considering the } \\
\text { transitions of care for home-cared patients and nursing home residents }\end{array}$ \\
\hline Methods & Randomised trial \\
\hline Participants & $\begin{array}{l}\text { Quote: "Patients aged } 65 \text { years and older admitted to one of the project wards for a } \\
\text { minimum period of } 3 \text { days" }\end{array}$ \\
\hline Interventions & $\begin{array}{l}\text { Quote: "Intensified pharmaceutical care: Participants in the intervention group will } \\
\text { receive both traditional care provided by physician and nurse on theward and } \\
\text { additional pharmaceutical care provided by a pharmacist during hospitalisation" }\end{array}$ \\
\hline \multirow[t]{2}{*}{ Outcomes } & Primary: drug-related hospital readmission \\
\hline & $\begin{array}{l}\text { Secondary: adverse drug events, number of potentially inappropriate medications } \\
\text { prescribed (PRISCUS-criteria), time to readmission, number of accepted } \\
\text { recommendations in the intervention group, timeforintervention, drug-related } \\
\text { problems }\end{array}$ \\
\hline Starting date & April 2012 \\
\hline Contact information & $\begin{array}{l}\text { Albrecht Eisert } \\
\text { University Hospital Aachen, Hospital Pharmacy, Steinbergweg 20, } 52074 \text { Aachen, } \\
\text { Germany } \\
\text { aeisert@ukaachen.de }\end{array}$ \\
\hline Notes & Intervention phase complete, no results currently published \\
\hline
\end{tabular}

NCT02942927 
Interventions to improve the appropriate use of polypharmacy for older people

\begin{tabular}{|c|c|}
\hline Study name & Team Approach to Polypharmacy Evaluation and Reduction (TAPER-RCT) \\
\hline Methods & Randomised trial \\
\hline Participants & $\begin{array}{l}\text { Quote: "Aged } 70 \text { years of age or older, currently taking more than } 5 \text { long term } \\
\text { medications" }\end{array}$ \\
\hline Interventions & $\begin{array}{l}\text { Quote: "The patient will then attend an appointment with a pharmacist to review } \\
\text { medications appropriate for discontinuation/dose reduction, after which the patient will } \\
\text { meet with his / her family physician to discuss patient preferences for } \\
\text { discontinuation/dose reduction. Both health care providers will have access to } \\
\text { TAPERMD, a web based program linked to evidence and tools to support reduction in } \\
\text { polypharmacy. } \\
\text { Intervention:TAPER - The intervention is medication reduction. This arm is comprised } \\
\text { of: } \\
\text { 1. Medication reconciliation } \\
\text { 2. Identification of patient priorities for care } \\
\text { 3. Identification of medications that are potentially } \\
\text { appropriatefor discontinuation/dose reduction } \\
\text { 4. Linked pharmacist/family physician consultations with } \\
\text { patient to discuss medication with intention to reduce } \\
\text { 5. Identification of medications for trial of } \\
\text { discontinuation/dose reduction (shared decision } \\
\text { making) } \\
\text { 6. Pause of medication and clinical monitoring } \\
\text { Control: Standard ofCare as waitlist control. Control groupwill be offered intervention } \\
\text { as part of usual clinical care at } 6 \text { months" }\end{array}$ \\
\hline Outcomes & $\begin{array}{l}\text { Beers, STOPP (personal communication) } \\
\text { Quality of life (EQ5D-5L and SF36v2) } \\
\text { Healthcare resource utilisation (hospital admissions) } \\
\text { Changes in medication side effects and symptoms (adverse) } \\
\text { Serious adverse events }\end{array}$ \\
\hline Starting date & April 2018 \\
\hline Contact information & $\begin{array}{l}\text { Prof. Dee Mangin } \\
\text { mangind@mcmaster.ca }\end{array}$ \\
\hline Notes & Recruitment and intervention phases ongoing \\
\hline
\end{tabular}

NCT02986425 
Interventions to improve the appropriate use of polypharmacy for older people

\begin{tabular}{|c|c|}
\hline Study name & $\begin{array}{l}\text { OPtimising thERapy to Prevent Avoidable Hospital Admissions in the Multimorbid } \\
\text { Older People (OPERAM) }\end{array}$ \\
\hline Methods & Randomised trial (cluster) \\
\hline \multirow[t]{4}{*}{ Participants } & Quote: “Inclusion Criteria: \\
\hline & People 70 years of age or older \\
\hline & $\begin{array}{l}\text { Multimorbidity: } 3 \text { or more coexistent chronic conditions defined by } 3 \text { distinct } \\
\text { International Classification of Diseases (ICD-10) codes with an estimated duration of } 6 \\
\text { months or more or based on a clinical decision }\end{array}$ \\
\hline & $\begin{array}{l}\text { Polypharmacy i.e. five or more different regular drugs (defined as authorised } \\
\text { medications with registration numbers) for more than } 30 \text { days" }\end{array}$ \\
\hline \multirow[t]{8}{*}{ Interventions } & $\begin{array}{l}\text { Quote: "The intervention will take place during the initial hospital admission (Index } \\
\text { Hospitalisation) or an equivalent situation for outpatients. STRIP is a structured } \\
\text { method to perform pharmacotherapy optimisation. The STRIP-intervention consists of } \\
9 \text { steps. } \\
\text { 1. structured history taking of medication } \\
\text { 2. recording medication and diagnoses in STRIPA } \\
\text { 3. structured drug review based on the STRIPA with the integrated Screening Tool of } \\
\text { Older Person's Prescriptions (STOPP)/ Screening Tool to Alert Doctors to the Right } \\
\text { Treatment (START) criteria }\end{array}$ \\
\hline & $\begin{array}{l}\text { 4. communication and discussion of the structured drug review with prescribing } \\
\text { physician with possible adaptation of the recommendation }\end{array}$ \\
\hline & $\begin{array}{l}\text { 5. shared decision-making with the patient with possible adaptation of the } \\
\text { recommendation }\end{array}$ \\
\hline & $\begin{array}{l}\text { 6. optional revision based on newaccumulating data during hospitalisation (e.g. new } \\
\text { diagnoses, adverse drug reactions) }\end{array}$ \\
\hline & 7. generation of general practioner (GP) report \\
\hline & $\begin{array}{l}\text { 8. delivery of the report to the patient and to the GP(optional additional direct } \\
\text { communication) }\end{array}$ \\
\hline & 9. follow-up \\
\hline & $\begin{array}{l}\text { Participants in the control group will receive medication review by the prescribing } \\
\text { physicians in accordance with usual care" }\end{array}$ \\
\hline \multirow[t]{6}{*}{ Outcomes } & $\begin{array}{l}\text { STOPP/START criteria (Number of drug overuse, Number of drug underuse, Number } \\
\text { of potentially inappropriate medications) }\end{array}$ \\
\hline & Patients' quality of life (EQ-5D) \\
\hline & Number of patients with hospitalisations \\
\hline & Patients' drug compliance - Morisky Medication Adherence Questionnaire (MMAS-8) \\
\hline & Number of clinically significant drug-drug interactions \\
\hline & Number of patients with a serious adverse event \\
\hline Starting date & December 2016 \\
\hline Contact information & $\begin{array}{l}\text { Prof. Nicolas Rodondi } \\
\text { nicolas.rodondi@insel.ch }\end{array}$ \\
\hline Notes & Intervention phase ongoing \\
\hline
\end{tabular}


Interventions to improve the appropriate use of polypharmacy for older people

\begin{tabular}{|c|c|}
\hline Study name & Impact of clinical pharmacist on adverse drug events in older adults \\
\hline Methods & Randomised trial \\
\hline \multirow[t]{2}{*}{ Participants } & 60 Years and older \\
\hline & Patients who are on pharmacological therapy \\
\hline \multirow[t]{3}{*}{ Interventions } & $\begin{array}{l}\text { Quote: "The intervention group will receive in addition to the usual care, it will receive } \\
\text { the Clinical Pharmacist Care during hospitalization, discharge and during } 2 \text { months } \\
\text { post-discharge, through a home visit at } 30 \pm 5 \text { days post-discharge and a telephone } \\
\text { call at } 60 \pm 5 \text { days. }\end{array}$ \\
\hline & $\begin{array}{l}\text { During hospitalization and at discharge a clinical pharmacist (CP) will monitor daily } \\
\text { pharmacological safety and efficacy of the medication to asses and make appropriate } \\
\text { recommendations. CP will explain the use reasons of each of the drugs. }\end{array}$ \\
\hline & $\begin{array}{l}\text { At } 30 \text { days post-discharge, the CP will review the updated clinical record of patient and } \\
\text { conduct a home visit to enhance and ask about adherence, self-medication, } \\
\text { medication use at that time and possible results of laboratorytests performed and } \\
\text { clarify doubts regarding the use of current medications. The sameactivities will be } \\
\text { made at } 60 \text { days by telephonic way, to reinforce the recommendations" }\end{array}$ \\
\hline \multirow[t]{4}{*}{ Outcomes } & $\begin{array}{l}\text { Incidence of potentially inappropriate medication (Beers criteria and STOPP/START } \\
\text { criteria) }\end{array}$ \\
\hline & Incidence of adverse drug events \\
\hline & Adherence measured with Morisky \& Green \\
\hline & Presence of clinically relevant drug interactions \\
\hline Starting date & May 2015 \\
\hline Contact information & $\begin{array}{l}\text { Dr. Jorge Hasbun } \\
\text { comiteetica@hcuch.cl }\end{array}$ \\
\hline Notes & Intervention phase ongoing \\
\hline
\end{tabular}


Interventions to improve the appropriate use of polypharmacy for older people

\begin{tabular}{|c|c|}
\hline Study name & Elderly Appropriate Treatment in Primary Care (EAT) (TAPAGE) \\
\hline Methods & Randomised trial \\
\hline Participants & $\begin{array}{l}\text { Quote: "Patient } 75 \text { years of age or older, with polypharmacy ( } \geq 5 \text { medications), not } \\
\text { institutionalized" }\end{array}$ \\
\hline \multirow[t]{2}{*}{ Interventions } & $\begin{array}{l}\text { Quote: "Intervention Group "STOPP/START": Training of General Practitioners with } \\
\text { the tool STOPP/START Systematic medication review by GP with STOPP/START }\end{array}$ \\
\hline & $\begin{array}{l}\text { Control group: Patient's usual care by the general practitioner (who will not be trained } \\
\text { in the STOPP/START tool)" }\end{array}$ \\
\hline \multirow[t]{3}{*}{ Outcomes } & STOPP/START used in the intervention \\
\hline & Percentage of unplanned hospitalisation \\
\hline & Decrease in the number of drugs on the prescription \\
\hline Starting date & August 2017 \\
\hline Contact information & Dr. Akim Souag \\
\hline & akim.souag@aphp.fr \\
\hline Notes & Intervention phase ongoing \\
\hline
\end{tabular}

NTR5750 
Interventions to improve the appropriate use of polypharmacy for older people

\begin{tabular}{|c|c|}
\hline Study name & $\begin{array}{l}\text { PROPOSE : PReoperative Optimization of Pharmacotherapy in frail Older patients } \\
\text { with use of STRIPassistant }\end{array}$ \\
\hline Methods & Randomised trial \\
\hline Participants & $\begin{array}{l}\text { Quote: "Age above } 70 \text { years with polypharmacy ( } 5 \text { of more different drugs) and } \\
\text { planned for elective otorhinolaryngological, oral, maxillofacial, cardial, gynecological or } \\
\text { colorectal surgery" }\end{array}$ \\
\hline \multirow[t]{2}{*}{ Interventions } & $\begin{array}{l}\text { Quote: "The intervention consists of a written pharmacotherapeuticadvice, which will } \\
\text { be generated by application of the STRIPassistant. TheSTRIPAssistant is an online } \\
\text { software system (i.e. electronic version of the STRIP) developed to aid general } \\
\text { practitioners and pharmacists to conduct a quick pharmacotherapeutic analysis. }\end{array}$ \\
\hline & $\begin{array}{l}\text { Input for the STRIP assistant are the patient's medication, medical history, vital signs } \\
\text { and relevant laboratory results. The application of the STRIP assistant will be } \\
\text { performed by an independent, clinically experienced resident, who is not involved in } \\
\text { patient care at that moment. The written advice will be provided in a fixed format to the } \\
\text { resident who performs the preoperative geriatric screening and will be used in the } \\
\text { generation of the preoperative advice for the surgeon, including advice concerning } \\
\text { medication" }\end{array}$ \\
\hline \multirow[t]{2}{*}{ Outcomes } & $\begin{array}{l}\text { The efficacy of the use of the STRIP assistant as a tool for polypharmacy optimisation } \\
\text { in addition to usual care in frail elderly patients in the clinical setting. The efficacy will } \\
\text { be defined as the number of Potentially Inappropriate Medications (PIMs) and } \\
\text { Potentially Prescribing Omissions (PPOs) identified per patient, compared to the 'usual } \\
\text { care' }\end{array}$ \\
\hline & $\begin{array}{l}\text { The number of missed, inadequate and potential deleterious advices will also be } \\
\text { reported. Also, well-known ADRs, interactions and dose adjustments will be noted }\end{array}$ \\
\hline Starting date & October 2014 \\
\hline Contact information & $\begin{array}{l}\text { Drs. Marijke Boersma } \\
\text { M.N.Boersma-2@umcutrecht.nl }\end{array}$ \\
\hline Notes & Intervention phase ongoing \\
\hline
\end{tabular}

Prados-Torres 2017 
Interventions to improve the appropriate use of polypharmacy for older people

\begin{tabular}{|c|c|}
\hline Study name & $\begin{array}{l}\text { Improving prescription in primary care patients with multimorbidity and polypharmacy } \\
\text { (Multi-PAP) }\end{array}$ \\
\hline Methods & Randomised clinical trial (cluster) \\
\hline Participants & $\begin{array}{l}\text { Age } 65 \text { to } 74 \text { years, multimorbidity, defined as } \geq 3 \text { chronic diseases, polypharmacy, } \\
\text { defined as } \geq 5 \text { drugs prescribed over at least the } 3 \text { months prior to inclusion in the } \\
\text { study }\end{array}$ \\
\hline Interventions & $\begin{array}{l}\text { Quote: "Intervention group: A complex intervention with two phases is conducted: } \\
\text { First phase: FP training. This will consist of a previously designed training activity, } \\
\text { delivered using the massive online open courses (MOOC) format, including basic } \\
\text { concepts relating to multimorbidity, appropriateness of prescribing, treatment } \\
\text { adherence, the Ariadne principles, and physician-patient shared decision making. } \\
\text { Second phase: Physician-patient interview based on the Ariadne principles. } \\
\text { Control group: Patients in the control group will receive usual clinical care based on } \\
\text { the provision of advice and information and will undergo examinations as } \\
\text { recommended in the CPGs corresponding to each of the patient's chronic diseases" }\end{array}$ \\
\hline Outcomes & $\begin{array}{l}\text { Medication appropriateness index (MAl) } \\
\text { Use of health services: unplanned and/or avoidable hospitalisations, use of emergency } \\
\text { services and PC (FP and nurse). } \\
\text { Quality of life: measured using the EuroQol 5D-5L questionnaire [38, 39]. } \\
\text { Medication safety: measured as the incidence of adverse drug reactions and } \\
\text { potentially hazardous interactions } \\
\text { Treatment adherence: measured using the Morisky-Green test and the Haynes- } \\
\text { Sackett questionnaire }\end{array}$ \\
\hline Starting date & November 2016 \\
\hline Contact information & $\begin{array}{l}\text { Alexandra Prados-Torres } \\
\text { sprados.iacs@aragon.es }\end{array}$ \\
\hline Notes & $\begin{array}{l}\text { NCT02866799 } \\
\text { Intervention phase ongoing }\end{array}$ \\
\hline
\end{tabular}

Romskaug 2017 
Interventions to improve the appropriate use of polypharmacy for older people

\begin{tabular}{|l|l|}
\hline Study name & $\begin{array}{l}\text { Cooperation between geriatricians and general practitioners forimproved } \\
\text { pharmacotherapy in home-dwelling elderly people receiving polypharmacy - the } \\
\text { COOP Study }\end{array}$ \\
\hline Methods & Cluster-randomised, single-blind, controlled trial \\
\hline Participants & $\begin{array}{l}\text { Quote: "The patients must be 70 years or older, use at least seven different } \\
\text { medications and have their medications administered by the home nursing service" }\end{array}$ \\
\hline Interventions & $\begin{array}{l}\text { Quote: "The intervention consists of three main parts: (1) clinical geriatric assessment } \\
\text { ofthe patient, combined with a thorough review of their medications; (2) a meeting } \\
\text { between the geriatrician and general practitioner, where the two physicians combine } \\
\text { their competence and knowledge and discuss the drug list systematically; (3) clinical } \\
\text { follow-up, depending on the medication changes that have been done" }\end{array}$ \\
\hline Outcomes & $\begin{array}{l}\text { Quote: "The primary outcome measure is health-related quality oflife according tothe } \\
15 D \text { instrument. Secondary outcome measures include physical and cognitive } \\
\text { functioning, medication appropriateness (MAl), falls, carer burden, use of health } \\
\text { services (hospital or nursing home admissions, use of home nursing services) and } \\
\text { mortality" }\end{array}$ \\
\hline Starting date & \begin{tabular}{l} 
March 2015 \\
\hline Contact information
\end{tabular} \\
\hline $\begin{array}{l}\text { Rita Romskaug } \\
\text { Department of Geriatric medicine, Institute of Clinical Medicine, University of Oslo, } \\
\text { Oslo, Norway } \\
\text { ritulf@gmail.com }\end{array}$ \\
\hline $\begin{array}{l}\text { NCT02379455 } \\
\text { Intervention phase ongoing }\end{array}$ \\
\hline
\end{tabular}

Selic 2016 
Interventions to improve the appropriate use of polypharmacy for older people

\begin{tabular}{|c|c|}
\hline Study name & Use of web-based application to improve prescribing in home-living elderly \\
\hline Methods & Randomised trial \\
\hline Participants & $\begin{array}{l}\text { Patient participants: chronically-ill elderly people, older than } 65 \text { years who live at home } \\
\text { and regularly receive at least one drug. }\end{array}$ \\
\hline Interventions & $\begin{array}{l}\text { Quote: "Participants' data will be entered into a web-based application and screened } \\
\text { for potentially inappropriate prescribing using STOPP and START criteria. Identified } \\
\text { potentially inappropriate prescriptions will be presented to participants' physicians for } \\
\text { consideration and change. Physicians of participants in the control group will not be } \\
\text { informed about potentially inappropriate prescriptions" }\end{array}$ \\
\hline Outcomes & $\begin{array}{l}\text { Quote: "Quality of life index (EQ-5D); quality of prescribing-the presence of } \\
\text { inappropriate prescribing according to the START/STOPP criteria (at least one } \\
\text { criterion from both lists was violated) or the presence of polypharmacy (more than } 5 \\
\text { concomitant medications); the number of active ingredients regularly taken by the } \\
\text { patient; adherence according to the Morisky 4-item questionnaire; non-planned } \\
\text { hospitalizations and non-planned/urgent visits to a clinical specialist; number of visits } \\
\text { to the emergency room or the emergency physician's home visits in the previous year; } \\
\text { number of visits to the GP in the year concerned; number of inappropriate } \\
\text { prescriptions according to the START/STOPPcriteria; and number of interactions } \\
\text { between the prescribed medications marked 'major"” }\end{array}$ \\
\hline Starting date & 2014 \\
\hline Contact information & $\begin{array}{l}\text { Polona Selic } \\
\text { Department of Family Medicine, Faculty of Medicine, University of Ljubljana, Poljanski } \\
\text { nasip 58, Ljubljana, Slovenia. } \\
\text { polona.selic@siol.net }\end{array}$ \\
\hline Notes & $\begin{array}{l}\text { Protocol: Selic et al. (2016). The Effects of a Web Application and Medical Monitoring } \\
\text { on the Quality of Medication, Adverse Drug Events and Adherence in the Elderly } \\
\text { Living at Home: a Protocol of the Study. Materia Socio-Medica, 28(6), 432-436 } \\
\text { Intervention phase complete, no results currently published }\end{array}$ \\
\hline
\end{tabular}

\section{Footnotes}

ADEs: adverse drug events

ADR: adverse drug reactions

CRR: Clinical Rule Reporter

CQC: Care Quality Commission

IADL: Instrumental Activities of Daily Living

MAI: Medication Appropriateness Index

MMAS-4: Morisky Medication Adherence Scale

PIMs: Potentially inappropriate medications

PIP: potentially inappropriate prescribing

PPOs: potential prescribing omissions

START: Screening Tool to Alert doctors to the Right Treatment

STOPP: Screening Tool of Older Person's Prescriptions

TRIM: Tool to Reduce Inappropriate Medication

TSQM: Treatment Satisfaction Questionnaire for Medication

\section{Summary of findings tables}

\section{Pharmaceutical care compared with usual care for older people receiving polypharmacy}

\section{Patient or population: older people receiving polypharmacy}

Settings: community, nursing home, hospital

Intervention: pharmaceutical care

Comparison: usual care 
Interventions to improve the appropriate use of polypharmacy for older people

\begin{tabular}{|c|c|c|c|c|c|c|}
\hline \multirow[t]{2}{*}{ Outcomes } & \multicolumn{2}{|l|}{ Effect estimate } & \multirow{2}{*}{$\begin{array}{l}\text { Relative } \\
\text { Risk } \\
\text { effect } \\
\text { e }(95 \% \mathrm{Cl})\end{array}$} & \multirow{2}{*}{$\begin{array}{l}\text { No. of } \\
\text { participants } \\
\text { (studies) }\end{array}$} & \multirow{2}{*}{$\begin{array}{l}\text { Certainty } \\
\text { of } \\
\text { evidence } \\
\text { (GRADE) }\end{array}$} & \multirow{2}{*}{ Comments } \\
\hline & Usual care & Pharmaceutical care & & & & \\
\hline \multirow{5}{*}{$\begin{array}{l}\text { Medication } \\
\text { appropriateness (as } \\
\text { measured by an } \\
\text { implicit tool) } \\
\text { From baseline to } \\
\text { follow-up } \\
\text { Follow-up: } 0 \text { to } 6 \\
\text { months }\end{array}$} & \multirow{5}{*}{$\begin{array}{l}\text { Medication } \\
\text { appropriateness (as } \\
\text { measured by an } \\
\text { implicit tool) across } \\
\text { control groups } \\
\text { ranged from } \\
-\mathbf{0 . 4 9} \text { to } 2.86\end{array}$} & \multirow{5}{*}{$\begin{array}{l}\text { Medication } \\
\text { appropriateness (as } \\
\text { measured by an } \\
\text { implicit tool) in the } \\
\text { intervention groups } \\
\text { was } \\
4.76 \text { lower } \\
\text { (0.33 to } 9.20 \text { lower) }\end{array}$} & & \multirow[t]{5}{*}{$\begin{array}{l}517 \\
\text { (5 studies) }\end{array}$} & \multirow{5}{*}{$\begin{array}{l}\oplus \ominus \ominus \ominus \\
\text { very low } \\
\text { a,b,c,d }\end{array}$} & \multirow{5}{*}{$\begin{array}{l}\text { MAl used as implicit tool } \\
\text { in the pooled studies } \\
\text { A sensitivity analysis } \\
\text { showed that medication } \\
\text { appropriateness (as } \\
\text { measured byan implicit } \\
\text { tool) in the intervention } \\
\text { group was } 0.50 \text { lower } \\
\text { ( } 2.27 \text { lower to } 1.28 \\
\text { higher) } \\
\text { Heterogeneity: } I^{2}=57 \% \text {, } \\
P=0.10\end{array}$} \\
\hline & & & & & & \\
\hline & & & & & & \\
\hline & & & & & & \\
\hline & & & & & & \\
\hline \multicolumn{7}{|c|}{ Potentially inappropriate medications } \\
\hline $\begin{array}{l}\text { The number of } \\
\text { potentially } \\
\text { inappropriate } \\
\text { medications (PIMs) } \\
\text { Follow-up: } 0 \text { to } 12 \\
\text { months }\end{array}$ & $\begin{array}{l}\text { The number of } \\
\text { PIMs (Standardised } \\
\text { mean§) across } \\
\text { control groups } \\
\text { ranged from } \\
\mathbf{0 . 0 4} \text { to } 1.29\end{array}$ & $\begin{array}{l}\text { The number of } \\
\text { PIMs } \\
\text { (Standardised } \\
\text { mean§) in the } \\
\text { intervention groups } \\
\text { was } 0.22 \text { lower } \\
(0.05 \text { to } 0.38 \text { lower) }\end{array}$ & & $\begin{array}{l}1832 \\
\text { (7 studies) }\end{array}$ & $\begin{array}{l}\oplus \ominus \ominus \ominus \\
\text { very low } \\
b, c\end{array}$ & $\begin{array}{l}\text { STOPP and Beers criteria } \\
\text { used as explicit tools in } \\
\text { the pooled studies }\end{array}$ \\
\hline \multirow{5}{*}{$\begin{array}{l}\text { The proportion of } \\
\text { patientswith one or } \\
\text { more potentially } \\
\text { inappropriate } \\
\text { medications (PIMs) } \\
\text { Follow-up: } 0 \text { to } 12 \\
\text { months }\end{array}$} & \multirow{5}{*}{421 per 1000} & \multirow{5}{*}{$\begin{array}{l}333 \text { per } 1000 \\
(257 \text { to } 430)\end{array}$} & \multirow{5}{*}{$\begin{array}{l}\text { RR } 0.79 \\
(0.61 \text { to } \\
1.02)\end{array}$} & \multirow{5}{*}{$\begin{array}{l}3079 \\
(11 \text { studies }\end{array}$} & \multirow{5}{*}{$\begin{array}{l}\oplus \ominus \ominus \ominus \\
\text { very lowa } \\
b, c\end{array}$} & \multirow{5}{*}{$\begin{array}{l}\text { STOPP and Beers criteria } \\
\text { used as explicit tools in } \\
\text { the pooled studies } \\
\text { A sensitivity analysis } \\
\text { showed that the } \\
\text { proportion of patients with } \\
\text { one or more potentially } \\
\text { inappropriate medications } \\
\text { in the intervention group } \\
\text { was lower (333 per 1000) } \\
\text { Heterogeneity: } \mathrm{I}^{2}=75 \% \text {, } \\
\mathrm{P}=0.24\end{array}$} \\
\hline & & & & & & \\
\hline & & & & & & \\
\hline & & & & & & \\
\hline & & & & & & \\
\hline \multicolumn{7}{|c|}{ Potential prescribing omissions } \\
\hline $\begin{array}{l}\text { The number of } \\
\text { potential prescribing } \\
\text { omissions (PPOs) } \\
\text { Follow-up: } 0 \text { to } 12 \\
\text { months }\end{array}$ & $\begin{array}{l}\text { The number of } \\
\text { PPOs } \\
\text { (Standardised } \\
\text { mean§) across } \\
\text { control groups } \\
\text { ranged from } \\
\mathbf{0 . 6 3} \text { to } 0.85\end{array}$ & $\begin{array}{l}\text { The number of } \\
\text { PPOs } \\
\text { (Standardised } \\
\text { mean§) in the } \\
\text { intervention groups } \\
\text { was } 0.81 \text { lower } \\
(0.64 \text { to } 0.98 \text { lower) }\end{array}$ & & $\begin{array}{l}569 \\
(2 \text { studies })\end{array}$ & $\operatorname{low}^{\oplus \oplus \ominus}$ & $\begin{array}{l}\text { START and ACOVE used } \\
\text { as explicit tools in the } \\
\text { pooled studies }\end{array}$ \\
\hline $\begin{array}{l}\text { The proportion of } \\
\text { patientswith one or } \\
\text { more potential } \\
\text { prescribing } \\
\text { omissions (PPOs) }\end{array}$ & 387 per 1000 & $\begin{array}{l}155 \text { per } 1000 \\
(70 \text { to } 329)\end{array}$ & $\begin{array}{l}\text { RR } 0.40 \\
(0.18 \text { to } \\
0.85)\end{array}$ & $\begin{array}{l}1310 \\
\text { (5 studies) }\end{array}$ & $\begin{array}{l}\oplus \ominus \ominus \ominus \\
\text { very low } \\
\text { c }\end{array}$ & $\begin{array}{l}\text { START and ACOVE used } \\
\text { as explicit tools in the } \\
\text { pooled studies }\end{array}$ \\
\hline $\begin{array}{l}\text { Follow-up: } 0 \text { to } 24 \\
\text { months }\end{array}$ & & & & & & \\
\hline
\end{tabular}


Interventions to improve the appropriate use of polypharmacy for older people

To assess the appropriateness of the drug, please answer the following questions and circle the applicable score.

1. Is there an indication for the drug?

Comments:

2. Is the medication effective for the condition?

Comments:

3. Is the dosagecorrect?

Comments:

4. Are the directions correct?

Comments:

5. Are the directions practical?

Comments:

6. Are there clinically significant drug-drug interactions?

Comments:

7. Are there clinically significant drug-disease/condition interactions?

Comments:

8. Is there unnecessary duplication with other drug(s)?

Comments:

9. Is the duration of therapy acceptable?

Comments:

10. Is this drug the least expensive alternative compared with others of equal utility?

Comments:

\begin{tabular}{|c|c|c|}
\hline 1 & 23 & \multirow{2}{*}{$\begin{array}{l}9 \\
\mathrm{DK}\end{array}$} \\
\hline Indicated & Not Indicated & \\
\hline 1 & 23 & -9 \\
\hline Effective & Ineffective & DK \\
\hline 1 & 23 & 9 \\
\hline Correct & Incorrect & DK \\
\hline 1 & 23 & -9 \\
\hline Correct & Incorrect & DK \\
\hline 1 & 23 & -9 \\
\hline Practical & Impractical & DK \\
\hline 1 & 23 & -9 \\
\hline Insignificant & Significant & DK \\
\hline 1 & 23 & -9 \\
\hline Insignificant & $\exists$ Significant & DK \\
\hline 1 & 23 & -9 \\
\hline Necessary & Unnecessary & DK \\
\hline 1 & 23 & 9 \\
\hline Acceptable & Unacceptable & DK \\
\hline 1 & 23 & -9 \\
\hline
\end{tabular}

Footnotes

DK: Don'tknow

2 Updated Beers (2003) criteria for potentially inappropriate medication use in older adults: independent of diagnosis or condition

\begin{tabular}{|c|c|c|}
\hline Drug & Concern & $\begin{array}{l}\text { Severity } \\
\text { rating } \\
\text { (high or } \\
\text { low) }\end{array}$ \\
\hline $\begin{array}{l}\text { Propoxyphene (Darvon) and combination products } \\
\text { (Darvon with ASA, Darvon-N and Darvocet-N) }\end{array}$ & $\begin{array}{l}\text { Offers few analgesic advantages over paracetamol } \\
\text { (acetaminophen), yet is associated with the adverse } \\
\text { effects of other narcotic drugs }\end{array}$ & Low \\
\hline Indomethacin (Indocin and Indocin SR) & $\begin{array}{l}\text { Of all available NSAIDs, this drug produces the most } \\
\text { CNS adverse effects }\end{array}$ & High \\
\hline Pentazocine (Talwin) & $\begin{array}{l}\text { Narcotic analgesic that causes more CNS adverse } \\
\text { effects, including confusion and hallucinations, more } \\
\text { commonly than other narcotic drugs. Additionally, it is } \\
\text { a mixed agonist and antagonist }\end{array}$ & High \\
\hline Trimethobenzamide (Tigan) & $\begin{array}{l}\text { One of the least effective antiemetic drugs, yet it can } \\
\text { cause extrapyramidal adverse effects }\end{array}$ & High \\
\hline $\begin{array}{l}\text { Muscle relaxants and antispasmodics: methocarbamol } \\
\text { (Robaxin), carisoprodol(Soma), chlorzoxazone (Paraflex), } \\
\text { metaxalone(Skelaxin), cyclobenzaprine(Flexeril) and } \\
\text { oxybutynin (Ditropan). Do notconsidertheextended- } \\
\text { release formulation of Ditropan XL }\end{array}$ & $\begin{array}{l}\text { Most muscle relaxants and antispasmodic drugsare } \\
\text { poorly tolerated by elderly patients because they cause } \\
\text { anticholinergic adverse effects, sedation and } \\
\text { weakness. Additionally, their effectiveness at doses } \\
\text { tolerated by elderly patients is questionable }\end{array}$ & High \\
\hline
\end{tabular}


Interventions to improve the appropriate use of polypharmacy for older people

\begin{tabular}{|c|c|c|}
\hline Flurazepam (Dalmane) & $\begin{array}{l}\text { This benzodiazepine hypnotichas an extremelylong } \\
\text { half-life in elderly patients (often days), producing } \\
\text { prolonged sedation and increasing the incidence of } \\
\text { falls and fracture. Medium- or short-acting } \\
\text { benzodiazepines are preferable }\end{array}$ & High \\
\hline $\begin{array}{l}\text { Amitriptyline (Elavil), chlordiazepoxide-amitriptyline } \\
\text { (Limbitrol) and perphenazine-amitriptyline (Triavil) }\end{array}$ & $\begin{array}{l}\text { Because of its strong anticholinergic and sedation } \\
\text { properties, amitriptyline is rarely the antidepressant of } \\
\text { choice for elderly patients }\end{array}$ & High \\
\hline Doxepin (Sinequan) & $\begin{array}{l}\text { Because of its strong anticholinergic and sedating } \\
\text { properties, doxepin is rarely the antidepressant of } \\
\text { choice for elderlypatients }\end{array}$ & High \\
\hline Meprobamate (Miltown and Equanil) & $\begin{array}{l}\text { This is a highly addictive and sedating anxiolytic. } \\
\text { Those using } \\
\text { meprobamate for prolonged periods may become } \\
\text { addicted and may need to be withdrawn slowly }\end{array}$ & High \\
\hline $\begin{array}{l}\text { Doses of short-acting benzodiazepines: doses greater } \\
\text { than lorazepam (Ativan) } 3 \mathrm{mg} \text {; oxazepam (Serax) } 60 \mathrm{mg} \text {; } \\
\text { iprazolam (Xanax) } 2 \mathrm{mg} \text {; temazepam (Restoril) } 15 \mathrm{mg} \text { and } \\
\text { triazolam (Halcion) } 0.25 \mathrm{mg}\end{array}$ & $\begin{array}{l}\text { Because of increased sensitivity to benzodiazepines in } \\
\text { elderlypatients, smaller doses maybe effective and } \\
\text { safer. Total daily doses should rarely exceed the } \\
\text { suggested maximum }\end{array}$ & High \\
\hline $\begin{array}{l}\text { Long-acting benzodiazepines: chlordiazepoxide (Librium), } \\
\text { chlordiazepoxide-amitriptyline (Limbitrol), clidinium- } \\
\text { chlordiazepoxide } \neg(\text { Librax), diazepam (Valium), quazepam } \\
\text { (Doral), halazepam (Paxipam) and chlorazepate } \\
\text { (Tranxene) }\end{array}$ & $\begin{array}{l}\text { These drugs have a long half-life in elderly patients } \\
\text { (often several days), producing prolonged sedation } \\
\text { and increasing the risk of falls and fractures. Short- } \\
\text { and intermediate-acting benzodiazepines are preferred } \\
\text { if a benzodiazepine is required } \\
\neg\end{array}$ & High \\
\hline $\begin{array}{l}\text { Disopyramide (Norpace and Norpace CR) } \\
\neg \\
\neg\end{array}$ & $\begin{array}{l}\text { Of all antiarrhythmic drugs, this is the most potent } \\
\text { negative inotrope and therefore may induce heart } \\
\text { failure in elderly patients. It also has strong } \\
\text { anticholinergic effects. Other } \neg \text { antiarrhythmic drugs } \\
\text { should be used as well }\end{array}$ & High \\
\hline $\begin{array}{l}\text { Digoxin (Lanoxin) (should not exceed } 0.125 \mathrm{mg} / \mathrm{d} \text { except } \\
\text { when treating atrial arrhythmias) }\end{array}$ & $\begin{array}{l}\text { Decreased renal clearance may lead to increased risk } \\
\text { of toxic effects }\end{array}$ & Low \\
\hline $\begin{array}{l}\text { Short-acting dipyridamole (Persantine). Do not consider } \\
\text { the long-acting dipyridamole (which has better properties } \\
\text { than the short-acting formulation in older adults) except } \\
\text { with patients with artificial } \\
\text { heart valves }\end{array}$ & May cause orthostatic hypotension & Low \\
\hline $\begin{array}{l}\text { Methyldopa (Aldomet) and methyldopa- } \\
\text { hydrochlorothiazide (Aldoril) }\end{array}$ & $\begin{array}{l}\text { May cause bradycardia and exacerbate depression in } \\
\text { elderly patients }\end{array}$ & High \\
\hline Reserpine at doses $>0.25 \mathrm{mg}$ & $\begin{array}{l}\text { Mayinduce depression, impotence, sedation and } \\
\text { orthostatic hypotension }\end{array}$ & Low \\
\hline Chlorpropamide (Diabinese) & $\begin{array}{l}\text { It has a prolonged half-life in elderly patients and could } \\
\text { cause prolonged hypoglycaemia. Additionally, it is the } \\
\text { only oral hypoglycaemic agent that causes SIADH }\end{array}$ & High \\
\hline $\begin{array}{l}\text { Gl antispasmodic drugs: dicyclomine (Bentyl), } \\
\text { hyoscyamine (Levsin and Levsinex), propantheline (Pro- } \\
\text { Banthine), belladonna alkaloids (Donnatal and others) } \\
\text { and clidinium-chlordiazepoxide (Librax) }\end{array}$ & $\begin{array}{l}\text { Gl antispasmodic drugs have potent anticholinergic } \\
\text { effects and have uncertain effectiveness. These drugs } \\
\text { should be avoided (especially for long-term use) } \\
\neg\end{array}$ & High \\
\hline $\begin{array}{l}\text { Anticholinergics and antihistamines: chlorpheniramine } \\
\text { (Chlor-Trimeton), diphenhydramine (Benadryl), } \\
\text { hydroxyzine } \\
\text { (Vistaril and Atarax), cyproheptadine } \neg \text { (Periactin), } \\
\text { promethazine (Phenergan), tripelennamine, } \\
\text { dexchlorpheniramine (Polaramine) }\end{array}$ & $\begin{array}{l}\text { All non-prescription and many prescription } \\
\text { antihistamines may have potent anticholinergic } \\
\text { properties. Non-anticholinergic antihistamines are } \\
\text { preferred in elderly patients for the treatment of allergic } \\
\text { reactions } \\
\neg\end{array}$ & High \\
\hline
\end{tabular}


Interventions to improve the appropriate use of polypharmacy for older people

\begin{tabular}{|c|c|c|}
\hline Diphenhydramine (Benadryl) & $\begin{array}{l}\text { May cause confusion and sedation. Should not be } \\
\text { used as a hypnotic, and when used to treat emergency } \\
\text { allergic reactions, it should be used in the smallest } \\
\text { possible dose }\end{array}$ & High \\
\hline $\begin{array}{l}\text { Ergot mesyloids (Hydergine) and cyclandelate } \\
\text { (Cyclospasmol) }\end{array}$ & $\begin{array}{l}\text { Have not been shown to be effective in the doses } \\
\text { studied }\end{array}$ & Low \\
\hline Ferrous sulphate $\neg>325 \mathrm{mg} / \mathrm{d}$ & $\begin{array}{l}\text { Doses }>325 \mathrm{mg} / \mathrm{d} \text { do not dramatically increase the } \\
\text { amount absorbed but greatly increase the incidence of } \\
\text { constipation }\end{array}$ & Low \\
\hline $\begin{array}{l}\text { All barbiturates (except phenobarbital) except when used } \\
\text { to control seizures }\end{array}$ & $\begin{array}{l}\text { Are highly addictive and cause more adverse effects } \\
\text { than most sedative or hypnotic drugs in elderly patients }\end{array}$ & High \\
\hline Meperidine (Demerol) & $\begin{array}{l}\text { Not an effective oral analgesic in doses commonly } \\
\text { used. May cause confusion and has many } \\
\text { disadvantages compared with other narcotic drugs }\end{array}$ & High \\
\hline Ticlopidine (Ticlid) & $\begin{array}{l}\text { Has been shown to be no better than aspirin in } \\
\text { preventing clotting and maybe considerablymore toxic } \\
\text { Safer, more effective alternatives exist }\end{array}$ & High \\
\hline Ketorolac (Toradol) & $\begin{array}{l}\text { Immediateandlong-term use should be avoided in } \\
\text { older people, as a significant number have } \\
\text { asymptomatic GI pathological conditions }\end{array}$ & High \\
\hline Amphetamines and anorexic agents & $\begin{array}{l}\text { These drugs have potential for causing dependence, } \\
\text { hypertension, angina and myocardial infarction }\end{array}$ & High \\
\hline $\begin{array}{l}\text { Long-term use of full-dosage, longer half-life, } \\
\text { non-COX-selective NSAIDs: naproxen (Naprosyn, } \\
\text { Avaproxand Aleve), oxaprozin (Daypro) and piroxicam } \\
\text { (Feldene) }\end{array}$ & $\begin{array}{l}\text { Have the potential to produce GI bleeding, renal } \\
\text { failure, hypertension and heart failure } \\
\neg\end{array}$ & High \\
\hline Daily fluoxetine (Prozac) & $\begin{array}{l}\text { Long half-life of drug and risk of producing excessive } \\
\text { CNS stimulation, sleep disturbances and increasing } \\
\text { agitation. Safer alternatives are available }\end{array}$ & High \\
\hline $\begin{array}{l}\text { Long-term use of stimulant laxatives: bisacodyl(Dulcolax), } \\
\text { cascara sagrada and Neoloid except in the presence of } \\
\text { opiate analgesic use }\end{array}$ & May exacerbate bowel dysfunction & High \\
\hline Amiodarone (Cordarone) & $\begin{array}{l}\text { Associated with QT interval problems and risk of } \\
\text { provoking torsades de pointes. Lack of efficacy in older } \\
\text { adults } \\
\neg\end{array}$ & High \\
\hline Orphenadrine (Norflex) & $\begin{array}{l}\text { Causes greater sedation and anticholinergic adverse } \\
\text { effects than saferalternatives }\end{array}$ & High \\
\hline Guanethidine (Ismelin) & $\begin{array}{l}\text { May cause orthostatic hypotension. Safer alternatives } \\
\text { are available }\end{array}$ & High \\
\hline Guanadrel (Hylorel) & May cause orthostatic hypotension & High \\
\hline Cyclandelate (Cyclospasmol) & Lack of efficacy & Low \\
\hline Isoxsurpine (Vasodilan) & Lack of efficacy & Low \\
\hline Nitrofurantoin (Macrodantin) & $\begin{array}{l}\text { Potential for renal impairment. Safer alternatives are } \\
\text { available }\end{array}$ & High \\
\hline Doxazosin (Cardura) & $\begin{array}{l}\text { Potential for hypotension, dry mouth and urinary } \\
\text { problems }\end{array}$ & Low \\
\hline Methyltestosterone (Android, Virilon and Testrad) & $\begin{array}{l}\text { Potential for prostatichyperplasiaand cardiac } \\
\text { problems }\end{array}$ & High \\
\hline Thioridazine (Mellaril) & $\begin{array}{l}\text { Greater potential for CNS and extrapyramidal adverse } \\
\text { effects }\end{array}$ & High \\
\hline Mesoridazine (Serentil) & CNS and extrapyramidal adverse effects & High \\
\hline
\end{tabular}


Interventions to improve the appropriate use of polypharmacy for older people

\begin{tabular}{|c|c|c|}
\hline Short-acting nifedipine (Procardia and Adalat) & Potential for hypotension and constipation & High \\
\hline Clonidine (Catapres) & $\begin{array}{l}\text { Potential for orthostatic hypotension and CNS adverse } \\
\text { effects }\end{array}$ & Low \\
\hline Mineral oil & $\begin{array}{l}\text { Potential for aspiration and adverse effects. Safer } \\
\text { alternatives are available }\end{array}$ & High \\
\hline Cimetidine (Tagamet) & CNS adverse effects including confusion & Low \\
\hline Ethacrynic acid (Edecrin) & $\begin{array}{l}\text { Potential for hypertension and fluid imbalances. Safer } \\
\text { alternatives are available }\end{array}$ & Low \\
\hline Desiccated thyroid & $\begin{array}{l}\text { Concerns about cardiac effects. Safer alternatives are } \\
\text { available }\end{array}$ & High \\
\hline $\begin{array}{l}\text { Amphetamines (excluding methylphenidate hydrochloride } \\
\text { and anorexic agents) }\end{array}$ & CNS stimulant adverse effects & High \\
\hline Oestrogens only (oral) & $\begin{array}{l}\text { Evidence of the carcinogenic (breast and endometrial } \\
\text { cancer) potential of these agents and lack of } \\
\text { cardioprotective effects in older women }\end{array}$ & Low \\
\hline
\end{tabular}

\section{Footnotes}

Source: Fick 2003.

CNS: central nervous system; COX: cyclo-oxygenase; CR: controlled release; GI: gastrointestinal; NSAID: non-steroidal antiinflammatory drug; SIADH: syndrome of inappropriate antidiuretic hormone hypersecretion; SR: slow release.

3 Updated Beers (2003) criteria for potentially inappropriate medication use in older adults: considering diagnoses or conditions

\begin{tabular}{|c|c|c|c|}
\hline Disease or condition & Drug & Concern & $\begin{array}{l}\text { Severity } \\
\text { rating } \\
\text { (high or } \\
\text { low) }\end{array}$ \\
\hline Heart failure & $\begin{array}{l}\text { Disopyramide (Norpace) and high-sodium-content drugs } \\
\text { (sodium and sodium salts (alginate bicarbonate, } \\
\text { biphosphate, citrate, phosphate, salicylate, and sulphate)) }\end{array}$ & $\begin{array}{l}\text { Negative inotropic effect. } \\
\text { Potential to promote fluid } \\
\text { retention and exacerbation of } \\
\text { heart failure }\end{array}$ & High \\
\hline Hypertension & $\begin{array}{l}\text { Phenylpropanolamine hydrochloride (removed from the } \\
\text { market in 2001), pseudoephedrine; diet pills and } \\
\text { amphetamines }\end{array}$ & $\begin{array}{l}\text { May produce elevation of } \\
\text { blood pressure secondary to } \\
\text { sympathomimetic activity }\end{array}$ & High \\
\hline $\begin{array}{l}\text { Gastric or duodenal } \\
\text { ulcers }\end{array}$ & NSAIDs and aspirin (> 325 mg) (COXIBs excluded) & $\begin{array}{l}\text { May exacerbate existing } \\
\text { ulcers or produce } \\
\text { new/additional ulcers }\end{array}$ & High \\
\hline Seizures or epilepsy & $\begin{array}{l}\text { Clozapine (Clozaril), chlorpromazine (Thorazine), } \\
\text { thioridazine (Mellaril) and thiothixene (Navane) }\end{array}$ & May lower seizure thresholds & High \\
\hline $\begin{array}{l}\text { Blood clotting } \\
\text { disorders } \\
\text { or receiving } \\
\text { anticoagulant therapy }\end{array}$ & $\begin{array}{l}\text { Aspirin, NSAIDs, dipyridamole (Persantin), ticlopidine (Ticlid) } \\
\text { and clopidogrel (Plavix) } \\
\neg\end{array}$ & $\begin{array}{l}\text { May prolong clotting time and } \\
\text { elevate INR values or inhibit } \\
\text { platelet } \neg \text { aggregation, } \\
\text { resulting in increased } \\
\text { potential for bleeding } \\
\neg\end{array}$ & High \\
\hline $\begin{array}{l}\text { Bladder outflow } \\
\text { obstruction }\end{array}$ & $\begin{array}{l}\text { Anticholinergics and antihistamines, gastrointestinal } \\
\text { antispasmodics, muscle relaxants, oxybutynin (Ditropan), } \\
\text { flavoxate (Urispas), anticholinergics, antidepressants, } \\
\text { decongestants and tolterodine } \neg \text { (Detrol) }\end{array}$ & $\begin{array}{l}\text { May decrease urinary flow, } \\
\text { leading to urinary } \\
\text { retention } \\
\neg\end{array}$ & High \\
\hline Stress incontinence & $\begin{array}{l}\alpha \text {-Blockers (doxazosin, prazosin and terazosin), } \\
\text { anticholinergics, tricyclic antidepressants (imipramine } \\
\text { hydrochloride, doxepin hydrochloride and amitriptyline } \\
\text { hydrochloride) and long-acting benzodiazepines }\end{array}$ & $\begin{array}{l}\text { May produce polyuria and } \\
\text { worsening of incontinence }\end{array}$ & High \\
\hline
\end{tabular}


Interventions to improve the appropriate use of polypharmacy for older people

\begin{tabular}{|c|c|c|c|}
\hline Arrhythmias & $\begin{array}{l}\text { Tricyclic antidepressants (imipramine hydrochloride, doxepin } \\
\text { hydrochloride and amitriptyline hydrochloride) }\end{array}$ & $\begin{array}{l}\text { Concern due to proarrhythmic } \\
\text { effects and ability to produce } \\
\text { QT interval changes }\end{array}$ & High \\
\hline Insomnia & $\begin{array}{l}\text { Decongestants, theophylline (Theodur), methylphenidate } \\
\text { (Ritalin), MAOls and amphetamines }\end{array}$ & $\begin{array}{l}\text { Concern due to CNS } \\
\text { stimulant effects }\end{array}$ & High \\
\hline Parkinson's disease & $\begin{array}{l}\text { Metoclopramide (Reglan), conventional antipsychotics and } \\
\text { tacrine (Cognex) }\end{array}$ & $\begin{array}{l}\text { Concern due to their } \\
\text { antidopaminergic/ } \\
\text { cholinergic effects }\end{array}$ & High \\
\hline Cognitive impairment & $\begin{array}{l}\text { Barbiturates, anticholinergics, antispasmodics and muscle } \\
\text { relaxants. CNS stimulants: dextroamphetamine (Adderall), } \\
\text { methylphenidate (Ritalin), methamphetamine (Desoxyn) and } \\
\text { pemolin }\end{array}$ & $\begin{array}{l}\text { Concern due to CNS-altering } \\
\text { effects }\end{array}$ & High \\
\hline Depression & $\begin{array}{l}\text { Long-term benzodiazepine use. Sympatholytic agents: } \\
\text { methyldopa (Aldomet), reserpine and guanethidine (Ismelin) }\end{array}$ & $\begin{array}{l}\text { May produce or exacerbate } \\
\text { depression }\end{array}$ & High \\
\hline $\begin{array}{l}\text { Anorexia and } \\
\text { malnutrition }\end{array}$ & $\begin{array}{l}\text { CNS stimulants: dextroamphetamine (Adderall), } \\
\text { methylphenidate (Ritalin), methamphetamine (Desoxyn), } \\
\text { pemolin and fluoxetine (Prozac) }\end{array}$ & $\begin{array}{l}\text { Concern due to appetite- } \\
\text { suppressing effects }\end{array}$ & High \\
\hline Syncope or falls & $\begin{array}{l}\text { Short- to intermediate-acting benzodiazepine and tricyclic } \\
\text { antidepressants (imipramine hydrochloride, } \\
\text { doxepin hydrochloride and amitriptyline hydrochloride) } \neg\end{array}$ & $\begin{array}{l}\text { May produce ataxia, impaired } \\
\text { psychomotor } \\
\text { function, syncope and } \\
\text { additional falls } \\
\text { ᄀ }\end{array}$ & High \\
\hline SIADH/hyponatraemia & $\begin{array}{l}\text { SSRIs: fluoxetine (Prozac), citalopram (Celexa), fluvoxamine } \\
\text { (Luvox), paroxetine (Paxil) and sertraline (Zoloft) }\end{array}$ & $\begin{array}{l}\text { May exacerbate or cause } \\
\text { SIADH }\end{array}$ & Low \\
\hline Seizure disorder & Bupropion (Wellbutrin) & Maylower seizure threshold & High \\
\hline Obesity & Olanzapine (Zyprexa) & $\begin{array}{l}\text { Maystimulate appetite and } \\
\text { increase weightgain }\end{array}$ & Low \\
\hline COPD & $\begin{array}{l}\text { Long-acting benzodiazepines: chlordiazepoxide (Librium), } \\
\text { chlordiazepoxide-amitriptyline (Limbitrol), clidinium- } \\
\text { chlordiazepoxide (Librax), diazepam (Valium), quazepam } \\
\text { (Doral), halazepam (Paxipam) and chlorazepate (Tranxene). } \\
\beta \text {-Blockers: propranolol } \\
\neg\end{array}$ & $\begin{array}{l}\text { CNS adverse effects. May } \\
\text { induce respiratory depression. } \\
\text { May exacerbate or cause } \\
\text { respiratory depression } \\
\neg\end{array}$ & High \\
\hline Chronic constipation & $\begin{array}{l}\text { Calcium channel blockers, anticholinergics and tricyclic } \\
\text { antidepressant (imipramine hydrochloride, doxepin } \\
\text { hydrochloride and amitriptyline hydrochloride) }\end{array}$ & May exacerbate constipation & Low \\
\hline
\end{tabular}

Footnotes

Source: Fick 2003.

COPD: chronic obstructive pulmonary disease; COXIB: cyclo-oxygenase inhibitor; INR: international normalized ratio; MAOI: monoamine oxidase inhibitor; NSAID: non-steroidal anti-inflammatory drug; SIADH: syndrome of inappropriate antidiuretic hormone secretion; SSRIs: selective serotonin reuptake inhibitors.

4 Updated Beers (2012) criteria for potentially inappropriate medication usage in older adults: independent of diagnosis or condition

\begin{tabular}{|c|c|c|c|c|}
\hline $\begin{array}{l}\text { Organ System or } \\
\text { Therapeutic Category or } \\
\text { Drug }\end{array}$ & Rationale & Recommendation & $\begin{array}{l}\text { Quality of } \\
\text { Evidence }\end{array}$ & $\begin{array}{l}\text { Strength of } \\
\text { Recommendation }\end{array}$ \\
\hline \multicolumn{5}{|c|}{ Anticholinergics (excludes TCAs) } \\
\hline
\end{tabular}


Interventions to improve the appropriate use of polypharmacy for older people

\begin{tabular}{|c|c|c|c|c|}
\hline $\begin{array}{l}\text { First-generation } \\
\text { antihistamines (as single } \\
\text { agent or as part of } \\
\text { combination products) } \\
\text { Brompheniramine } \\
\text { Carbinoxamine } \\
\text { Chlorpheniramine } \\
\text { Clemastine } \\
\text { Cyproheptadine } \\
\text { Dexbrompheniramine } \\
\text { Dexchlorpheniramine } \\
\text { Diphenhydramine (oral) } \\
\text { Doxylamine } \\
\text { Hydroxyzine } \\
\text { Promethazine } \\
\text { Triprolidine }\end{array}$ & $\begin{array}{l}\text { Highly anticholinergic; clearance } \\
\text { reduced with advanced age, and } \\
\text { tolerance develops when used as } \\
\text { hypnotic; greater risk of confusion, dry } \\
\text { mouth, constipation and other } \\
\text { anticholinergic effects and toxicity } \\
\text { Use of diphenhydramine in special } \\
\text { situations such as short-term treatment } \\
\text { of severe allergic reaction may be } \\
\text { appropriate }\end{array}$ & Avoid & $\begin{array}{l}\text { Hydroxyzine } \\
\text { and } \\
\text { promethazine: } \\
\text { high; } \\
\text { all others: } \\
\text { moderate }\end{array}$ & Strong \\
\hline $\begin{array}{l}\text { Antiparkinson agents } \\
\text { Benztropine (oral) } \\
\text { Trihexyphenidyl }\end{array}$ & $\begin{array}{l}\text { Not recommended for prevention of } \\
\text { extrapyramidal symptoms with } \\
\text { antipsychotics; more effective agents } \\
\text { availablefortreatmentofParkinson's } \\
\text { disease }\end{array}$ & Avoid & Moderate & Strong \\
\hline $\begin{array}{l}\text { Antispasmodics } \\
\text { Belladonna alkaloids } \\
\text { Clidinium- } \\
\text { chlordiazepoxide } \\
\text { Dicyclomine } \\
\text { Hyoscyamine } \\
\text { Propantheline } \\
\text { Scopolamine }\end{array}$ & $\begin{array}{l}\text { Highly anticholinergic, uncertain } \\
\text { effectiveness }\end{array}$ & $\begin{array}{l}\text { Avoid exceptin short- } \\
\text { term palliative care to } \\
\text { decrease oral secretions }\end{array}$ & Moderate & Strong \\
\hline \multicolumn{5}{|l|}{ Antithrombotics } \\
\hline $\begin{array}{l}\text { Dipyridamole, oral short- } \\
\text { acting*(does not apply } \\
\text { to extended-release } \\
\text { combination with aspirin) }\end{array}$ & $\begin{array}{l}\text { Maycause orthostatichypotension; } \\
\text { more effective alternatives available; } \\
\text { intravenous form acceptable for use in } \\
\text { cardiac stress testing }\end{array}$ & Avoid & Moderate & Strong \\
\hline Ticlopidine* & Safer effective alternatives available & Avoid & Moderate & Strong \\
\hline \multicolumn{5}{|l|}{ Anti-infective } \\
\hline Nitrofurantoin & $\begin{array}{l}\text { Potential for pulmonary toxicity; safer } \\
\text { alternatives available; lack of efficacy in } \\
\text { patients with } \mathrm{CrCl}<60 \mathrm{~mL} / \mathrm{min} \text { due to } \\
\text { inadequate drug concentration in the } \\
\text { urine }\end{array}$ & $\begin{array}{l}\text { Avoid for long-term } \\
\text { suppression; avoid in } \\
\text { patientswith } \mathrm{CrCl}<60 \\
\mathrm{~mL} / \mathrm{min}\end{array}$ & Moderate & Strong \\
\hline \multicolumn{5}{|l|}{ Cardiovascular } \\
\hline $\begin{array}{l}\text { Alpha }{ }_{1} \text {-blockers } \\
\text { Doxazosin } \\
\text { Prazosin } \\
\text { Terazosin }\end{array}$ & $\begin{array}{l}\text { High risk of orthostatic hypotension; not } \\
\text { recommended as routine treatment for } \\
\text { hypertension; alternative agents have } \\
\text { superior risk/benefitprofile }\end{array}$ & $\begin{array}{l}\text { Avoid use as an } \\
\text { antihypertensive }\end{array}$ & Moderate & Strong \\
\hline
\end{tabular}


Interventions to improve the appropriate use of polypharmacy for older people

\begin{tabular}{|c|c|c|c|c|}
\hline $\begin{array}{l}\text { Alpha-agonists, central } \\
\text { Clonidine } \\
\text { Guanabenz* } \\
\text { Guanfacine* } \\
\text { Methyldopa* } \\
\text { Reserpine }(>0.1 \mathrm{mg} / \mathrm{d}) *\end{array}$ & $\begin{array}{l}\text { High risk of adverseCNS effects; may } \\
\text { cause bradycardia and orthostatic } \\
\text { hypotension; not recommended as } \\
\text { routinetreatment forhypertension }\end{array}$ & $\begin{array}{l}\text { Avoid clonidine as a } \\
\text { first-line } \\
\text { antihypertensive } \\
\text { Avoid others as listed }\end{array}$ & Low & Strong \\
\hline $\begin{array}{l}\text { Antiarrhythmic drugs } \\
\text { (Class la, Ic, III) } \\
\text { Amiodarone } \\
\text { Dofetilide } \\
\text { Dronedarone } \\
\text { Flecainide } \\
\text { Ibutilide } \\
\text { Procainamide } \\
\text { Propafenone } \\
\text { Quinidine } \\
\text { Sotalol }\end{array}$ & $\begin{array}{l}\text { Data suggest that rate control yields } \\
\text { better balance of benefits and harms } \\
\text { than rhythm control for most older } \\
\text { adults } \\
\text { Amiodarone is associated with multiple } \\
\text { toxicities, including thyroid disease, } \\
\text { pulmonary disorders and QT interval } \\
\text { prolongation }\end{array}$ & $\begin{array}{l}\text { Avoid antiarrhythmic } \\
\text { drugs as first-line } \\
\text { treatment of atrial } \\
\text { fibrillation }\end{array}$ & High & Strong \\
\hline Disopyramide* & $\begin{array}{l}\text { Disopyramide is a potent negative } \\
\text { inotrope and therefore may induce } \\
\text { heart failure in older adults; strongly } \\
\text { anticholinergic; other antiarrhythmic } \\
\text { drugs preferred }\end{array}$ & Avoid & Low & Strong \\
\hline Dronedarone & $\begin{array}{l}\text { Worse outcomes have been reported in } \\
\text { patients taking dronedarone who have } \\
\text { permanent atrial fibrillation or heart } \\
\text { failure. In general, rate control is } \\
\text { preferred over rhythm control for atrial } \\
\text { fibrillation }\end{array}$ & $\begin{array}{l}\text { Avoid in patients with } \\
\text { permanent atrial } \\
\text { fibrillation or heart } \\
\text { failure }\end{array}$ & Moderate & Strong \\
\hline Digoxin $>0.125 \mathrm{mg} / \mathrm{d}$ & $\begin{array}{l}\text { In heart failure, higher dosages are } \\
\text { associated with no additional benefit } \\
\text { and may increase risk of toxicity; slow } \\
\text { renal clearance may lead to risk of toxic } \\
\text { effects }\end{array}$ & Avoid & Moderate & Strong \\
\hline $\begin{array}{l}\text { Nifedipine, immediate } \\
\text { release* }\end{array}$ & $\begin{array}{l}\text { Potential for hypotension; risk of } \\
\text { precipitating myocardial ischaemia }\end{array}$ & Avoid & High & Strong \\
\hline $\begin{array}{l}\text { Spironolactone }>25 \\
\mathrm{mg} / \mathrm{d}\end{array}$ & $\begin{array}{l}\text { In heart failure, the risk of } \\
\text { hyperkalaemia is higherin older adults, } \\
\text { especially iftaking }>25 \mathrm{mg} / \text { d ortaking } \\
\text { concomitant NSAID, angiotensin- } \\
\text { converting enzyme inhibitor, } \\
\text { angiotensin receptor blocker or } \\
\text { potassium supplement }\end{array}$ & $\begin{array}{l}\text { Avoid in patients with } \\
\text { heart failure or with a } \\
\mathrm{CrCl}<30 \mathrm{~mL} / \mathrm{min}\end{array}$ & Moderate & Strong \\
\hline
\end{tabular}


Interventions to improve the appropriate use of polypharmacy for older people

\begin{tabular}{|c|c|c|c|c|}
\hline $\begin{array}{l}\text { Tertiary TCAs, alone or } \\
\text { in combination: } \\
\text { Amitriptyline } \\
\text { Chlordiazepoxide- } \\
\text { amitriptyline } \\
\text { Clomipramine } \\
\text { Doxepin }>6 \mathrm{mg} / \mathrm{d} \\
\text { Imipramine } \\
\text { Perphenazine- } \\
\text { amitriptyline } \\
\text { Trimipramine }\end{array}$ & $\begin{array}{l}\text { Highly anticholinergic, sedating and } \\
\text { causing orthostatic hypotension; safety } \\
\text { profile of low-dose doxepin }(\leq 6 \mathrm{mg} / \mathrm{d}) \\
\text { is comparable with that of placebo }\end{array}$ & Avoid & High & Strong \\
\hline $\begin{array}{l}\text { Antipsychotics, first } \\
\text { (conventional) and } \\
\text { second (atypical) } \\
\text { generation (see AGS } \\
2012 \text { for full list) }\end{array}$ & $\begin{array}{l}\text { Increased risk of cerebrovascular } \\
\text { accident (stroke) and mortality in } \\
\text { persons with dementia }\end{array}$ & $\begin{array}{l}\text { Avoid use for } \\
\text { behavioural problems of } \\
\text { dementia unless non- } \\
\text { pharmacological options } \\
\text { have failed and patient } \\
\text { is threat to self or others }\end{array}$ & Moderate & Strong \\
\hline $\begin{array}{l}\text { Thioridazine } \\
\text { Mesoridazine }\end{array}$ & $\begin{array}{l}\text { Highly anticholinergic and risk ofQT } \\
\text { interval prolongation }\end{array}$ & Avoid & Moderate & Strong \\
\hline $\begin{array}{l}\text { Barbiturates } \\
\text { Amobarbital* } \\
\text { Butabarbital* } \\
\text { Butalbital } \\
\text { Mephobarbital* } \\
\text { Pentobarbital* } \\
\text { Phenobarbital } \\
\text { Secobarbital* }\end{array}$ & $\begin{array}{l}\text { High rate of physical dependence; } \\
\text { tolerance to sleep benefits; risk of } \\
\text { overdose at low dosages }\end{array}$ & Avoid & High & Strong \\
\hline $\begin{array}{l}\text { Benzodiazepines } \\
\text { Short-and intermediate- } \\
\text { acting: } \\
\text { Alprazolam } \\
\text { Estazolam } \\
\text { Lorazepam } \\
\text { Oxazepam } \\
\text { Temazepam } \\
\text { Triazolam } \\
\text { Long-acting: } \\
\text { Clorazepate } \\
\text { Chlordiazepoxide } \\
\text { Chlordiazepoxide- } \\
\text { amitriptyline } \\
\text { Clidinium- } \\
\text { chlordiazepoxide } \\
\text { Clonazepam } \\
\text { Diazepam } \\
\text { Flurazepam } \\
\text { Quazepam }\end{array}$ & $\begin{array}{l}\text { Older adults have increased sensitivity } \\
\text { to benzodiazepines and slower } \\
\text { metabolism of long-acting agents. In } \\
\text { general, all benzodiazepines increase } \\
\text { risk of cognitive impairment, delirium, } \\
\text { falls, fractures and motor vehicle } \\
\text { accidents in older adults } \\
\text { May be appropriate for seizure } \\
\text { disorders, rapid eye movement sleep } \\
\text { disorders, benzodiazepine withdrawal, } \\
\text { ethanol withdrawal, severe generalized } \\
\text { anxiety disorder, periprocedural } \\
\text { anaesthesia and end-of-life care }\end{array}$ & $\begin{array}{l}\text { Avoid benzodiazepines } \\
\text { (any type) for treatment } \\
\text { of insomnia, agitation or } \\
\text { delirium }\end{array}$ & High & Strong \\
\hline
\end{tabular}


Interventions to improve the appropriate use of polypharmacy for older people

\begin{tabular}{|c|c|c|c|c|}
\hline Chloral hydrate* & $\begin{array}{l}\text { Tolerance occurs within } 10 \text { days, and } \\
\text { risks outweigh benefits in light of } \\
\text { overdose with doses only } 3 \text { times the } \\
\text { recommended dose }\end{array}$ & Avoid & Low & Strong \\
\hline Meprobamate & $\begin{array}{l}\text { High rate of physical dependence; very } \\
\text { sedating }\end{array}$ & Avoid & Moderate & Strong \\
\hline $\begin{array}{l}\text { Non-benzodiazepine } \\
\text { hypnotics } \\
\text { Eszopiclone } \\
\text { Zolpidem } \\
\text { Zaleplon }\end{array}$ & $\begin{array}{l}\text { Benzodiazepine-receptor agonists that } \\
\text { have adverse events similar to those of } \\
\text { benzodiazepines in older adults (e.g. } \\
\text { delirium, falls, fractures); minimal } \\
\text { improvement in sleep latency and } \\
\text { duration }\end{array}$ & $\begin{array}{l}\text { Avoid long-term use (> } \\
90 \text { days) }\end{array}$ & Moderate & Strong \\
\hline $\begin{array}{l}\text { Ergot mesylates* } \\
\text { Isoxsuprine* }\end{array}$ & Lack of efficacy & Avoid & High & Strong \\
\hline \multicolumn{5}{|l|}{ Endocrine } \\
\hline $\begin{array}{l}\text { Androgens } \\
\text { Methyltestosterone* } \\
\text { Testosterone }\end{array}$ & $\begin{array}{l}\text { Potential for cardiac problems and } \\
\text { contraindicated in men with prostate } \\
\text { cancer }\end{array}$ & $\begin{array}{l}\text { Avoid unless indicated } \\
\text { for moderate to severe } \\
\text { hypogonadism }\end{array}$ & Moderate & Weak \\
\hline Desiccated thyroid & $\begin{array}{l}\text { Concerns about cardiac effects; safer } \\
\text { alternatives available }\end{array}$ & Avoid & Low & Strong \\
\hline \multirow[t]{3}{*}{$\begin{array}{l}\text { Oestrogens with or } \\
\text { without progestins }\end{array}$} & \multirow{3}{*}{$\begin{array}{l}\text { Evidence of carcinogenic potential } \\
\text { (breast and endometrium); lack of } \\
\text { cardioprotective effect and cognitive } \\
\text { protection in older women } \\
\text { Evidence that vaginal oestrogens for } \\
\text { treatment of vaginal dryness are safe } \\
\text { and effective in women with breast } \\
\text { cancer, especially at dosages of } \\
\text { estradiol }<25 \mu \mathrm{g} \text { twice weekly }\end{array}$} & $\begin{array}{l}\text { Avoid oral and topical } \\
\text { patch }\end{array}$ & $\begin{array}{l}\text { Oral and } \\
\text { patch: high }\end{array}$ & $\begin{array}{l}\text { Oral and patch: } \\
\text { strong }\end{array}$ \\
\hline & & \multirow{2}{*}{$\begin{array}{l}\text { Topical vaginal cream: } \\
\text { acceptable to use low- } \\
\text { dose intravaginal } \\
\text { oestrogen for the } \\
\text { management of } \\
\text { dyspareunia, lower } \\
\text { urinary tract infection } \\
\text { and other vaginal } \\
\text { symptoms }\end{array}$} & \multirow[t]{2}{*}{$\begin{array}{l}\text { Topical: } \\
\text { moderate }\end{array}$} & \multirow[t]{2}{*}{ Topical: weak } \\
\hline & & & & \\
\hline Growth hormone & $\begin{array}{l}\text { Effect on body composition is small and } \\
\text { is associated with oedema, arthralgia, } \\
\text { carpal tunnel syndrome, } \\
\text { gynaecomastia, impaired fasting } \\
\text { glucose }\end{array}$ & $\begin{array}{l}\text { Avoid, except as } \\
\text { hormone replacement } \\
\text { after pituitary gland } \\
\text { removal }\end{array}$ & High & Strong \\
\hline Insulin, sliding scale & $\begin{array}{l}\text { Higher risk of hypoglycaemia without } \\
\text { improvement in hyperglycaemia } \\
\text { management regardless of care setting }\end{array}$ & Avoid & Moderate & Strong \\
\hline Megestrol & $\begin{array}{l}\text { Minimal effect on weight; increases risk } \\
\text { of thromboticevents and possibly death } \\
\text { in older adults }\end{array}$ & Avoid & Moderate & Strong \\
\hline $\begin{array}{l}\text { Sulphonylureas, long } \\
\text { duration } \\
\text { Chlorpropamide } \\
\text { Glyburide }\end{array}$ & $\begin{array}{l}\text { Chlorpropamide: prolonged half-life in } \\
\text { older adults; can cause prolonged } \\
\text { hypoglycaemia; causes syndrome of } \\
\text { inappropriate antidiuretic hormone } \\
\text { secretion. }\end{array}$ & Avoid & High & Strong \\
\hline & $\begin{array}{l}\text { Glyburide: greater risk of severe } \\
\text { prolonged hypoglycaemia in older } \\
\text { adults }\end{array}$ & & & \\
\hline \multicolumn{5}{|l|}{ Gastrointestinal } \\
\hline Metoclopramide & $\begin{array}{l}\text { Can cause extrapyramidal effects } \\
\text { including tardive dyskinesia; risk may } \\
\text { be even greaterinfrail older adults }\end{array}$ & $\begin{array}{l}\text { Avoid, unless for } \\
\text { gastroparesis }\end{array}$ & Moderate & Strong \\
\hline Mineral oil, oral & $\begin{array}{l}\text { Potential for aspiration and adverse } \\
\text { effects; safer alternatives available }\end{array}$ & Avoid & Moderate & Strong \\
\hline
\end{tabular}


Interventions to improve the appropriate use of polypharmacy for older people

\begin{tabular}{|c|c|c|c|c|}
\hline Trimethobenzamide & $\begin{array}{l}\text { One of the least effective antiemetic } \\
\text { drugs; can cause extrapyramidal } \\
\text { adverse effects }\end{array}$ & Avoid & Moderate & Strong \\
\hline \multicolumn{5}{|l|}{ Pain } \\
\hline Meperidine & $\begin{array}{l}\text { Not an effective oral analgesic in } \\
\text { dosages commonly used; may cause } \\
\text { neurotoxicity; safer alternatives } \\
\text { available }\end{array}$ & Avoid & High & Strong \\
\hline $\begin{array}{l}\text { Non-COX-selective } \\
\text { NSAIDs, oral } \\
\text { Aspirin > } 325 \mathrm{mg} / \mathrm{d} \\
\text { Diclofenac } \\
\text { Diflunisal } \\
\text { Etodolac } \\
\text { Fenoprofen } \\
\text { Ibuprofen } \\
\text { Ketoprofen } \\
\text { Meclofenamate } \\
\text { Mefenamic acid } \\
\text { Meloxicam } \\
\text { Nabumetone } \\
\text { Naproxen } \\
\text { Oxaprozin } \\
\text { Piroxicam } \\
\text { Sulindac } \\
\text { Tolmetin }\end{array}$ & $\begin{array}{l}\text { Increase risk of GI bleeding and peptic } \\
\text { ulcer disease in high-risk groups, } \\
\text { including those aged }>75 \text { or taking oral } \\
\text { or parenteral corticosteroids, } \\
\text { anticoagulants or antiplatelet agents. } \\
\text { Use of proton pump inhibitor or } \\
\text { misoprostol reduces but does not } \\
\text { eliminaterisk. UpperGlulcers, gross } \\
\text { bleeding or perforation caused by } \\
\text { NSAIDs occurs in approximately } 1 \% \text { of } \\
\text { patients treated for } 3 \text { to } 6 \text { months and } \\
\text { inapproximately } 2 \% \text { to } 4 \% \text { of patients } \\
\text { treated for } 1 \text { year. These trends } \\
\text { continue with longer duration of use }\end{array}$ & $\begin{array}{l}\text { Avoid long-term use } \\
\text { unless other alternatives } \\
\text { are not effective and } \\
\text { patient can take } \\
\text { gastroprotective agent } \\
\text { (proton pump inhibitor or } \\
\text { misoprostol) }\end{array}$ & Moderate & Strong \\
\hline $\begin{array}{l}\text { Indomethacin } \\
\text { Ketorolac, includes } \\
\text { parenteral }\end{array}$ & $\begin{array}{l}\text { Increase risk of GI bleeding and peptic } \\
\text { ulcer disease in high-risk groups (see } \\
\text { above Non-COX-selective NSAIDs) } \\
\text { Of all the NSAIDs, indomethacin has } \\
\text { the most adverse effects }\end{array}$ & Avoid & $\begin{array}{l}\text { Indomethacin: } \\
\text { moderate } \\
\text { Ketorolac: high }\end{array}$ & Strong \\
\hline Pentazocine* & $\begin{array}{l}\text { Opioid analgesic that causes CNS } \\
\text { adverse effects, including confusion } \\
\text { andhallucinations, more commonly } \\
\text { than other narcotic drugs; also a mixed } \\
\text { agonist and antagonist; safer } \\
\text { alternatives available }\end{array}$ & Avoid & Low & Strong \\
\hline $\begin{array}{l}\text { Skeletal muscle } \\
\text { relaxants } \\
\text { Carisoprodol } \\
\text { Chlorzoxazone } \\
\text { Cyclobenzaprine } \\
\text { Metaxalone } \\
\text { Methocarbamol } \\
\text { Orphenadrine }\end{array}$ & $\begin{array}{l}\text { Most muscle relaxants are poorly } \\
\text { tolerated by olderadults because of } \\
\text { anticholinergic adverse effects, } \\
\text { sedation, risk of fracture; effectiveness } \\
\text { at dosages tolerated by older adults is } \\
\text { questionable }\end{array}$ & Avoid & Moderate & Strong \\
\hline \multicolumn{5}{|c|}{$\begin{array}{l}\text { Source: } \text { AGS } 2012 . \\
\text { CNS = central nervous system; } \mathrm{COX}=\text { cyclo-oxygenase; } \mathrm{CrCl}=\text { creatinine clearance; } \mathrm{GI}=\text { gastrointestinal; NSAID = non- } \\
\text { steroidal anti-inflammatory drug; } \mathrm{TCA}=\text { tricyclic antidepressant. } \\
\text { *Infrequently used drugs. }\end{array}$} \\
\hline
\end{tabular}


Interventions to improve the appropriate use of polypharmacy for older people

drug-disease or drug-syndrome interactions that may exacerbate the disease or syndrome

\begin{tabular}{|c|c|c|c|c|c|}
\hline $\begin{array}{l}\text { Disease or } \\
\text { syndrome }\end{array}$ & Drug & Rationale & Recommendation & Quality of evidence & $\begin{array}{l}\text { e Strength of } \\
\text { recommendation }\end{array}$ \\
\hline \multicolumn{6}{|c|}{ Cardiovascular } \\
\hline Heart failure & $\begin{array}{l}\text { NSAIDs and COX-2 } \\
\text { inhibitors } \\
\text { Non-dihydropyridine } \\
\text { CCBs (avoid only for } \\
\text { systolic heart failure) } \\
\text { Diltiazem } \\
\text { Verapamil } \\
\text { Pioglitazone, } \\
\text { rosiglitazone } \\
\text { Cilostazol } \\
\text { Dronedarone }\end{array}$ & $\begin{array}{l}\text { Potential to promote fluid } \\
\text { retention and exacerbate } \\
\text { heart failure }\end{array}$ & Avoid & $\begin{array}{l}\text { NSAIDs: moderate } \\
\text { CCBs: moderate } \\
\text { Thiazolidinediones } \\
\text { (glitazones): high } \\
\text { Cilostazol: low } \\
\text { Dronedarone: } \\
\text { moderate }\end{array}$ & Strong \\
\hline Syncope & $\begin{array}{l}\text { AChEls } \\
\text { Peripheral alpha- } \\
\text { blockers } \\
\text { Doxazosin } \\
\text { Prazosin } \\
\text { Terazosin } \\
\text { Tertiary TCAs } \\
\text { Chlorpromazine, } \\
\text { thioridazine and } \\
\text { olanzapine }\end{array}$ & $\begin{array}{l}\text { Increase risk of } \\
\text { orthostatic hypotension } \\
\text { or bradycardia }\end{array}$ & Avoid & $\begin{array}{l}\text { Alpha-blockers: } \\
\text { high } \\
\text { TCAs, AChEIs and } \\
\text { antipsychotics: } \\
\text { moderate }\end{array}$ & $\begin{array}{l}\text { AChEls and } \\
\text { TCAs: strong } \\
\text { Alpha-blockers } \\
\text { and } \\
\text { antipsychotics: } \\
\text { weak }\end{array}$ \\
\hline \multicolumn{6}{|c|}{ Central nervous system } \\
\hline $\begin{array}{l}\text { Chronic } \\
\text { seizures or } \\
\text { epilepsy }\end{array}$ & $\begin{array}{l}\text { Bupropion } \\
\text { Chlorpromazine } \\
\text { Clozapine } \\
\text { Maprotiline } \\
\text { Olanzapine } \\
\text { Thioridazine } \\
\text { Thiothixene } \\
\text { Tramadol }\end{array}$ & $\begin{array}{l}\text { Lower seizure threshold; } \\
\text { may be acceptable in } \\
\text { patients with well- } \\
\text { controlled seizures in } \\
\text { whom alternative agents } \\
\text { have not been effective }\end{array}$ & Avoid & Moderate & Strong \\
\hline Delirium & $\begin{array}{l}\text { All TCAs } \\
\text { Anticholinergics (see } \\
\text { ACS 2012 for full list) } \\
\text { Benzodiazepines } \\
\text { Chlorpromazine } \\
\text { Corticosteroids } \\
\mathrm{H}_{2} \text {-receptor antagonist } \\
\text { Meperidine } \\
\text { Sedative-hypnotics } \\
\text { Thioridazine }\end{array}$ & $\begin{array}{l}\text { Avoid in olderadults with } \\
\text { or athigh risk of delirium } \\
\text { because of inducing or } \\
\text { worsening delirium in } \\
\text { older adults; if } \\
\text { discontinued drugs used } \\
\text { long-term, taper to avoid } \\
\text { withdrawal symptoms } \\
\end{array}$ & Avoid & Moderate & Strong \\
\hline
\end{tabular}


Interventions to improve the appropriate use of polypharmacy for older people

\begin{tabular}{|c|c|c|c|c|c|}
\hline \multirow{2}{*}{$\begin{array}{l}\text { Dementia and } \\
\text { cognitive } \\
\text { impairment }\end{array}$} & $\begin{array}{l}\text { Anticholinergics (see } \\
\text { AGS } 2012 \text { for full list) }\end{array}$ & $\begin{array}{l}\text { Avoid because of } \\
\text { adverse CNS effects }\end{array}$ & \multirow[t]{2}{*}{ Avoid } & \multirow[t]{2}{*}{ High } & \multirow[t]{2}{*}{ Strong } \\
\hline & $\begin{array}{l}\text { Benzodiazepines } \\
\mathrm{H}_{2} \text {-receptor antagonists } \\
\text { Zolpidem } \\
\text { Antipsychotics, long- } \\
\text { term and as-needed use } \\
\end{array}$ & $\begin{array}{l}\text { Avoid antipsychotics for } \\
\text { behavioural problems of } \\
\text { dementia unless non- } \\
\text { pharmacological options } \\
\text { have failed and patient is } \\
\text { a threat to himself or } \\
\text { others. Antipsychotics } \\
\text { are associated with } \\
\text { increased risk of } \\
\text { cerebrovascular accident } \\
\text { (stroke) and mortality in } \\
\text { persons with dementia }\end{array}$ & & & \\
\hline $\begin{array}{l}\text { History of falls } \\
\text { or fractures } \\
\qquad\end{array}$ & $\begin{array}{l}\text { Anticonvulsants } \\
\text { Antipsychotics } \\
\text { Benzodiazepines } \\
\text { Non-benzodiazepine } \\
\text { hypnotics } \\
\text { Eszopiclone } \\
\text { Zaleplon } \\
\text { Zolpidem } \\
\text { TCAs and selective } \\
\text { serotonin reuptake } \\
\text { inhibitors }\end{array}$ & $\begin{array}{l}\text { Ability to produce ataxia, } \\
\text { impaired psychomotor } \\
\text { function, syncope and } \\
\text { additional falls; shorter- } \\
\text { acting benzodiazepines } \\
\text { are not safer than long- } \\
\text { acting ones }\end{array}$ & $\begin{array}{l}\text { Avoid unless safer } \\
\text { alternatives are not } \\
\text { available; avoid } \\
\text { anticonvulsants } \\
\text { except for seizure } \\
\text { disorders }\end{array}$ & High & Strong \\
\hline Insomnia & $\begin{array}{l}\text { Oral decongestants } \\
\text { Pseudoephedrine } \\
\text { Phenylephrine } \\
\text { Stimulants } \\
\text { Amphetamine } \\
\text { Methylphenidate } \\
\text { Pemoline } \\
\text { Theobromines } \\
\text { Theophylline } \\
\text { Caffeine }\end{array}$ & CNS stimulant effects & Avoid & Moderate & Strong \\
\hline $\begin{array}{l}\text { Parkinson's } \\
\text { disease }\end{array}$ & $\begin{array}{l}\text { Allantipsychotics (see } \\
\text { AGS2012 forfull list, } \\
\text { except for quetiapine } \\
\text { and clozapine) } \\
\text { Antiemetics } \\
\text { Metoclopramide } \\
\text { Prochlorperazine } \\
\text { Promethazine }\end{array}$ & $\begin{array}{l}\text { Dopamine receptor } \\
\text { antagonists with potential } \\
\text { to worsen parkinsonian } \\
\text { symptoms } \\
\text { Quetiapine and clozapine } \\
\text { appear to be less likely to } \\
\text { precipitate worsening of } \\
\text { Parkinson's disease }\end{array}$ & Avoid & Moderate & Strong \\
\hline
\end{tabular}


Interventions to improve the appropriate use of polypharmacy for older people

\begin{tabular}{|c|c|c|c|c|c|}
\hline $\begin{array}{l}\text { Chronic } \\
\text { constipation }\end{array}$ & 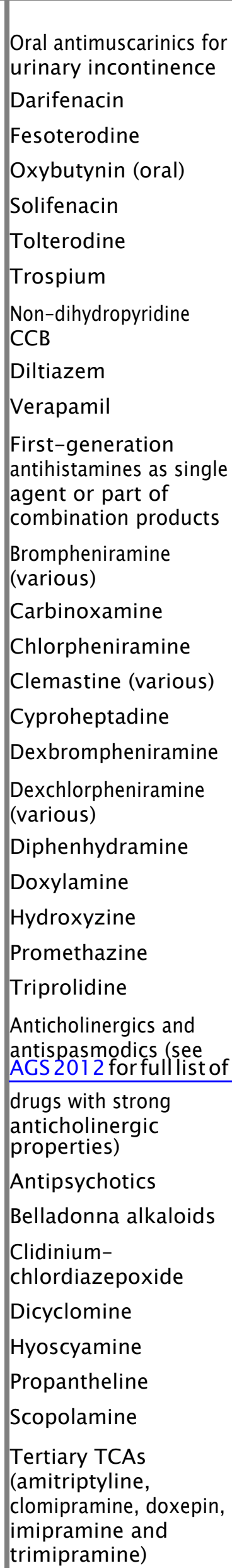 & $\begin{array}{l}\text { Can worsen constipation; } \\
\text { agents for urinary } \\
\text { incontinence: } \\
\text { Antimuscarinics overall } \\
\text { differ in incidence of } \\
\text { constipation; response } \\
\text { variable; consider } \\
\text { alternative agent if } \\
\text { constipation develops }\end{array}$ & $\begin{array}{l}\text { Avoid unless no } \\
\text { other alternatives }\end{array}$ & $\begin{array}{l}\text { For urinary } \\
\text { incontinence: high } \\
\text { All others: } \\
\text { moderate to low }\end{array}$ & Weak \\
\hline
\end{tabular}


Interventions to improve the appropriate use of polypharmacy for older people

\begin{tabular}{|c|c|c|c|c|c|}
\hline $\begin{array}{l}\text { History of } \\
\text { gastric or } \\
\text { duodenal } \\
\text { ulcers }\end{array}$ & $\begin{array}{l}\text { Aspirin }(>325 \mathrm{mg} / \mathrm{d}) \\
\text { Non-COX-2-selective } \\
\text { NSAIDs }\end{array}$ & $\begin{array}{l}\text { May exacerbate existing } \\
\text { ulcers or cause new or } \\
\text { additional ulcers }\end{array}$ & $\begin{array}{l}\text { Avoid unless other } \\
\text { alternatives are not } \\
\text { effective and patient } \\
\text { can take } \\
\text { gastroprotective } \\
\text { agent (proton pump } \\
\text { inhibitor or } \\
\text { misoprostol) }\end{array}$ & Moderate & Strong \\
\hline \multicolumn{6}{|c|}{ Kidney and urinary tract } \\
\hline $\begin{array}{l}\text { Chronic } \\
\text { kidney } \\
\text { disease } \\
\text { Stages IV and } \\
\text { V }\end{array}$ & $\begin{array}{l}\text { NSAIDs } \\
\text { Triamterene (alone or in } \\
\text { combination) }\end{array}$ & $\begin{array}{l}\text { May increase risk of } \\
\text { kidney injury }\end{array}$ & Avoid & $\begin{array}{l}\text { NSAIDs: moderate } \\
\text { Triamterene: low }\end{array}$ & $\begin{array}{l}\text { NSAIDs: strong } \\
\text { Triamterene: } \\
\text { weak }\end{array}$ \\
\hline \begin{tabular}{l|} 
Urinary \\
incontinence \\
(all types) in \\
women
\end{tabular} & $\begin{array}{l}\text { Oestrogen oral and } \\
\text { transdermal (excludes } \\
\text { intravaginal oestrogen) }\end{array}$ & Aggravate incontinence & Avoid in women & High & Strong \\
\hline $\begin{array}{l}\text { Lower urinary } \\
\text { tract } \\
\text { symptoms, } \\
\text { benign } \\
\text { prostatic } \\
\text { hyperplasia }\end{array}$ & $\begin{array}{l}\text { Inhaled anticholinergic } \\
\text { agents } \\
\text { Strongly anticholinergic } \\
\text { drugs, except } \\
\text { antimuscarinics for } \\
\text { urinary incontinence } \\
\text { (see ACS 2012 for } \\
\text { complete list) }\end{array}$ & $\begin{array}{l}\text { May decrease urinary } \\
\text { flow and cause urinary } \\
\text { retention }\end{array}$ & Avoid in men & Moderate & $\begin{array}{l}\text { Inhaled agents: } \\
\text { strong } \\
\text { All others: weak }\end{array}$ \\
\hline $\begin{array}{l}\text { Stress or } \\
\text { mixed urinary } \\
\text { incontinence }\end{array}$ & $\begin{array}{l}\text { Alpha-blockers } \\
\text { Doxazosin } \\
\text { Prazosin } \\
\text { Terazosin }\end{array}$ & Aggravate incontinence & Avoid in women & Moderate & Strong \\
\hline
\end{tabular}

Footnotes

6 Updated Beers (2012) criteria for potentially inappropriate medications to be used with caution in older adults 
Interventions to improve the appropriate use of polypharmacy for older people

\begin{tabular}{|c|c|c|c|c|}
\hline Drug & Rationale & Recommendation & $\begin{array}{l}\text { Quality of } \\
\text { evidence }\end{array}$ & $\begin{array}{l}\text { Strength of } \\
\text { recommendation }\end{array}$ \\
\hline $\begin{array}{l}\text { Aspirin for primary } \\
\text { prevention of cardiac events }\end{array}$ & $\begin{array}{l}\text { Lack of evidence of benefit versus risk in } \\
\text { individuals aged } \geq 80\end{array}$ & $\begin{array}{l}\text { Use with caution in } \\
\text { adults aged } \geq 80\end{array}$ & Low & Weak \\
\hline Dabigatran & $\begin{array}{l}\text { Greater risk of bleeding than with warfarin } \\
\text { in adults aged } \geq 75 \text {; lack of evidence of } \\
\text { efficacy and safety in individuals with } \mathrm{CrCl} \\
<30 \mathrm{~mL} / \mathrm{min}\end{array}$ & $\begin{array}{l}\text { Use with caution in } \\
\text { adults aged } \geq 75 \text { or if } \\
\mid \mathrm{CrCl}<30 \mathrm{~mL} / \mathrm{min}\end{array}$ & Moderate & Weak \\
\hline Prasugrel & $\begin{array}{l}\text { Greater risk of bleeding in older adults; } \\
\text { risk may be offset by benefit in highest- } \\
\text { risk older adults (e.g. with prior } \\
\text { myocardial infarction or diabetes mellitus) }\end{array}$ & $\begin{array}{l}\text { Use with caution in } \\
\text { adults aged } \geq 75\end{array}$ & Moderate & Weak \\
\hline $\begin{array}{l}\text { Antipsychotics } \\
\text { Carbamazepine } \\
\text { Carboplatin } \\
\text { Cisplatin } \\
\text { Mirtazapine } \\
\text { Serotonin-norepinephrine } \\
\text { reuptake inhibitor } \\
\text { Selectiveserotonin reuptake } \\
\text { inhibitor } \\
\text { Tricyclic antidepressants } \\
\text { Vincristine }\end{array}$ & $\begin{array}{l}\text { May exacerbate or cause syndrome of } \\
\text { inappropriate antidiuretic hormone } \\
\text { secretion or hyponatraemia; need to } \\
\text { monitor sodium level closely when } \\
\text { starting or changing dosages in older } \\
\text { adults because of increased risk }\end{array}$ & Use with caution & Moderate & Strong \\
\hline Vasodilators & $\begin{array}{l}\text { May exacerbate episodes of syncope in } \\
\text { individuals with history of syncope }\end{array}$ & & & \\
\hline
\end{tabular}

Footnotes

\section{References to studies}

\section{Included studies}

\section{Basger 2015}

Published data only (unpublished sought but not used) [CRSSTD: 9077325]

Basger BJ, Moles RJ, Chen TF. Impact of an enhanced pharmacy discharge service on prescribing appropriateness criteria: A randomised controlled trial. International Journal of Clinical Pharmacy 201 5;37(6):1 194-205. [CRSREF: 9077326]

\section{Bladh 2011}

[CRSSTD: 3179216$]$

Bladh L, Ottosson E, Karlsson J, Klintberg L, Wallerstedt SM. Effects of a clinical pharmacist service on health-related quality of life and prescribing of drugs: a randomised controlled trial. BMJ Quality \& Safety 201 1;20(9):738-46. [CRSREF: 3179217 ]

\section{Bucci 2003}

[CRSSTD: 3179151$]$

Bucci C, Jackevicius C, McFarlane K, Liu P. Pharmacist's contribution in a heart function clinic: Patient perception and medication appropriateness. Canadian Journal of Cardiology 2003;19(4):391-6. [CRSREF: 3179152]

\section{Campins 2017}

\section{[CRSSTD: 9077327]}

* Campins L, Serra-Prat M, Gozalo I, Lopez D, Palomera E, Agusti C, et al. Randomized controlled trial of an intervention to improve drug appropriateness in community-dwelling polymedicated elderly people. Family Practice 201 7;34(1):36-42. [CRSREF: 9077328]

Campins L, Serra-Prat M, Palomera E, Bolibar I, Martinez M A, Gallo P. Reduction of pharmaceutical expenditure by a drug appropriateness intervention in polymedicated elderly subjects in Catalonia (Spain). Gaceta Sanitaria 2017; Epub ahead of print:1-6. [CRSREF: 9077329]

\section{Chiu 2018}


[CRSSTD: 9077330]

Chiu PK, Lee AW, See TY, Chan FH. Effectiveness of a pharmacist-led medication review programmeon medication appropriateness and hospital readmissions among geriatric in-patients in Hong Kong. Hong Kong MedicalJournal 2018 ; 24(2):98-106. [CRSREF: 9077331]

\section{Clyne 2015}

[CRSSTD: 9077332]

*Clyne B, Smith SM, Hughes CM, Boland F, Bradley MC, CooperJ A, et al. Effectiveness of a multifaceted intervention for potentially inappropriate prescribing in older patients in primary care: Acluster-randomized controlled trial (OPTI-SCRIPT Study). Annals of Family Medicine 2015;13(6):545-53. [CRSREF: 9077333]

Clyne B, Smith SM, Hughes CM, Boland F, CooperJA, Fahey T, et al. Sustained effectiveness of a multifaceted intervention to reduce potentially inappropriate prescribing in older patients in primary care (OPTI-SCRIPT study). Implementation Science 2016;11(1):79. [CRSREF: 9077334]

\section{Crotty 2004a}

[CRSSTD: 3179153 ]

Crotty M, HalbertJ, Rowett D, Giles L, Birks R, Williams H, et al. An outreach geriatric medication advisory service in residential aged care: a randomised controlled trial of case conferencing. Age \& Ageing 2004;33(6):612-7. [CRSREF: $3179154]$

\section{Crotty $2004 b$}

Published and unpublished data [CRSSTD: 3179155$]$

Crotty M, Rowett D, Spurling L, Giles LC, Phillips PA. Does the addition of a pharmacist transition coordinatorimprove evidence-based medication management and health outcomes in older adults moving from the hospital to a long-term care facility? Results of a randomized, controlled trial. American Journal Geriatric Pharmacotherapy 2004;2(4):257-64. [CRSREF: $3179156]$

\section{Dalleur 2014}

[CRSSTD: 3179157$]$

Boland B, Dalleur O, Losseau C, Spinewine A. Reduction of inappropriate medications in frail older inpatients through recommendations by a geriatrician within the internal liaison team. European Geriatric Medicine 2012;3(S1):120. [CRSREF: $3179158]$

* Dalleur O, Boland B, Losseau C, Henrard S, Wouters D, Speybroeck N, et al. Reduction of potentially inappropriate medications using the STOPP criteria in frail older inpatients: A randomised controlled study. Drugs \& Aging 2014; 31 (4):291-8. [CRSREF: 3179159$]$

\section{Franchi 2016}

Published and unpublished data [CRSSTD: 9077335]

FranchiC, Tettamanti M, Djade CD, Pasina L, Mannucci PM, Onder G, et al; ELICADHEInvesigators. E-learning in order to improve drug prescription for hospitalized older patients: A cluster-randomized controlled study. BritishJournal ofClinical Pharmacology 2016;82(1):53-63. [CRSREF: 9077336]

\section{Frankenthal 2014}

Published and unpublished data [CRSSTD: 9077337]

Frankenthal D, Israeli A, Caraco Y, Lerman Y, Kalendaryev E, Zandman-Goddard G. Long-term outcomes of medication intervention using the screening tool of older persons potentially inappropriate prescriptions screening tool to alert doctors to right treatment criteria. Journal of the American Geriatrics Society 2017;65(2):e33-8. [CRSREF: 9077338]

*Frankenthal D, KalendaryevE, Lerman Y. Intervention with the screening tool of older persons potentially inappropriate prescriptions/screening tool to alert doctors to right treatment criteria in elderly residents of a chronic geriatric facility: A randomized clinical trial.Journal of the American Geriatrics Society 201 4;62(9):1658-65. [CRSREF: 9077339]

\section{Fried 2017}

[CRSSTD: 9077340]

Fried TR, NiehoffKM, Street RL, CharpentierPA, Rajeevan N, MillerPL, et al. Effect of the tool to reduce inappropriate medications on medication communication and deprescribing.Journal of the American Geriatrics Society 2017 ; 65(10):2265-71. [CRSREF: 9077341]

\section{Gallagher 2011}

[CRSSTD: 3179160$]$

Gallagher PF, O'Connor MN, O'Mahony D. Prevention of potentially inappropriate prescribing for elderly patients: A randomized controlled trial using STOPP/START criteria. Clinical Pharmacology and Therapeutics 2011;89(6):845-54. [CRSREF: 3179161 ] 


\section{Garcia-Gollarte 2014}

Published data only (unpublished sought but not used) [CRSSTD: 9077342]

Garcia-Gollarte F, Baleriola-JulvezJ, Ferrero-Lopez I, Cuenllas-Diaz A, Cruz-Jentoft A. An educational intervention on drug use in nursing homes improves health outcomes resource utilization and reduces inappropriate drug prescription. Journal of the American Medical Directors Association 2014;15(12):885-91 . [CRSREF: 9077343]

\section{Haag 2016}

[CRSSTD: 9077344]

Haag JD, Davis AZ, Hoel RW, Armon JJ, Odell LJ, Dierkhising RA, et al. Impact of pharmacist-provided medication therapy management on healthcare quality and utilization in recently discharged elderly patients. American Health $\&$ Drug Benefits 2016;9(5):259-68. [CRSREF: 9077345]

\section{Hanlon 1996}

Published data only (unpublished sought but not used) [CRSSTD: 3179162]

HanlonJT, Weinberger M, Samsa GP, Schmader KE, Uttech KM, Lewis IK, et al. A randomized, controlled trial of a clinical pharmacist intervention to improve inappropriate prescribing in elderly outpatients with polypharmacy. American Journal of Medicine 1996;100(4):428-37. [CRSREF: 3179163]

\section{Koberlein-Neu 2016}

[CRSSTD: 9077346]

* Koberlein-Neu J, Mennemann H, Hamacher S, Waltering I, Jaehde U, Schaffert C, et al. Interprofessional medication management in patients with multiple morbidities. Deutsches Ärzteblatt international 2016;113(44):741-8. [CRSREF: 9077347]

Rose O, Mennemann H, John C, Lautenschlager M, Mertens-Keller D, Richling K, et al. Priority setting and influential factors on acceptance of pharmaceutical recommendations in collaborative medication reviews in an ambulatory care setting analysis of a cluster randomized controlled trial (WestGem-Study). PLOS One 2016;1 1 (6):e01 56304. [CRSREF: 9077348]

Rose O, Mennemann HS, HamacherS, Waltering I,JaehdeU, Koberlein-NeuJ. Whom to serve first with a Medication Review? International Journal of Clinical Pharmacy 2016;38(4):1009. [CRSREF: 9077349]

Rose O, Schaffert C, CzarneckiK, Mennemann HS, Waltering I, Hamacher S, et al. PMC4508809; Effect evaluation of an interprofessional medication therapy management approach for multimorbid patients in primary care: a cluster-randomized controlled trial in community care (WestGem study protocol). BMC Family Practice 201 5; 16:84. [CRSREF: 9077350]

\section{Michalek 2014}

Published data only (unpublished sought but not used) [CRSSTD: 9077351]

Michalek C, Wehling M, SchlitzerJ, Frohnhofen H. Effects of "fit fOR the aged" (FORTA) on pharmacotherapy and clinical endpoints: A pilot randomized controlled study. European Journal of Clinical Pharmacology 2014;70(10):1261-7. [CRSREF: 9077352]

\section{Milos 2013}

[CRSSTD: 3179405$]$

Milos V, Rekman E, Bondesson A, Eriksson T, Jakobsson U, Westerlund T, et al. Improving the quality of pharmacotherapy in elderly primary care patients through medication reviews: a randomised controlled study. Drugs \& Aging 2013; 30(4):235-46. [CRSREF: 3179406$]$

\section{Muth 2016}

[CRSSTD: 9077353]

Muth C, HarderS, UhImann L, RochonJ, Fullerton B, Guthlin C, et al. Pilot study to test the feasibility of a trial design and complex intervention on PRIoritising MUltimedication in Multimorbidity in general practices (PRIMUMpilot). BMJ Open 2016; 6(7):e011613. [CRSREF: 9077354]

\section{Muth 2018}

[CRSSTD: 9077355]

Muth C, Uhlmann L, Haefeli WE, RochonJ, van den Akker M, Perera R, et al. Effectiveness of a complex intervention on Prioritising Multimedication in Multimorbidity (PRIMUM) in primary care: results of a pragmatic cluster randomised controlled trial. BMJ Open 2018;8(2):e017740. [CRSREF: 9077356]

\section{Olsson 2012}

[CRSSTD: 3179433 ]

Olsson IN, Runnamo R, Engfeldt P. Drug treatment in the elderly: an intervention in primary care to enhance prescription quality and quality of life. Scandinavian Journal of Primary Health Care 2012;30(1):3-9. [CRSREF: 31 79434]

\section{Pitkala 2014}

Published and unpublished data [CRSSTD: 9077357] 
Pitkala KH, Juola AL, Kautiainen H, Soini H, Finne-Soveri U, Bell JS, et al. Education to reduce potentially harmful medication use among residents of assisted living facilities: A randomized controlled trial. Journal of the American Medical Directors Association 2014;15(12):892-8. [CRSREF: 9077358]

\section{Schmader 2004}

Published data only (unpublished sought but not used) [CRSSTD: 3179164]

Schmader KE, HanlonJT, Pieper CF, Sloane R, Ruby CM, TwerskyJ, et al. Effects of geriatric evaluation and management on adverse drug reactions and suboptimal prescribing in the frail elderly. American Journal of Medicine 2004;116(6):394-401. [CRSREF: 3179165 ]

\section{Spinewine 2007}

Published and unpublished data [CRSSTD: 3179166$]$

Spinewine A, Swine C, DhillonS, Lambert P, NachegaJB, Wilmotte L, et al. Effect of a collaborative approach on the quality of prescribing for geriatricinpatients: A randomized controlled trial.Journal of the American Geriatrics Society 2007; 55(5):658-65. [CRSREF: 3179167$]$

\section{Tamblyn 2003}

[CRSSTD: 3179168$]$

Tamblyn R, Huang A, Perreault R, Jacques A, Roy D, Hanley J, et al. The medical office of the 21 st century (MOXXI): Effectiveness of computerised decision-making support in reducing inappropriate prescribing in primary care. Canadian Medical Association Journal 2003;169(6):549-56. [CRSREF: 3179169]

\section{Taylor 2003}

Published data only (unpublished sought but not used) [CRSSTD: 3179170 ]

Taylor CT, Byrd DC, Krueger K. Improving primary care in rural Alabama with a pharmacy initiative. American Journal of Health-System Pharmacy 2003;60(11):1123-9. [CRSREF: 3179171]

\section{Thyrian 2017}

Published and unpublished data [CRSSTD: 9077359]

ThyrianJ R, HertelJ, Wucherer D, Eichler T, Michalowsky B, Dreier-Wolfgramm A, et al. Effectiveness and safety of dementia care management in primary care: a randomized clinical trial. JAMA Psychiatry 2017;74(10):996-1004. [CRSREF: 9077360]

\section{Trygstad 2005}

Published data only (unpublished sought but not used) [CRSSTD: 3179172]

Trygstad TK, Christensen D, Garmise J, Sullivan R, Wegner S. Pharmacist response toalerts generated from Medicaid pharmacy claims in a long-term care setting: Results from the North Carolina polypharmacy initiative. Journal of Managed Care Pharmacy 2005;11(7):575-83. [CRSREF:3179173]

\section{Trygstad 2009}

Published and unpublished data [CRSSTD: 3179174$]$

Trygstad TK, Christensen DB, Wegner SE, Sullivan R, Garmise JM. Analysis of the North Carolina long-term care polypharmacy initiative: A multiple-cohort approach using propensity-score matching for both evaluation and targeting. Clinical Therapeutics 2009;31(8):2018-37. [CRSREF: 3179175]

\section{Van der Linden 2017}

\section{[CRSSTD: 9077361$]$}

Van der Linden L, Decoutere L, Walgraeve K, Milisen K, FlamaingJ, Spriet I, et al. Combined use of the Rationalization of home medication by an Adjusted STOPP in older Patients (RASP) list and a pharmacist-led medication review in very old inpatients: impact on quality of prescribing and clinical outcome. Drugs \& Aging 2017;34(2):123-33. [CRSREF: 9077362]

\section{Wehling 2016}

Published data only (unpublished sought but not used) [CRSSTD: 9077363]

Pazan F, Burkhardt H, Frohnhofen H, Weiss C, Throm C, Kuhn-Thiel A, et al. Changes in prescription patterns in older hospitalized patients: the impact ofFORTA on disease-related over-and under-treatments. EuropeanJournal of Clinical Pharmacology 2017;74(3):339-47. [CRSREF: 9077364]

*Wehling M, Burkhardt H, Kuhn-Thiel A, Pazan F, Throm C, Weiss C, etal. VALFORTA: A randomised trial to validate the FORTA (fit fOR the aged) classification. Age and Ageing 2016;45(2):262-7. [CRSREF: 9077365]

\section{Excluded studies}

\section{Aitichou 2015}

[CRSSTD: 9077366]

Aitichou M, Colloud V, Chaumard-Billotey N, Perrin S, Albrand G, Terret C. Input of a pharmacist-led medication evaluation 
Interventions to improve the appropriate use of polypharmacy for older people

in the management of older patients with cancer. Supportive Care in Cancer 2015;23:S90. [CRSREF: 9077367]

Alassaad 2014

[CRSSTD: 9077368]

Alassaad A, Bertilsson M, Gillespie U, SundstromJ, Hammarlund-Udenaes M, Melhus H. The effects of pharmacist intervention on emergency department visits in patients 80 years and older: subgroup analyses by number of prescribed drugs and appropriate prescribing. PLOS One 2014;9(11):e111797. [CRSREF: 9077369]

\section{Alexopoulos 2008}

[CRSSTD: 9077370]

Alexopoulos GS, Canuso CM, Gharabawi GM, Bossie CA, Greenspan A, Turkoz I, et al. Placebo-controlled study of relapse prevention with risperidone augmentation in older patients with resistant depression. American Journal ofCeriatric Psychiatry 2008;16(1):21-30. [CRSREF: 9077371]

\section{Alkema 2006}

[CRSSTD: 9077372]

Alkema GE, Frey D. Implications of translating research into practice: a medication management intervention. Home Health Care Services Quarterly 2006;25(1-2):33-54. [CRSREF: 9077373]

\section{Allard 2001}

[CRSSTD: 9077374]

Allard J, Hebert R, Rioux M, AsselinJ, Voyer L. Efficacy of a clinical medication review on the number of potentially inappropriate prescriptions prescribed for community dwelling elderly people. Canadian Medical Association Journal 2001; 164(9):1291-6. [CRSREF: 9077375]

\section{Allen 1986}

[CRSSTD: 9077376]

Allen CM, Becker PM, McVey LJ, Saltz C, FeussnerJR, Cohen HJ. A randomized, controlled clinical trial of a geriatric consultation team. Compliance with recommendations.JAMA 1986;255(19):2617-21. [CRSREF: 9077377]

\section{Allen 2011}

[CRSSTD: 3179184$]$

*Allen KR, Hazelett SE, Jarjoura D, Wright K, Fosnight SM, Kropp DJ, et al. The after discharge care management of low income frail elderly (AD-LIFE) randomized trial: theoretical framework and study design. Population Health Management $2011 ; 14(3): 137-42$. [CRSREF: 3179185 ]

Mussey L, Wright K, Gareri M, Hazelett S, Pfister E, Allen K. Poly-management syndrome: lessons from the AD-LIFE trial. In: Annual Scientific Meeting of the American Geriatrics Society Orlando, FL, United States. 201 0. [CRSREF: 31 791 86]

\section{Allen 2012}

[CRSSTD: 3179187 ]

Allen KR, Hazelett SE, Radwany S, Ertle D, Fosnight SM, Moore PS. The Promoting Effective Advance Care for Elders (PEACE) randomized pilot study: theoretical framework and study design. Population Health Management 2012;1 5(2):71-7. [CRSREF: 3179188 ]

\section{Altiner 2012}

[CRSSTD: 3179189$]$

Altiner A, Schafer I, Mellert C, Loffler C, Mortsiefer A, Ernst A, et al. Activating GENeral practitioners dialogue with patients on their Agenda (MultiCare AGENDA) study protocol for a cluster randomized controlled trial. BMC Family Practice 2012; 12(13):118. [CRSREF: 3179190$]$

\section{Anonymous 2005}

[CRSSTD: 3179191 ]

Anonymous. Community interventions aid self-care, prevention: program has reduced LOS, readmissions. Hospital Case Management 2005;13:181. [CRSREF: 3179192]

\section{Anonymous 2011}

[CRSSTD: 3179193 ]

Anonymous. CMEPOSTTEST.Journal of the American Academy of PhysicianAssistants $2011 ; 24(4)$ :56. [CRSREF: $3179194]$

Anonymous. Erratum in. JAAPA: Journal of the American Academy of Physician Assistants 201 1;24:56. [CRSREF: 3179195 ] 
Anonymous. Systematic practice-based interventions may help reduce the widespread use of antipsychotic polypharmacy. Drugs \& Therapy Perspectives 2012;28:24-6. [CRSREF: 3179197]

\section{Anonymous 2016}

[CRSSTD: 9077378]

Anonymous. Pharmaceutical care interventions for medication underuse in older people. Drugand Therapeutics Bulletin 2016;54:4. [CRSREF: 9077379]

\section{Anrys 2015}

[CRSSTD: 9077380]

Anrys P, Strauven G, Spinewine A, Foulon V. The optimization of medication use of Belgian nursing home residents based on a multidisciplinary collaboration (the Come-On study): Study protocol. International Journal of Clinical Pharmacy 2015; 37(2):418. [CRSREF: 9077381$]$

\section{Arvisais 2015}

[CRSSTD: 9077382]

Arvisais K, Bergeron-Wolff S, Bouffard C, Michaud A S, Bergeron J, Mallet L, et al. A pharmacist-physician intervention model using a computerized alert system to reduce high-risk medication use in elderly inpatients. Drugs \& Aging 2015 ; 32(8):663-70. [CRSREF: 9077383]

\section{Atkin 1996}

[CRSSTD: 3179198$]$

Atkin PA, Ogle SJ, Finnegan TP, Shenfield GM. Influence of "academic detailing" on prescribing for elderly patients. Health Promotion Journal of Australia 1996;6(3): 14-20. [CRSREF: 3179199$]$

\section{Avorn 1992}

[CRSSTD: 3179200$]$

AvornJ, Soumerai SB, Everitt DE, Ross-Degnan D, Beers MH, Sherman D, et al. A randomized trial of a program to reduce the use of psychoactive drugs in nursing homes. New England Journal of Medicine 1992;327(6):168-73. [CRSREF: 31 79201]

\section{Bartlett 2008}

[CRSSTD: 3179204$]$

Bartlett G, Blais R, Tamblyn R, Clermont RJ, MacGibbon B. Impact of patient communication problems on the risk of preventable adverse events in acute care settings. Canadian Medical Association Journal 2008; 1 78(12):1 555-62. [CRSREF: $3179205]$

\section{Beckett 2012}

[CRSSTD: 3179206$]$

Beckett RD, Crank CW, Wehmeyer A. Effectiveness and feasibility of pharmacist-led admission medication reconciliation for geriatric patients. Journal of Pharmacy Practice 2012;25(2):136-41. [CRSREF: 3179207]

\section{Beer 2011}

[CRSSTD: 3179208 ]

Beer C, Loh P, Peng YG, Potter K, Millar A. A pilot randomized controlled trial of deprescribing. Therapeutic Advances in Drug Safety $2011 ; 2(2): 37-43$. [CRSREF: 3179209]

\section{Bell 2011}

[CRSSTD: 3179210$]$

BellJS, Kalisch LM, RamsayEN, Pratt NL, BarrattJD, Leblanc T. Prescriber feedback to improve quality use of medicines among older people:The Veterans' MATES program.Journal of Pharmacy Practice and Research 2011;41 (4):316-9. [CRSREF: 3179211 ]

\section{Bergert 2014}

[CRSSTD: 9077384]

Bergert FW, Braun M, Ehrenthal K, FesslerJ, GrossJ, HuttnerU, et al. Recommendations for treating adult and geriatric patients on multimedication. International Journal of Clinical Pharmacology and Therapeutics 2014;52:S1-S64. [CRSREF: 9077385]

\section{Blais 2008}

[CRSSTD: 3179218 ]

Blais R, Laurier C, Pare M. Effect of feedback letters to physicians and pharmacists on the appropriate use of medication in the treatment of asthma. Journal of Asthma 2008;45(3):227-31. [CRSREF: 31 79219] 
[CRSSTD: 3179220$]$

Bloomfield HE, Nelson DB, Van RM, Neil BJ, Koets NJ, BasileJN, et al. A trial of education, prompts, and opinion leaders to improve prescription of lipid modifying therapy by primary care physicians for patients with ischemic heart disease. Quality and Safety in Health Care 2005; 14(4):258-63. [CRSREF: 3179221 ]

\section{Bosma 2008}

[CRSSTD: 3179222$]$

BosmaL, Jansman FG, Franken AM, HartingJW, Van den Bemt PM. Evaluation of pharmacist clinical interventions in a Dutch hospital setting. Pharmacy World \& Science 2008;30(1):31 -8. [CRSREF: 3179223 ]

\section{Buckmaster 2006}

[CRSSTD: 3179224$]$

Buckmaster ND, HeazlewoodV, ScottIA, Jones M, HaererW, HillierK. Using aclinical pathway and education to reduce inappropriate prescribing of enoxaparin in patients with acute coronary syndromes: a controlled study. Internal Medicine Journal 2006;36(1):12-8. [CRSREF: 3179225]

\section{Burnett 2009}

Published data only (unpublished sought but not used) [CRSSTD: 3179226]

Burnett KM, Scott MG, Fleming GF, Clark CM, McElnay JC. Effects of an integrated medicines management program on medication appropriateness in hospitalised patients. American Journal of Health-System Pharmacy 2009;66(9):854-9. [CRSREF: 3179227 ]

\section{Burns 1995}

[CRSSTD: 3179228 ]

Burns R, Nichols LO, Graney MJ, Cloar FT. Impact of continued geriatric outpatient management on health outcomes of older veterans. Archives of Internal Medicine 1995;155(12):1313-8. [CRSREF: 31 79229]

\section{Carey 2008}

[CRSSTD: 3179230$]$

Carey N, Courtenay M,JamesJ, Hills M, RolandJ. An evaluation of a diabetes specialist nurse prescriber on the system of delivering medicines to patients with diabetes. Journal of Clinical Nursing 2008;1 7(12):1635-44. [CRSREF: 31 79231]

\section{Claesson 1998}

[CRSSTD: 3179234$]$

Claesson CB, Schmidt IK. Drug use in Swedish nursing homes. Clinical Drug Investigation 1998;1 6(6):441-52. [CRSREF: $3179235]$

\section{Clyne 2013}

[CRSSTD: 3179236$]$

Clyne B, Bradley MC, Smith SM, Hughes CM, Motterlini N, Clear D. Effectiveness of medicines review with web-based pharmaceutical treatment algorithms in reducing potentially inappropriate prescribing in older people in primary care: a cluster randomized trial (OPTI-SCRIPT study protocol). Trials [Electronic Resource] 201 3; 14(72). [CRSREF: 31 79237]

\section{Clyne 2013a}

[CRSSTD: 9077386]

Clyne B, Hughes C, Smith SM, Fahey T. Feasibility of medicines review to reduce potentially inappropriate medicines in the elderly: The opti-script cluster randomized controlled trial. Value in Health 201 3;16:A485. [CRSREF: 9077387]

\section{Coleman 1999}

[CRSSTD: 3179238$]$

Coleman EA, Grothaus LC, Sandhu N, Wagner EH. Chronic care clinics: a randomized controlled trial of a new model of primary care for frail older adults. Journal of the American Geriatrics Society 1999;47(7):775-83. [CRSREF: 31 79239]

\section{Colpaert 2006}

[CRSSTD: 3179240$]$

Colpaert K, Claus B, Somers A, Vandewoude K, Robays H, Decruyenaere J. Impact of computerized physician order entry on medication prescription errors in the intensive care unit: a controlled cross-sectional trial. Critical Care 2006;1 0(1):R21 . [CRSREF: 3179241 ]

\section{Corbi 2015}

[CRSSTD: 9077388]

Corbi G, Gambassi G, Pagano G, Russomanno G, Conti V, Rengo G, et al. Impact of an innovative educational strategyon medication appropriate use and length of stay in elderly patients. Medicine 201 5;94:e918. [CRSREF: 9077389] 
Interventions to improve the appropriate use of polypharmacy for older people

\section{Courtenay 2007}

[CRSSTD: 3179242$]$

Courtenay M, Carey N, James J, Hills M, Roland J. An evaluation of a specialist nurse prescriber on diabetes in-patient service delivery. Practical Diabetes International 2007;24(2):69-74. [CRSREF: 3179243 ]

\section{Darcy 2014}

[CRSSTD: 9077390]

Darcy C, Miller R, Friel A, Scott M. Consultant pharmacist case management of elderly patients in intermediate care. Age \& Ageing 2014;43:ii2. [CRSREF: 9077391]

\section{Davis 2007}

[CRSSTD: 3179244$]$

Davis RG, Hepfinger CA, Sauer KA, Wilhardt MS. Retrospective evaluation of medication appropriateness and clinical pharmacist drug therapy recommendations for home-based primary care veterans. American Journal Geriatric Pharmacotherapy 2007;5(1):40-7. [CRSREF: 3179245$]$

\section{Delate 2008}

[CRSSTD: 3179246$]$

Delate T, Chester EA, Stubbings TW, Barnes CA. Clinical outcomes of a home-based medication reconciliation program after discharge from a skilled nursing facility. Pharmacotherapy 2008;28(4):444-52. [CRSREF: 31 79247]

\section{Denneboom 2007}

[CRSSTD: 3179248$]$

Denneboom W, Dautzenberg MG, Grol R, de Smet PA. Treatment reviews of older people on polypharmacy in primary care: cluster controlled trial comparing two approaches. British Journal of General Practice 2007;57(542):723-31. [CRSREF: $3179249]$

\section{Der 1997}

[CRSSTD: 3179250$]$

DerEH, Rubenstein LZ, Choy GS. The benefits of in-home pharmacy evaluation for older persons. Journal of the American Geriatrics Society 1997;45(2):211-4. [CRSREF: 3179251]

\section{Desborough 2014}

[CRSSTD: 9077392]

Desborough J, Somally D. Multi-professional medication reviews in care homes for older people: What were the interventions in the CAREMED study? International Journal of Pharmacy Practice 2014;22:10-1 . [CRSREF: 9077393]

\section{Diaz 2003}

[CRSSTD: 3179252$]$

Diaz Masip MD, Madridejos MR, Modamio CP, Marino Hernandez EL. Profile of the polymedicated patient in primary health care and intervention aimed at reducing anxiolytic polymedication [Perfil de paciente polimedicado en atencion primaria e intervencion para disminuir la polimedicacion de ansioliticos]. Pharmaceutical Care Espana 2003;5(3):124-31 . [CRSREF: $3179253]$

\section{Di Marzio 2012}

[CRSSTD: 9077394]

Di Marzio M, Byrne S. Inappropriate prescribing in the elderly - an audit of elderly patients in long term care facilities. In: Prescribing And Research In Medicines Management (UK \& Ireland), London, United Kingdom. 2012. [CRSREF: 9077395]

\section{Dresden 2013}

[CRSSTD: 3179254$]$

Dresden S, Aldeen A, Courtney DM, Gravenor S, Malik S, Adams J. Feasibility of implementing a focused nursing assessment for geriatric patients in the emergency department. In: American College of Emergency Physicians Research Forum, Seattle, WA, United States. 2013. [CRSREF: 3179255 ]

\section{Easthall 2014}

[CRSSTD: 9077396]

Easthall C, Scrimshaw P, Wright D, Bhattachrya D. Can a domiciliary medicines support service reduce the risk of medicines related harm in an elderly population? International Journal of Pharmacy Practice 2014;22:4. [CRSREF: 9077397]

\section{Eckert 1991}

[CRSSTD: 3179256$]$

Eckert GM, Ioannides-Demos LL, McLean AJ. Measuring and modifying hospital drug use. Medical Journal of Australia 1991 ; 
Interventions to improve the appropriate use of polypharmacy for older people

154(9):587-92. [CRSREF: 3179257$]$

\section{Edmans 2013}

[CRSSTD: 3179258 ]

Edmans J, Bradshaw L, Franklin M, Gladman J, Conroy S. Specialist geriatric medical assessment for patients discharged from hospital acute assessment units: randomised controlled trial. BMJ 201 3;347:f5874. [CRSREF: 31 79259]

\section{Elliott 2012}

[CRSSTD: 3179260$]$

Elliott RA, Martinac G, Campbell S, ThornJ, Woodward MC. Pharmacist-led medication review to identify medication-related problems in older people referred to an Aged Care Assessment Team: a randomized comparative study. Drugs \&Aging 2012;29(7):593-605. [CRSREF: 3179261]

\section{Eriksson 2012}

[CRSSTD: 3179262$]$

Eriksson T, Bondesson A, Holmdahl L, Midlov P, Hoglund P. The Lund integrated medicines management model, health outcomes and processes development. In: European Association of Hospital Pharmacists Congress, Milan, Italy. 2012. [CRSREF: 3179263 ]

Eriksson T. Lund integrated medicines management (LIMM)-model improves the health care process and patient outcomes. In: 28th International Conference on Pharmacoepidemiology and Therapeutic Risk Management, Barcelona, Spain. 2012. [CRSREF: 3179264$]$

\section{Essock 2011}

[CRSSTD: 3179265$]$

Essock SM, Schooler NR, Stroup TS, McEvoyJP, Rojas I, Jackson C, et al. Effectiveness of switching from antipsychotic polypharmacy to monotherapy. American Journal of Psychiatry 201 1;168(7):702-8. [CRSREF: 31 79266]

\section{Farris 2014}

[CRSSTD: 9077398]

Farris KB, Carter BL, Xu Y, Dawson JD, Shelsky C, Weetman DB, et al. Effect of a care transition intervention by pharmacists: an RCT. BMC Health Services Research 2014;14(1):1. [CRSREF: 9077399]

\section{Feder 1999}

[CRSSTD: 3179267$]$

Feder G, Griffiths C, Eldridge S, Spence M. Effect of postal prompts to patients and general practitioners on the quality of primary care after a coronary event (POST): randomised controlled trial. BMJ 1999;31 8(7197): 1 522-6. [CRSREF: 31 79268]

\section{Feldstein 2006}

[CRSSTD: 3179269$]$

Feldstein AC, Smith DH, Perrin N, Yang X, Simon SR, Krall M, et al. Reducing warfarin medication interactions: an interrupted time series evaluation. Archives of Internal Medicine 2006;166(9):1009-1 5. [CRSREF: 31 79270]

\section{Fick 2004}

Published data only (unpublished sought but not used) [CRSSTD: 3179271$]$

Fick DM, Maclean JR, Rodriguez NA, Short L, Heuvel RV, Waller JL, et al. A randomized study to decrease the use of potentially inappropriate medications among community-dwelling older adults in a Southeastern managed care organization. American Journal of Managed Care 2004;10(11):761-8. [CRSREF: 31 19272]

\section{Flanagan 2002}

[CRSSTD: 3179273 ]

Flanagan PS, Mackinnon NJ, Hanlon N, Robertson H. Identification of intervention strategies to reduce preventable drugrelated morbidity in older adults. Geriatrics Today 2002;5:76-80. [CRSREF: 3179274]

\section{Flores Dorado 2013}

[CRSSTD: 9077400]

Flores Dorado M, Baena Parejo I,Jiménez MartínJ, Faus Dáder MJ. Medication review of the polymedicated patient in primary care. Atencion Primaria 2013;45(4):222-3. [CRSREF: 9077401]

\section{Fontaine 2006}

[CRSSTD: 3179275$]$

Fontaine A, Mahe I, BergmannJF, FiessingerJN, Dhote R, Cohen P, et al. Effectiveness of written guidelines on the appropriateness of thromboprophylaxis prescriptions for medical patients: a prospective randomized study. Journal of Internal Medicine 2006;260(4):369-76. [CRSREF: 3179276] 
Interventions to improve the appropriate use of polypharmacy for older people

\section{Frankenthal 2014a}

[CRSSTD: 9077402]

Frankenthal D, KalendaryevE, Lerman Y. Intervention with the STOPP/START criteria among elderly residents of a chronic geriatric facility: A randomized clinical trial. European Geriatric Medicine 2014;5:S68-9. [CRSREF: 9077403]

\section{Freeman 2012}

[CRSSTD: 9077404]

Freeman PB. Ninety is the new...ninety! Optometry (St.Louis, Mo.) 2012;83(2):61-2. [CRSREF: 9077405]

Frohnhofen 2013

[CRSSTD: 9077406]

Frohnhofen H, Schlitzer J, Wehling M. Pharmacotherapy and frequency of inhos pital falls among geriatric patients. Osteoporosis International 2013;24:S311. [CRSREF: 9077407]

\section{Gaede 2008}

[CRSSTD: 3179277 ]

Gaede P, Lund-Andersen H, Parving HH, Pedersen O. Effect of a multifactorial intervention on mortality in type 2 diabetes. New England Journal of Medicine 2008;358(6):580-91 . [CRSREF: 3179278 ]

\section{Galindo-Ocana 2010}

[CRSSTD: 9077408]

Galindo-OcanaJ, Gil-Navarro M, Garcia-MorilloJ, Bernabeu-Wittel M, Ollero-Baturone M, Ortiz-Camunez M. Drug-drug interactions in multicentre polypathological polymedicated patients]. Spanish]. Revista Clinica Espanola 2010;210(6):270-8. [CRSREF: 9077409]

\section{Ganz 2010}

[CRSSTD: 3179279$]$

* Ganz DA, Koretz BK, BailJK, McCreath HE, Wenger NS, Roth CP, et al. Nurse practitioner comanagement for patients in an academic geriatric practice. American Journal of Managed Care 201 0;1 6(12):e343-55. [CRSREF: 31 79280]

Ganz DA, Koretz BK, McCreath HE, WengerNS, Roth CP, BailJK, et al. The effect of nurse practitioner co-management on quality of care of patients with chronic conditions in an academic geriatric practice. In: Annual Scientific Meeting of the American Geriatrics Society, Orlando, FL, United States. 2010. [CRSREF: 3179281]

\section{Garcia 2013}

[CRSSTD: 9077410]

Garcia BH, Giverhaug T, Utnes J, Smabrekke L. A follow-up program for patients with established coronary heart disease led by a clinical pharmacist: A randomized controlled trial. International Journal of Clinical Pharmacy 201 3;35:1255-6. [CRSREF: $9077411]$

\section{Garcia 2014}

[CRSSTD: 9077412 ]

Garcia LE, Pastewait S, Rebecca R, Chen-pin W, MacCarthy D, Moris M, et al. A pharmacy-based transitional care program to reduce hospital readmissions in high risk older veterans. Journal of the American Geriatrics Society 201 4;62:S230-1. [CRSREF: 9077413 ]

\section{Garcia 2015}

[CRSSTD: 9077414$]$

Garcia BH, Giverhaug T, Hogli JU, Skjold F, Smabrekke L. A pharmacist-led follow-up program for patients with established coronary heart disease in North Norway - A randomized controlled trial. Pharmacy Practice 201 5;1 3:1 - 10. [CRSREF: 9077415]

\section{Garfinkel 2007}

[CRSSTD: 3179282 ]

Garfinkel D, Zur-Gil S, Ben-IsraelJ. The war against polypharmacy: a new cost-effective geriatric-positive approach for improving drug therapy in disabled elderly people. Israel Medical Association Journal 2007;9(6):430-4. [CRSREF: 3179283 ]

\section{Gerber 2008}

[CRSSTD: 3179284$]$

Gerber A, Stollenwerk B, Lauterbach KW, StockS, Buscher G, Rath T, et al. Evaluation of multi-dose repackaging for individual patients in long-term care institutions: savings from the perspective of statutory health insurance in Germany. International Journal of Pharmacy Practice 2008;16(6):387-94. [CRSREF: 3179285] 
[CRSSTD: 9077416]

Geurts MME, Stewart RE, Brouwers JRBJ, de Graeff PA, de Gier JJ. Patient beliefs about medicines and quality of life after a clinical medication review and follow-up by a pharmaceutical care plan: A study in elderly polypharmacy patients with a cardiovascular disorder.Journal of Pharmaceutical Health Services Research 2015;6(4):171 -6. [CRSREF: 907741 7]

Geurts 2016

[CRSSTD: 9077418 ]

Geurts MM, Stewart RE, Brouwers JR, de Graeff PA, de Gier JJ. Implications of a clinical medication review and a pharmaceutical care plan of polypharmacy patients with a cardiovascular disorder. Int JClin Pharm 2016;38(4):808-81 5. [CRSREF: 9077419$]$

Gill 2001

[CRSSTD: 3179286$]$

Gill SS, Misiaszek BC, Brymer C. Improving prescribing in the elderly: a study in the long term care setting. Canadian Journal of Clinical Pharmacology 2001;8(2):78-83. [CRSREF: 3179287 ]

\section{Gillespie 2009}

[CRSSTD: 3179288 ]

GillespieU, Alassaad A, Hammarlund-Udenaes M, Morlin C, Henrohn D, Bertilsson M, etal. Effects of pharmacists' interventions on appropriateness of prescribing and evaluation of the instruments' (MAI, STOPP and STARTs') ability to predict hospitalization-analyses from a randomized controlled trial. PLOS One [Electronic Resource] 201 3;8:e62401. [CRSREF: 3179289$]$

* Gillespie U, Alassaad A, Henrohn D, Garmo H, Hammarlund-Udenaes M, Toss H, et al. A comprehensive pharmacist intervention to reduce morbidity in patients 80 years or older. a randomised controlled trial. Archives of Internal Medicine 2009;169(9):894-900. [CRSREF: 3179290]

\section{Gillespie 2017}

[CRSSTD: 9077420]

Gillespie P, Clyne B, Raymakers A, Fahey T, Hughes CM, Smith S M. Reducing Potentially Inappropriate Prescribing for Older People in Primary Care: Cost-Effectiveness of the Opti-Script Intervention. International Journal of Technology Assessment in Health Care 201 7;33(4):494-503. [CRSREF: 9077421 ]

\section{Ginzburg 2012}

[CRSSTD: 3179291$]$

Ginzburg R, Ng N. Decreasing inappropriate prescribing in elderly patients. In: Annual Meeting of the American College of Clinical Pharmacy, Hollywood, FL, United States. 2012. [CRSREF: 31 79292]

\section{Gislason 2007}

[CRSSTD: 3179293 ]

Gislason GH, RasmussenJN, AbildstromSZ, Schramm TK, Hansen ML, Buch P, et al. Persistent use of evidence-based pharmacotherapy in heart failure is associated with improved outcomes. Circulation 2007; 1 16(7):737-44. [CRSREF: $3179294]$

\section{Giunta 2015}

[CRSSTD: 9077422]

Giunta N, Cain K. Community-based case management and health care use in older adults: outcomes of a collaborative multiagency approach. Care Management Journals : Journal of case management; The journal of long term home health care 2015;16(1):20-9. [CRSREF: 9077423]

\section{Gorup 2012}

[CRSSTD: 3179295$]$

Gorup EC. Effectiveness of a medication review in elderly nursing home residents. In: European General Practice Research Network Meeting, Ljubljana, Slovenia. 2012. [CRSREF: 3179296 ]

\section{Gradman 2002}

[CRSSTD: 31 79297]

Gradman AH, Brady WE, Gazdick LP, Lyle P, Zeldin RK. A multicenter, randomized, double-blind, placebo-controlled, 8week trial of the efficacy and tolerability of once-daily losartan $100 \mathrm{mg} / \mathrm{hydrochlorothiazide} 25 \mathrm{mg}$ and losartan $50 \mathrm{mg} /$ hydrochlorothiazide $12.5 \mathrm{mg}$ in the treatment of moderate-to-severe essential hypertension. Clinical Therapeutics 2002; 24(7):1049-61. [CRSREF: 3179298]

\section{Graffen 2004}

[CRSSTD: 3179299$]$ 
Interventions to improve the appropriate use of polypharmacy for older people

Graffen M, Kennedy D, Simpson M. Quality use of medicines in the rural ambulant elderly: a pilot study. Rural and Remote Health 2004;4(3):40-6. [CRSREF: 3179300 ]

\section{Gramage 2014}

[CRSSTD: 9077424$]$

Gramage CT, Crespillo RF, Alvarez DA, Perez Menendez-Conde C, Delgado Silveira E, Munoz GM, et al. Application of electronic alerts of the STOPP criteria in an assisted electronic prescription program. Atencion Farmaceutica 2014; 16(2):137-40. [CRSREF: 9077425]

\section{Guptha 2003}

[CRSSTD: 3179301$]$

Guptha SH, Mittra R, Puthrasingam S, Johnson GM, Ellis CDW, Hill-Smith I, et al. Application of evidence-based prescribing indicators in primary care: a pilot. Quality in Primary Care 2003; 11 (2):1 07-16. [CRSREF: 31 79302]

\section{Gwadry-Sridhar 2005}

[CRSSTD: 3179303 ]

Gwadry-SridharFH, ArnoldJM, ZhangY, BrownJE, Marchiori G, Guyatt G. Pilot studyto determine the impact of a multidisciplinary educational intervention in patients hospitalized with heart failure. American HeartJournal 2005; 150(5):982-90. [CRSREF: 3179304$]$

\section{Hamilton 2007}

[CRSSTD: 3179305$]$

Hamilton W, Russell D, Stabb C, Seamark D, Campion-Smith C, Britten N. The effect of patient self-completion agenda forms on prescribing and adherence in general practice: a randomized controlled trial. Family Practice 2007;24(1):77-83. [CRSREF: 3179306 ]

\section{Hasler 2015}

[CRSSTD: 9077426]

Hasler S, Senn O, Rosemann T, Neuner-Jehle S. Effect of a patient-centered drug review on polypharmacy in primary care patients: study protocol for a cluster-randomized controlled trial. Trials 201 5; 16:380. [CRSREF: 9077427]

\section{Hawes 2014}

[CRSSTD: 9077428]

Hawes EM, Maxwell WD, White SF, Mangun J, Lin FC. Impact of an outpatient pharmacist intervention on medication discrepancies and health care resource utilization in posthospitalization care transitions. Journal of Primary Care \& Community Health 2014;5(1):14-8. [CRSREF: 9077429]

\section{Hellstrom 2011}

[CRSSTD: 3179307$]$

Hellstrom LM, Bondesson A, Hoglund P, Midlov P, Holmdahl L, Rickhag E. Impact of the Lund Integrated Medicines Management (LIMM) model on medication appropriateness and drug-related hospital revisits. European Journal of Clinical Pharmacology $2011 ; 67(7): 741-52$. [CRSREF: 3179308 ]

\section{Hobbs 2006}

[CRSSTD: 3179309$]$

Hobbs FDR, Gensini G, Mancini GBJ, Manolis AJ, Bauer B, BohlerS, et al. Can combining different risk interventions into a single formulation contribute to improved cardiovascular disease risk reduction? Rationale and design for an international, open-label program to assess the effectiveness of a single pill (amlodipine/atorvastatin) to attain recommended target levels for blood pressure and lipids (The JEWEL Program). International Journal of Cardiology 2006;1 10(2):242-50. [CRSREF: $3179310]$

\section{Hogg 2009}

[CRSSTD: 3179311$]$

FletcherJ, Hogg W, Farrell B, Woodend K, Dahrouge S, Lemelin J, et al. Effect of nurse practitioner and pharmacist counseling on inappropriate medication use in family practice. Canadian Family Physician 2012;58(8):862-8. [CRSREF: $3179312]$

* Hogg W, Lemelin J, Dahrouge S, Liddy C, Armstrong CD, Legault F, et al. Randomized controlled trial of anticipatory and preventive multidisciplinary team care: for complex patients in a community-based primary care setting. Canadian Family Physician (Medecin de Famille Canadien) 2009;55(12):e76-85. [CRSREF: 3179313 ]

\section{Houghton 2014}

[CRSSTD: 9077430]

Houghton J, Kirthisinga V, DesboroughJ A. 65 multi-professional medication reviews in care homes for older people: results from the Care Med randomised controlled trial. Age \& Ageing 2014;43(Suppl 2):ii 19-ii20. [CRSREF: 9077431 ] 


\section{Howard 2014}

[CRSSTD: 9077432]

Howard R, Rodgers S, Avery AJ, Sheikh A. Description and process evaluation of pharmacists' interventions in a pharmacistled information technology-enabled multicentre cluster randomised controlled trial for reducing medication errors in general practice (PINCER trial). International Journal of Pharmacy Practice 2014;22(1):59-68. [CRSREF: 9077433]

\section{Hugtenburg 2017}

[CRSSTD: 9077434]

HugtenburgJG. The effectiveness of optimised clinical medication reviews for geriatric patients: a cluster randomized controlled trial. Pharmacoepidemiology and Drug Safety 201 7;26:194. [CRSREF: 9077435]

\section{Humphries 2007}

[CRSSTD: 3179314$]$

Humphries TL, Carroll N, Chester EA, Magid D, Rocho B. Evaluation of an electronic critical drug interaction program coupled with active pharmacist intervention. Annals of Pharmacotherapy 2007;41 (12):1 979-85. [CRSREF:3179315]

\section{Hung 2012}

[CRSSTD: 3179316$]$

Hung WW, Dunn CM, Moodhe NE, Gottesman EM, Morano B, Boockvar KS. Improving quality of care for older veterans through a RHI oenhanced care transitions intervention (CTI). In: Annual Scientific Meeting of the American Geriatrics Society Seattle, WA, United States. 2012. [CRSREF: 3179317]

\section{Ilic 2015}

\section{[CRSSTD: 9077436]}

Ilic D, Bukumiric Z,Jankovic S. Impact of educational intervention on prescribing inappropriate medication to elderly nursing homes residents. Srpski Arhiv za Celokupno Lekarstvo 201 5; 143(3-4):174-9. [CRSREF: 9077437]

\section{Izquierdo 2007}

\section{[CRSSTD: 3179318 ]}

Izquierdo R, MeyerS, StarrenJ, Goland R, TeresiJ, Shea S, et al. Detection and remediation of medically urgent situations using telemedicine case management for older patients with diabetes mellitus. Therapeutics and Clinical Risk Management 2007;3(3):485-9. [CRSREF: 3179319 ]

\section{Jabalquinto 2007}

[CRSSTD: 3179320$]$

Jabalquinto GA, Toro JC, Escolar CR, Garcia JI, Munoz LG. Coordination of geriatric care to improve drug prescription and dispensation in a nursing home [Coordinacion de servicios sociosanitarios para la mejora de la prescripcion y dispensacion farmacologica en una residencia de ancianos]. Revista Espanola de Geriatria y Gerontologia 2007;42(6):333-41. [CRSREF: $3179321]$

\section{Jean-Bart 2014}

[CRSSTD: 9077438]

Jean-Bart E, Faure R, Omrani S, Guilli T, Roubaud C, Krolak-Salmon P, et al. Role of clinical pharmacist in the therapeutical optimization in geriatric outpatient hospital. French]. Annales Pharmaceutiques Francaises 201 4;72(3): 1 84-93. [CRSREF: 9077439]

\section{Jensen 2003}

[CRSSTD: 3179322$]$

Jensen L. Self-administered cardiac medication program evaluation. Canadian Journal of Cardiovascular Nursing 2003; 13(2):35-44. [CRSREF: 3179323 ]

\section{Jódar-Sánchez 2015}

[CRSSTD: 9077440]

Jódar-Sánchez F, Malet-Larrea A, Martín J, García-Mochón L, López Del Amo MP, Martínez-Martínez F, et al. Cost-utility analysis of a medication review with follow-up service for older adults with polypharmacy in community pharmacies in Spain: the conSIGUE program. PharmacoEconomics 2015;33(6):599-610. [CRSREF: 9077441]

\section{Juola 2015}

\section{[CRSSTD: 9077442]}

Juola A L, Bjorkman M P, Pylkkanen S, Finne-Soveri H, Soini H, Kautiainen H, et al. Nurse education to reduce harmful medication use in assisted living facilities: effects of a randomized controlled trial on falls and cognition. Drugs \& Aging 2015 ; 32(1 1):947-55. [CRSREF: 9077443] 
Interventions to improve the appropriate use of polypharmacy for older people

\section{Kaboli 2004}

[CRSSTD: 9077444]

Kaboli PJ, Hoth AB, Carter BL. The VA enhanced pharmacy outpatient clinic (EPOC) study: a randomized-controlled pharmacist-physician intervention trial. In: 27th Annual Meeting of the Society of General Internal Medicine, Chicago, Illinois. 2004. [CRSREF: 9077445]

\section{Kairuz 2008}

[CRSSTD: 3179324$]$

Kairuz T, Bye L, Birdsall R, Deng T, Man L, Ross A, et al. Identifying compliance issues with prescription medicines among older people: a pilot study. Drugs and Aging 2008;25(2):1 53-62. [CRSREF: 3179325]

\section{Kashyap 2015}

[CRSSTD: 9077446]

Kashyap M, Rohit M, Kapur V, D'CruzS, Sachdev A, Tiwari P. An indian study on assessment of the suitability of pharmacotherapy in elderly patients and its enhancement. Pharmacoepidemiology and Drug Safety 2015;24:390-1. [CRSREF: 9077447]

\section{Kassam 2001}

[CRSSTD: 3179326$]$

Kassam R, Farris KB, Burback L, Volume CI, Cox CE, Cave A. Pharmaceutical care research and education project: pharmacists' interventions.Journal of the American Pharmaceutical Association 2001;41 (3):401 - 10. [CRSREF:31 79327]

\section{Kassam 2003}

[CRSSTD: 3179328$]$

Kassam R, Martin LG, Farris KB. Reliability of a modified medication appropriateness index in community pharmacies. Annals of Pharmacotherapy 2003;37(1):40-6. [CRSREF: 3179329]

\section{Kastrissios 1998}

[CRSSTD: 3179330$]$

Kastrissios H, Suarez JR, Katzenstein D, Girard P, Sheiner LB, Blaschke TF. Characterizing patterns of drug-taking behavior with a multiple drug regimen in an AIDS clinical trial. AIDS 1998;12(17):2295-303. [CRSREF: 3179331]

\section{Katzourakis 2010}

[CRSSTD: 9077448]

Katzourakis M, Pathak R, Macdonald D. The va initial pre-visit planning trial: The V.I.P. Trial. Pharmacotherapy 2010; 30:371 e. [CRSREF: 9077449]

\section{Kavanagh 2014}

[CRSSTD: 9077450]

KavanaghJ, BishopT, Chiang C, DePasquale AM, Kales HC, SireyJA. Simplifying the assessment of antidepressant adherence through automated pill count calculation: Experience from the TIP studies. American Journal of Geriatric Psychiatry 2014;22:S138-9. [CRSREF: 9077451]

\section{Keith 2013}

[CRSSTD: 3179332 ]

* Keith SW, Maio V, Dudash K, Templin M, Del Canale S. A physician-focused intervention to reduce potentially inappropriate medication prescribing in older people: a 3-year, Italian, prospective, proof-of-concept study. Drugs \& Aging 2013;30(2):119-27. [CRSREF: 3179333]

Lopatto J, Keith SW, Templin M, Maio V, Del Canale S. Are quality improvements sustained? long-term effectiveness of a physician-focused intervention to reduce potentially inappropriate medication prescribing in the elderly in Italy. In: ISPOR 18th Annual International Meeting, New Orleans, LA, United States. 2013. [CRSREF: 31 79334]

\section{Keller 2012}

[CRSSTD: 3179335$]$

Keller H, Krones T, Becker A, Hirsch O, Sonnichsen AC, Popert U, et al. Arriba: effects of an educational intervention on prescribing behaviour in prevention of CVD in general practice. EuropeanJournal of Preventive Cardiology 2012; 19(3):322-9. [CRSREF: 3179336 ]

\section{Key 2010}

[CRSSTD: 3179337 ]

Key C, Lee S, Garza M, Sanchez-Reilly SE. Impact of a geriatric consultation on the prescription of potentially inappropriate medications and opioids in elderly patients. In: Annual Scientific Meeting of the American Geriatrics Society, Orlando, FL, United States. 2010. [CRSREF: 3179338 ] 
Interventions to improve the appropriate use of polypharmacy for older people

\section{Kjekshus 2005}

[CRSSTD: 3179339$]$

KjekshusJ, Dunselman P, Blideskog M, EskilsonC, Hjalmarson A, McMurrayJV, et al. Astatin in the treatment of heart failure? Controlled rosuvastatin multinational study in heart failure (CORONA): study design and baseline characteristics. European Journal of Heart Failure 2005;7(6):1059-69. [CRSREF: 31 79340]

\section{Klopotowska 2011}

[CRSSTD: 3179341$]$

KlopotowskaJE, Wierenga PC, de Rooij SE, Stuijt CC, Arisz L, Kuks PF, et al. The effect of an active on-ward participation of hos pital pharmacists in Internal Medicine teams on preventable Adverse Drug Events in elderly inpatients: protocol of the WINCS study (Ward-oriented pharmacy in newly admitted geriatric seniors). BMC Health Services Research 201 1;1 1:124. [CRSREF: 3179342]

\section{Kojima 2012}

[CRSSTD: 3179343 ]

Kojima G, Bell C, Tamura B, Inaba M, Lubimir K, Blanchette PL, et al. Reducing cost by reducing polypharmacy: the polypharmacy outcomes project. Journal of the American Medical Directors Association 2012;13(9):81 8. e 1 1 -5. [CRSREF: $3179344]$

\section{Kojima 2014}

[CRSSTD: 9077452]

Kojima G, Bell C L, Tamura B, Davis J, Inaba M, Lorenzo P, et al. NIHMS596058 PMC4190157; Combining quality improvement and geriatrics training: the nursing home polypharmacy outcomes project. Gerontology \& Geriatrics Education 2014;35(4):395-408. [CRSREF: 9077453]

\section{Kolhatkar 2016}

[CRSSTD: 9077454]

Kolhatkar A, Cheng L, Chan FK, Harrison M, Law MR. The impact of medication reviews by community pharmacists. Journal of the American Pharmacists Association 2016;56(5):513-20. [CRSREF: 9077455]

\section{Kouladjian 2015}

[CRSSTD: 9077456]

Kouladjian L, Chen TF, Hilmer SN. First do no harm: a real need to deprescribe in older patients. Medical journal of Australia 2015;202(4): 179. [CRSREF: 9077457]

\section{Kroenke 1990}

[CRSSTD: 3179345$]$

Kroenke K, Pinholt EM. Reducing polypharmacy in the elderly. A controlled trial of physician feedback. Journal of the American Geriatrics Society 1990;38(1):31-6. [CRSREF: 3179346]

\section{Kwan 2007}

[CRSSTD: 3179347$]$

Kwan Y, Fernandes OA, Nagge JJ, Wong GG, HuhJH, Hurn DA, et al. Pharmacist medication assessments in a surgical preadmission clinic. Archives of Internal Medicine 2007; 167(10): 1034-40. [CRSREF: 31 79348]

\section{Kwint 2015}

[CRSSTD: 9077458]

Kwint HF, Faber A, Gussekloo J, Bouvy M. Optimizing medication use for elderly patients. Huisarts en Wetenschap 2015; 58(3):134-8. [CRSREF: 9077459]

\section{Ladouceur 2014}

[CRSSTD: 9077460]

Ladouceur R. Primum non nocere. Canadian Family Physician: Medecin de Famille Canadien 2014;60(7):596-7. [CRSREF: 9077461]

\section{Lalonde 2008}

[CRSSTD: 3179353 ]

Lalonde L, Lampron A, Vanier M, Levasseur P, Khaddag R, Chaar N. Effectiveness of a medication discharge plan for transitions of care from hospital to outpatient settings. American Journal of Health-System Pharmacy 2008;65(15):1451-7. [CRSREF: 3179354$]$

\section{Lapane 2007}

[CRSSTD: 3179355$]$ 


\section{Interventions to improve the appropriate use of polypharmacy for older people}

Lapane KL, Hughes CM, Quilliam BJ. Does incorporating medications in the surveyors' interpretive guidelines reduce the use of potentially inappropriate medications in nursing homes? Journal of the American Geriatrics Society 2007;55(5):666-73. [CRSREF: 3179356$]$

\section{Lapane 2011}

[CRSSTD: 3179357$]$

Lapane KL, Hughes CM, Daiello LA, Cameron KA, Feinberg J. Effect of a pharmacist-led multicomponent intervention focusing on the medication monitoring phase to prevent potential adverse drug events in nursing homes. Journal of the American Geriatrics Society 2011;59(7):1238-45. [CRSREF: 3179358]

\section{Laroche 2006}

[CRSSTD: 3179359$]$

Laroche ML, Charmes JP, Nouaille Y, Fourrier A, Merle L. Impact of hospitalisation in an acute medical geriatric unit on potentially inappropriate medication use. Drugs and Aging 2006;23(1):49-59. [CRSREF: 3179360 ]

\section{Larson 2015}

[CRSSTD: 9077462]

Larson CK, Kao H. Hospice diagnosis: polypharmacy: a teachable moment. JAMA Internal Medicine 201 5;1 75(11):1750-1. [CRSREF: 9077463]

\section{Leach 2013}

[CRSSTD: 3179361 ]

Leach $\mathrm{H}$, Walsh K. Multiple medication recommendations to decrease incidence of falls in a geriatric inpatient psychiatric unit. In: 16th Annual Meeting of the College of Psychiatric and Neurologic Pharmacists, Colorado Springs, CO, United States. 2013. [CRSREF: 3179362$]$

\section{Ledwidge 2004}

[CRSSTD: 3179363 ]

Ledwidge M, Travers B, Ryder M, Ryan E, McDonald K. Specialist care of heart failure improves appropriate pharmacotherapy at the expense of greater polypharmacy and drug-interactions. EuropeanJournal of Heart Failure 2004; 6(2):235-43. [CRSREF: 3179364$]$

\section{Lee 2006}

[CRSSTD: 3179365$]$

Lee JK, Grace KA, Taylor AJ. Effect of a pharmacy care program on medication adherence and persistence, blood pressure, and low-density lipoprotein cholesterol: a randomized controlled trial. JAMA 2006;296(21):2563-71 . [CRSREF: 31 79366]

\section{Lee 2013}

[CRSSTD: 9077464]

Lee VWY, Law S, Chung NKH, Chan PKH, Luk FKM, Yin PT, et al. Effect and sustainability of pharmacy outreach services in elderly adults: A 5-year experience in Hong Kong. Journal of the American Geriatrics Society 2013;61 (12):2242-4. [CRSREF: 9077465]

\section{Leendertse 2013}

[CRSSTD: 9077466]

Leendertse AJ, de Koning GH, Goudswaard AN, BelitserSV, Verhoef M, de Gier HJ, etal. Preventing hospital admissions by reviewing medication (PHARM) in primary care: an open controlled study in an elderly population. Journal of Clinical Pharmacy \& Therapeutics 2013;38(5):379-87. [CRSREF: 9077467]

\section{Legrain 2011}

[CRSSTD: 9077468]

Bonnet-Zamponi D, d'Arailh L, Konrat C, Delpierre S, Lieberherr D, Lemaire A, et al. Drug-related readmissions to medical units of older adults discharged from acute geriatric units: results of the Optimization of Medication in AGEd multicenter randomized controlled trial. Age and Ageing 2013;61(1):113-21. [CRSREF: 9077469]

Lacaille S, Bonnet-Zamponi D, Lasserre-Moutet A, Lieberherr D, Lemaire A, Tubach F, et al. A new intervention for elderly inpatients with multiple chronic conditions and medications: the OMAGE trial. In: Annual Scientific Meeting of the American Geriatrics Society, Orlando, FL, United States. 2010. [CRSREF: 9077470]

* Legrain S, Tubach F, Bonnet-Zamponi D, Lemaire A, Aquino JP, Paillaud E, et al. A new multimodal geriatric dischargeplanning intervention to prevent emergencyvisits and rehospitalizations of older adults: the optimization of medication in AGEd multicenter randomized controlled trial. Journal of the American Geriatrics Society 201 1;59(1 1):2017-28. [CRSREF: 9077471]

\section{Leguelinel 2013}

[CRSSTD: 9077472] 
Interventions to improve the appropriate use of polypharmacy for older people

Leguelinel G, Palassin P, Di Trapani L, KinowskiJM, Richard H. Maintaining an annual long-stay prescriptions review: Impact on the iatrogenic risk control. International Journal of Clinical Pharmacy 201 3;35(6):1255. [CRSREF: 9077473]

\section{Lemmens 2015}

[CRSSTD: 9077474]

Lemmens LC, Delwel GO, Meijler AP, Weda M. Pharmacotherapeutic care for vulnerable groups with polypharmacy has to get better. Dutch]. Tijdschrift voor Gerontologie en Geriatrie 201 5;46(4):1 89-95. [CRSREF: 9077475]

\section{Lemmer 2014}

[CRSSTD: 9077476]

Lemmer B. Misconduct in prescription in an elderly patient]. Deutsche Medizinische Wochenschrift 2014;139(19):1015. [CRSREF: 9077477]

\section{Lenaghan 2007}

[CRSSTD: 3179367$]$

Lenaghan E, Holland R, Brooks A. Home-based medication review in a high risk elderly population in primary care-the POLYMED randomised controlled trial. Age \& Ageing 2007;36(3):292-7. [CRSREF: 31 79368]

\section{Lichtman 2015}

[CRSSTD: 9077478]

Lichtman SM. Polypharmacy: Geriatric oncology evaluation should become mainstream. Journal of Clinical Oncology 2015; 33(13):1422-3. [CRSREF: 9077479]

\section{Lidsky 2014}

[CRSSTD: 9077480]

Lidsky ME, Speicher PJ, McDonald S, PoerCM, Yanamadala M, Landerman L, et al. Perioperative optimization of senior health (POSH): A multidisciplinary approach to improve post-surgical outcomes in an older, high-risk population.Journal of Surgical Research 2014;186(2):609. [CRSREF:9077481]

\section{Lim 2004}

[CRSSTD: 3179369$]$

LimWS, Low HN, Chan SP, Chen HN, Ding YY, Tan TL. Impact of a pharmacist consult clinic on a hospital-based geriatric outpatient clinic in Singapore. Annals of the Academy of Medicine,Singapore 2004;33(2):220-7. [CRSREF: 31 79370]

\section{Linden 2013}

[CRSSTD: 9077482]

Linden L, Decoutere L, FlamaingJ, Spriet I, Willems L, Milisen K, et al. Reduction of polypharmacy in geriatric inpatients using the RASP list: A cluster-randomized controlled trial. European Geriatric Medicine 201 3;4(1):S1 83. [CRSREF: 9077483]

\section{Linton 2010}

[CRSSTD: 3179371 ]

Linton A, BaconTA, TriceS, DevineJ, Cottrell L, McGinnis TJ, et al. Results from a mailed promotion of medication reviews among Department of Defense beneficiaries receiving 10 or more chronic medications. Journal of Managed Care Pharmacy 2010;16(8):578-92. [CRSREF: 3179372]

\section{Lipscomb 2013}

[CRSSTD: 9077484]

LipscombC. Increased quality of life for nursing home residents with dementia: non-pharmacological interventions. ASBN Update 2013;17:14-6. [CRSREF: 9077485]

\section{Lipton 1992}

Published data only (unpublished sought but not used) [CRSSTD: 3179373]

Lipton HL, Bero LA, Bird JA, McPhee SJ. The impact of clinical pharmacists' consultations on physicians' geriatric drug prescribing. A randomized controlled trial. Medical Care 1992;30(7):646-58. [CRSREF: 3179374 ]

\section{Lipton 1994}

[CRSSTD: 3179375$]$

Lipton HL, Bird JA. The impact of clinical pharmacists' consultations on geriatric patients' compliance and medical care use: a randomized controlled trial. Gerontologist 1994;34(3):307-5. [CRSREF: 3179376]

\section{Logue 2002}

[CRSSTD: 3179377 ]

Logue R. The impact of advanced practice nursing on improving medication adherence in the elderly: an educational 
Interventions to improve the appropriate use of polypharmacy for older people

intervention. American Journal for Nurse Practitioners 2002;6:9-15. [CRSREF: 3179378 ]

\section{Lopatto 2014}

[CRSSTD: 9077486]

Lopatto J, Keith S W, Del Canale S, Templin M, Maio V. Evaluating sustained quality improvements: Long-term effectiveness of a physician-focused intervention to reduce potentially inappropriate medication prescribing in an older population. Journal of Clinical Pharmacy and Therapeutics 2014;39(3):266-71 . [CRSREF: 9077487]

\section{Lourens 1994}

[CRSSTD: 3179379$]$

Lourens H, Woodward MC. Impact of a medication card on compliance in older people. Australian Journal on Ageing 1994; 13(2):72-6. [CRSREF: 3179380]

\section{Mador 2004}

[CRSSTD: 3179381$]$

Mador JE, Giles L, Whitehead C, Crotty M. A randomized controlled trial of a behavior advisory service for hospitalized older patients with confusion. International Journal of Geriatric Psychiatry 2004;1 9(9):858-3. [CRSREF: 31 79382]

\section{Majumdar 2007}

[CRSSTD: 3179383 ]

MajumdarSR, Tsuyuki RT, McAlister FA. Impact of opinion leader-endorsed evidence summaries on the quality of prescribing for patients with cardiovascular disease: a randomized controlled trial. American Heart Journal 2007;153(1):22-8. [CRSREF: 3179384$]$

\section{Mannheimer 2006}

[CRSSTD: 3179385$]$

Mannheimer B, Ulfvarson J, Eklof S, Bergqvist M, Andersen-Karlsson E, Pettersson H, et al. Drug-related problems and pharmacotherapeutic advisory intervention at a medicine clinic. European Journal of Clinical Pharmacology 2006; 62(12):1075-81. [CRSREF: 3179386$]$

\section{Mansur 2008}

[CRSSTD: 3179387$]$

Mansur N, Weiss A, BelooseskyY. Relationship of in-hospital medication modifications of elderly patients to postdischarge medications, adherence, and mortality. Annals of Pharmacotherapy 2008;42(6):783-9. [CRSREF: 31 79388]

\section{Martin 2013}

[CRSSTD: 3179389$]$

Martin P, Tamblyn R, Ahmed S, Tannenbaum C. An educational intervention to reduce the use of potentially inappropriate medications among older adults (EMPOWER study): protocol for a cluster randomized trial. Trials [Electronic Resource] 2013;14(80). [CRSREF: 3179390$]$

\section{Masoudi 2005}

[CRSSTD: 3179391$]$

MasoudiFA, Baillie CA, Wang Y, Bradford WD, SteinerJF, Havranek EP, et al. The complexity and cost of drug regimens of older patients hospitalized with heart failure in the United States, 1998-2001. Archives of Internal Medicine 2005; 165(18):2069-76. [CRSREF: 3179392]

\section{Mattison 2010}

[CRSSTD: 3179393$]$

Mattison ML, Afonso KA, Ngo LH, Mukamal KJ. Preventing potentially inappropriate medication use in hospitalized older patients with a computerized provider order entrywarning system. Archives of Internal Medicine 2010;1 70(15):1331-6. [CRSREF: 3179394$]$

\section{Mendes 2016}

[CRSSTD: 9077488]

Mendes A. Triple threats of ageing, multiple morbidity and polypharmacy. Nurse Prescribing 2016;14(1):6-7. [CRSREF: 9077489]

\section{Meredith 2002}

[CRSSTD: 3179395$]$

Meredith S, Feldman P, Frey D, Giammarco L, Hall K, Arnold K, etal. Improving medication use in newly admitted home healthcare patients: a randomized controlled trial. Journal of the American Geriatrics Society 2002;50(8):1484-91 . [CRSREF: $3179396]$ 
Interventions to improve the appropriate use of polypharmacy for older people

\section{Messerli 2016}

[CRSSTD: 9077490]

Messerli M, Blozik E, Vriends N, Hersberger KE. Impact of a community pharmacist-led medication review on medicines use in patients on polypharmacy-a prospective randomised controlled trial. BMC Health Services Research 2016;16(1):1.

[CRSREF: 9077491]

\section{Mestres 2015}

[CRSSTD: 9077492]

Mestres C, Agusti A, Puerta L, Barba M. Prescription of potentially inappropriate drugs for geriatric patients in long-term care: Improvement through pharmacist's intervention. European Journal of Hospital Pharmacy 2015;22:198-201. [CRSREF: 9077493]

\section{Meulendijk 2013}

[CRSSTD: 9077494]

Meulendijk M, Spruit M, Drenth-van Maanen C, Numans M, Brinkkemper S, Jansen P. General practitioners' attitudes towards decision-supported prescribing: An analysis of the Dutch primarycare sector. Health InformaticsJournal 2013; 19(4):247-63. [CRSREF: 9077495]

\section{Meulendijk 2015}

[CRSSTD: 9077496]

Meulendijk MC, Spruit MR, Drenth-van Maanen AC, Numans ME, Brinkkemper S, Jansen PA, et al. Computerized decision support improves medication review effectiveness: an experiment evaluating the STRIP assistant's usability. Drugs \& Aging 2015;32(6):495-503. [CRSREF: 9077497]

\section{Meyer 1991}

[CRSSTD: 3179397$]$

Meyer TJ, Van Kooten D, Marsh S, Prochazka AV. Reduction of polypharmacy by feedback to clinicians. Journal of General Internal Medicine 1991;6(2):133-6. [CRSREF: 3179398]

\section{Midlov 2002}

[CRSSTD: 3179399$]$

Midlov P, Bondesson A, Eriksson T, PeterssonJ, Minthon L, Hoglund P. Descriptive study and pharmacotherapeutic intervention in patients with epilepsy or Parkinson's disease at nursing homes in southern Sweden. European Journal of Clinical Pharmacology 2002;57(12):903-10. [CRSREF: 3179400]

\section{Miller 2008}

[CRSSTD: 3179401$]$

Miller SL, Miller S, Balon J, Helling TS. Medication reconciliation in a rural trauma population. Annals of Emergency Medicine 2008;52(5):483-91. [CRSREF: 3179402]

\section{Miller 2014}

[CRSSTD: 9077498]

Miller R, Darcy C, Friel A, Scott M, Toner S. The introduction of a new consultant pharmacist case management service on the care of elderly patients in the intermediate care setting. International Journal of Pharmacy Practice 2014;22:1 05-6.

[CRSREF: 9077499]

\section{Mills 2008}

[CRSSTD: 3179403 ]

Mills PD, Neily J, Kinney LM, Bagian J, Weeks WB. Effective interventions and implementation strategies to reduce adverse drug events in the Veterans Affairs (VA) system. Quality and Safety in Health Care 2008;17(1):37-46. [CRSREF: 3179404]

\section{Mistler 2009}

[CRSSTD: 3179407 ]

Mistler LA, Mellman TA, Drake RE. A pilot study testing a medication algorithm to reduce polypharmacy. Quality and Safety in Health Care 2009; 18(1):55-8. [CRSREF: 3179408]

\section{Mo 2014}

[CRSSTD: 9077500]

Mo L, Yang X, HeJ, Dong B. Evaluation of potentially inappropriate medications in older inpatients in China. Journal of the American Geriatrics Society 2014;62(1 1):2216-8. [CRSREF: 9077501]

\section{Moczygemba 2011}

[CRSSTD: 3179409$]$ 
Moczygemba LR, BarnerJC, Lawson KA, Brown CM, Gabrillo ER, GodleyP, et al. Impact of telephone medication therapy management on medication and health-related problems, medication adherence, and Medicare Part D drug costs: a 6-month follow up. American Journal of Geriatric Pharmacotherapy 201 1;9(5):328-38. [CRSREF: 3179410 ]

\section{Moga 2017}

\section{[CRSSTD: 9077502]}

Moga DC, Abner EL, Rigsby DN, Eckmann L, Huffmyer M, Murphy RR, et al. Optimizing medication appropriateness in older adults: a randomized clinical interventional trial to decrease anticholinergic burden. Alzheimer's Research \& Therapy 2017 ; 9(1):36. [CRSREF: 9077503]

\section{Monane 1998}

[CRSSTD: 3179411$]$

Monane M, Matthias DM, Nagle BA, Kelly MA. Improving prescribing patterns for the elderly through an online drug utilization review intervention: a system linking the physician, pharmacist, and computer. JAMA 1998;280(14):1249-52. [CRSREF: 3179412]

\section{Montero-Balosa 2015}

\section{[CRSSTD: 9077504]}

Montero-Balosa M, Palma-Morgado D, Ma Jose Leon-Almenara, Real FSD, Sagrista-Gonzalez M, Fernandez-Urrusuno R. Effectiveness of medication review in patients with polypharmacy. International Journal of Clinical Pharmacy 2015;37:277-8. [CRSREF: 9077505]

\section{Moore 1998}

\section{[CRSSTD: 3179413 ]}

Moore SW, Hamdy RC, Cancellaro LA. A medication evaluation clinic to reduce polypharmacy in an institutional setting. Age and Ageing 1998;27:58-9. [CRSREF:3179414]

\section{Morecroft 2014}

\section{[CRSSTD: 9077506]}

Morecroft C, Stokes L, Mackridge A. Emergency supply of prescription-only medicines (ESoPoMs): A multi-phase evaluation of community pharmacists' role in optimising safe and appropriate medicines use in response to patient requests. International Journal of Pharmacy Practice 2014;22:20-1. [CRSREF: 9077507]

\section{Moss 2014}

[CRSSTD: 9077508]

Moss J, Bryan W, Wilkerson L, Jackson G, Stevens M, Powers J, et al. Impact of clinical pharmacy specialists on the design and implementation of quality improvement initiatives aimed to decrease inappropriate medications in a veterans affairs emergency department. Journal of the American Geriatrics Society 201 4;62:S1 86. [CRSREF: 9077509]

\section{Moss 2016}

\section{[CRSSTD: 9077510$]$}

Moss JM, Bryan WE, Wilkerson LM, Jackson GL, Owenby RK, Van Houtven C, et al. Impact of clinical pharmacy specialists on the design and implementation of a quality improvement initiative to decrease inappropriate medications in a veterans affairs emergency department. Journal of Managed Care and Specialty Pharmacy 201 6;22(1):74-80. [CRSREF: 907751 1]

\section{Moulis 2014}

\section{[CRSSTD: 9077512$]$}

Moulis M, Gibert P, Payen M, Grevy A, Gavazzi G, Bedouch P, et al. Pharmaceutical conciliation at discharge: A way to keep therapeutic improvements after hospitalization? European Geriatric Medicine 201 4;5:S2 19. [CRSREF: 90775 1 3]

\section{Muir 2001}

[CRSSTD: 3179415$]$

Muir AJ, Sanders LL, Wilkinson WE, Schmader K. Reducing medication regimen complexity: a controlled trial. Journal of General Internal Medicine 2001;16(2):77-82. [CRSREF: 3179416$]$

\section{Muller-Mundt 2011}

[CRSSTD: 3179417 ]

Muller-Mundt G, Schaeffer D. Coping with chronic illness and multiple medicines in older age: self-management support as an obligation in nursing. Zeitschrift fur Gerontologie und Geriatrie 201 1;44(1):6-12. [CRSREF: 31 794 18]

\section{Muntinga 2012}

[CRSSTD: 3179419$]$

Muntinga ME, Hoogendijk EO, van Leeuwen KM, van Hout HP, TwiskJW, van der Horst HE, et al. Implementing the chronic care model for frail olderadults in the Netherlands: study protocol of ACT (frail older adults: care in transition). BMC 
Interventions to improve the appropriate use of polypharmacy for older people

Geriatrics 2012;12:19. [CRSREF: 3179420$]$

\section{Murray 2004}

[CRSSTD: 3179421 ]

Murray MD, Young JM, Morrow DG, Weiner M, Tu W, Hoke SC, et al. Methodology of an ongoing randomised controlled trial to improve drug use for elderly patients with chronic heart failure. American Journal of Geriatric Pharmacotherapy 2004; 2(1):53-65. [CRSREF: 3179422]

\section{Murray 2007}

[CRSSTD: 3179423$]$

Murray MD, Young J, Hoke S, Tu W, Weiner M, Morrow D, et al. Pharmacist intervention to improve medication adherence in heart failure. Annals of Internal Medicine 2007; 146(10):714-25. [CRSREF: 3179424 ]

\section{Murray 2009}

[CRSSTD: 3179425$]$

Murray MD, Ritchie ME, Wu J, Tu W. Effect of a pharmacist on adverse drug events and medication errors in outpatients with cardiovascular disease. Archives of Internal Medicine 2009;169(8):757-63. [CRSREF: 31 79426]

\section{Nassaralla 2014}

[CRSSTD: 9077514$]$

Nassaralla C, Khosla S, White H, Yanamadala M. Reducing medication use in a skilled nursing facility - a quality improvement project. Journal of the American Medical Directors Association 2014;1 5:B22-3. [CRSREF: 907751 5]

\section{Naveiro-Rilo 2014}

[CRSSTD: 9077516$]$

Naveiro-Rilo J, Diez-Juarez D, Flores-Zurutuza M, Molina-Mazo R, Alberte-Perez C. [Intervention in elderly patients with multiple morbidities and multiple medications: results of the prescription and the quality of life]. Revistade Calidad Asistencial 2014;29(5):256-62. [CRSREF: 9077517]

\section{Neutel 2007}

[CRSSTD: 3179427 ]

Neutel Cl, Campbell NRC. Antihypertensive medication use by recently diagnosed hypertensive Canadians. Canadian Journal of Cardiology 2007;23(7):561-5. [CRSREF: 3179428 ]

\section{Nickerson 2005}

[CRSSTD: 3179429$]$

Nickerson A, MacKinnon NJ, Roberts N, Saulnier L. Drug-therapy problems, inconsistencies and omissions identified during a medication reconciliation and seamless care service. Healthcare Quarterly 2005;8(special):65-72. [CRSREF: 31 79430]

\section{O'Sullivan 2014}

[CRSSTD: 9077518 ]

O'Sullivan D, O'Mahony D, O'Connor MN, Gallagher P, Cullinan S, O'Sullivan R, et al. The impact of a structured pharmacist intervention on the appropriateness of prescribing in older hospitalized patients. Drugs and Aging 2014;31 (6):471-81 . [CRSREF: 9077519]

\section{Ogihara 2008}

[CRSSTD: 3179431 ]

Ogihara T, Nakao K, Fukui T, Fukiyama K, Fujimoto A, Ueshima K, et al. The optimal target blood pressure for antihypertensive treatment in Japanese elderly patients with high-risk hypertension: a subanalysis of the Candesartan Antihypertensive Survival Evaluation in Japan (CASE-J) trial. Hypertension Research 2008;31 (8):1 595-601 . [CRSREF: 3179432]

\section{Ortega 2013}

[CRSSTD: 3179435$]$

Ortega Blanco Jose A, Atienza Martin F, Baz Montero S, Lopez AguilarJ, Rioja UlgarJ, Perez Marquez A. Effectiveness of an intervention to reduce drugs in polymedicated patients. Atencion Farmaceutica 201 3; 15(3): 1 85-91 . [CRSREF: 31 79436]

\section{Owens 1990}

[CRSSTD: 31 79437]

Owens NJ, Sherburne NJ, Silliman RA, Fretwell MD. The Senior Care Study. The optimal use of medications in acutelyill older patients. Journal of the American Geriatrics Society 1990;38(10):1082-7. [CRSREF: 3179438 ]

\section{Oyarzun-Gonzalez 2015}

[CRSSTD: 9077520] 
Interventions to improve the appropriate use of polypharmacy for older people

Oyarzun-Gonzalez X, Taylor KC, Myers SR, Muldoon SB, Baumgartner RN. Cognitive decline and polypharmacy in an elderly population. Journal of the American Geriatrics Society 201 5;63(2):397-9. [CRSREF: 9077521 ]

\section{Ozturk 2015}

[CRSSTD: 9077522]

Ozturk GB, Ozkaya H, Kilic C, Muratli S, Ilhan B, Tufan A, et al. Efficacy and safety of training program concentrating on the Garfinkel method as a tool for reducing polypharmacy in nursing home residents. European Geriatric Medicine 201 5;6:S68. [CRSREF: 9077523]

\section{Pagaiya 2005}

[CRSSTD: 3179439$]$

Pagaiya N, Garner P. Primary care nurses using guidelines in Thailand: a randomized controlled trial. Tropical Medicine \& International Health 2005;10(5):471-7. [CRSREF: 3179440]

\section{Paluch 2007}

[CRSSTD: 3179441$]$

Paluch Z, Jedlickova V, Skibova J, Adamek T, Alusik S. The effectiveness of antiplatelet treatment with aspirin in polymorbid patients. International Angiology 2007;26(3):206-12. [CRSREF: 3179442]

\section{Patterson 2010}

[CRSSTD: 3179443 ]

Patterson SM, Hughes CM, Crealey G, CardwellC, Lapane KL. An evaluation of an adapted U.S. model of pharmaceutical care to improve psychoactive prescribing for nursing home residents in Northern Ireland (Fleetwood Northern Ireland study). Journal of the American Geriatrics Society 201 0;58(1):44-53. [CRSREF: 3179444$]$

\section{Payne 2015}

[CRSSTD: 9077524]

Payne R, Duerden M. Medicines optimisation in the care home setting. Prescriber 201 5;26:20-4. [CRSREF: 9077525]

Pepine 1998

[CRSSTD: 3179445$]$

Pepine CJ, Handberg-Thurmond E, Marks RG, Conlon M, Cooper-Dehoff R, Volkers P, et al. Rationale and design of the International Verapamil SR/Trandolapril Study (INVEST): an Internet-based randomized trial in coronary artery disease patients with hypertension. Journal of the American College of Cardiology 1998;32(5):1228-37. [CRSREF: 31 79446]

\section{Peterson 2014}

[CRSSTD: 9077526]

PetersonJF, Kripalani S, Danciu I, Harrell D, Marvanova M, Mixon AS, et al. Electronic surveillance and pharmacist intervention for vulnerable older inpatients on high-risk medication regimens. Journal of the American Geriatrics Society 2014;62(1 1):2148-52. [CRSREF: 9077527]

\section{Pfister 2017}

[CRSSTD: 9077528]

Pfister B, Jonsson J, Gustafsson M. Drug-related problems and medication reviews among old people with dementia. BMC Pharmacology and Toxicology 2017;18(1):52. [CRSREF: 9077529]

\section{Phelan 2008}

[CRSSTD: 3179447 ]

Phelan EA, Genshaft S, Williams B, LogerfoJP, Wagner EH. A comparison of how generalists and fellowship-trained geriatricians provide "geriatric" care. Journal of the American Geriatrics Society 2008;56(1 0): 1 807-1 1. [CRSREF: 31 79448]

\section{Pimlott 2003}

[CRSSTD: 3179449$]$

Pimlott NJ, HuxJE, Wilson LM, Kahan M, Li C, RosserWW. Educating physicians to reduce benzodiazepine use by elderly patients: a randomized controlled trial. Canadian Medical Association Journal 2003;168(7):835-9. [CRSREF: 31 79450]

\section{Pit 2007}

Published data only (unpublished sought but not used) [CRSSTD: 3179451]

Pit SW, Byles JE, Henry DA, Holt L, Hansen V, Bowman DA. A Quality Use of Medicines program for general practitioners and older people: a cluster randomised controlled trial. Medical Journal of Australia 2007; 187(1):23-30. [CRSREF: 31 79452]

\section{Pitkala 2001}

[CRSSTD: 3179453 ]

Pitkala KH, Strandberg TE, Tilvis RS. Is it possible to reduce polypharmacy in the elderly? A randomised, controlled trial. 
Interventions to improve the appropriate use of polypharmacy for older people

Drugs and Aging 2001;18(2):143-9. [CRSREF: 3179454]

\section{Pitkala 2012}

[CRSSTD: 3179455$]$

Pitkala KH, Juola AL, Soini H, Laakkonen ML, Kautiainen H, Teramura-Gronblad M, et al. Reducing inappropriate, anticholinergic and psychotropic drugs among older residents in assisted living facilities: study protocol for a randomized controlled trial. Trials [Electronic Resource] 2012;13(85). [CRSREF: 3179456]

\section{Planton 2010}

[CRSSTD: 9077530]

Planton J, Edlund BJ. Strategies for reducing polypharmacy in older adults. Journal of Gerontological Nursing 2010 ; 36(1):8-12. [CRSREF: 9077531]

\section{Pool 2007}

[CRSSTD: 3179457 ]

Pool JL, Glazer R, Weinberger M, Alvarado R, HuangJ, Graff A. Comparison of valsartan/hydrochlorothiazide combination therapy at doses up to 320/25 mg versus monotherapy: a double-blind, placebo-controlled study followed by long-term combination therapy in hypertensive adults. Clinical Therapeutics 2007;29(1):61 -73. [CRSREF: 31 79458]

\section{Potter 2016}

[CRSSTD: 9077532]

Potter K, Flicker L, Page A, Etherton-Beer C. Deprescribing in frail older people: a randomised controlled trial. PLOS One 2016;11(3):e0149984. [CRSREF: 9077533]

\section{Przytula 2015}

[CRSSTD: 9077534]

Przytula K, BaileySC, GalanterWL, Lambert BL, Shrestha N, Dickens C, et al. A primary care, electronic health recordbased strategy to promote safe drug use: study protocol for a randomized controlled trial. Trials 2015;16:17. [CRSREF: 9077535]

\section{Pugh 2006}

[CRSSTD: 3179461$]$

Pugh MJV, Hanlon JT, Zeber JE, Bierman A, Cornell J, Berlowitz DR. Assessing potentially inappropriate prescribing in the elderly Veterans Affairs population using the HEDIS 2006 quality measure. Journal of Managed Care Pharmacy 2006; 12(7):537-45. [CRSREF: 3179462 ]

\section{Puvanendran 2011}

[CRSSTD: 9077536]

Puvanendran R, Mamun K, Lim KH. Polypharmacy and unneccessary medication use in elderly patients discharged from acute hospitals to community hospital. Proceedings of Singapore Healthcare $2011 ; 20: 167$. [CRSREF:9077537]

\section{Qian 2016}

[CRSSTD: 9077538]

Qian S, Yu P, Hailey DM, Wang N. Factors influencing nursing time spent on administration of medication in an Australian residential aged care home. Journal of Nursing Management 2016;24(3):427-34. [CRSREF: 9077539]

\section{Rababa 2016}

[CRSSTD: 9077540]

Rababa M. Proton pump inhibitors and the prescribing cascade.Journal ofGerontological Nursing 2016;42(4):23-31. [CRSREF: 9077541]

\section{Raebel 2007}

[CRSSTD: 3179463 ]

Raebel MA, CharlesJ, DuganJ, Carroll NM, KornerEJ, Brand DW, et al. Randomized trial to improve prescribing safety in ambulatory elderly patients. Journal of the American Geriatrics Society 2007;55(7):977-85. [CRSREF: 31 79464]

\section{Rantz 2015}

[CRSSTD: 9077542]

Rantz MJ, Flesner MK, FranklinJ, Galambos C, PudlowskiJ, Pritchett A, et al. Better care, better quality. Journal of Nursing Care Quality 201 5;30:290-7. [CRSREF: 9077543]

\section{Raphael 2015}

[CRSSTD: 9077544]

Raphael KL, Beddhu S. Hypertension and polypharmacy in elderly nursing home residents: When less is more. American 
Interventions to improve the appropriate use of polypharmacy for older people

Journal of Kidney Diseases 2015;66(4):561-3. [CRSREF: 9077545]

\section{Reboredo-Garcia 2014}

[CRSSTD: 9077546]

Reboredo-GarciaS, Mateo CG, Casal-Llorente C. Implantation of a program for polymedicated patients within the framework of the Galician Strategy for Integrated Chronic Care]. Atencion Primaria 201 4;46 Suppl 3:33-40. [CRSREF: 9077547]

\section{RESPECT 2010}

Published data only (unpublished sought but not used) [CRSSTD: 3179465]

RESPECT trial team. Effectiveness of shared pharmaceutical care for older patients. British Journal of General Practice 2010;60(570):e10. [CRSREF: 3179466$]$

\section{Reuben 2010}

[CRSSTD: 3179467$]$

Anonymous. Erratum in. Age and Ageing 2010;58:1623. [CRSREF: 3179468]

Reuben DB, Roth CP, FrankJC, Hirsch SH, Katz D, McCreath H, et al. Assessing care of vulnerable elders--Alzheimer's disease: a pilot study of a practice redesign intervention to improve the quality of dementia care. Journal of the American Geriatrics Society 2010;58(2):324-9. [CRSREF: 3179469 ]

\section{Reynders 2013}

[CRSSTD: 9077548]

Reynders E. Multidisciplinary guideline on polypharmacy in the elderly. [Dutch]. Huisarts en Wetenschap 201 3;56:550. [CRSREF: 9077549]

\section{Rose 2015}

[CRSSTD: 9077550]

Rose VO, Fechtrup C, Derendorf H. An elderly female patient under polypharmacy. Deutsche Apotheker Zeitung 2015; 155(30):1. [CRSREF: 9077551 ]

\section{Roughead 2007a}

[CRSSTD: 9077552]

Roughead E, Pratt N, Peck R, Gilbert A. Improving medication safety: influence of a patient-specific prescriber feedback program on rate of medication reviews performed by Australiangeneral medical practitioners. Pharmacoepidemiologyand Drug Safety 2007;16(7):797-803. [CRSREF:9077553]

\section{Roughead 2007b}

[CRSSTD: 9077554]

Roughead EE, Anderson B, Gilbert AL. Potentially inappropriate prescribing among Australian veterans and war widows / widowers. Internal Medicine Journal 2007;37(6):402-5. [CRSREF: 9077555]

\section{Roughead 2013}

[CRSSTD: 9077556]

Roughead EE, Kalisch ELM, Ramsay EN, Pratt NL, Barratt JD, LeBlanc VT, et al. Bridging evidence-practice gaps: improving use of medicines in elderly Australian veterans. BMC Health Services Research 2013;13:514. [CRSREF: 9077557]

\section{Sakakibara 2015}

[CRSSTD: 9077558]

Sakakibara M, Igarashi A, Takase Y, Kamei H, Nabeshima T. Effects of prescription drug reduction on quality of life in community-dwelling patients with dementia. Journal of Pharmacy and Pharmaceutical Sciences 201 5; 1 8(5):705-12. [CRSREF: 9077559]

\section{Saltvedt 2002}

[CRSSTD: 3179478 ]

Saltvedt I, MoES, Fayers P, KaasaS, Sletvold O. Reduced mortality in treatingacutely sick, frail older patients in ageriatric evaluation and management unit. A prospective randomized trial. Journal of the American Geriatrics Society 2002; 50(5):792-8. [CRSREF: 3179479$]$

\section{Santolaya-Perrin 2016}

[CRSSTD: 9077560]

Santolaya-Perrin R, Jimenez-Diaz G, Galan-Ramos N, Moreno Carvajal MT, Rodriguez-Camacho JM, Sierra-Sanchez JF, et al. A randomised controlled trial on the efficacy of a multidisciplinary health care team on morbidity and mortality of elderly patients attending the Emergency Department. Study design and preliminary results. Farmacia Hos pitalaria 2016; 
Interventions to improve the appropriate use of polypharmacy for older people

40(5):371-84. [CRSREF: 9077561]

\section{Schmidt 2008}

[CRSSTD: 3179480$]$

Schmidt S, Sheikzadeh S, Beil B, Patten M, Stettin J. Acceptance of telemonitoring to enhance medication compliance in patients with chronic heart failure. Telemedicine and e-Health 2008; 14(5):426-33. [CRSREF: 3179481 ]

\section{Schmidt-Mende 2017}

[CRSSTD: 9077562]

Schmidt-Mende K, Andersen M, Wettermark B, HasselstromJ. An educationalinterventionto reduce acute health care consumption in elderly patients with inappropriate drugs - A cluster randomised trial in primary care. Pharmacoepidemiology and Drug Safety 2016;25:378-9. [CRSREF: 9077563]

*Schmidt-Mende K, Andersen M, Wettermark B, Hasselstrom J. Educational intervention on medication reviews aiming to reduce acute healthcare consumption in elderly patients with potentially inappropriate medicines-A pragmatic open-label cluster-randomized controlled trial in primary care. Pharmacoepidemiology and Drug Safety 2017;26(11):1347-56. [CRSREF: 9077564]

\section{Schnipper 2006}

[CRSSTD: 3179482$]$

SchnipperJL, KirwinJL, Cotugno MC, WahlstromSA, Brown BA, Tarvin E, et al. Role of pharmacist counseling in preventing adverse drug events after hospitalization. Archives of Internal Medicine 2006;1 66(5):565-71 . [CRSREF: 31 79483]

\section{Schoenenberger 2013}

[CRSSTD: 9077565]

Schoenenberger JA, Rius J, Cano M, Martinez B, Pons N, Martinez V. Pharmacy intervention to reduce medication related problems in elderly people between hospital admission and discharge. Using the screening tool of older persons potentially inappropriate (STOPP). International Journal of Clinical Pharmacy 201 3;35:91 1. [CRSREF: 9077566]

\section{Schrader 1996}

[CRSSTD: 3179484$]$

Schrader SL, Dressing B, Blue R, Jensen G, Miller D, Zawada ET. The Medication Reduction Project: combating polypharmacyinSouth Dakota elders through community-based interventions. South DakotaJournal of Medicine 1996; 49(12):441-8. [CRSREF: 3179485$]$

\section{Schroder 2012}

[CRSSTD: 3179486$]$

Schroder S, Martus P, Odin P, Schaefer M. Impact of community pharmaceutical care on patient health and quality of drug treatment in Parkinson's disease. International Journal of Clinical Pharmacy 2012;34(5):746-56. [CRSREF: 31 79487]

\section{Sellors 2001}

[CRSSTD: 3179488 ]

Sellors C, Dalby DM, Howard M, KaczorowskiJ, SellorsJ. A pharmacist consultation service in community-basedfamily practices: a randomized, controlled trial in seniors. Journal of Pharmacy Technology 2001;1 7(6):264-9. [CRSREF: 31 79489]

\section{Sellors 2003}

[CRSSTD: 3179490$]$

Sellors J, Kaczorowski J, Sellors C, Dolovich L, Woodward C, Willan A, et al. A randomized controlled trial of a pharmacist consultation program for family physicians and their elderlypatients. Canadian Medical AssociationJournal 2003; 169(1):17-22. [CRSREF: 3179491$]$

\section{Sennesael 2017}

[CRSSTD: 9077567]

Sennesael A L, Dalleur O, Henrard S, Artoisenet C, Schoevaerdts D, Spinewine A. Implementing a screening tool to improve prescribing in hospitalized older patients: a pilot study. International Journal of Clinical Pharmacy 2017;40(1):1 5-9. [CRSREF: 9077568]

\section{Shrestha 2006}

[CRSSTD: 3179492$]$

Shrestha N, Samir KC, Baltussen R, Kafle KK, Bishai D, Niessen L. Practical approach to lung health in Nepal: better prescribing and reduction of cost. Tropical Medicine \& International Health 2006; 1 1 (5):765-72. [CRSREF: 31 79493]

\section{Sicras Mainar 2004}

[CRSSTD: 3179494$]$ 


\section{Interventions to improve the appropriate use of polypharmacy for older people}

Sicras Mainar A, Pelaez de Lono J, Marti Lopez J. Impact of a program to improve appropriate prescribing of medications in residential facilities for older persons. Results after one year [Impacto de un programa de adecuacion de la prescripcion de medicamentos en centros residenciales geriatricos. Resultados al ano de su implantacion]. Atencion Primaria 2004; 33(4): 174-82. [CRSREF: 3179495$]$

\section{Sicras Mainar 2005}

[CRSSTD: 3179496$]$

Sicras Mainar A, Pelaez de LonoJ. Improving adequacy for drug use and effects in geriatric centers using an intervention program [Mejora de la adecuacion de uso de medicamentos y efectos en centros geriatricos medicante un programa de intervencion]. Farmacia Hospitalaria 2005;29(5):303-11. [CRSREF: 3179497]

\section{Sicras Mainar 2007}

[CRSSTD: 3179498 ]

Sicras Mainar A, Pelaez de LonoJ, Castella Rosales A, Navarro Artieda R. Effectiveness of an intervention to modifydrugs use in nursing homes. Results 3 years after its implantation [Eficacia de una intervencion en la adecuacion del uso de medicamentos en centros residenciales geriatricos. Resultados a los 3 anos de su implantacion]. RevistaEspanola de Geriatria y Gerontologia 2007;42(suppl. 1):5-15. [CRSREF: 3179499]

\section{Silkey 2005}

[CRSSTD: 3179500$]$

Silkey B, Preskorn SH, Golbeck A, Shah R, Neff M, Jones TL, et al. Complexity of medication use in the Veterans Affairs healthcare system: Part II. Antidepressant use among younger and older outpatients. Journal of Psychiatric Practice 2005; $11(1): 16-26$. [CRSREF: 3179501$]$

\section{Simon 2005}

[CRSSTD: 3179502$]$

Simon SR, Majumdar SR, Prosser LA, Salem-Schatz S, Warner C, Kleinman K, et al. Group versus individual academic detailing to improve the use of antihypertensive medications in primary care: a cluster-randomized controlled trial. American Journal of Medicine 2005;1 18(5):521-8. [CRSREF: 31 79503]

\section{Simon 2006}

[CRSSTD: 3179504$]$

Simon SR, Smith DH, Feldstein AC, Perrin N, Yang X, Zhou Y, et al. Computerized prescribing alerts and group academic detailing to reduce the use of potentially inappropriate medications in older people. Journal of the American Geriatrics Society 2006;54(6):963-8. [CRSREF: 3179505 ]

\section{Simonson 2015}

[CRSSTD: 9077569]

Simonson W. Pharmacy Column Polypharmacy, MRPs, PIMs and deprescribing. Geriatric nursing 201 5;36(6):467-8. [CRSREF: 9077570]

\section{Sinnott 2015}

[CRSSTD: 9077571$]$

Sinnott C, Mercer SW, Payne RA, Duerden M, Bradley CP, Byrne M. Improving medication management in multimorbidity: development of the MultimorbiditY COllaborative Medication Review And DEcision making (MY COMRADE) intervention using the Behaviour Change Wheel. Implementation Science 201 5;10(1):1 . [CRSREF: 9077572]

\section{Smeets 2013}

[CRSSTD: 9077573]

Smeets CH, Smalbrugge M, Gerritsen DL, Nelissen-Vrancken M, Wetzels RB, Spek K, et al. Improving psychotropic drug prescription in nursing home patients with dementia: design of a cluster randomized controlled trial. BMC Psychiatry 2013 ; 13:280. [CRSREF: 9077574]

\section{Smith 1996}

[CRSSTD: 3179506$]$

Smith DM, CoxMR, Brizendine EJ, HuiSL, FreedmanJA, Martin DK, et al. An intervention on discharge polypharmacy. Journal of the American Geriatrics Society 1996;44(4):416-9. [CRSREF: 31 79507]

\section{Sorensen 2004}

[CRSSTD: 3179508$]$

Sorensen L, StokesJA, Purdie DM, Woodward M, Elliott R, Roberts MS. Medication reviews in the community: results of a randomized, controlled effectiveness trial. [erratum appears in British Journal of Clinical Pharmacology 2005;59(3):376]. British Journal of Clinical Pharmacology 2004;58(6):648-64. [CRSREF: 3179509] 
Interventions to improve the appropriate use of polypharmacy for older people

[CRSSTD: 3179510$]$

Soumerai SB, McLaughlin TJ, GurwitzJH, Guadagnoli E, Hauptman PJ, Borbas C, et al. Effect of local medical opinion leaders on quality of care for acute myocardial infarction.JAMA 1998;279(1 7):1358-63. [CRSREF: 3179511 ]

\section{Straand 2006}

[CRSSTD: 3179512$]$

Straand J, Fetveit A, Rognstad S, Gjelstad S, Brekke M, Dalen I. A cluster-randomized educational intervention to reduce inappropriate prescription patterns for elderly patients in general practice - The Prescription Peer Academic Detailing (RxPAD) study [NCT00281 450]. BMC Health Services Research 2006;6:72-81 . [CRSREF: 3179513 ]

\section{Stuck 1995}

[CRSSTD: 3179514$]$

Stuck AE, Zwahlen HG, Neuenschwander BE, Meyer Schweizer RA, Bauen G, Beck JC. Methodologic challenges of randomized controlled studies on in-home comprehensive geriatric assessment: the EIGER project. Evaluation of In-Home Geriatric Health Visits in Elderly Residents. [erratum appears in Aging (Milano) 1 995;7(4):237]. Aging-Clinical \& Experimental Research 1995;7(3):218-23. [CRSREF: 3179515$]$

\section{Sturgess 2003}

[CRSSTD: 3179516$]$

Sturgess IK, McElnay JC, Hughes CM, Crealey G. Community pharmacy based provision of pharmaceutical care to older patients. Pharmacy World \& Science 2003;25(5):218-26. [CRSREF: 3179517 ]

\section{Tallon 2016}

[CRSSTD: 9077575]

Tallon M, BarragryJ, Allen A, Breslin N, Deasy E, Moloney E, et al. Impact of the Collaborative Pharmaceutical Care at Tallaght Hospital (PACT) model on medication appropriateness of older patients. European Journal of Hospital Pharmacy 2016;23(1):16-21. [CRSREF: 9077576]

\section{Teichert 2013}

[CRSSTD: 3179518 ]

Teichert M, Luijben SN, WereldsmaA, SchalkT, JanssenJ, Wensing M, etal. Implementation of medication reviews in community pharmacies and their effect on potentially inappropriate drug use in elderly patients. InternationalJournal of Clinical Pharmacy 2013;35(5):719-26. [CRSREF: 3179519]

\section{Terceros 2007}

[CRSSTD: 3179520$]$

Terceros Y, Chahine-Chakhtoura C, Malinowski JE, Rickley WF. Impact of a pharmacy resident on hospital length of stay and drug-related costs. Annals of Pharmacotherapy 2007;41(5):742-8. [CRSREF: 3179521 ]

\section{Terrell 2009}

[CRSSTD: 3179522$]$

Anonymous. Computerized support to avoid inappropriate prescribing to seniors. Brown University Geriatric Psychopharmacology Update 2009;13:4-4. [CRSREF: 3179523]

Terrell KM, Perkins AJ, Dexter PR, Hui SL, Callahan CM, Miller DK. "Decision support for inappropriate prescribing": Response letter to Dr. Ito. Age and Ageing 2010;58:417. [CRSREF: 3179524 ]

* Terrell KM, Perkins AJ, Dexter PR, Hui SL, Callahan CM, Miller DK. Computerized decision support to reduce potentially inappropriate prescribing to older emergency department patients: a randomized, controlled trial. Journal of the American Geriatrics Society 2009;57(8):1 388-94. [CRSREF: 31 79525]

\section{Thiem 2011}

[CRSSTD: 3179526$]$

Thiem U, Hinrichs T, Muller CA, Holt-Noreiks S, Nagl A, Bucchi C, et al. Prerequisites for a new health care model for elderly people with multiple morbidities: results and conclusions from 3 years of research in the PRISCUS consortium. Zeitschrift fur Gerontologie und Geriatrie 2011 ;44(Suppl 2):101-12. [CRSREF: 31 79527]

\section{Thomas 2014}

[CRSSTD: 9077577]

Thomas J, Hyson A, Mecca MC, Niehoff K, Zapatka SA, Langerman ST, et al. A new approach to outpatient geriatrics training: An interprofessional polypharmacy intervention using the shared medical appointment model. Journal of General Internal Medicine 2014;29:S501-2. [CRSREF: 9077578]

\section{Thompson 2008}


Harrison G. The DEBIT-trial: An intervention to reduce antipsychotic polypharmacy prescribing in adult wards. In: European Conference on Schizophrenia Research: From Research to Practice, Berlin, German. 2009. [CRSREF: 3179529$]$

*Thompson A, Sullivan SA, Barley M, Strange SO, Moore L, Rogers P, et al. The DEBIT trial: an intervention to reduce antipsychotic polypharmacy prescribing in adult psychiatry wards - a cluster randomized controlled trial. Psychological Medicine 2008;38(5):705-15. [CRSREF: 3179530]

\section{Thurmann 2011}

[CRSSTD: 3179531 ]

Thurmann P. Potentially inappropriate medications for the elderly-Evidence, validity and usefulness of check-lists. In: 10 th Congress of the European Association for Clinical Pharmacology and Therapeutics, Budapest, Hungary. 2011 . [CRSREF: $3179532]$

\section{Thyrian 2012}

[CRSSTD: 3179533$]$

Thyrian JR, Fis T, Dreier A, Bowing G, Angelow A, Lueke S, et al. Life- and person-centred help in Mecklenburg-Western Pomerania, Germany (DelpHi): study protocol for a randomised controlled trial. Trials [Electronic Resource] 2012;13(56). [CRSREF: 3179534$]$

\section{Tomaes 2015}

[CRSSTD: 9077579]

Tomaes LC, Poortvliet R K, Kwint H F, Gussekloo J. [Medication review in older people: identification of a new risk group]. Nederlands Tijdschrift voor Geneeskunde 201 5;159:A8929. [CRSREF: 9077580]

\section{Touchette 2012}

[CRSSTD: 3179535$]$

Touchette DR, Masica AL, Dolor RJ, Schumock GT, Choi YK, Kim Y, et al. Safety-focused medication therapy management: a randomized controlled trial. Journal of the American Pharmacists Association 2012;52(5):603-12. [CRSREF: 31 79536]

\section{Tse 2008}

[CRSSTD: 3179537$]$

Tse W, Frisina PG, Halbig TD, Gracies J, Liang L, Tarshish C, et al. The effects of withdrawal of dopaminergic medication in nursing home patients with advanced Parkinsonism. Journal of the American Medical Directors Association 2008;9(9):670-5. [CRSREF: 3179538 ]

\section{Van Balen 2014}

[CRSSTD: 9077581]

Van Balen J, Damen-Van Beek Z, Nelissen-Vrancken M, Verduijn M, Van Woerkom M. Implementation and evaluation of the Dutch multidisciplinary guideline (MDR) polypharmacy in the elderly. International Journal of Clinical Pharmacy $2014 ; 36: 855$. [CRSREF: 9077582]

\section{Van Den Broucke 2014}

[CRSSTD: 9077583]

Van Den Broucke, Verhaeghe A, Debruyne PR, Verhelle K. Value of a clinical pharmacist in the oncology department and optimalisation of the applicability of geriatric tools assessing potential inappropriate medication use in geriatric patients (Drug Burden Indexand de Beers criteria)]. French].Journal de Pharmacie de Belgique 201 4;94(1):28-36. [CRSREF: 9077584]

\section{Van der Elst 2006}

[CRSSTD: 3179539$]$

Van Der Elst ME, Bouvy ML, de Blaey CJ, De BA. Improving pharmacotherapy after myocardial infarction by group academic detailing using feedback data on a patient level. Pharmacotherapy 2006;26(2):254-9. [CRSREF: 31 79540]

\section{van Hees 2008}

[CRSSTD: 3179541$]$

van Hees BC, de Ruiter E, Wiltink EH, de Jongh BM, Tersmette M. Optimizing use of ciprofloxacin: a prospective intervention study. Journal of Antimicrobial Chemotherapy 2008;61 (1):210-3. [CRSREF: 31 79542]

\section{van Marum 2015}

[CRSSTD: 9077585]

van Marum RJ, Koopmans RT, Bouvy M. Does it still make sense? Deprescribing in the frail elderly. Dutch]. Nederlands Tijdschrift voor Geneeskunde 2015;159:A8947. [CRSREF: 9077586]

\section{Vejar 2015}

[CRSSTD: 9077587] 
Vejar MV, Makic MB, Kotthoff-Burrell E. Medication management for elderly patients in an academic primary care setting: a quality improvement project. Journal of the American Association of Nurse Practitioners 2015;27(2):72-8. [CRSREF: 9077588]

\section{Verrue 2010}

[CRSSTD: 9077589]

Verrue C, Mehuys E, BousseryK, RemonJP, Petrovic M. Optimisation of medication use in nursing homes: Roles of the (clinical) pharmacist. European Geriatric Medicine 2010;1:S79. [CRSREF: 9077590]

\section{Vetter 1992}

[CRSSTD: 3179543 ]

Vetter NJ, Lewis PA, Ford D. Can health visitors prevent fractures in elderly people? BMJ 1992;304(6831):888-90.

[CRSREF: 3179544$]$

\section{Viktil 2006}

[CRSSTD: 3179545$]$

Viktil KK, Blix HS, MogerTA, Reikvam A. Interview of patients by pharmacists contributes significantly to the identification of drug-related problems (DRPs). Pharmacoepidemiology and Drug Safety 2006; 1 5(9):667-74. [CRSREF: 31 79546]

\section{Volume 2001}

[CRSSTD: 3179547$]$

Volume CI, Farris KB, Kassam R, Cox CE, Cave A. Pharmaceutical care research and education project: patient outcomes. Journal of the American Pharmaceutical Association 2001;41(3):411-20. [CRSREF: 3179548 ]

\section{Wallis 2015}

[CRSSTD: 9077591$]$

Wallis KA. Ageing is not for the faint-hearted: are we making it worse? Polypharmacy-related harm in the elderly. Journal of Primary Health Care 201 5;7(2):167-9. [CRSREF: 9077592]

\section{Watson 2014}

[CRSSTD: 9077593]

Watson LC, Esserman DA, Ivey JL, Lewis CL, Hansen R, Weinberger M, et al. Enhancing Quality in Psychiatry with Psychiatrists (EQUIPP)--results from a pilot study. American Journal of Geriatric Psychiatry 2014;22(9):884-8. [CRSREF: 9077594]

\section{Weber 2008}

[CRSSTD: 3179549$]$

Weber V, White A, Mcllvried R. An electronic medical record (EMR)-based intervention to reduce polypharmacy and falls in an ambulatory rural elderly population. Journal of General Internal Medicine 2008;23(4):399-404. [CRSREF: 31 79550]

\section{Wehling 2015}

[CRSSTD: 9077595]

Wehling M, Kuhn-Thiel A, Throm C, Burkhardt H, Frohnhofen H, Pazan F, et al. Clinical validation of the FORTA(FitfOR The Aged) List in a prospective randomized controlled clinical study. European Geriatric Medicine 201 5;6:S1 46. [CRSREF: 9077596]

\section{Weingart 2008}

[CRSSTD: 3179551$]$

Weingart SN, Hamrick HE, Tutkus S, Carbo A, Sands DZ, Tess A, et al. Medication safety messages for patients via the web portal: the MedCheck intervention. International Journal of Medical Informatics 2008;77(3):161-8. [CRSREF: 31 79552]

\section{Wenger 2007}

[CRSSTD: 31 79553]

Wenger NS, Roth CP, Shekelle P, ACOVE investigators. Introduction to the Assessing Care Of Vulnerable Elders - 3 quality indicator measurement set. Journal of the American Geriatrics Society 2007;55(Suppl 2):S247-52. [CRSREF: 31 79554]

\section{Wessell 2008}

[CRSSTD: 3179555$]$

Wessell AM, Nietert PJ, Jenkins RG, Nemeth LS, Ornstein SM. Inappropriate medication use in the elderly: results from a quality improvement project in 99 primary care practices. American Journal Geriatric Pharmacotherapy 2008;6(1):21-7. [CRSREF: 3179556$]$

\section{Westberg 2014}

[CRSSTD: 9077597] 


\section{Interventions to improve the appropriate use of polypharmacy for older people}

Westberg SM, Swanoski MT, Renier CM, Gessert CE. Evaluation of the impact of comprehensive medication management services delivered posthospitalization on readmissions and emergency department visits. Journal of Managed Care \& Specialty Pharmacy 2014;20(9):886-93. [CRSREF: 9077598]

\section{Whalen 2014}

[CRSSTD: 9077599]

Whalen R, Larion S, Lynch T. Improved renal and cognitive function in a hospice patient after polypharmacy reduction. Annals of Long Term Care 2014;22(10):37-40. [CRSREF: 9077600]

\section{Willcox 1994}

[CRSSTD: 3179557$]$

Willcox SM, Himmelstein DU, Woolhandler S. Inappropriate drug prescribing for the community dwelling elderly.JAMA 1994; 272(4):292-6. [CRSREF: 3179558 ]

\section{Willeboordse 2017}

[CRSSTD: 9077601]

WilleboordseF, Schellevis FG, Chau SH, HugtenburgJG, Elders PJM. The effectiveness of optimised clinical medication reviews for geriatric patients: Opti-Med a cluster randomised controlled trial. Family Practice 2017;34(4):437-45. [CRSREF: 9077602]

\section{Williams 2004}

[CRSSTD: 3179559$]$

Williams ME, Pulliam CC, Hunter R, Johnson TM, Owens JE, Kincaid J, et al. The short-term effect of interdisciplinary medication review on function and cost in ambulatory elderly people. Journal of the American Geriatrics Society 2004; 52(1):93-8. [CRSREF: 3179560$]$

\section{Wouters 2017}

[CRSSTD: 9077603]

Taxis K, Scheper J, Koning H, Brouwer C, TwiskJ, Meer H, et al. Discontinuing inappropriate medication in nursing home residents (DIM-NHR study)-a cluster randomized controlled trial. Pharmacoepidemiology and Drug Safety 2017;26:449-50. [CRSREF: 9077604]

*Wouters H, ScheperJ, Koning H, Brouwer C, TwiskJW, van derMeer H, etal. Discontinuing inappropriate medication use in nursing home residents: a cluster randomized controlled trial. Annals of Internal Medicine 201 7;167(9):609-1 7. [CRSREF: 9077605]

\section{Wu 2006}

[CRSSTD: 3179561$]$

Wu JYF, Leung WYS, Chang S, Lee B, Zee B, Tong PCY, et al. Effectiveness of telephone counselling by a pharmacist in reducing mortality in patients receiving polypharmacy: randomised controlled trial. BM] 2006;333(7567):522-7. [CRSREF: $3179562]$

\section{Wu 2016}

[CRSSTD: 9077606]

Wu S, Mirzaian E, Arouchanova D. The impact of a pharmacist intervention program for high-risk medications on star ratings and identifying trends in patient resistance to high-risk medication interventions in an independent community pharmacy practice. Journal of the American Pharmacists Association 2016;56(3):e25. [CRSREF: 9077607]

\section{Xin 2016}

[CRSSTD: 9077608]

Xin C, Ge X, Zheng L, Huang P. Evaluation of pharmaceutical care in a diabetes ward from China: a pre-and postintervention study. International Journal of Clinical Pharmacy 2016;38(1):34-40. [CRSREF: 9077609]

\section{Zermansky 2006}

[CRSSTD: 3179563 ]

Zermansky AG, Alldred DP, Petty DR, Raynor DK, Freemantle N, EastaughJ, et al. Clinical medication review bya pharmacist of elderly people living in care homes - randomised controlled trial. Age and Ageing 2006;35(6):586-91. [CRSREF: 3179564$]$

\section{Zuckerman 2005}

[CRSSTD: 3179565$]$

Zuckerman IH, Hernandez JJ, Gruber-Baldini AL, Hebel JR, Stuart B, Zimmerman S, et al. Potentially inappropriate prescribing before and after nursing home admission among patients with and without dementia. American Journal Geriatric Pharmacotherapy 2005;3(4):246-54. [CRSREF: 3179566$]$ 


\section{Studies awaiting classification}

\section{Cossette 2016}

[CRSSTD: 9077610$]$

CossetteB, BergeronJ, Ricard G, EthierJF,Joly-Mischlich T, Levine M, etal. Knowledgetranslation strategyto reduce the use of potentially inappropriate medications in hospitalized elderly adults. Journal of the American Geriatrics Society 2016 ; 64(12):2487-94. [CRSREF: 9077611 ]

\section{Cossette 2017}

[CRSSTD: 9077612$]$

Cossette B, Ethier J, Joly-Mischlich T, Bergeron J, Ricard G, Brazeau S, et al. Reduction in potentially inappropriate medication use in elderly inpatients: a pragmatic randomized controlled trial. In:Journal of the American Geriatrics Society. Vol. 65. 2017:S109-10. [CRSREF:9077613]

Cossette B, Ethier JF, Joly-Mischlich T, Bergeron J, Ricard G, Brazeau S, et al. Reduction in targeted potentially inappropriate medication use in elderly inpatients: a pragmatic randomized controlled trial. EuropeanJournal of Clinical Pharmacology 2017;73(10):1237-45. [CRSREF: 9077614]

\section{Leguelinel-Blache 2018}

[CRSSTD: 9077615$]$

Leguelinel-Blache G, Castelli C, Roux-Marson C, Bouvet S, Andrieu S, Cestac P, et al. Impact of collaborative pharmaceutical care on in-patients' medication safety: Study protocol for a stepped wedge cluster randomized trial (MEDREV study). Trials 2018;19(1):19. [CRSREF: 9077616]

\section{Lenander 2017}

[CRSSTD: 9077617$]$

Lenander C, Bondesson A, Viberg N, Jakobsson U, Beckman A, Midlov P. Effects of an intervention (SAKLAK) on prescription of potentially inappropriate medication in elderly patients. Family Practice 2017;34(2):213-8. [CRSREF: 9077618]

\section{Ongoing studies \\ ACTRN12617000665336}

Unpublished data only [CRSSTD: 9077619]

ACTRN12617000665336. Impact of clinical pharmacist medication review on appropriate prescribing in elderly patients: A randomized, controlled trial. anzctr.org.au/Trial/Registration/TrialReview.aspx?id=372670 (first received 30 March 2017). [CRSREF: 9077620]

\section{Anrys 2016}

\section{[CRSSTD: 9077621 ]}

Anrys P, Goedele S, Foulon V, Spinewine A. The COME-ON study: Collaborative approach to Optimise MEdication use for Older people in Nursing homes-process evaluation protocol. International Journal of Clinical Pharmacy 201 6a;38(4): 1019. [CRSREF: 9077622]

*Anrys P, Strauven G, Boland B, DalleurO, Declercq A, DegryseJM, et al. Collaborative approach to Optimise MEdication use for Older people in Nursing homes (COME-ON): study protocol of a cluster controlled trial. Implementation Science 2016;11:35. [CRSREF: 9077623]

\section{Dauphinot 2017}

[CRSSTD: 9077624]

Dauphinot V, Jean-Bart E, Krolak-Salmon P, Mouchoux C. A multi-center, randomized, controlled trial to assess the efficacy of optimization of drug prescribing in an elderly population, at 18 months of follow-up, in the evolution of functional autonomy: the OPTIM study protocol. BMC Geriatrics 2017;17(1):195. [CRSREF: 9077625]

\section{Desborough 2011}

[CRSSTD: 3179571$]$

Desborough J, Houghton J, Wood J, Wright D, Holland R, Sach T, et al. Multi-professional clinical medication reviews in care homes for the elderly: study protocol for a randomised controlled trial with cost effectiveness analysis. Trials 201 1;12:218. [CRSREF: 3179572$]$

\section{DRKS00003610}

Unpublished data only [CRSSTD: 9077626; Other: DRKS00003610]

DRKS00003610. Reduction of potentially inappropriate medication in the elderyTrial Acronym.

drks.de/drks_web/navigate.do?navigationld=trial.HTML\&TRIAL_ID=DRKS00003610 (first received 05 April 2012). [CRSREF: 9077627] 
Interventions to improve the appropriate use of polypharmacy for older people

\section{DRKS00012246}

Unpublished data only [CRSSTD: 9077628]

DRKS00012246. SiMbA- Optimizing nursing home residents `safety by checking prescribed medication. apps.who.int/trialsearch/Trial2.aspx?TrialID=DRKS00012246 (first received 16 May 2017). [CRSREF: 9077629]

\section{DRKS00013588}

Unpublished data only [CRSSTD: 9077630]

DRKS00013588. HIOPP-3-iTBX: Appropriate and safe medication for nursing home residents using an interdisciplinary toolbox (AMTS-Toolbox). drks.de/drks_web/navigate.do?navigationld=trial.HTML\&TRIAL_ID=DRKS00013588 (first received 25 January 2018). [CRSREF: 9077631 ]

\section{Husebo 2015}

[CRSSTD: 9077632]

Husebo BS, Flo E, Aarsland D, Selbaek G, Testad I, Gulla C, et al. COSMOS - improving the quality of life in nursing home patients: protocol for an effectiveness-implementation cluster randomized clinical hybrid trial. Implementation Science 2015; 10:131. [CRSREF: 9077633]

\section{ISRCTN18427377}

Unpublished data only [CRSSTD: 9077634]

ISRCTN18427377. Hospital discharge study. isrctn.com /ISRCTN1 8427377?q=\&filters=\&sort=\&offset=3\&totalResults=16551 \&page = 1 \&pageSize=10\&search Type=basic search 2018;(first received 03 January 2018). [CRSREF: 9077635]

\section{Jäger 2013}

[CRSSTD: 9077636]

Jäger C, Freund T, SteinhäuserJ, Joos S, Wensing M, SzecsenyiJ. A tailored implementation intervention to implement recommendations addressing polypharmacy in multimorbid patients: study protocol of a cluster randomized controlled trial. Trials 2013;14(1): 1. [CRSREF: 9077637]

\section{Johansen 2018}

[CRSSTD: 9077638]

JohansenJS, Havnes K, Halvorsen KH, Haustreis S, Skaue LW, Kamycheva E, et al. Interdisciplinary collaboration across secondary and primary care to improve medication safety in the elderly (IMMENSE study): study protocol for a randomised controlled trial. BMJ Open 2018;8(1):e020106. [CRSREF: 9077639]

NCT02816086. A new interdisciplinary collaboration structure to improve medication safety in the elderly. clinicaltrials.gov/ct2/show/NCT02816086 (first received 28 June 2016). [CRSREF: 9077640]

\section{Kua 2017}

Published and unpublished data [CRSSTD: 9077641]

* Kua CH, Yeo CYY, Char CWT, Tan CWY, Tan PC, Mak VS, et al. Nursing home team-care deprescribing study: a stepped-wedge randomised controlled trial protocol. BMJ Open 2017;7(5):e015293. [CRSREF: 9077642]

NCT02863341. Nursing Home Team-Care Deprescribing Study. clinicaltrials.gov/ct2/show/NCT02863341 2018;(first received 11 August 2016). [CRSREF: 9077643]

\section{Loffler 2014}

[CRSSTD: 9077644]

LofflerC, DrewelowE, PaschkaSD, Frankenstein M, EgerJ,Jatsch L, et al. Optimizing polypharmacy among elderly hospital patients with chronic diseases: Study protocol of the cluster randomized controlled POLITE-RCT trial. Implementation science 2014;9:151. [CRSREF: 9077645]

\section{McCarthy 2017}

Published and unpublished data [CRSSTD: 9077646]

ISRCTN12752680. Supporting medicines management in older adults with multiple medical conditions. isrctn.com /ISRCTN12752680?q=\&filters=\&sort=\&offset=1\&totalResults=15064\&page=1\&pageSize=10\&searchType=basicsearch (first received 26 September 2016). [CRSREF: 9077647]

* McCarthy C, Clyne B, Corrigan D, Boland F, Wallace E, Moriarty F, et al. Supporting prescribing in older people with multimorbidityand significant polypharmacy in primary care (SPPiRE): a cluster randomised controlled trial protocol and pilot. Implementation Science 2017;12(1):99. [CRSREF: 9077648]

\section{Mestres 2017}

[CRSSTD: 9077649]

Mestres Gonzalvo C, de Wit HA, van Oijen BP, Hurkens KP, Janknegt R, Schols JM, et al. Supporting clinical rules engine in 
Interventions to improve the appropriate use of polypharmacy for older people

the adjustment of medication (SCREAM): protocol of a multicentre, prospective, randomised study. BMC Geriatrics 2017 ; 17(1):35. [CRSREF: 9077650]

\section{NCT00844025}

Unpublished data only [CRSSTD: 9077651]

NCT00844025. Pharmaceutical care and clinical outcomes for the elderly taking potentially inappropriate medication. clinicaltrials.gov/ct2/show/NCT00844025 (first received 13 February 2009). [CRSREF: 9077652]

\section{NCT01034761}

Unpublished data only [CRSSTD: 9077653; ClinicalTrials.gov: NCT01034761]

NCT01034761. Using clinical alerts to decrease inappropriate medication prescribing.

clinicaltrials.gov/ct2/show/NCT01034761 (first received 17 December 2009). [CRSREF: 9077654]

\section{NCT01534559}

Unpublished data only [CRSSTD: 9077655; ClinicalTrials.gov: NCT01534559]

NCT01534559. Pharmacist-led Medicines Management Outpatient Service (MMC). clinicaltrials.gov/ct2/show/NCT01534559

(first received 16 February 2012). [CRSREF: 9077656]

\section{NCT01578525}

Unpublished data only [CRSSTD: 9077657; ClinicalTrials.gov: NCT01578525]

NCT01578525. Medication safety of elderly patients in hospital and ambulatory setting.

clinicaltrials.gov/ct2/show/NCT01578525 (first received 17 April 2012). [CRSREF: 9077658]

\section{NCT02942927}

Published and unpublished data [CRSSTD: 9077659]

NCT02942927. Team approach to polypharmacy evaluation and reduction. clinicaltrials.gov/ct2/show/NCT02942927 (first received 24 October 2016). [CRSREF: 9077660]

\section{NCT02986425}

Unpublished data only [CRSSTD: 9077661]

* NCT02986425. OPtimising thERapy to prevent Avoidable hospital admissions in the Multimorbid older people (OPERAM). clinicaltrials.gov/ct2 / show/NCT02986425;(first received 08 December 2016). [CRSREF: 9077662]

NTR6012. OPtimising thERapy to prevent Avoidable hospital admissions in the Multimorbid elderly. trialregister.nl/trialreg/admin/rctview.asp?TC=6012;(first received 28 July 2016). [CRSREF: 9077663 ]

\section{NCT03156348}

Unpublished data only [CRSSTD: 9077664]

NCT031 56348. Impact of clinical pharmacist on adverse drug events in older adults. clinicaltrials.gov/ct2/show/NCT03156348;(first received 17 May 2017). [CRSREF: 9077665]

\section{NCT03298386}

Unpublished data only [CRSSTD: 9077666]

NCT03298386. Elderly Appropriate Treatment in primary care (EAT). clinicaltrials.gov/ct2/show/NCT03298386;(first received 02 October 2017). [CRSREF: 9077667]

\section{NTR5750}

Unpublished data only [CRSSTD: 9077668]

NTR5750. PROPOSE : PReoperative Optimization of Pharmacotherapy in frail Older patients with use of STRIP assistant. trialregister.nl/trialreg/admin/rctview.asp?TC=5750;(first received 12 February 2016). [CRSREF: 9077669]

\section{Prados-Torres 2017}

Published and unpublished data [CRSSTD: 9077670]

NCT02866799. Multi-PAP RCT: Improving prescription in primary care patients with multimorbidity andpPolypharmacy. clinicaltrials.gov/ct2/show/NCT02866799 (first received 15 August 2016). [CRSREF: 9077671]

*Prados-Torres A, Del Cura-GonzalezI, Prados-Torres D, Lopez-RodriguezJA, Leiva-Fernandez F, Calderon-Larranaga A, et al. Effectiveness of an intervention for improving drug prescription in primary care patients with multimorbidity and polypharmacy: study protocol of a cluster randomized clinical trial (Multi-PAP project). Implementation Science 2017; 12(1):54. [CRSREF: 9077672]

\section{Romskaug 2017}

[CRSSTD: 9077673]

Romskaug R, Molden E, Straand J, Kersten H, Skovlund E, Pitkala KH, et al. Cooperation between geriatricians and general practitioners for improved pharmacotherapy in home-dwelling elderly people receiving polypharmacy-the COOPStudy: 
Interventions to improve the appropriate use of polypharmacy for older people

study protocol for a cluster randomised controlled trial. Trials 2017;18(1):158. [CRSREF: 9077674]

\section{Selic 2016}

[CRSSTD: 9077675]

Cedilnik Gorup E, Petek-Ster M. Use of web-based application to improve prescribing in home-living elderly: A randomised controlled study protocol. In: 9th Congress of the European Union Geriatric Medicine Society, Venice, Italy. 2013. [CRSREF: 9077676]

* Selic P, Gorup EC, Gorup S, Ster MP, Rifel J, Ketis ZK. The effects of a web application and medical monitoring on the quality of medication, adverse drug events and adherence in the elderly living at home: a protocol of the study. Materia Socio Medica 2016;28(6):432-6. [CRSREF: 9077677]

\section{Other references}

\section{Additional references \\ Agbabiaka 2017}

Agbabiaka TB, Wider B, Watson LK, Goodman C. Concurrent use of prescription drugs and herbal medicinal products in older adults: a systematic review protocol. Drugs \& Aging 201 7;34(12):891-905.

\section{AGS 2012}

American Geriatrics Society 2012. American Geriatrics Society updated Beers Criteria for potentially inappropriate medication use in older adults. Journal of the American Geriatrics Society 2012;60(4):61 6-31.

\section{Alldred 2016}

Alldred DP, Kennedy MC, Hughes C, Chen TF, Miller P. Interventions to optimise prescribing for older people in care homes. Cochrane Database of Systematic Reviews 2016, Issue 2. Art. No.: CD009095 DOI: 10.1 002/14651858.CD009095.pub3.

\section{Appleton 2014}

Appleton SC, Abel GA, Payne RA. Cardiovascular polypharmacy is not associated with unplanned hospitalisation: Evidence from a retrospective cohort study. BMC Family Practice 2014;15(1):58.

\section{Aronson 2006}

Aronson JK. Polypharmacy, appropriate and inappropriate. British Journal of General Practice 2006;56(528):484-5.

\section{Barnett 2012}

Barnett K, Mercer SW, Norbury M, Watt G, Wyke S, Guthrie B. Epidemiology of multimorbidity and implications for health care, research, and medical education: A cross-sectional study. The Lancet 2012;380(9836):37-43.

\section{Basger 2012}

Basger B , Chen TF, Moles RJ. Validation of prescribing appropriateness criteria for older Australians using the RAND/UCLA appropriateness method. BMJ Open 2012;2(5):e001431.

\section{Beers 1991}

Beers MH, Ouslander JG, Rollingher I, Reuben DB, Brooks J, Beck JC. Explicit criteria for determining inappropriate medication use in nursing home residents. Archives of Internal Medicine 1991;151(9):1825-32.

\section{Beers 1997}

Beers MH. Explicit criteria for determining potentially inappropriate medication use by the elderly: an update. Archives of Internal Medicine 1997;157(14):1531-1536.

\section{Bradley 2012}

Bradley MC, Fahey T, Cahir C, Bennett K, O'Reilly D, Parsons C, et al. Potentially inappropriate prescribing and cost outcomes for older people: A cross-sectional study using the Northern Ireland Enhanced Prescribing Database. Eu ropean Journal of Clinical Pharmacology 2012;68(10):1425-33.

\section{Burt 2016}

Burt J, Elmore N, Rodgers S, Payne R. Systematic Review protocol: Developing and evaluating a measure of inappropriate polypharmacy in primary care. Available from www.crd.york.ac.uk/PROSPEROFILES/491 76_PROTOCOL_20160910.pdf (accessed 10 August 2017).

\section{Bushardt 2008}

Bushardt RL, Massey EB, Simpson TW, Ariail JC, Simpson KN. Polypharmacy: misleading, but manageable. Clinical Interventions in Aging 2008;3(2):383-9.

\section{Cadogan 2016}

Cadogan CA, Ryan C, Francis JJ, Gormley GJ, Passmore P, Kerse N, et al. Development of an intervention to improve appropriate polypharmacy in older people in primary care using a theory-based method. BMC Health Services Research 2016;16(1):661. 
Interventions to improve the appropriate use of polypharmacy for older people

\section{Cadogan 2016a}

Cadogan CA, Ryan C, Hughes CM. Appropriate polypharmacy and medicine safety: when many is not too many. Drug Safety 2016;39(2):109-16.

\section{Cahir 2010}

Cahir C, Fahey T, Teeling M, Teljeur C, Feely J, Bennett K. Potentially inappropriate prescribing and cost outcomes for older people: A national population study. British Journal of Clinical Pharmacology 201 0;69(5):543-52.

\section{Cahir 2014}

Cahir C, Moriarty F, Teljeur C, Fahey T, Bennett K. Potentially inappropriate prescribing and vulnerability and hospitalization in older community-dwelling patients. Annals of Pharmacotherapy 2014;48(12):1 546-54.

\section{Christensen 2004}

Christensen D, Trygstad T, Sullivan R, Garmise J, Wegner SE. A pharmacy management intervention for optimizing drug therapy for nursing home patients. American Journal of Geriatric Pharmacotherapy 2004;2(4):248-56.

\section{EPOC 2015}

Effective Practice and Organisation of Care (EPOC). EPOC Taxonomy, 2015. Available at: epoc.cochrane.org/sites/epoc.cochrane.org/files/public/uploads/epoc_taxonomy_13.12.16.pdf.

\section{EPOC 2016}

Effective Practice and Organisation of Care (EPOC). The EPOC taxonomy of health systems interventions. EPOC Resources for review authors. Oslo: Norwegian Knowledge Centre for the Health Services, 2016. Available at: epoc.cochrane.org/epoc-specific-resources-review-authors.

\section{EPOC 2017}

Cochrane Effective Practice and Organisation of Care (EPOC). What study designs should be included in an EPOC review? EPOC Resources for review authors, 2017. Available at: epoc.cochrane.org/sites/epoc.cochrane.org/files/public/uploads/Resources-forauthors 2017 /what_study_designs_should_be_included_in_an_epoc_review.pdf.

\section{EPOC 2017b}

Effective Practice and Organisation of Care (EPOC). EPOC worksheets for preparing a 'Summary of findings' table using GRADE. EPOC resources for review authors, 2017. Available at: epoc.cochrane.org/epoc-specific-resources-review-authors.

\section{Fastbom 2015}

Fastbom J, Johnell K. National indicators for quality of drug therapy in older persons: the Swedish experience from the first 10 years. Drugs \& Aging 2015;32(3):189-199.

\section{Fick 2003}

Fick DM, CooperJW, Wade WE, WallerJL, MacleanJR, Beers MH. Updating the Beers criteria for potentially inappropriate medication use in older adults. Archives of Internal Medicine 2003;163:2716-24.

\section{Fick 2008}

Fick DM, Mion LC, Beers MH, Waller JL. Health outcomes associated with potentially inappropriate medication use in older adults. Research in Nursing and Health 2008;31(1):42-51.

\section{Fulton 2005}

Fulton MM, Allen ER. Polypharmacy in the elderly: A literature review. Journal of the American Academy of Nurse Practitioners 2005;17(4):123-32.

\section{Furniss 2000}

Furniss LBA, Craig SK, Scobie S, Cooke J, Faragher B. Effects of a pharmacists medication review in nursing homes. Randomised controlled trial. British Journal of Psychiatry 2000;1 76:563-7.

\section{Gallagher 2001}

GallagherLP. The potential for adverse drug reactions in elderly patients. Applied Nursing Research 2001;14(4):220-4. Gallagher 2008

Gallagher P, Ryan C, Byrne S, KennedyJ, O'Mahony D. STOPP (Screening Tool of Older Person's Prescriptions) and START (Screening Tool to Alert doctors to Right Treatment). Consensus validation. International Journal of Clinical Pharmacology and Therapeutics 2008;46(2):72-83.

\section{Galvin 2014}

Galvin R, Moriarty F, Cousins G, Cahir C, Motterlini N, Bradley M, et al. Prevalence of potentially inappropriate prescribing and prescribing omissions in olderlrishadults: findings from The Irish LongituDinalStudy on Ageing study(TILDA). European Journal of Clinical Pharmacology 2014;70(5):599-606. 
Interventions to improve the appropriate use of polypharmacy for older people

\section{GRADEpro GDT 2015}

GRADEpro GDT: GRADEpro Guideline Development Tool [Computer program]. McMaster University (developed by Evidence Prime), 2015.Available from gradepro.org.

\section{Guthrie 2015}

Guthrie B, Makubate B, Hernandez-Santiago V, Dreischulte T. The rising tide of polypharmacyand drug-drug interactions: population database analysis 1995-2010. BMC Medicine 2015;13(1):74.

\section{Guyatt 2008}

GuyattGH, Oxman AD, Vist GE, Kunz R, Falck-YtterY, Alonso-CoelloP, et al. GRADE: an emerging consensus on rating quality of evidence and strength of recommendations. BMJ 2008;336(7650):924-6.

\section{Hanlon 1992}

Hanlon JT, Schmader KE, Samsa GP, Weinberger M, Uttech KM, Lewis IK, et al. A method for assessing drug therapy appropriateness. Journal of Clinical Epidemiology 1992;45(10):1045-51.

\section{Hepler 1990}

Hepler CD, Strand LM. Opportunities and responsibilities in pharmaceutical care. American Journal of Hospital Pharmacy 1990;47(3):533-43.

\section{Higgins 2011}

HigginsJPT, AltmanDG, Sterne,JAC (editors). Chapter 8: Assessing risk of bias in included studies. In: Higgins JPT, Green S, editors(s). Cochrane Handbook for Systematic Reviews of Interventions. Version 5.1.0 [updated March 201 1]. The Cochrane Collaboration, 2011 Available from www.handbook.cochrane.org.

\section{Hoffmann 2014}

Hoffmann TC, Glasziou PP, Boutron I, Milne R, Perera R, Moher D, et al. Better reporting of interventions: Template for intervention description and replication (TIDieR) checklist and guide. BMJ 2014;348:g1687.

\section{Holland 2007}

Holland R, Desborough J, Goodyer L, Hall S, Wright D, Loke YK. Does pharmacist-led medication review help to reduce hospital admissions and deaths in older people? A systematic reviewand meta-analysis. BritishJournal ofClinical Pharmacology 2007;65(3):303-16.

\section{Holt 2010}

Holt S, SchmiedI S, Thürmann PA. Potentially inappropriate medications in the elderly: the PRISCUS list. Deutsches Ärzteblatt International 2010;107(31-32):543-551.

\section{Hughes 2012}

Hughes LD, McMurdo MET, Guthrie B. Guidelines for people not for diseases: the challenges of applying UK clinical guidelines to people with multimorbidity. Age and Ageing 2012;42(1):62-9.

\section{Information Centre 2017}

Prescribing and Medicines Team, NHS Digital. Prescriptions dispensed in the community. Statistics for $2006-16$. www.digital.nhs.uk/publication/s/o/pres-disp-com-eng-2006-16-rep.pdf(accessed 16 April 2018 ).

\section{Jeffery 1999}

Jeffery S, Ruby CM, Hanlon JT, Twersky J. The impact of an interdisciplinary team on suboptimal prescribing in a long term care facility. Consultant Pharmacist 1999;14:1386-9.

\section{Johansson 2016}

Johansson T, Abuzahra ME, KellerS, MannE, Faller B, Sommerauer C, et al. Impact of strategies to reduce polypharmacy on clinically relevant endpoints: A systematic review and meta-analysis. British Journal of Clinical Pharmacology 2016 ; 82(2):532-48.

\section{Kantor 2015}

KantorED, Rehm CD, Haas JS, Chan AT, Giovannucci EL. Trends in prescription drug use among adults in the United States from 1999-2012. Jama 2015;314(17):1818-30.

\section{Kaufmann 2014}

Kaufmann CP, Tremp R, Hersberger KE, Lampert ML. Inappropriate prescribing: A systematic overview of published assessment tools. European Journal of Clinical Pharmacology 2014;70(1):1-11.

\section{Kaur 2009}

Kaur S, Mitchell G, Vitetta L, Roberts MS. Interventions that can reduce inappropriate prescribing in the elderly. A systematic review. Drugs \& Aging2009;26(12):1013-28. 
The King's Fund. Polypharmacy and medicines optimisation: Making it safe and sound. www.kingsfund.org.uk/sites/default/files/field/field_publication_file/polypharmacy-and-medicines-optimisation-kingsfundnov13.pdf (accessed 26 April 2016).

\section{Kirkham 2016}

KirkhamJJ, Gorst S, Altman DG, BlazebyJM, Clarke M, Devane D, et al. Core outcome set STAndards for reporting: The COS-STAR statement. PLOS Medicine 2016;13(10):e1002148.

\section{Ko 2004}

Ko DT, Mamdani M, Alter DA. Lipid-lowering therapy with statins in high-risk elderly patients: the treatment-risk paradox. JAMA 2004;291(15):1864-70.

\section{Kuhn-Thiel 2014}

Kuhn-Thiel AM, Weiss C, Wehling M. Consensus Validation of the FORTA (Fit fOR The Aged) list: A clinical tool for increasing the appropriateness of pharmacotherapy in the elderly. Drugs \& Aging 2014;31(2):131-40.

\section{Kuijpers 2007}

Kuijpers MA, van Marum RJ, Egberts AC, Jansen PA; OLDY (OLd people Drugs \& dYsregulations) Study Group. Relationship between polypharmacy and underprescribing. British Journal of Clinical Pharmacology 2007;65(1):130-3.

\section{Lee 2005}

Lee DS, Tu JV, Juurlink DN, Alter DA, Ko DT, Austin PC, et al. Risk-treatment mismatch in the pharmacotherapy of heart failure. JAMA 2005;294(24):1240-7.

\section{Mangoni 2003}

Mangoni AA, Jackson SHD. Age-related changes in pharmacokinetics and pharmacodynamics: Basic principles and practical applications. British Journal of Clinical Pharmacology 2003;57(1):6-14.

\section{McGarrigle 2017}

McGarrigle C, Donoghue O, Scarlett S, Kenny RA. Health and Wellbeing: Active Ageing for Older Adults in Ireland. Dublin: The Irish Longitudinal Study on Ageing (TILDA), 2017.

\section{McLeod 1997}

McLeod PJ, Huang AR, Tamblyn RM, Gayton DC. Defining inappropriate practices in prescribing for elderly people: A national consensus panel. Canadian Medical Association Journal 1997;156(3):385-91.

\section{Meid 2015}

Meid AD, Lampert A, Burnett A, Seidling HM, Haefeli WE. The impact of pharmaceutical care interventions for medication underuse in older people: A systematic review and meta-analysis. BritishJjournal of Clinical Pharmacology 2015 ; 80(4):768-76.

\section{Michie 2011}

Michie S, Abraham C, Eccles MP, Francis JJ, Hardeman W, Johnston M. Strengthening evaluation and implementation by specifying components of behaviourchange interventions: A study protocol. Implementation Science 201 1;6:1 0.

\section{Montamat 2004}

Montamat SC, Cusack B. Overcoming problems with polypharmacy and drug misuse in the elderly. Clinics in Geriatric Medicine 1992;8(1):143-58.

\section{MRC 2008}

Medical Research Council. A framework for the development and evaluation of RCTs for complex interventions to improve health. Medical Research Council, UK 2008.

\section{NICE 2016}

National Institute for Health and Clinical Excellence. Multimorbidity: clinical assessment and management. National Institute for Health and Clinical Excellence; 2016:NICE guideline (NG56) (accessed 16 February 2017).

\section{O' Connor 2012}

O'Connor MN, Gallagher P, O'Mahony D. Inappropriate prescribing. Drugs \& aging 2012;29(6):437-52.

\section{Proctor 2013}

Proctor EK, Powell BJ, McMillen JC. Implementation strategies: recommendations for specifying and reporting. Implementation Science 2013;8:139.

\section{Rankin 2018}

Rankin A, Cadogan CA, Ryan C, Clyne B, Smith SM, Hughes CM. Core Outcome Set for trials aimed at improving the appropriateness of polypharmacy in older people in primary care. Journal of the American Geriatrics Society 201 8; Epub ahead of print: $1-7$. 
Interventions to improve the appropriate use of polypharmacy for older people

\section{RevMan 2014}

Review Manager (RevMan) [Computer program]. Version 5.3. Copenhagen: The Nordic Cochrane Centre, The Cochrane Collaboration, 2014.

\section{Rogers 2003}

Rogers EM. Diffusion of Innovations. 5th edition. New York: Free Press, 2003.

\section{Rollason 2003}

Rollason V, Vogt N. Reduction of polypharmacy in the elderly. A systematic review of the role of the pharmacist. Drugs \& Aging 2003;20(11):817-32.

\section{Scott 2010}

Scott IA, Guyatt GH. Cautionary tales in the interpretation of clinical studies involving older persons. Archives of Internal Medicine 2010;170(7):587-9.

\section{Scottish Government Model of Care 2018}

Scottish Government Model of Care Polypharmacy Working Group Polypharmacy Guidance. Polypharmacy Guidance. Scottish Government. April 2018;3rd edition:http://www.therapeutics.scot.nhs.uk/wp-content/uploads/2018/04/PolypharmacyGuidance-2018.pdff (accessed 01 June2018).

\section{Simonson 2005}

Simonson W, Feinberg JL. Medication-related problems in the elderly. Drugs Aging 2005;22(7):559-69.

\section{Sinnott 2017}

Sinnott C, Byrne M, Bradley CP. Improving medication management for patients with multimorbidity in primary care: a qualitative feasibility study of the MY COMRADE implementation intervention. Pilot and Feasibility Studies 201 7;3(1): 14.

\section{Smith 2016}

Smith SM, Wallace E, O'Dowd T, Fortin M. Interventions for improving outcomes in patients with multimorbidity in primary care and community settings. Cochrane Database of Systematic Reviews 2016, Issue 3. Art. No.: CD006560 DOI: 10.1002/14651858.CD006560.pub3.

\section{Spinewine 2007a}

Spinewine A, Schmader KE, Barber N, Hughes C, Lapane KL, Swine C, et al. Appropriate prescribing in elderly people: How well can it be measured and optimised? Lancet 2007;370(9582):173-84.

\section{Steinman 2007}

Steinman MA. Polypharmacy and the balance of medication benefits and risks. American Journal of Geriatric Pharmacotherapy 2007;5(4):314-5.

\section{Stewart 1990}

Stewart RB. Polypharmacy in the elderly: a fait accompli? Drug Intelligence and Clinical Pharmacy 1990;24(3):321-3.

\section{Stewart 2017}

Stewart D, Mair A, Wilson M, Kardas P, Lewek P, Alonso A, et al. Guidance to manage inappropriate polypharmacy in older people: systematic review and future developments. Expert Opinion on Drug Safety 201 7; 16(2):203-13.

\section{Wells 2012}

Wells M, Williams B, Treweek S, Coyle J, Taylor J. Intervention description is not enough: Evidence from an in-depth multiple case study on the untold role and impact of context in randomised controlled trials of seven complex interventions. Trials 2012;13:95.

\section{Wenger 2001}

Wenger NS, Shekelle PG. Assessing care of vulnerable elders: ACOVE project overview. Annals Internal Medicine 2001; 135(8 Pt 2):642-6.

\section{Werder 2003}

Werder SF, Preskorn SH. Managing polypharmacy. Walking the fine line between help and harm. Current Psychiatry 2003; 2(2):24-36.

\section{Williamson 2017}

Williamson PR, Altman DG, Bagley H, Barnes KL, BlazebyJM, Brookes ST, et al. The COMET Handbook: version 1.0. Trials 2017;18(3):280.

\section{Other published versions of this review}


PattersonSM, Hughes C, Kerse N, Cardwell CR. Interventions to improve the appropriate use of polypharmacy for older people. Cochrane Database of Systematic Reviews 2009, Issue 4. Art. No.: CD008165 DOI: 10.1002/14651858.CD008165.

\section{Patterson 2012}

Patterson SM, Hughes C, Kerse N, Cardwell CR, Bradley MC. Interventions to improve the appropriate use of polypharmacy for older people. Cochrane Database of Systematic Reviews 2012, Issue 5. Art. No.: CD008165 DOI: 10.1002/14651858.CD008165.pub2.

\section{Patterson 2014}

PattersonSM, Cadogan CA, Kerse N, Cardwell CR, BradleyMC, Ryan C, et al. Interventions to improve the appropriate use of polypharmacy for older people. Cochrane Database ofSystematic Reviews 2014, Issue 10. Art. No.: CD008165 DOI: 10.1002/14651858.CD008165.pub3.

\section{Classification pending references}

\section{Data and analyses}

\section{Postintervention analysis}

\begin{tabular}{|c|c|c|c|c|}
\hline Outcome or Subgroup & Studies & Partıcıpants & Statıstıcal IMethod & Ettect Estımate \\
\hline $\begin{array}{l}\text { 1.1 Medication appropriateness (as } \\
\text { measured by an implicit tool) }\end{array}$ & 5 & 517 & $\begin{array}{l}\text { Mean Difference(IV, Random, 95\% } \\
\text { CI) }\end{array}$ & $-4.76[-9.20,-0.33]$ \\
\hline $\begin{array}{l}1.2 \text { Medication appropriateness (as } \\
\text { measured by an implicit tool) (excl } \\
\text { Crotty 2004a) }\end{array}$ & 4 & 446 & $\begin{array}{l}\text { Mean Difference(IV, Random, 95\% } \\
\text { CI) }\end{array}$ & $-5.16[-11.04,0.72]$ \\
\hline $\begin{array}{l}1.3 \text { Medication appropriateness (as } \\
\text { measured by an implicit tool) (excl } \\
\text { Crotty } 2004 \text { a and Spinewine } 2007 \text { ) }\end{array}$ & 3 & 260 & $\begin{array}{l}\text { Mean Difference(IV, Random, 95\% } \\
\mathrm{Cl})\end{array}$ & $-0.50[-2.27,1.28]$ \\
\hline $\begin{array}{l}1.4 \text { The number of potentially } \\
\text { inappropriate medications }\end{array}$ & 7 & 1832 & $\begin{array}{l}\text { Std. Mean Difference(IV, Random, } \\
95 \% \mathrm{Cl})\end{array}$ & $-0.22[-0.38,-0.05]$ \\
\hline $\begin{array}{l}1.5 \text { The proportion of patients with } \\
\text { one or more potentially inappropriate } \\
\text { medications }\end{array}$ & 11 & 3079 & Risk Ratio(M-H, Random, 95\% Cl) & $0.79[0.61,1.02]$ \\
\hline $\begin{array}{l}\text { 1.6 The proportion of patients with } \\
\text { one or more potentially inappropriate } \\
\text { medications (excl Spinewine } 2007)\end{array}$ & 10 & 2893 & Risk Ratio(M-H, Random, 95\% Cl) & $0.79[0.61,1.02]$ \\
\hline $\begin{array}{l}1.7 \text { The proportion of patients with } \\
\text { one or more potentially inappropriate } \\
\text { medications (exclSpinewine } 2007 \\
\text { and Gallagher } 2011)\end{array}$ & 9 & 2535 & Risk Ratio(M-H, Random, 95\% Cl) & $0.88[0.72,1.09]$ \\
\hline $\begin{array}{l}1.8 \text { The number of potential } \\
\text { prescribing omissions }\end{array}$ & 2 & 569 & $\begin{array}{l}\text { Std. Mean Difference(IV, Random, } \\
95 \% \mathrm{CI})\end{array}$ & $-0.81[-0.98,-0.64]$ \\
\hline $\begin{array}{l}1.9 \text { The proportion of patients with } \\
\text { one or more potential prescribing } \\
\text { omissions }\end{array}$ & 5 & 1310 & Risk Ratio(M-H, Random, 95\% Cl) & $0.40[0.18,0.85]$ \\
\hline
\end{tabular}

\section{Figures}

\section{Figure 1}


Interventions to improve the appropriate use of polypharmacy for older people

\section{2 studies included in previous version of review (Patterson 2014)}

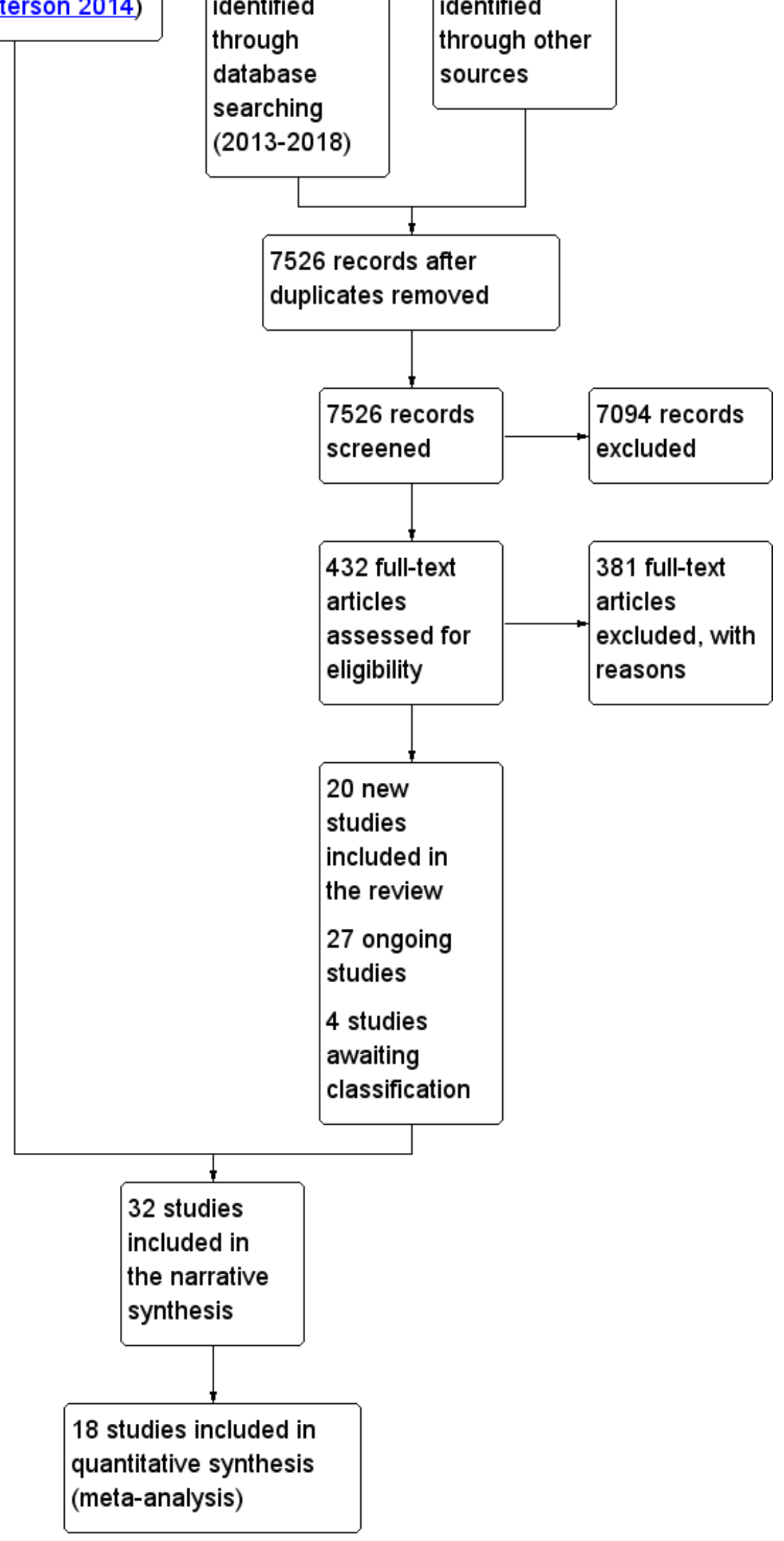

11 additional records identified through other 11,938 records identified through database searching 013-2018)

7526 records after plicates removed

20 new studies included in 4 studies awaiting 
Interventions to improve the appropriate use of polypharmacy for older people

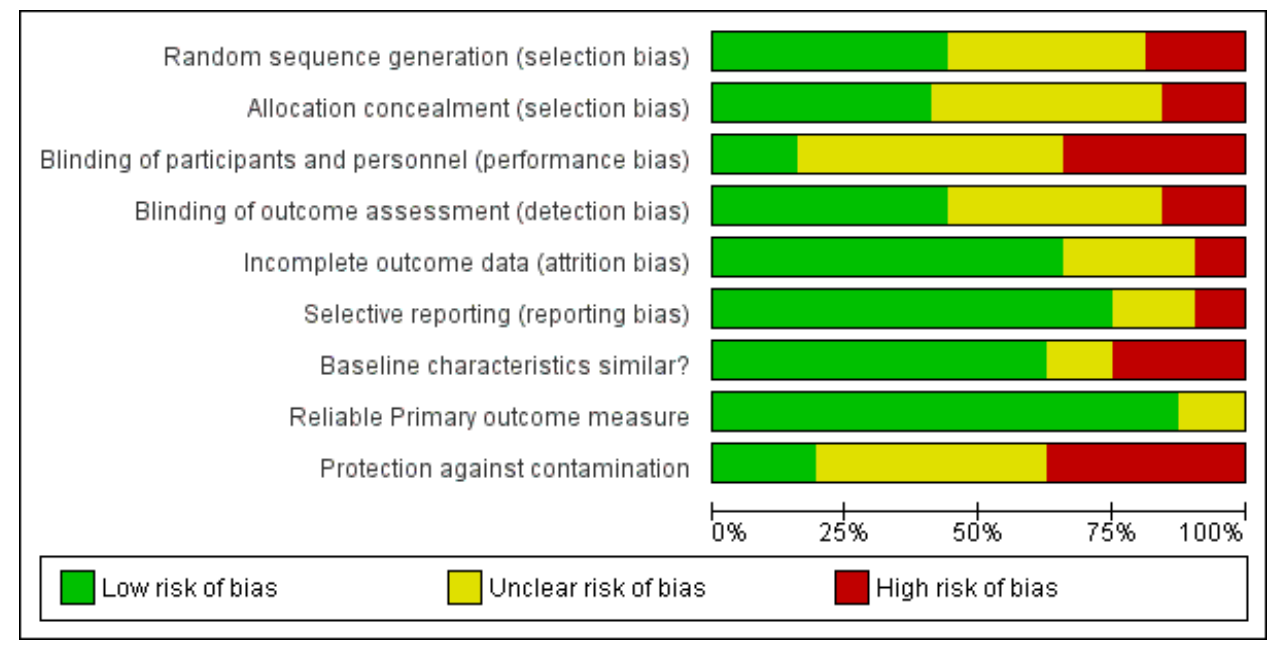

\section{Caption}

'Risk of bias' graph: review authors' judgements about each risk of bias item presented as percentages across all included studies.

\section{Figure 3}

\begin{tabular}{|c|c|c|c|c|c|c|c|c|c|}
\hline & 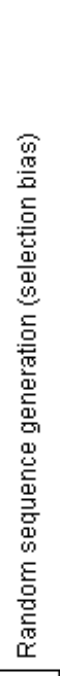 & 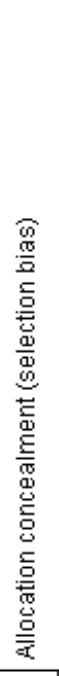 & 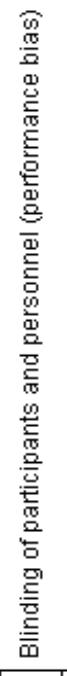 & 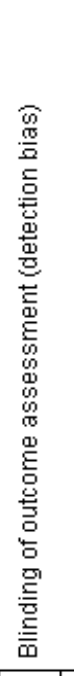 & 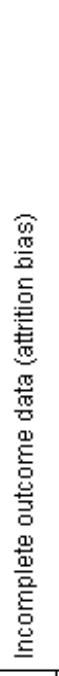 & 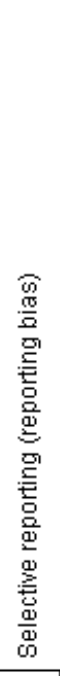 & 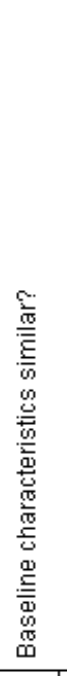 & 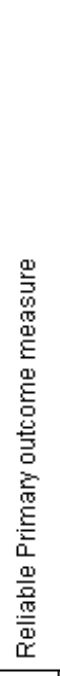 & 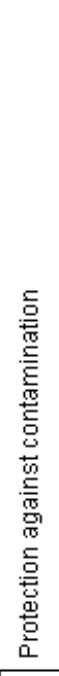 \\
\hline Basger 2015 & $?$ & $?$ & $\theta$ & $?$ & $\Theta$ & $\odot$ & $\odot$ & $\odot$ & $?$ \\
\hline Bladh 2011 & $?$ & $\odot$ & $?$ & $?$ & $\odot$ & + & $?$ & $\odot$ & - \\
\hline Bucci 2003 & $\odot$ & $?$ & $?$ & $\odot$ & + & + & $\odot$ & $\odot$ & $\odot$ \\
\hline Campins 2017 & $\odot$ & $\odot$ & $\theta$ & $\theta$ & $\odot$ & $\odot$ & $\odot$ & $\odot$ & $\theta$ \\
\hline Chiu 2018 & $\odot$ & $\odot$ & $\ominus$ & $\Theta$ & $?$ & + & $\odot$ & $\odot$ & $\odot$ \\
\hline Clyne 2015 & $\odot$ & $\odot$ & - & $\odot$ & $\odot$ & + & $\odot$ & $\odot$ & + \\
\hline Crotty 2004a & $\odot$ & $\odot$ & $?$ & $?$ & $\odot$ & + & $?$ & $\odot$ & + \\
\hline Crotty $2004 \mathrm{~b}$ & $\odot$ & $\odot$ & $?$ & $\odot$ & $\odot$ & $?$ & $\odot$ & $\odot$ & $\theta$ \\
\hline Dalleur 2014 & $?$ & $?$ & $?$ & + & $?$ & $?$ & $\odot$ & $\odot$ & $?$ \\
\hline Franchi 2016 & $?$ & $?$ & - & $\odot$ & $\odot$ & + & $\odot$ & $\odot$ & $?$ \\
\hline Frankenthal 2014 & $?$ & $\odot$ & $\theta$ & + & $\odot$ & + & + & $\odot$ & $?$ \\
\hline Fried 2017 & $?$ & $?$ & $?$ & $?$ & $?$ & + & + & $?$ & $?$ \\
\hline Gallagher 2011 & $\odot$ & $\odot$ & - & $\odot$ & $\odot$ & + & $\odot$ & $\odot$ & $?$ \\
\hline Garcia-Gollarte 2014 & $\odot$ & $?$ & $\odot$ & $?$ & $?$ & + & $\odot$ & $\odot$ & $?$ \\
\hline Haag 2016 & $\odot$ & $\odot$ & 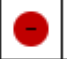 & $\odot$ & $\odot$ & + & $\odot$ & $\odot$ & $\odot$ \\
\hline Hanlon 1996 & $\odot$ & $?$ & $?$ & $\odot$ & $\odot$ & $?$ & $\odot$ & $\odot$ & 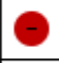 \\
\hline Koberlein-Neu 2016 & $?$ & $\odot$ & $?$ & $\Theta$ & $?$ & $\theta$ & $\Theta$ & $\odot$ & $\odot$ \\
\hline
\end{tabular}


Interventions to improve the appropriate use of polypharmacy for older people

\begin{tabular}{|c|c|c|c|c|c|c|c|c|c|}
\hline Michalek 2014 & - & + & + & $?$ & + & + & + & + & + \\
\hline Milos 2013 & $\odot$ & + & $?$ & $?$ & $\oplus$ & + & $\oplus$ & $\oplus$ & $?$ \\
\hline Muth 2016 & $?$ & $?$ & $?$ & + & $\odot$ & $\odot$ & $?$ & $\odot$ & $?$ \\
\hline Muth 2018 & $\odot$ & $\odot$ & $\odot$ & $?$ & $?$ & $\odot$ & $\odot$ & $\odot$ & + \\
\hline Olsson 2012 & $?$ & $?$ & + & $?$ & 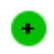 & $\odot$ & + & 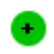 & $?$ \\
\hline Pitkala 2014 & + & + & $\oplus$ & + & $\odot$ & $\odot$ & $\odot$ & $\odot$ & + \\
\hline Schmader 2004 & $\odot$ & - & $?$ & $\odot$ & $?$ & $\odot$ & $\odot$ & $?$ & $?$ \\
\hline Spinewine 2007 & $?$ & $\odot$ & $\odot$ & $\odot$ & $\odot$ & $\odot$ & $\odot$ & 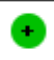 & - \\
\hline Tamblyn 2003 & $?$ & $?$ & $?$ & + & $\odot$ & 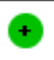 & $?$ & $?$ & $?$ \\
\hline Taylor 2003 & $?$ & $?$ & $?$ & $?$ & 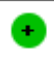 & $\odot$ & + & $?$ & - \\
\hline Thyrian 2017 & + & $?$ & $\odot$ & $\odot$ & $\odot$ & $\odot$ & 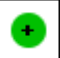 & + & + \\
\hline Trygstad 2005 & - & $?$ & $?$ & $?$ & $\odot$ & $?$ & $\odot$ & $\odot$ & $?$ \\
\hline Trygstad 2009 & $\odot$ & $?$ & $?$ & $?$ & $?$ & $?$ & $\odot$ & $\odot$ & $?$ \\
\hline Van der Linden 2017 & ค & - & $?$ & $?$ & $\odot$ & $\odot$ & 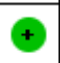 & $\oplus$ & \\
\hline Wehling 2016 & & + & $\odot$ & $\odot$ & $\odot$ & $\odot$ & $\odot$ & $\odot$ & \\
\hline
\end{tabular}

\section{Caption}

'Risk of bias' summary: review authors' judgements about each 'Risk of bias' item for each included study.

Figure 4 (Analysis 1.1)

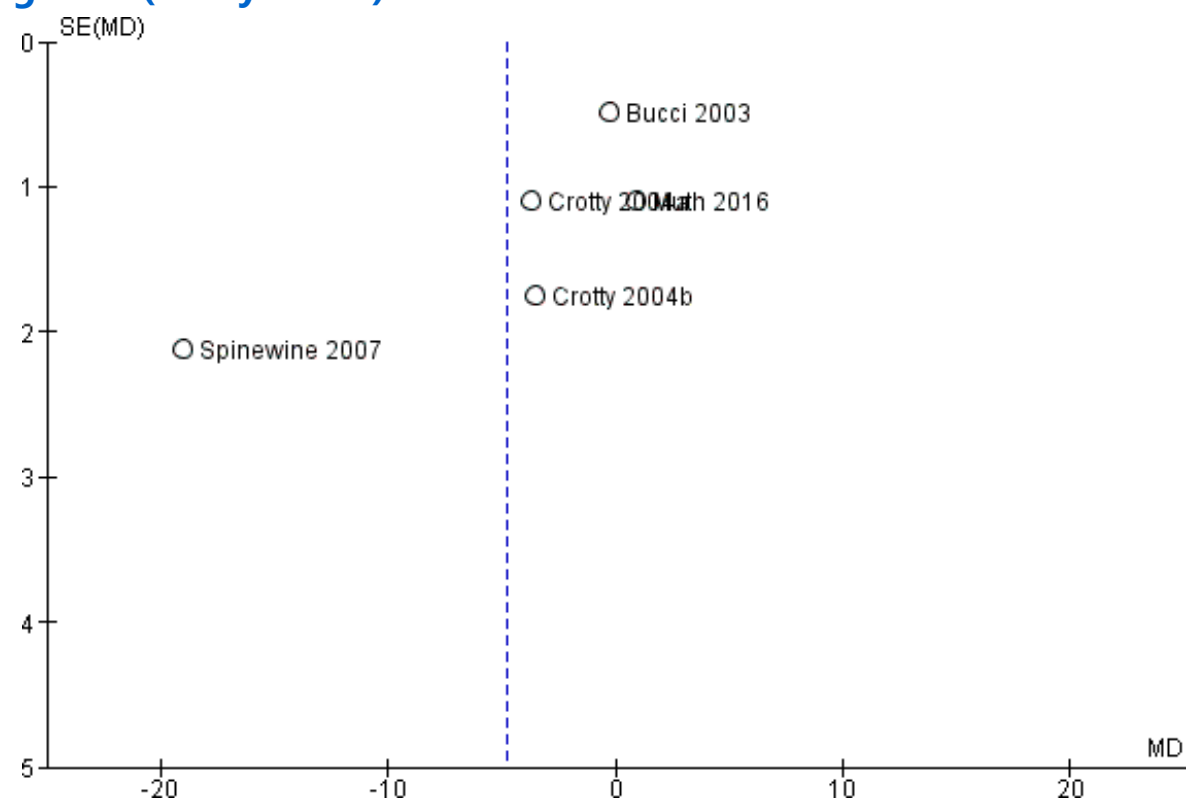

Caption

Funnel plot of comparison: 1 Postintervention analysis, outcome: 1.1 Medication appropriateness (as measured by an implicit tool).

Figure 5 (Analysis 1.4) 


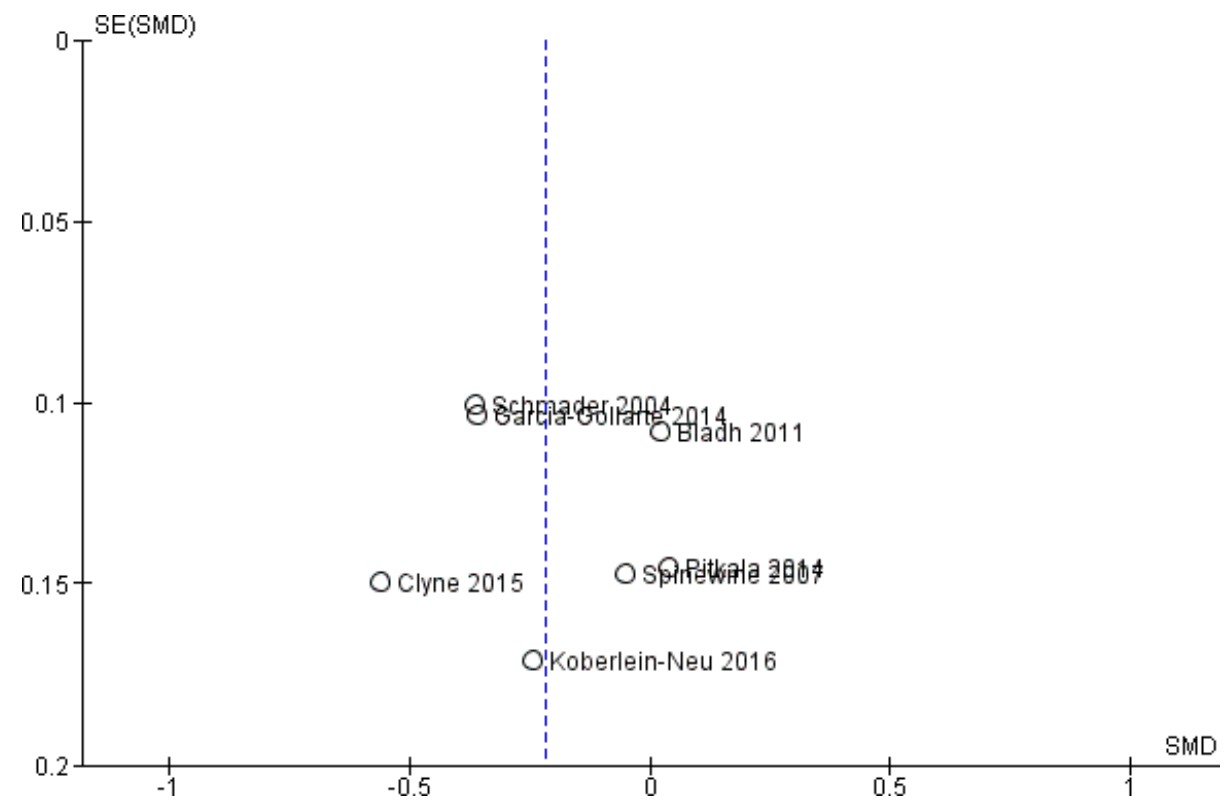

Caption

Funnel plot of comparison: 1 Postintervention analysis, outcome: 1.4 The number of potentially inappropriate medications.

\section{Figure 6 (Analysis 1.5)}

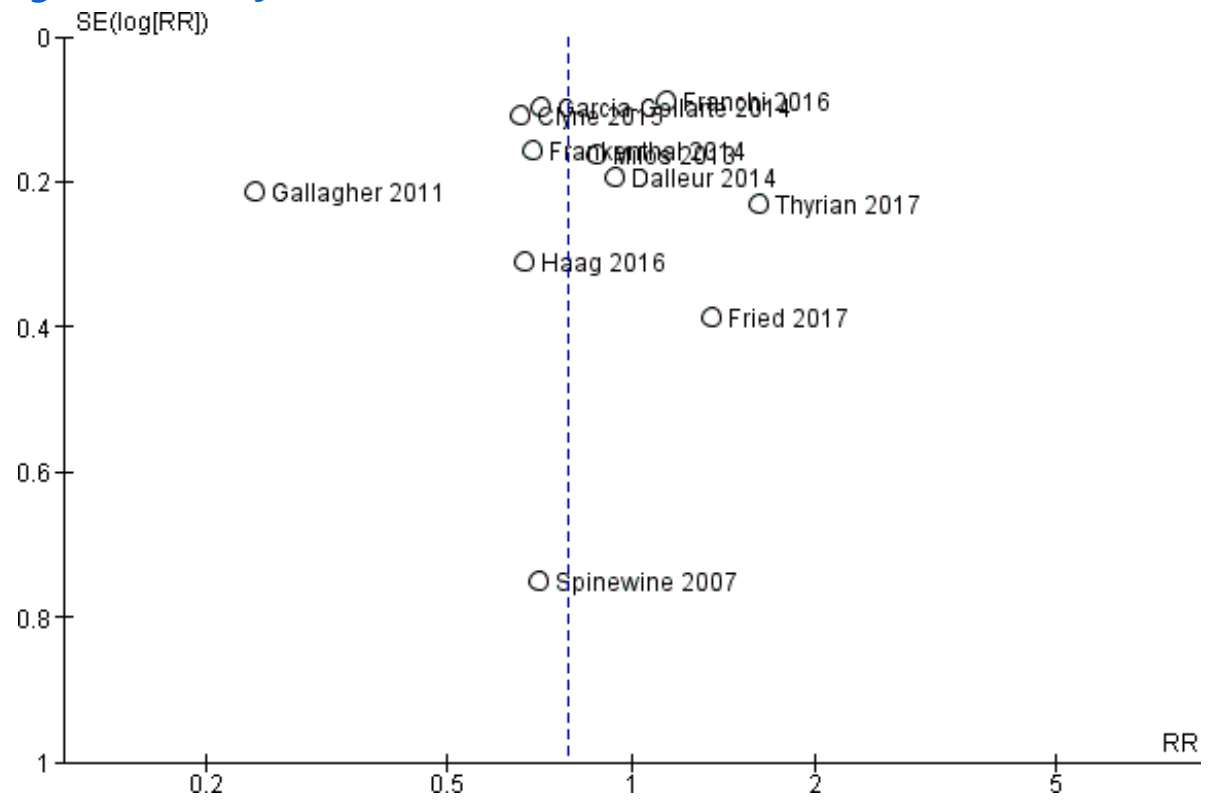

\section{Caption}

Funnel plot of comparison: 1 Postintervention analysis, outcome: 1.5 The proportion of patients with one or more potentially inappropriate medications.

\section{Sources of support}

\section{Internal sources}

- Queen's University Belfast, School of Pharmacy, UK

\section{External sources}

- Research and Development Office, Northern Ireland, UK

Fellowship awarded to Dr. Susan Patterson to undertake the original review for 2 years, 2 days per week

- The Dunhill Medical Trust, London, UK

A grant from the Dunhill Medical Trust supported Dr. Cathal Cadogan to undertake an update of the original review [grant number: R298/0513]

- The Health Research Board (HRB) Centre for Primary Care Research, Royal College of Surgeons in Ireland (RCSI), Dublin, Ireland

A grant from the HRB Centre for Primary Care Research supported Dr. Audrey Rankin to undertake an update of the 
Interventions to improve the appropriate use of polypharmacy for older people

original review [grant number: HRC/2014/1]

\section{Feedback}

\section{Appendices}

\section{The Medication Appropriateness Index (MAI) and the Beers criteria}

The MAI was designed to assist physicians and pharmacists in assessing the appropriateness of a medication for a given patient. The MAI requires clinicians to rate 10 explicit criteria to determine whether a given medication is appropriate for an individual. For each criterion, the index has operational definitions, explicit instructions and examples, and the evaluator rates whether the particular medication is "appropriate," "marginally appropriate" or "inappropriate" (Table 1).

The 10 explicit criteria are:

1. Indication: the sign, symptom, disease or condition for which the medication is prescribed.

2. Effectiveness: producing a $\neg$ beneficial result.

3. Dosage: total amount of medication taken per 24-hour period.

4. Directions: instructions to the patient for proper use of a medication.

5. Practicality: capability of being used or being put into practice.

6. Drug-drug interaction: the effect that administration of one medication has on another drug; clinical significance connotes a harmful interaction.

7. Drug-disease interaction: the effect that the drughas on a pre-existing disease or condition; clinical significance connotes a harmful interaction.

8. Unnecessaryduplication: non-beneficial or risky prescribing of two or more drugs from the same chemical or pharmacological class.

9. Duration: length of therapy.

10. Expensiveness: cost of drug in comparison with other agents of equal efficacy and safety.

These are measured on a 3-point scale (Table 1).

Toassess the effects of the interventions on prescribing appropriateness, patient MAI scores may be determined by summing MAI medication scores across all evaluated medications. Thus, this patient MAl score depends on the number of medications taken by the patient and the MAI score per medication.

Furthermore, to determine a single summated score for each drug, in addition to an overall score for the patient, a weighting scheme was developed. A weight of three was given for indication and effectiveness. A weight of two was assigned to dosage, correct directions, drug-drug interactions and drug-disease interactions. A weight of one was assigned to practical directions, expense, duplication and duration.

The Beers criteria are consensus explicit criteria used to enhance safe medication use in older adults when precise clinical information is lacking (see Table 2; Table 3; Table 4; Table 5; Table 6). The Beers criteria are based on expert consensus developed through an extensive literature review with a bibliography and a questionnaire evaluated by nationally recognised experts in geriatric care, clinical pharmacology and psychopharmacology using a modified Delphi technique to reach consensus. These criteria have been used to survey clinical medication usage, to analyse computerised administrative data sets and to evaluate intervention studies to decrease medication problems in older adults.

The most recent version of Beers criteria (AGS2012) comprises three lists. The first list comprises 34 individual medications or classes of medications that should be avoided in older adults and their concerns (Table 4). The second list includes diseases or conditions and drugs that should be avoided in older adults with these conditions (Table 5).

The third list provides medications to be used with caution in older adults (Table 6). The statements in each list are rated on the basis of quality of evidence and the strength of recommendations using the American College of Physicians' Guideline Grading System.

\section{Search strategies 2016}

\section{MEDLINE (Ovid)}

Epub Ahead of Print, In-Process \& Other Non-Indexed Citations, Ovid MEDLINE Daily and Ovid MEDLINE 1946 to Present Search date: 5 May 2016

\begin{tabular}{|r|r|}
\hline 1 polypharmacy/ & 2956 \\
\hline \hline 2 inappropriate prescribing/ & 1360 \\
\hline \hline 3 potentially inappropriate medication list/ & 20 \\
\hline 4 deprescriptions/ & 10 \\
\hline \hline 5 medication errors/ & 11203 \\
\hline \hline 6 polypharma*.ti,ab. & 4661 \\
\hline \hline & ((beer* or shan? or mcleod?) adj3 criter*).ti,ab. \\
\hline
\end{tabular}




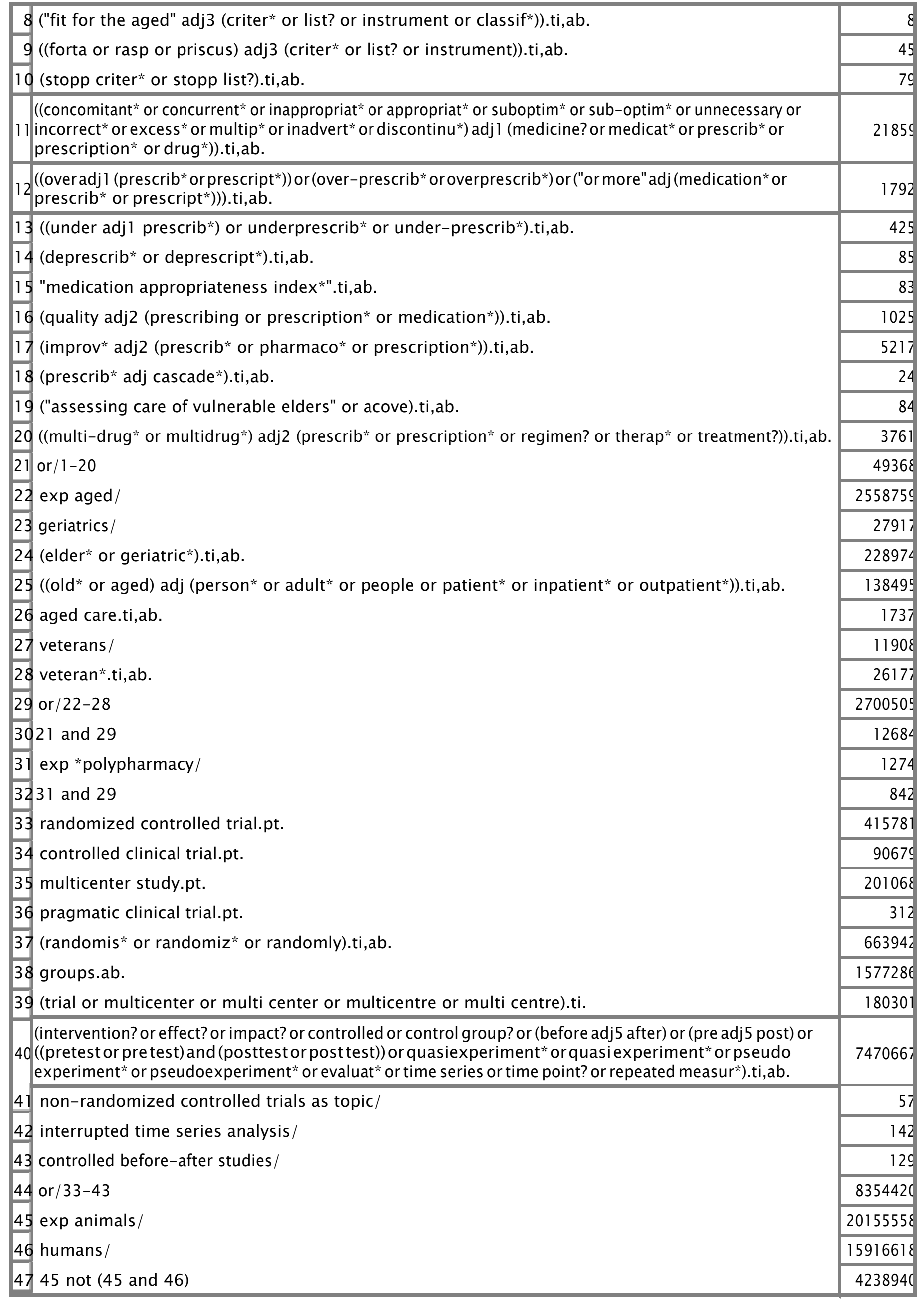




\begin{tabular}{|l|r|}
\hline 48 review.pt. & 211498 \\
\hline 49 meta analysis.pt. & 65371 \\
\hline 50 news.pt. & 176496 \\
\hline 51 comment.pt. & 662585 \\
\hline 52 editorial.pt. & 402997 \\
\hline 53 cochrane database of systematic reviews.jn. & 12298 \\
\hline 54 comment on.cm. & 662586 \\
\hline 55 (systematic review or literature review).ti. & 76420 \\
\hline 56 or/47-55 & 7298360 \\
\hline 5744 not 56 & 5788963 \\
\hline 5830 and 57 & 6760 \\
\hline 5932 or 58 & 7209 \\
\hline 60 (20131* or $2014 *$ or $2015^{*}$ or $\left.2016 *\right) . d c, d p, e d, e p, y r$. & 352815 \\
\hline 6159 and 60 & 1876 \\
\hline
\end{tabular}

\section{Embase (Ovid)}

Embase 1974 to 2016 May 04

Search date: 5 May 2016

\begin{tabular}{|c|c|}
\hline 1 polypharmacy/ & 9311 \\
\hline 2 inappropriate prescribing/ & 2174 \\
\hline 3 medication error/ & 14470 \\
\hline 4 polypharma*.ti,ab. & 7297 \\
\hline 5 ((beer* or shan? or mcleod?) adj3 criter*).ti,ab. & 692 \\
\hline 6 ("fit for the aged" adj3 (criter* or list? or instrument or classif*)).ti,ab. & 13 \\
\hline 7 ((forta or rasp or priscus) adj3 (criter* or list? or instrument)).ti,ab. & 79 \\
\hline 8 (stopp criter* or stopp list?).ti,ab. & 194 \\
\hline $\begin{array}{l}\text { ((concomitant* or concurrent* or inappropriat* or appropriat* or suboptim* or sub-optim* or unnecessary or } \\
9 \text { incorrect* or excess" or multip* or inadvert* or discontinu*) adj } 1 \text { (medicine? or medicat* or prescrib* or } \\
\text { prescription* or drug*)).ti,ab. }\end{array}$ & 33028 \\
\hline $\begin{array}{l}10((\text { overadj } 1 \text { (prescrib* or prescript*)) or (over-prescrib* or overprescrib*) or ("or more" adj (medication*or } \\
\text { prescrib* or prescript*))).ti,ab. }\end{array}$ & 2678 \\
\hline 11 ((under adj 1 prescrib*) or underprescrib* or under-prescrib*).ti,ab. & 601 \\
\hline 12 (deprescrib* or deprescript*).ti,ab. & 108 \\
\hline 13 "medication appropriateness index*".ti,ab. & 125 \\
\hline 14 (quality adj2 (prescribing or prescription* or medication*)).ti,ab. & 1614 \\
\hline 15 (improv* adj2 (prescrib* or pharmaco* or prescription*)).ti,ab. & 7311 \\
\hline 16 (prescrib* adj cascade*).ti,ab. & 32 \\
\hline 17 ("assessing care of vulnerable elders" or acove).ti,ab. & 131 \\
\hline 18 ((multi-drug* or multidrug*) adj2 (prescrib* or prescription* or regimen? or therap* or treatment?)).ti,ab. & 4674 \\
\hline 19 or $/ 1-18$ & 72518 \\
\hline 20 aged/ & 2406413 \\
\hline 21 frail elderly/ & 7267 \\
\hline 22 very elderly/ & 87611 \\
\hline 23 aged hospital patient/ & 557 \\
\hline 24 veteran/ & 14932 \\
\hline
\end{tabular}


Interventions to improve the appropriate use of polypharmacy for older people

\begin{tabular}{|c|c|c|}
\hline & exp geriatrics/ & 46527 \\
\hline 26 & (elder* or geriatric*).ti,ab. & 313574 \\
\hline 27 & $(($ old* or aged) adj (person* or adult* or people or patient* or inpatient* or outpatient*)).ti,ab. & 178986 \\
\hline 28 & aged care.ti,ab. & 1777 \\
\hline 29 & veteran*.ti,ab. & 31673 \\
\hline 30 & or $/ 20-29$ & 2618872 \\
\hline 31 & *polypharmacy/ & 2108 \\
\hline 32 & 30 and 31 & 1082 \\
\hline 33 & 19 and 30 & 16095 \\
\hline 34 & randomized controlled trial/ & 402955 \\
\hline 35 & controlled clinical trial/ & 393267 \\
\hline 36 & quasi experimental study/ & 2895 \\
\hline 37 & pretest posttest control group design/ & 254 \\
\hline 38 & time series analysis / & 16880 \\
\hline 39 & experimental design/ & 12369 \\
\hline 40 & multicenter study/ & 136615 \\
\hline 41 & (randomis* or randomiz* or randomly).ti,ab. & 879958 \\
\hline 42 & groups.ab. & 2061105 \\
\hline 43 & (trial or multicentre or multicenter or multi centre or multi center).ti. & 24386 \\
\hline & $\begin{array}{l}\text { (intervention? or effect? or impact? or controlled or control group? or (before adj } 5 \text { after) or (pre adj5 post) or } \\
\text { ((pretest or pre test) and (posttest or post test)) or quasiexperiment* or quasi experiment* or pseudo } \\
\text { experiment* or pseudoexperiment* or evaluat* or time series or time point? or repeated measur*).ti,ab. }\end{array}$ & 931123 \\
\hline 45 & or/34-44 & 10393792 \\
\hline 46 & (systematic review or literature review).ti. & 89371 \\
\hline 47 & "cochrane database of systematic reviews".jn. & 3951 \\
\hline 48 & $\begin{array}{l}\text { exp animals / or exp invertebrate / or animal experiment/ or animal model/ or animal tissue / or animal cell/ or } \\
\text { nonhuman/ }\end{array}$ & 23072412 \\
\hline 49 & human/ or normal human/ or human cell/ & 17208417 \\
\hline 50 & 48 not (48 and 49$)$ & 591075 \\
\hline 51 & 46 or 47 or 50 & 6003257 \\
\hline 52 & 45 not 51 & 7854630 \\
\hline 53. & 33 and 52 & 10126 \\
\hline 54 & 32 or 53 & 10609 \\
\hline 55 & $\left(20131^{*}\right.$ or $2014^{*}$ or $2015^{*}$ or $\left.2016^{*}\right) \cdot d p, d d, y r, e m$. & 4637633 \\
\hline & 54 and 55 & 3269 \\
\hline
\end{tabular}

\section{The Cochrane Library (Wiley)}

Search date: 5 May 2016 
Interventions to improve the appropriate use of polypharmacy for older people

\begin{tabular}{|c|c|c|}
\hline$\# 1$ & [mh polypharmacy] & 126 \\
\hline$\# 2$ & [mh "inappropriate prescribing"] & 71 \\
\hline \#3 & [mh "potentially inappropriate medication list"] & 0 \\
\hline \#4 & [mh deprescriptions] & 0 \\
\hline \#5 & [mh "medication errors"] & 331 \\
\hline \#6 & polypharma*:ti,ab & 234 \\
\hline$\# 7$ & $(($ beer* or shan* or mcleod*) near/3 criter*):ti,ab & 23 \\
\hline$\# 8$ & ("fit for the aged" near/3 (criter* or list* or instrument or classif*)):ti,ab & 1 \\
\hline$\# 9$ & $(($ forta or rasp or priscus) near $/ 3$ (criter* or list* or instrument)):ti,ab & 5 \\
\hline$\# 10$ & (stopp criter* or stopp list*):ti,ab & 24 \\
\hline$\# 11$ & $\begin{array}{l}((\text { concomitant* or concurrent* or inappropriat* or appropriat* or suboptim* or sub-optim* or unnecessary or } \\
\text { incorrect*or excess*or multip* or inadvert*or discontinu*) near } / 1 \text { (medicine* or medicat*or prescrib* or } \\
\text { prescription* or drug*)):ti,ab }\end{array}$ & 2379 \\
\hline$\# 12$ & $\begin{array}{l}((\text { over near } / 1(\text { prescrib* or prescript*)) or (over-prescrib* or overprescrib*) or ("or more" near } / 1 \text { (medication* or } \\
\text { prescrib* or prescript*))):ti,ab }\end{array}$ & 154 \\
\hline$\# 13$ & ((under near $/ 1$ prescrib*) or underprescrib* or under-prescrib*):ti,ab & 20 \\
\hline$\# 14$ & (deprescrib* or deprescript*):ti,ab & 6 \\
\hline$\# 15$ & (quality near/2 (prescribing or prescription* or medication*)):ti,ab & 151 \\
\hline$\# 16$ & (improv* near/2 (prescrib* or pharmaco* or prescription*)):ti,ab & 476 \\
\hline$\# 17$ & (prescri* near/1 cascade*):ti,ab & 0 \\
\hline \#18 & ("assessing care of vulnerable elders" or acove):ti,ab & 10 \\
\hline$\# 19$ & $(($ multi-drug*or multidrug*) near/2 (prescrib* or prescription*or regimen*or therap*or treatment*)):ti,ab & 364 \\
\hline$\# 20$ & $\{$ or \#1-\#19\} & 3932 \\
\hline \#21 & [mh aged] & 993 \\
\hline$\# 22$ & [mh geriatrics] & 216 \\
\hline$\# 23$ & (elder* or geriatric*):ti,ab & 19391 \\
\hline \#24 & $(($ old* or aged) near/ 1 (person* or adult* or people or patient* or inpatient* or outpatient*)):ti,ab & 21045 \\
\hline \#25 & aged next care:ti,ab & 130 \\
\hline$\# 26$ & [mh veterans] & 614 \\
\hline$\# 27$ & veteran*:ti,ab & 2559 \\
\hline \#28 & $\{$ or \#21-\#27\} & 39695 \\
\hline \#29 & \#20 and \#28 Publication Year from 2013 to 2016 & 165 \\
\hline
\end{tabular}

\section{CINAHL (EBSCO)}

Search date: 5 May 2016

\begin{tabular}{|l|r|r|}
\hline No. & Search terms & Results \\
\hline S1 & (MH "Polypharmacy") & 1,832 \\
\hline S2 & (MH "Inappropriate Prescribing") & 491 \\
\hline S3 & (MH "Medication Errors") & 8,808 \\
\hline S4 & polypharma* & 2,376 \\
\hline S5 & (beer* or shan* or mcleod*) N3 criter* & 171 \\
\hline S6 & "fit for the aged" N3 (criter* or list* or instrument or classif*) & 3 \\
\hline S7 & (forta or rasp or priscus) N3 (criter* or list* or instrument) & 3 \\
\hline S8 & stopp criter* or stopp list* & 28 \\
\hline
\end{tabular}


Interventions to improve the appropriate use of polypharmacy for older people

\begin{tabular}{|c|c|c|}
\hline & $\begin{array}{l}\text { (concomitant* or concurrent* or inappropriat* or appropriat* or suboptim* or sub-optim* or unnecessary or } \\
\text { incorrect* or excess* or multip* or inadvert* or discontinu*) N1 (medicine* or medicat* or prescrib* or } \\
\text { prescription* or drug*) }\end{array}$ & 7,963 \\
\hline S10 & $\begin{array}{l}((\text { overN1 (prescrib*or prescript*)) or (over-prescrib* or overprescrib*) or ("or more" N0 (medication* or } \\
\text { prescrib* or prescript*))) }\end{array}$ & 1,551 \\
\hline S11 & (under N1 prescrib*) or underprescrib* or under-prescrib* & 107 \\
\hline S12 & deprescrib* or deprescript** & 28 \\
\hline 513 & "medication appropriateness index*" & 25 \\
\hline S14 & quality N2 (prescribing or prescription* or medication*) & 427 \\
\hline S15 & prescrib* N0 cascade* & 11 \\
\hline S16 & "assessing care of vulnerable elders" or acove & 44 \\
\hline S17 & $($ multi-drug* or multidrug*) N2 (prescrib* or prescription* or regimen* or therap* or treatment*) & 616 \\
\hline 518 & improv* N2 (prescrib* or pharmaco* or prescription*) & 1,003 \\
\hline S19 & $\begin{array}{l}\text { S1 OR S2 OR S3 OR S4 OR S5 OR S6 OR S7 OR S8 OR S9 OR S10 OR S1 } 1 \text { OR S12 OR S1 } 3 \text { OR S14 } \\
\text { OR S15 OR S16 OR S17 OR S18 }\end{array}$ & 21,470 \\
\hline S20 & $(\mathrm{MH}$ "Aged+") & 373,520 \\
\hline S21 & (MH "Geriatrics") & 2,766 \\
\hline S22 & (MH "Veterans") & 7,998 \\
\hline S23 & elder* or geriatric* & 74,995 \\
\hline S24 & (old* or aged) N0 (person* or adult* or people or patient* or inpatient* or outpatient*) & 57,731 \\
\hline S25 & "aged care" & 2,138 \\
\hline S26 & veteran* & 15,551 \\
\hline S27 & S20 OR S21 OR S22 OR S23 OR S24 OR S25 OR S26 & 415,048 \\
\hline S28 & S19 AND S27 & 5,108 \\
\hline S29 & (MM "Polypharmacy") & 765 \\
\hline$S 30$ & S27 AND S29 & 538 \\
\hline S31 & PT randomized controlled trial & 30,497 \\
\hline$S 32$ & PT clinical trial & 52,762 \\
\hline S33 & PT research & 988,005 \\
\hline S34 & (MH "Randomized Controlled Trials") & 26,240 \\
\hline S35 & (MH "Clinical Trials") & 84,279 \\
\hline$S 36$ & (MH "Intervention Trials") & 5,986 \\
\hline S37 & (MH "Nonrandomized Trials") & 170 \\
\hline S38 & (MH "Experimental Studies") & 14,818 \\
\hline S39 & (MH "Pretest-Posttest Design+") & 26,855 \\
\hline S40 & (MH "Quasi-Experimental Studies+") & 8,473 \\
\hline S41 & (MH "Multicenter Studies") & 11,426 \\
\hline S42 & (MH "Health Services Research") & 7,374 \\
\hline S43 & $\mathrm{TI}$ ( randomis* or randomiz* or randomly) OR AB (randomis* or randomiz* or randomly) & 111,004 \\
\hline S4 & 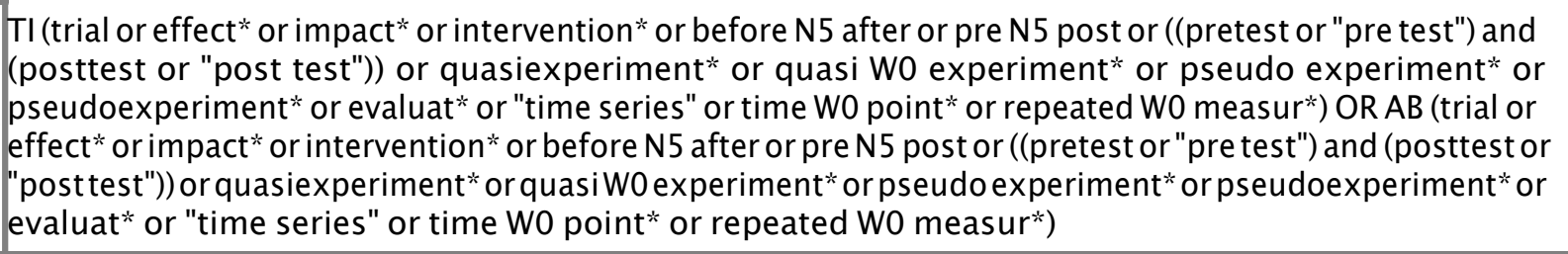 & 762,000 \\
\hline
\end{tabular}


Interventions to improve the appropriate use of polypharmacy for older people

\begin{tabular}{|l|r|r|}
\hline S45 S31 OR S32 OR S33 OR S34 OR S35 OR S36 OR S37 OR S38 OR S39 OR S40 OR S41 OR S42 OR S43 & $1,297,160$ \\
\hline S46 S44 & S28 AND S45 & 3,669 \\
\hline S47 S30 OR S46 & 3,901 \\
\hline S48 S47 Limiters - Exclude MEDLINE records & 726 \\
\hline S49 & S48 Limiters - Published Date: 20131001-20161231 & 141 \\
\hline
\end{tabular}

ClinicalTrials.gov, US National Institutes of Health (NIH) http://clinicaltrials.gov/

Search date: 5 May 2016

\begin{tabular}{|l|r|}
\hline polypharmacy | senior & 69 \\
\hline "inappropriate prescribing" | senior & 26 \\
\hline appropriate prescribing | senior & 5 \\
\hline "inappropriate medication" | senior & 30 \\
\hline "appropriate medication" | senior & 16 \\
\hline deprescribing | senior & 1 \\
\hline Total= & 147 \\
\hline
\end{tabular}

WHO International Clinical Trials Registry Platform (ICTRP)

Search date: 5 May 2016

\begin{tabular}{|l|r|}
\hline polypharmacy & 60 \\
\hline inappropriate prescribing & 11 \\
\hline appropriate prescribing & 6 \\
\hline inappropriate medication & 12 \\
\hline appropriate medication & 4 \\
\hline deprescribing & 6 \\
\hline Total= & 99 \\
\hline
\end{tabular}

\section{Search strategies 2018}

\section{MEDLINE (Ovid)}

Epub Ahead of Print, In-Process \& Other Non-Indexed Citations, Ovid MEDLINE Daily and Ovid MEDLINE 1946 to January 31,2018

Search date: 7 February 2018

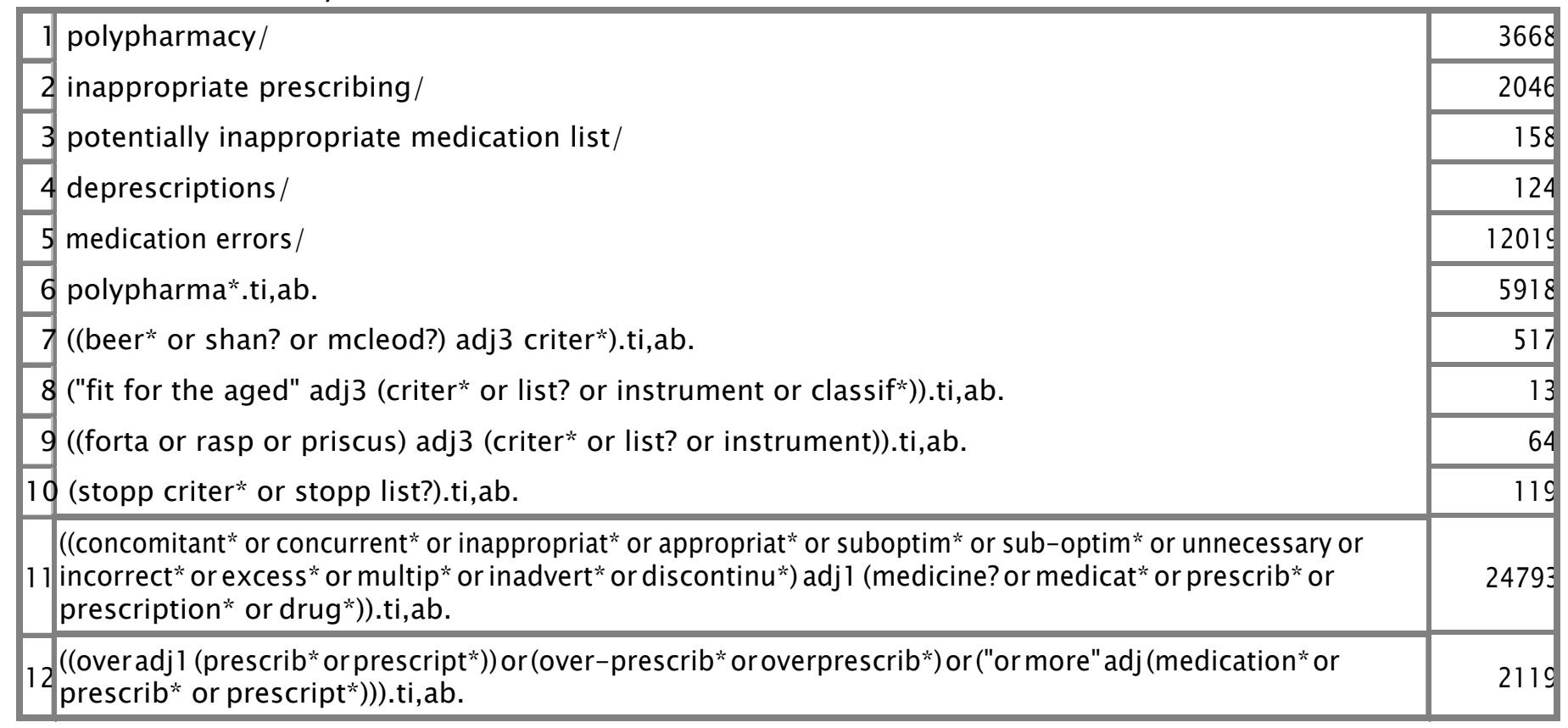




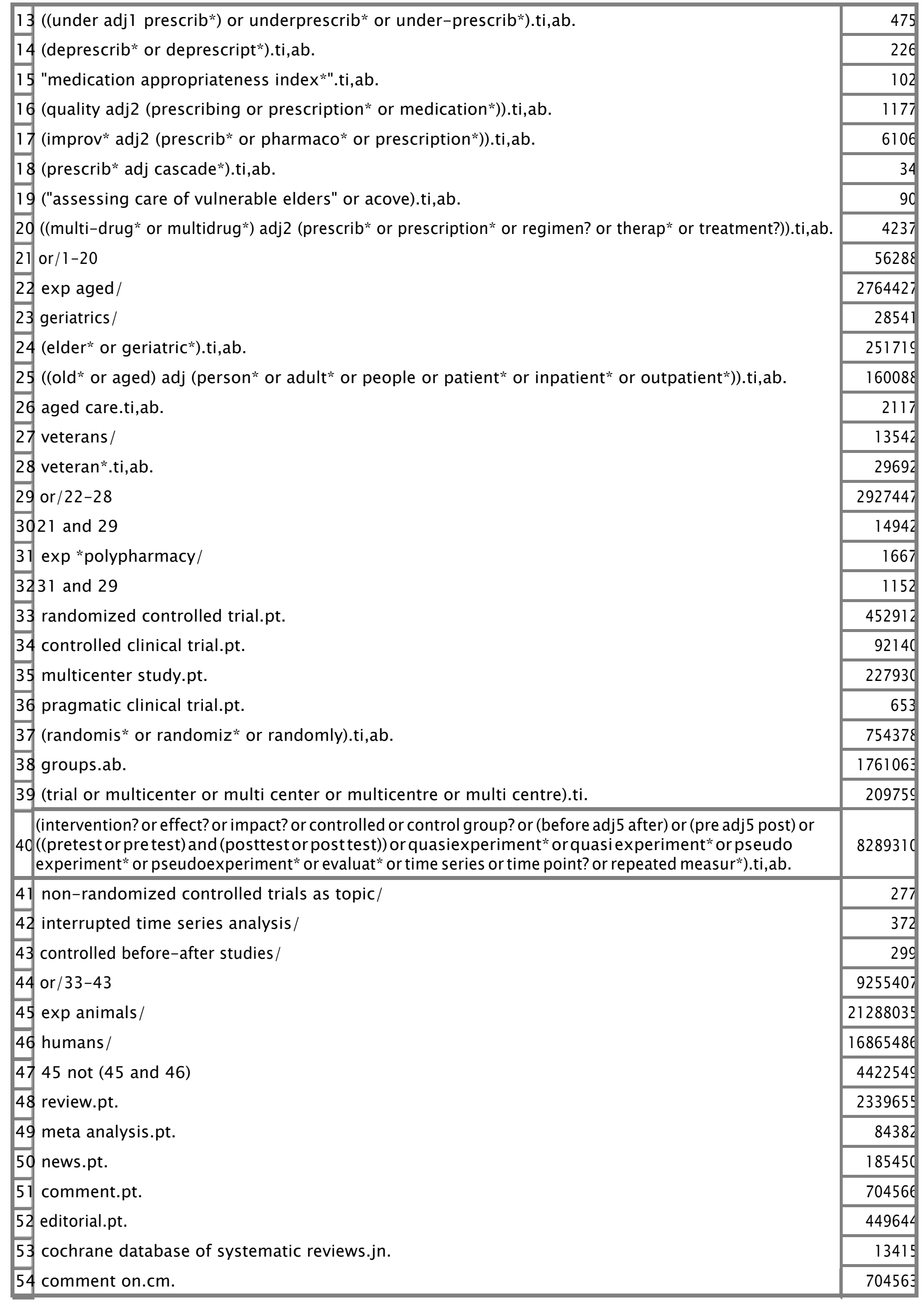




\begin{tabular}{|l|r|}
\hline 55 (systematic review or literature review).ti. & 105999 \\
\hline 56 or/47-55 & 7800161 \\
\hline 5744 not 56 & 6467868 \\
\hline 5830 and 57 & 8109 \\
\hline 5932 or 58 & 8711 \\
\hline 60 (2016* or $2017^{*}$ or $\left.2018^{*}\right) . d t, d p, e d, e p, y r$. & 3317707 \\
\hline 6159 and 60 & 2095 \\
\hline
\end{tabular}

\section{Embase (Ovid)}

Embase 1974 to 2018 February 6

Search date: 7 February 2018

\begin{tabular}{|c|c|c|}
\hline \multirow{31}{*}{\multicolumn{2}{|c|}{ 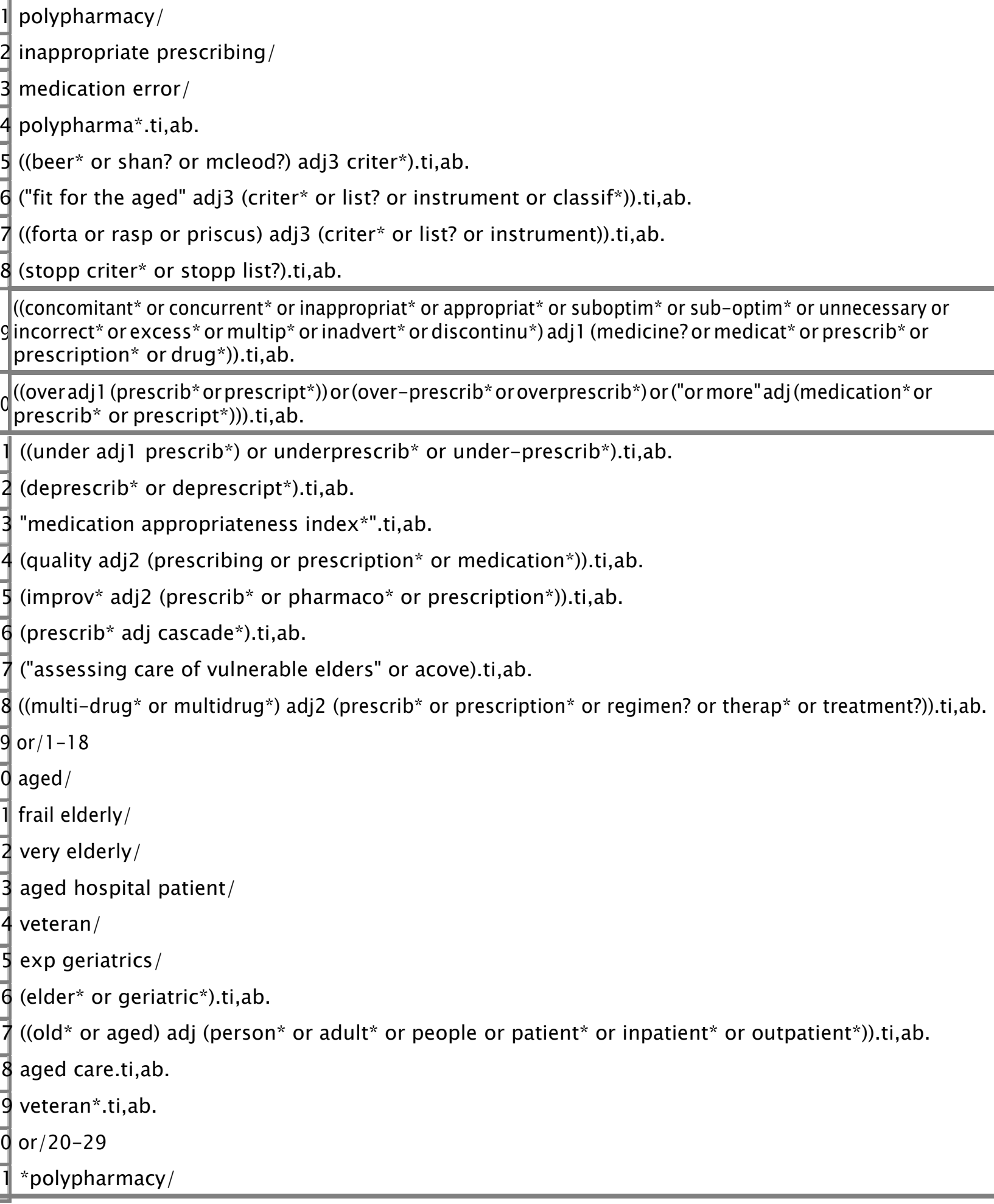 }} & \\
\hline & & \\
\hline & & \\
\hline & & \\
\hline & & \\
\hline & & \\
\hline & & \\
\hline & & \\
\hline & & \\
\hline & & \\
\hline & & \\
\hline & & \\
\hline & & \\
\hline & & \\
\hline & & \\
\hline & & \\
\hline & & \\
\hline & & \\
\hline & & \\
\hline & & \\
\hline & & \\
\hline & & 2502 \\
\hline & & \\
\hline & & \\
\hline & & \\
\hline & & \\
\hline & & \\
\hline & & \\
\hline & & \\
\hline & & \\
\hline & & \\
\hline
\end{tabular}


Interventions to improve the appropriate use of polypharmacy for older people

\begin{tabular}{|c|c|}
\hline 3230 and 31 & 1516 \\
\hline 3319 and 30 & 19946 \\
\hline 34 randomized controlled trial/ & 485990 \\
\hline 35 controlled clinical trial/ & $45422 \varepsilon$ \\
\hline 36 quasi experimental study/ & 4178 \\
\hline 37 pretest posttest control group design/ & 325 \\
\hline 38 time series analysis / & 20120 \\
\hline 39 experimental design/ & 15072 \\
\hline 40 multicenter study/ & 174951 \\
\hline 41 (randomis* or randomiz* or randomly).ti,ab. & 1034240 \\
\hline 42 groups.ab. & 2380261 \\
\hline 43 (trial or multicentre or multicenter or multi centre or multi center).ti. & 290689 \\
\hline $\begin{array}{l}44(\text { (intervention? or effect? or impact? or controlled or control group? or (before adj } 5 \text { after) or (pre adj } 5 \text { post) or } \\
\text { experiment or or pseudoexperiment" or evaluat"* or time series or time point? or repeated measur*).ti,ab. }\end{array}$ & 10531597 \\
\hline 45 or $/ 34-44$ & 11748867 \\
\hline 46 (systematic review or literature review).ti. & 124542 \\
\hline 47 "cochrane database of systematic reviews".jn. & 7188 \\
\hline $\begin{array}{l}48 \text { exp animals/or exp invertebrate/ or animal experiment/ or animal model/or animal tissue / or animal cell/ or } \\
\text { nonhuman/ }\end{array}$ & 25510736 \\
\hline 49 human/ or normal human/ or human cell/ & 19263193 \\
\hline 5048 not (48 and 49$)$ & 6295392 \\
\hline 5146 or 47 or 50 & 6425940 \\
\hline 5245 not 51 & 8956795 \\
\hline 5333 and 52 & 12699 \\
\hline 5432 or 53 & 13345 \\
\hline 55 limit 54 to $y r=" 2016$-Current" & 2944 \\
\hline
\end{tabular}

\section{The Cochrane Library (Wiley)}

Search date: 7 February 2018 
Interventions to improve the appropriate use of polypharmacy for older people

\begin{tabular}{|c|c|c|}
\hline$\# 1$ & [mh polypharmacy] & 174 \\
\hline$\# 2$ & [mh "inappropriate prescribing"] & 110 \\
\hline \#3 & [mh "potentially inappropriate medication list"] & 5 \\
\hline \#4 & [mh deprescriptions] & 7 \\
\hline \#5 & [mh "medication errors"] & 413 \\
\hline \#6 & polypharma*:ti,ab & 415 \\
\hline$\# 7$ & ((beer* or shan* or mcleod*) near/3 criter*):ti,ab & 42 \\
\hline$\# 8$ & ("fit for the aged" near/3 (criter* or list* or instrument or classif*)):ti,ab & 5 \\
\hline$\# 9$ & $(($ forta or rasp or priscus) near $/ 3$ (criter* or list* or instrument)):ti,ab & 7 \\
\hline & (stopp criter* or stopp list*):ti,ab & 52 \\
\hline & $\begin{array}{l}((\text { concomitant* or concurrent* or inappropriat* or appropriat* or suboptim* or sub-optim* or unnecessary or } \\
\text { incorrect* or excess* or multip* or inadvert* or discontinu*) near } / 1 \text { (medicine* or medicat* or prescrib* or } \\
\text { prescription* or drug*)):ti,ab }\end{array}$ & 3473 \\
\hline$\# 12$ & $\begin{array}{l}((\text { over near } / 1(\text { prescrib* or prescript*)) or (over-prescrib* or overprescrib*) or ("or more" near/1 (medication* or } \\
\text { prescrib* or prescript*))):ti,ab }\end{array}$ & 230 \\
\hline$\# 13$ & ((under near/ 1 prescrib*) or underprescrib* or under-prescrib*):ti,ab & 37 \\
\hline$\# 14$ & (deprescrib* or deprescript*):ti,ab & 23 \\
\hline \#15 & (quality near/2 (prescribing or prescription* or medication*)):ti,ab & 224 \\
\hline \#16 & (improv* near/2 (prescrib* or pharmaco* or prescription*)):ti,ab & 654 \\
\hline$\# 17$ & (prescri* near $/ 1$ cascade*):ti,ab & 1 \\
\hline$\# 18$ & ("assessing care of vulnerable elders" or acove):ti,ab & 12 \\
\hline$\# 19$ & $(($ multi-drug*or multidrug*) near/2 (prescrib* or prescription*or regimen*or therap*ortreatment*)):ti,ab & 441 \\
\hline$\# 20$ & $\{$ or \#1-\#19\} & 5560 \\
\hline \#21 & [mh aged] & 1214 \\
\hline$\# 22$ & [mh geriatrics] & 227 \\
\hline$\# 23$ & (elder* or geriatric*):ti,ab & 23878 \\
\hline \#24 & $(($ old* or aged) near/ 1 (person* or adult* or people or patient* or inpatient* or outpatient*)):ti,ab & 28530 \\
\hline \#25 & aged next care:ti,ab & 188 \\
\hline$\# 26$ & [mh veterans] & 770 \\
\hline$\# 27$ & veteran*:ti,ab & 3200 \\
\hline$\# 28$ & $\{$ or \#21-\#27\} & 51051 \\
\hline \#29 & $\# 20$ and \#28 & 814 \\
\hline$\# 30$ & \#20 and \#28 Publication Year from 2016 to 2018 & 243 \\
\hline
\end{tabular}

\section{CINAHL (EBSCO)}

Search date: 7 February 2018

\begin{tabular}{|l|r|r|}
\hline S1 & (MH "Polypharmacy") & 2,245 \\
\hline S2 & (MH "Inappropriate Prescribing") & 900 \\
\hline S3 & (MH "Medication Errors") & 9,416 \\
\hline S4 & polypharma* & 2,980 \\
\hline S5 & (beer* or shan* or mcleod*) N3 criter* & 232 \\
\hline S6 & "fit for the aged" N3 (criter* or list* or instrument or classif*) & 7 \\
\hline S7 & (forta or rasp or priscus) N3 (criter* or list* or instrument) & 8 \\
\hline S8 & stopp criter* or stopp list* & 55 \\
\hline
\end{tabular}


Interventions to improve the appropriate use of polypharmacy for older people

\begin{tabular}{|c|c|c|}
\hline S9 i & $\begin{array}{l}\text { (concomitant* or concurrent* or inappropriat* or appropriat* or suboptim* or sub-optim* or unnecessary or } \\
\text { incorrect* or excess* or multip* or inadvert* or discontinu*) N1 (medicine* or medicat* or prescrib* or } \\
\text { prescription* or drug*) }\end{array}$ & 9,773 \\
\hline S10 & $\begin{array}{l}((\text { overN1 }(\text { prescrib*or prescript*)) or (over-prescrib*or overprescrib*) or ("or more"N0 (medication* or } \\
\text { prescrib* or prescript*))) }\end{array}$ & 1,968 \\
\hline S11 & (under N1 prescrib*) or underprescrib* or under-prescrib* & 136 \\
\hline S12 & deprescrib* or deprescript* & 107 \\
\hline 513 & "medication appropriateness index*" & 33 \\
\hline S14 & quality N2 (prescribing or prescription* or medication*) & 529 \\
\hline S15 & prescrib* N0 cascade* & 15 \\
\hline S16 & "assessing care of vulnerable elders" or acove & 47 \\
\hline S17 & (multi-drug* or multidrug*) N2 (prescrib* or prescription* or regimen* or therap* or treatment*) & 705 \\
\hline 518 & improv*N2 (prescrib* or pharmaco* or prescription*) & 1,262 \\
\hline S19 & $\begin{array}{l}\text { S1 OR S2 OR S3 OR S4 OR S5 OR S6 OR S7 OR S8 OR S9 OR S10 OR S11 OR S12 OR S13 OR S14 } \\
\text { OR S15 OR S16 OR S17 OR S18 }\end{array}$ & 24,995 \\
\hline S20 & (MH "Aged+") & 420,836 \\
\hline S21 & (MH "Geriatrics") & 3,197 \\
\hline S22 & (MH "Veterans") & 9,527 \\
\hline S23 & elder* or geriatric* & 85,606 \\
\hline S24 & (old* or aged) N0 (person* or adult* or people or patient* or inpatient* or outpatient*) & 73,337 \\
\hline S25 & "aged care" & 2,662 \\
\hline S26 & veteran* & 18,258 \\
\hline S27 & S20 OR S21 OR S22 OR S23 OR S24 OR S25 OR S26 & 474,552 \\
\hline S28 & S19 AND S27 & 6,315 \\
\hline$S 29$ & (MM "Polypharmacy") & 966 \\
\hline S30 & S27 AND S29 & 692 \\
\hline S31 & PT randomized controlled trial & 42,401 \\
\hline$S 32$ & PT clinical trial & 55,753 \\
\hline S33 & PT research & $1,173,449$ \\
\hline S34 & (MH "Randomized Controlled Trials") & 39,459 \\
\hline S35 & (MH "Clinical Trials") & 92,614 \\
\hline S36 & (MH "Intervention Trials") & 6,848 \\
\hline S37 & (MH "Nonrandomized Trials") & 248 \\
\hline S38 & (MH "Experimental Studies") & 17,542 \\
\hline S39 & (MH "Pretest-Posttest Design+") & 30,465 \\
\hline S40 & (MH "Quasi-Experimental Studies+") & 10,104 \\
\hline S41 & (MH "Multicenter Studies") & 34,001 \\
\hline S42 & (MH "Health Services Research") & 7,958 \\
\hline S43 & $\mathrm{TI}$ ( randomis* or randomiz* or randomly) OR AB ( randomis* or randomiz* or randomly) & 139,254 \\
\hline S44 & 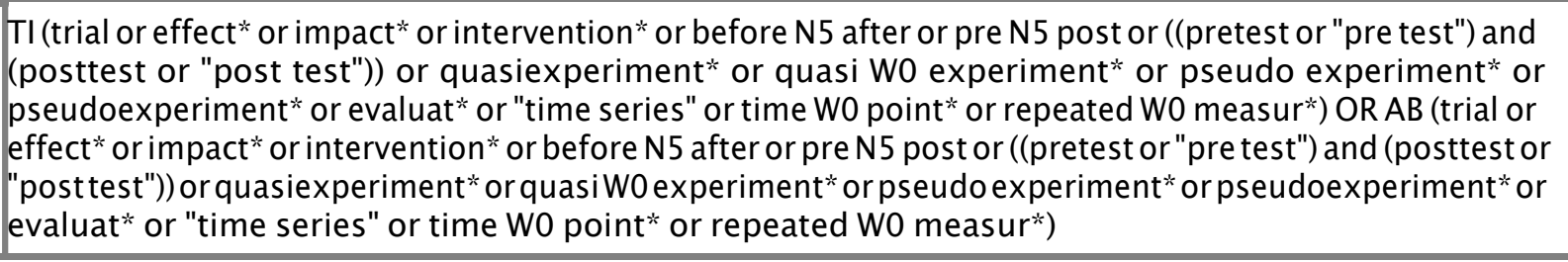 & 954,170 \\
\hline
\end{tabular}


Interventions to improve the appropriate use of polypharmacy for older people

\begin{tabular}{|l|r|r|}
\hline S45 & S31 OR S32 OR S33 OR S34 OR S35 OR S36 OR S37 OR S38 OR S39 OR S40 OR S41 OR S42 OR S43 & $1,556,024$ \\
\hline S46 S28 AND S45 & 4,714 \\
\hline S47 S30 OR S46 & 4,974 \\
\hline S48 & S47 Limiters - Exclude MEDLINE records & 1,336 \\
\hline S49 & S48 Limiters - Published Date: 20160101-20181231 & 566 \\
\hline
\end{tabular}

ClinicalTrials.gov, US National Institutes of Health (NIH) http://clinicaltrials.gov/

Search date: 7 February 2018

\begin{tabular}{|l|r|}
\hline polypharmacy | senior & 106 \\
\hline "inappropriate prescribing" | senior & 20 \\
\hline appropriate prescribing | senior & 9 \\
\hline "inappropriate medication" | senior & 16 \\
\hline "appropriate medication" | senior & 8 \\
\hline deprescribing | senior & 25 \\
\hline Total = & 184 \\
\hline
\end{tabular}

\section{WHO International Clinical Trials Registry Platform (ICTRP)}

Search date: 7 February 2018

\begin{tabular}{|l|l|}
\hline polypharmacy & \\
\hline inappropriate prescribing & \\
\hline appropriate prescribing & \\
\hline inappropriate medication & \\
\hline appropriate medication & \\
\hline deprescribing & \\
\hline Total= & 209 \\
\hline
\end{tabular}

\section{Reviews screened for included studies}

(1) Fulton MM, Allen ER. Polypharmacy in the elderly: a literature review. Journal of the American Academy of Nurse Practitioners 2005 Apr; 17(4):123-32.

(2) Garcia RM. Five ways you can reduce inappropriate prescribing in the elderly: a systematic review. Journal of Family Practice 2006 Apr;55(4):305-12.

(3) George J, Elliott RA, Stewart DC. A systematic review of interventions to improve medication taking in elderly patients prescribed multiple medications. Drugs \& Aging 2008;25(4):307-24.

(4) Hajjar ER, Cafiero AC, Hanlon JT. Polypharmacy in elderly patients. American Journal of Geriatric Pharmacotherapy 2007;5(4):345-51.

(5) Haynes RB, Ackloo E, Sahota N, McDonald HP, Yao X. Interventions for enhancing medication adherence. Cochrane Database of Systematic Reviews 2008;2(CD000011).

(6) Holland R, Desborough J, Goodyer L, Hall S, Wright D, Loke YK. Does pharmacist-led medication review help to reduce hospital admissions and deaths in older people? A systematic review and meta-analysis. British Journal of Clinical Pharmacology 2008 Mar;65(3):303-16.

(7) Huss A, Stuck AE, Rubenstein LZ, Egger M, Clough-Gorr KM. Multidimensional preventive home visit programs for community-dwelling older adults: a systematic review and meta-analysis of randomized controlled trials. The Journals of Gerontology Series A, Biological Sciences and Medical Sciences 2008;63(3):298-307. 
Interventions to improve the appropriate use of polypharmacy for older people

(8) Jano E, Aparasu RR. Healthcare outcomes associated with Beers' criteria: a systematic review. The Annals of Pharmacotherapy 2007 Mar;41(3):438-47.

(9) Kaur S, Mitchell G, Vitetta L, Roberts MS. Interventions that can reduce inappropriate prescribing in the elderly: a systematic review. Drugs \& Aging 2009;26(12):1013-28.

(10) Maeda K. Systematic review of the effects of improvement of prescription to reduce the number of medications in the elderly with polypharmacy. Yakugaku Zasshi 2009 May; 129(5):631-45.

(1 1) Milton JC, Hill-Smith I, Jackson SH. Prescribing for older people. BMJ 2008 Mar 15;336(7644):606-9.

(12) Rollason V, Vogt N. Reduction of polypharmacy in the elderly: a systematic review of the role of the pharmacist. Drugs \& Aging 2003;20(11):817-32.

(13) Royal S, Smeaton L, Avery AJ, Hurwitz B, Sheikh A. Interventions in primary care to reduce medication related adverse events and hospital admissions: systematic review and meta-analysis. Quality \& Safety in Health Care 2006 Feb; 15(1):23-31.

(14) Spinewine A, SchmaderKE, BarberN, Hughes C, Lapane KL, SwineC, etal. Appropriate prescribing in elderly people: how well can it be measured and optimised? Lancet 2007;370(9582):173-84.

(15) Wenger NS, Roth CP, Shekelle P, ACOVE I. Introduction to the assessing care of vulnerable elders-3 quality indicator measurement set. Journal of the American Geriatrics Society 2007 Oct;55(Suppl 2):S247-s52.

(16) Yourman L, ConcatoJ, AgostiniJV. Use of computer decision support interventions to improve medication prescribing in older adults: a systematic review. American Journal of Geriatric Pharmacotherapy 2008 Jun;6(2):1 19-29.

(17) Alldred DP, Raynor DK, Hughes C, Barber N, Chen TF, Spoor P. Interventions to optimise prescribing for older people in care homes. Cochrane Database of Systematic Reviews 201 3; 2:CD009095.

(18) Christensen M, Lundh A. Medication review in hospitalised patients to reduce morbidity and mortality. Cochrane Database of Systematic Reviews 2013;2:CD008986.

(19) Clyne B, Bradley MC, Hughes C, Fahey T, Lapane KL. Electronic prescribing and other forms of technology to reduce inappropriate medication use and polypharmacy in older people: a review of current evidence. Clinics in Geriatric Medicine 2012;28(2):301-22.

(20) Fleming A, Browne J, Byrne S. The effect of interventions to reduce potentially inappropriate antibiotic prescribing in long-term care facilities: a systematic review of randomised controlled trials. Drugs \&Aging 2013;30(6):401-8.

(20) Forsetlund L, Eike MC, Gjerberg E, Vist GE. Effect of interventions to reduce potentially inappropriate use of drugs in nursing homes: a systematic review of randomised controlled trials. BMC Geriatrics 2011;11:16.

(21) Frazier SC. Health outcomes and polypharmacy in elderly individuals: an integrated literature review. Journal of Gerontological Nursing 2005;31(9):4-11.

(22) George J, Elliott RA, Stewart DC. A systematic review of interventions to improve medication taking in elderly patients prescribed multiple medications. Drugs \& Aging 2008;25(4):307-24.

(23) Loganathan M, Singh S, Franklin BD, Bottle A, Majeed A. Interventions to optimise prescribing in care homes: systematic review. Age and Ageing 2011;40(2):150-62.

(24) Maeda K. Systematic review of the effects of improvement of prescription to reduce the number of medications in the elderly with polypharmacy.YakugakuZasshi:Journal of the PharmaceuticalSociety ofJapan 2009;129(5):631-45.

(25) Tani H, Uchida H, Suzuki T, Fujii Y, Mimura M. Interventions to reduce antipsychotic polypharmacy: a systematic review. Schizophrenia Research 2013;143(1):215-20.

(26) TjiaJ, Velten SJ, Parsons C, ValluriS, Briesacher BA. Studies to reduce unnecessary medication use in frail older adults: a systematic review. Drugs \& Aging 2013;30(5):285-307.

(27) Alldred DP, Kennedy M, Hughes C, Chen TF, Miller P. Interventions to optimise prescribing for older people in care homes. Cochrane Database of Systematic Reviews 2016;2:CD009095.

(28) Christensen M, Lundh A. Medication review in hospitalised patients to reduce morbidity and mortality. Cochrane Database of Systematic Reviews 2016;2: CD008986.

(29) Curtain C, Peterson G. Review of computerized clinical decision support in community pharmacy.J Clin Pharm Ther 2014;39(4):343-348.

(30) Desborough J, Twigg M. Pharmacist-led medication reviews in primary care. Reviews in Clinical Gerontology 2014; 24(01):1-9.

(31) Fried TR, O'LearyJ, Towle V, Goldstein MK, Trentalange M, Martin DK. Health Outcomes Associated with Polypharmacy in Community-Dwelling Older Adults: A Systematic Review.J Am Geriatr Soc 2014;62(12):2261-2272. 
Interventions to improve the appropriate use of polypharmacy for older people

(32) Hill-Taylor B, Walsh K, Stewart S, Hayden J, Byrne S, Sketris I. Effectiveness of the STOPP/START (Screening Tool of Older Persons' potentially inappropriate Prescriptions/Screening Tool to Alert doctors to the Right Treatment) criteria: systematic review and meta-analysis of randomized controlled studies.J Clin Pharm Ther 2016;41 (2):1 58-169.

(33) Lehnbom EC, Stewart MJ, Manias E, Westbrook JI. Impact of medication reconciliation and review on clinical outcomes. Ann Pharmacother 2014 Oct;48(10):1298-1312.

(34) Lonsdale DO, Baker EH. Understanding and managing medication in elderly people. Best Practice \& Research Clinical Obstetrics \& Gynaecology 2013;27(5):767-788.

(35) Maher RL, Hanlon J, Hajjar ER. Clinical consequences of polypharmacy in elderly. Expert opinion on drug safety 2014; 13(1):57-65.

(36) PengeJ, Crome P. Appropriate prescribing in older people. Reviews in Clinical Gerontology 2014;24(01):58-77.

(37) Petrovic M, Somers A, Onder G. Optimization of geriatric pharmacotherapy: role of multifaceted cooperation in the hospital setting. Drugs Aging 2016;33(3):179-188.

(38) Shade MY, Berger AM, Chaperon C. Potentially inappropriate medications in community-dwelling older adults. Research in gerontological nursing 2014;7(4):178-192.

(39) Walsh KA, O'Riordan D, Kearney PM, Timmons S, Byrne S. Improving the appropriateness of prescribing in older patients: a systematic review and meta-analysis of pharmacists' interventions in secondary care. Age Ageing 2016; 45(2):201-209.

5 GRADE evidence profile: Pharmaceutical care compared with usual care for older people receiving polypharmacy

Certainty assessment of evidence for each outcome

\begin{tabular}{|l|l|l|l|l|l|l|l}
$\begin{array}{l}\text { No of } \\
\text { studies }\end{array}$ & Design & $\begin{array}{l}\text { Risk of } \\
\text { bias }\end{array}$ & Inconsistency & Indirectness ${ }^{\dagger}$ & Imprecision & Other* & $\begin{array}{l}\text { Certainty } \\
\text { (overall } \\
\text { score) })^{\S}\end{array}$ \\
\hline
\end{tabular}

Outcome: Medication appropriateness (as measured by an implicit tool)

\begin{tabular}{|c|c|c|c|c|c|c|}
\hline 5 studies & $\begin{array}{l}\text { Randomised } \\
\text { trials }\end{array}$ & $\begin{array}{l}\text { Very } \\
\text { serious }\end{array}$ & Very serious & Serious & Serious & None \\
\hline
\end{tabular}

Outcome: The number of potentially inappropriate medications

\begin{tabular}{l|l|l|l|l|l|l|l}
\hline 7 studies & $\begin{array}{l}\text { Randomised } \\
\text { trials }\end{array}$ & $\begin{array}{l}\text { Very } \\
\text { serious }\end{array}$ & Very serious & Serious & $\begin{array}{l}\text { No serious } \\
\text { imprecision }\end{array}$ & None & $\begin{array}{l}\oplus \ominus \ominus \ominus \\
\text { verylow }\end{array}$ \\
\hline
\end{tabular}

Outcome: The proportion of patients with one or more potentially inappropriate medications

\begin{tabular}{l|l|l|l|l|l|l|l}
\hline 11 studies & $\begin{array}{l}\text { Randomised } \\
\text { trials }\end{array}$ & $\begin{array}{l}\text { Very } \\
\text { serious }\end{array}$ & Very serious & Serious & $\begin{array}{l}\text { No serious } \\
\text { imprecision }\end{array}$ & None & $\begin{array}{l}\oplus \Theta \Theta \Theta \\
\text { verylow }\end{array}$ \\
\hline
\end{tabular}

Outcome: The number of potential prescribing omissions

\begin{tabular}{|l|l|l|l|l|l|l|l}
\hline 2 studies & $\begin{array}{l}\text { Randomised } \\
\text { trials }\end{array}$ & $\begin{array}{l}\text { Very } \\
\text { serious }\end{array}$ & $\begin{array}{l}\text { No serious } \\
\text { inconsistency }\end{array}$ & $\begin{array}{l}\text { No serious } \\
\text { indirectness }\end{array}$ & $\begin{array}{l}\text { No serious } \\
\text { imprecision }\end{array}$ & None & $\begin{array}{l}\oplus \oplus \Theta \Theta \\
\text { low }\end{array}$ \\
\hline
\end{tabular}

Outcome: The proportion of patients with one or more potential prescribing omissions

\begin{tabular}{|c|c|c|c|c|c|c|c|}
\hline 5 studies & $\begin{array}{l}\text { Randomised } \\
\text { trials }\end{array}$ & $\begin{array}{l}\text { Very } \\
\text { serious }\end{array}$ & Very serious & $\begin{array}{l}\text { No serious } \\
\text { indirectness }\end{array}$ & $\begin{array}{l}\text { No serious } \\
\text { imprecision }\end{array}$ & None & $\begin{array}{l}\oplus \ominus \ominus \ominus \\
\text { verylow }\end{array}$ \\
\hline \multicolumn{8}{|c|}{ Outcome: Hospital admissions } \\
\hline 12 studies & $\begin{array}{l}\text { Randomised } \\
\text { trials }\end{array}$ & $\begin{array}{l}\text { Very } \\
\text { serious }\end{array}$ & $\begin{array}{l}\text { No serious } \\
\text { inconsistency }\end{array}$ & Not estimable & $\begin{array}{l}\text { No serious } \\
\text { imprecision }\end{array}$ & $\begin{array}{l}\text { Not } \\
\text { estimable }\end{array}$ & $\begin{array}{l}\oplus \oplus \ominus \ominus \\
\text { low }\end{array}$ \\
\hline \multicolumn{8}{|c|}{ Outcome: Quality of life } \\
\hline 12 studies & $\begin{array}{l}\text { Randomised } \\
\text { trials }\end{array}$ & $\begin{array}{l}\text { Very } \\
\text { serious }\end{array}$ & $\begin{array}{l}\text { No serious } \\
\text { inconsistency }\end{array}$ & Not estimable & $\begin{array}{l}\text { No serious } \\
\text { imprecision }\end{array}$ & $\begin{array}{l}\text { Not } \\
\text { estimable }\end{array}$ & $\begin{array}{l}\oplus \oplus \Theta \Theta \\
\text { low }\end{array}$ \\
\hline
\end{tabular}

\section{Footnotes}

† Indirectness includes consideration of:

- Indirect (between study) comparisons

- Indirect (surrogate) outcomes 
- Applicability (study populations, interventions or comparisons that are different than those of interest)

[1] Other considerations for downgrading include publication bias. Other considerations for upgrading include a strong association with no plausible confounders, a dose response relationship, and if all plausible confounders or biases would decrease the size of the effect (if there is evidence of an effect), or increase it if there is evidence of no harmful effect (safety)

$\S 4 \mathrm{High}=$ This research provides a very good indication of the likely effect. The likelihood that the effect will be substantially different $* *$ is low.

3 Moderate $=$ This research provides a good indication of the likely effect. The likelihood that the effect will be substantially different ${ }^{* *}$ is moderate.

2 Low $=$ This research provides some indication of the likely effect. However, the likelihood that it will be substantially different ${ }^{* *}$ is high.

1 Very low $=$ This research does not provide a reliable indication of the likely effect. The likelihood that the effect will be substantially different** is veryhigh.

** Substantially different $=$ a large enough difference that it might affect a decision 
Interventions to improve the appropriate use of polypharmacy for older people

1.1 Medication appropriateness (as measured by an implicit tool)

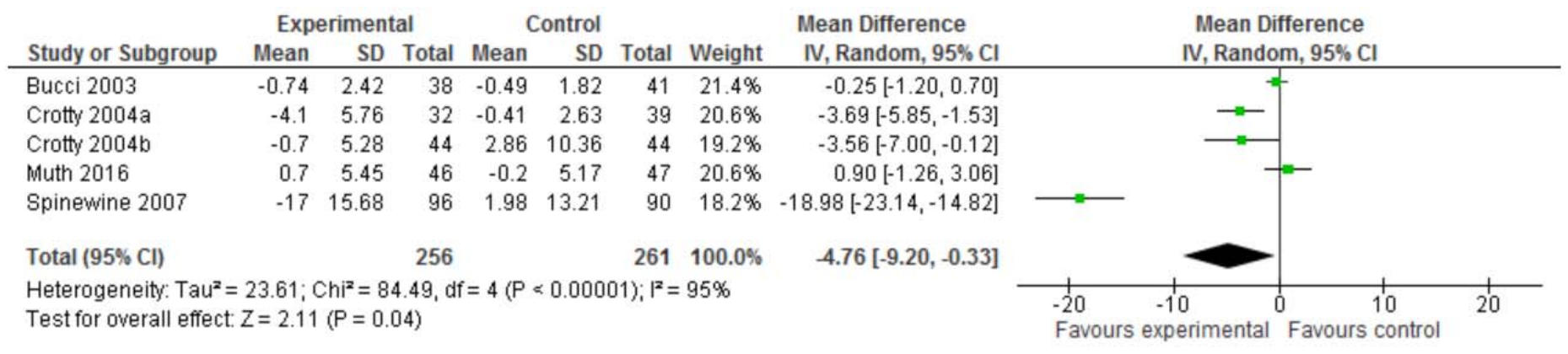

1.2 Medication appropriateness (as measured by an implicit tool) (excl Crotty 2004a)

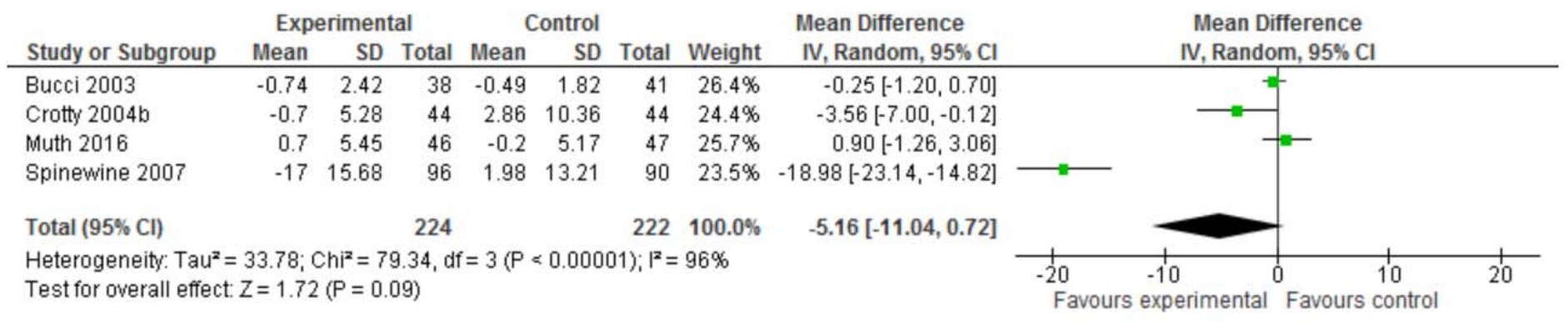

1.3 Medication appropriateness (as measured by an implicit tool) (excl Crotty 2004a and Spinewine 2007)

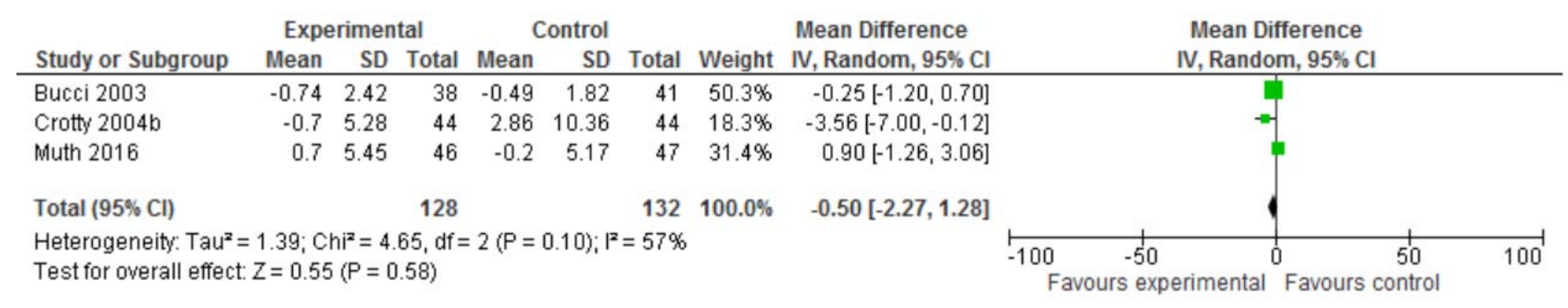

1.4 The number of potentially inappropriate medications

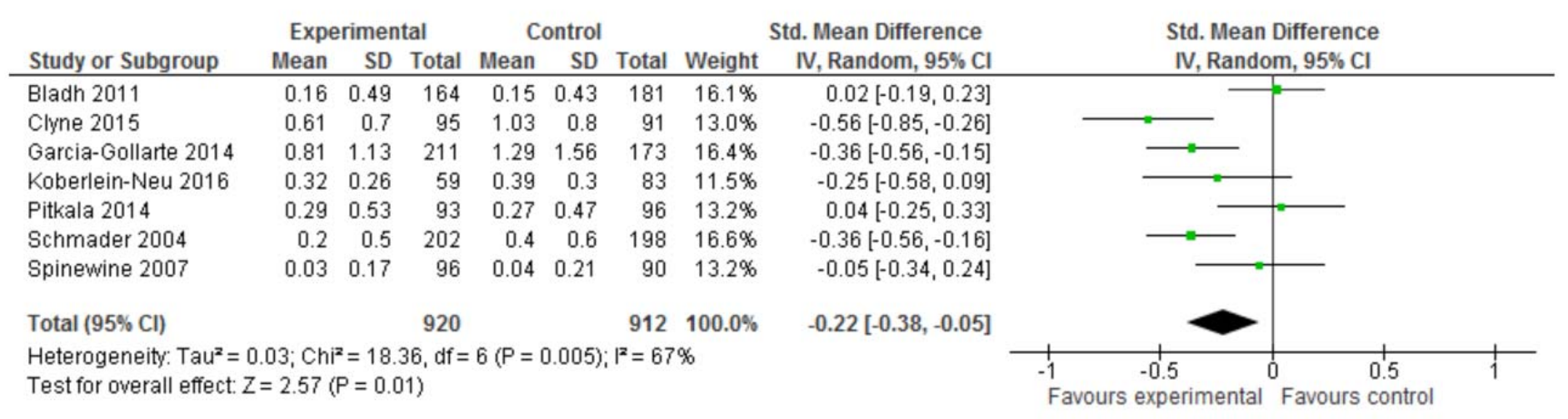


Interventions to improve the appropriate use of polypharmacy for older people

1.5 The proportion of patients with one or more potentially inappropriate medications

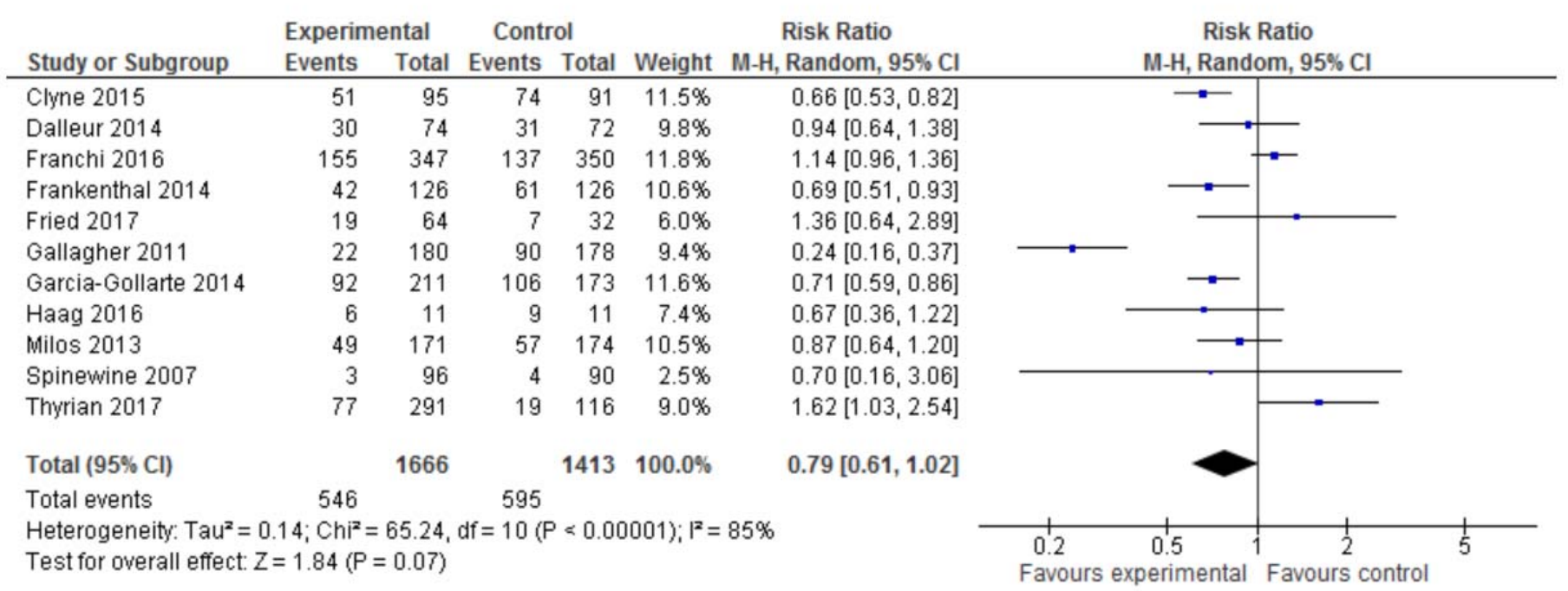

1.6 The proportion of patients with one or more potentially inappropriate medications (excl Spinewine 2007)

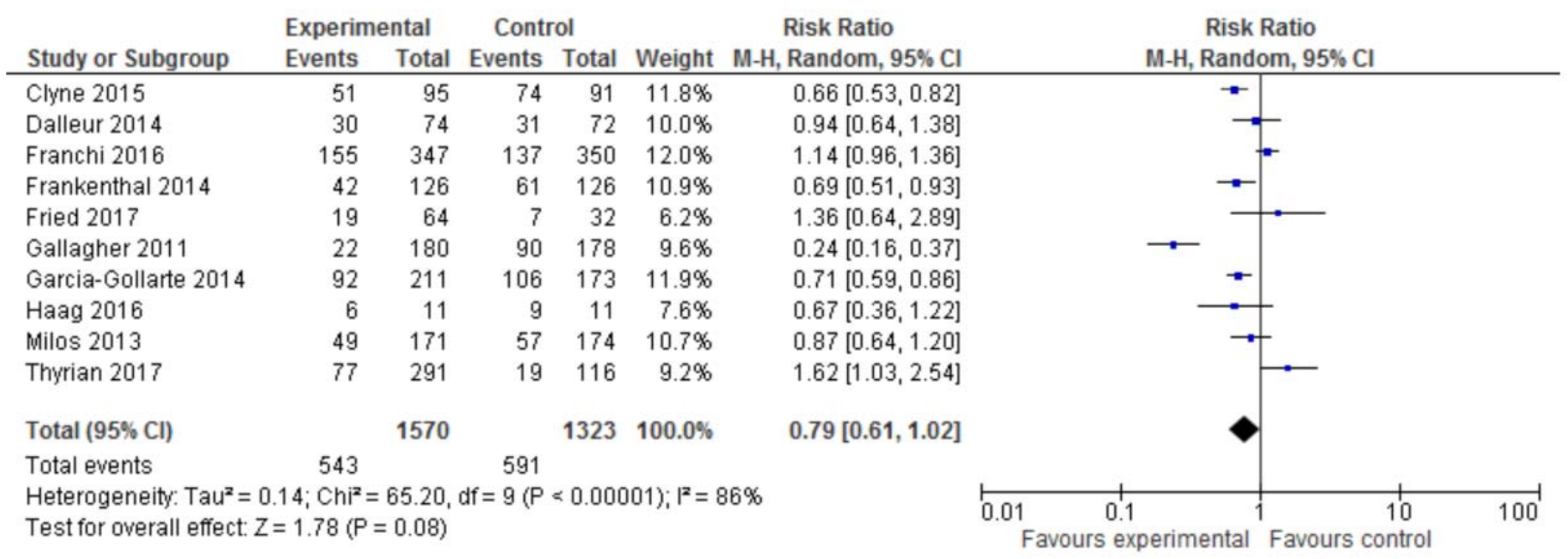

1.7 The proportion of patients with one or more potentially inappropriate medications (excl Spinewine 2007 and Gallagher 2011)

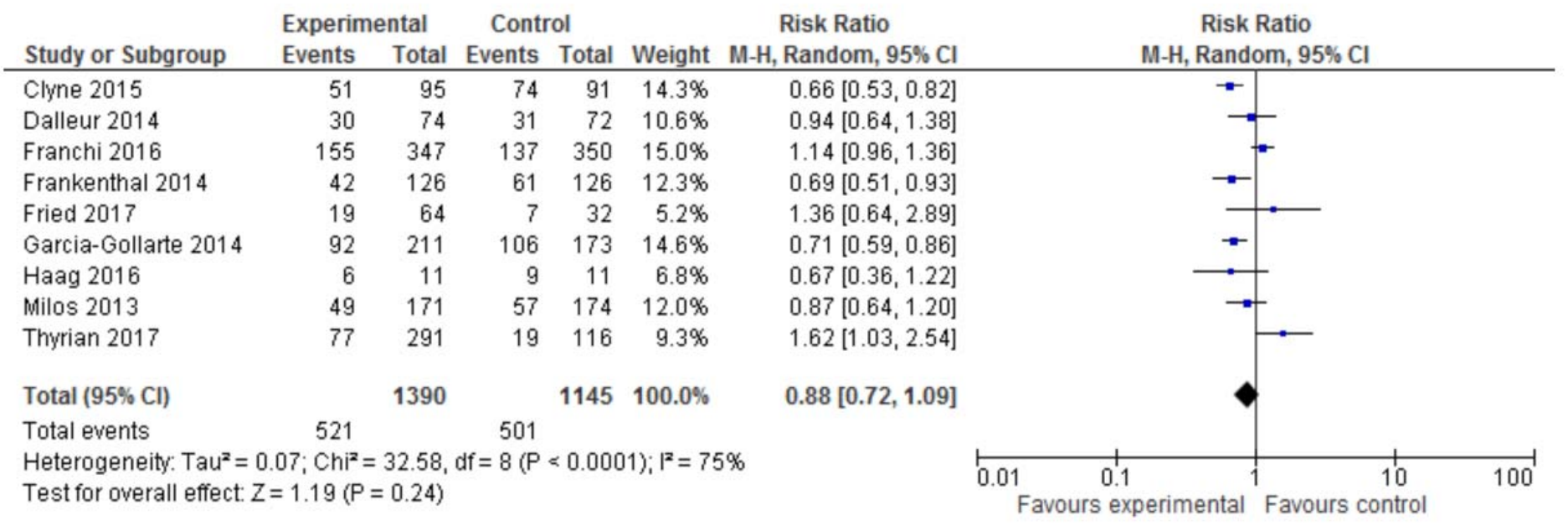


1.8 The number of potential prescribing omissions

\begin{tabular}{|c|c|c|c|c|c|c|c|c|c|c|c|}
\hline \multirow[b]{2}{*}{ Study or Subgroup } & \multicolumn{3}{|c|}{ Experimental } & \multicolumn{3}{|c|}{ Control } & \multicolumn{2}{|r|}{ Std. Mean Difference } & \multirow{2}{*}{\multicolumn{3}{|c|}{$\begin{array}{l}\text { Std. Mean Difference } \\
\text { IV, Random, } 95 \% \mathrm{Cl}\end{array}$}} \\
\hline & Mean & SD & Total & Mean & SD & Total & Weight & IV, Random, $95 \% \mathrm{CI}$ & & & \\
\hline Garcia-Gollarte 2014 & 0.13 & 0.44 & 183 & 0.85 & 1.08 & 200 & $66.7 \%$ & $-0.86[-1.07,-0.65]$ & - & & \\
\hline Spinewine 2007 & 0.17 & 0.43 & 96 & 0.63 & 0.81 & 90 & $33.3 \%$ & $-0.71[-1.01,-0.42]$ & & & \\
\hline Total $(95 \% \mathrm{Cl})$ & & & 279 & & & 290 & $100.0 \%$ & $-0.81[-0.98,-0.64]$ & & & \\
\hline $\begin{array}{l}\text { Heterogeneity: } \mathrm{Tau}^{2}= \\
\text { Test for overall effect: }\end{array}$ & $\begin{array}{l}00 ; \mathrm{Chi} \\
=9.27 \text { ( }\end{array}$ & $\begin{array}{l}=0.6 \\
P<0.0\end{array}$ & $\begin{array}{l}\text { 1, } d f=1 \\
00001)\end{array}$ & $(P=0$. & 43); $1^{2}$ & $=0 \%$ & & & $\begin{array}{cc}1 & 1 \\
-2 & -1 \\
& \text { Favours experimer }\end{array}$ & $\begin{array}{l}0 \\
\text { Favours col }\end{array}$ & introl \\
\hline
\end{tabular}

1.9 The proportion of patients with one or more potential prescribing omissions

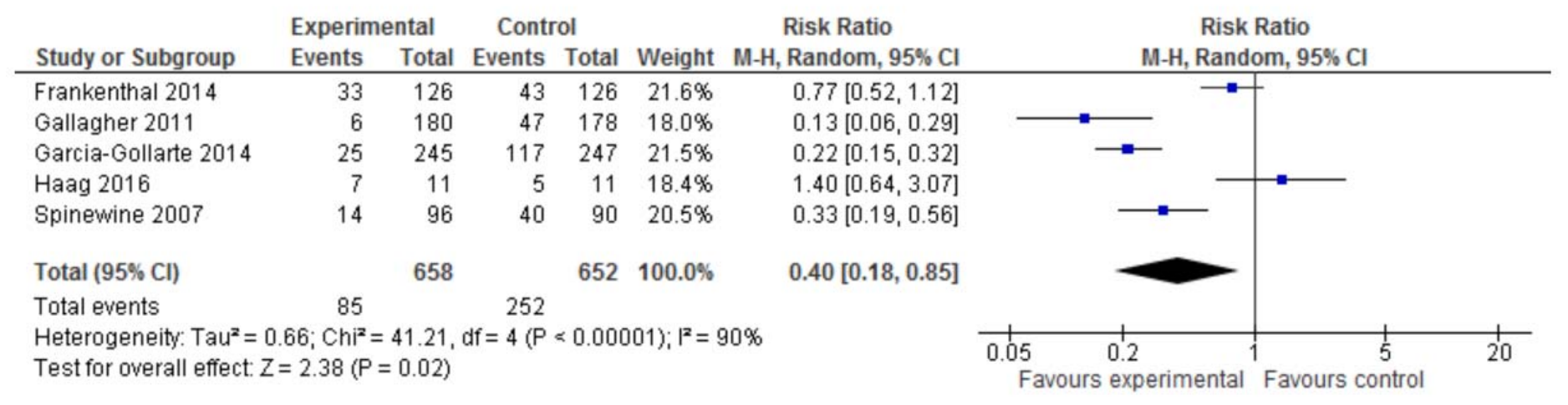

